
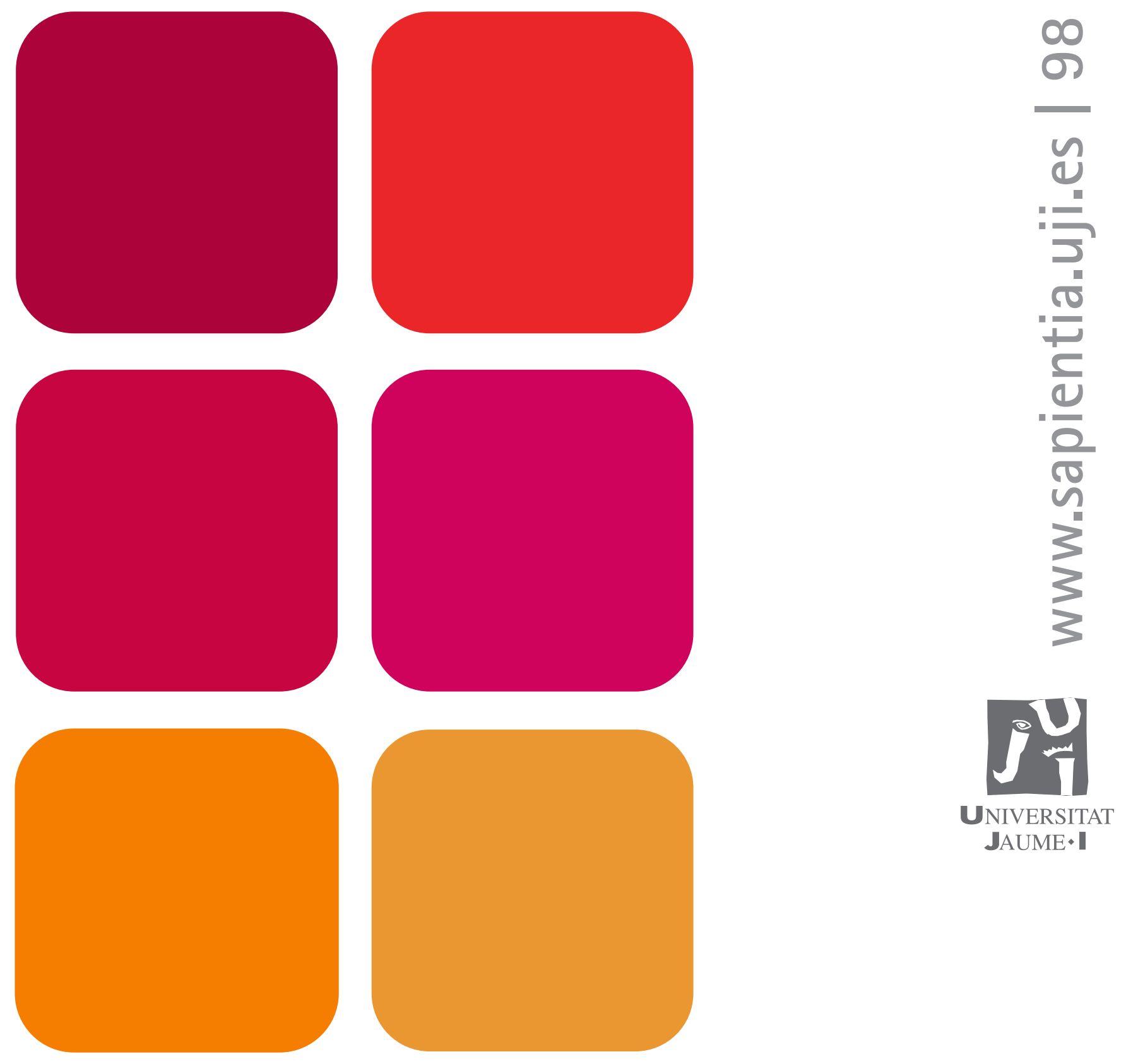

\title{
Principios de marketing estratégico
}

Teresa Vallet-Bellmunt (coord.) Antonio Vallet-Bellmunt Ilu Vallet-Bellmunt Emilia Casanova-Calatayud Víctor del Corte-Lora Marta Estrada-Guillén Juan Carlos Fandos-Roig Valentín Gallart-Camahort

Pilar Monte-Collado 



\section{Principios de marketing estratégico}

Teresa Vallet-Bellmunt (coord.)

Antonio Vallet-Bellmunt

Ilu Vallet-Bellmunt

Emilia Casanova-Calatayud

Víctor del Corte-Lora

Marta Estrada-Guillén

Juan Carlos Fandos-Roig

Valentín Gallart-Camahort

Pilar Monte-Collado

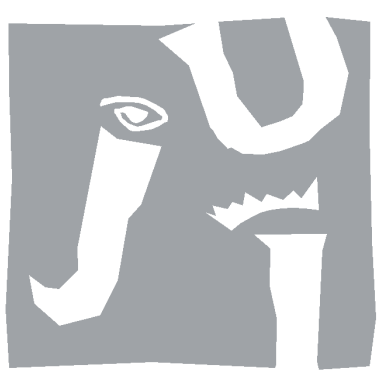

Departament d'Administració d'Empresas

I Màroueting

- Codis d'assignatura AE1018

FC1018

EC1018

\section{UNIVERSITAT \\ JAUME•I}


Edita: Publicacions de la Universitat Jaume I. Servei de Comunicació i Publicacions Campus del Riu Sec. Edifici Rectorat i Serveis Centrals. 12071 Castelló de la Plana http://www.tenda.uji.es e-mail: publicacions@uji.es

Col·lecció Sapientia 98

www.sapientia.uji.es

Primera edició, 2015

ISBN: 978-84-697-1552-9

17 Publicacions de la Universitat Jaume I és una editorial membre de l'UNE, cosa que en garanteix la difusió de les obres en els àmbits nacional i inter-

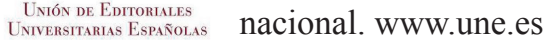

\section{(c) (i) (2)}

Reconeixement-CompartirIgual

\section{BY-SA}

Aquest text està subjecte a una llicència Reconeixement-CompartirIgual de Creative Commons, que permet copiar, distribuir i comunicar públicament l'obra sempre que s'especifique l'autor i el nom de la publicació fins i tot amb objectius comercials i també permet crear obres derivades, sempre que siguen distribuïdes amb aquesta mateixa llicència.

http://creativecommons.org/licenses/by-sa/3.0/legalcode 


\section{ÍNDICE}

Introducción

La asignatura Fundamentos de marketing en la Universitat Jaume I

y los proyectos de innovación educativa

Teresa Vallet-Bellmunt

Capítulo 1. El proceso de marketing en la empresa

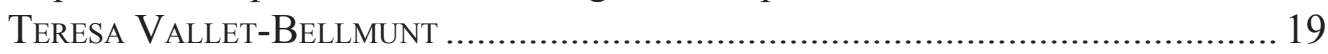

1.1. El proceso de marketing en la empresa.................................................. 21

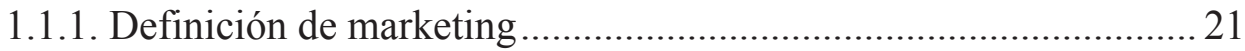

1.1.2. El proceso de marketing para crear valor para el cliente .............. 24

1.1.3. Estructura de este manual........................................................... 26

1.2. Marketing estratégico versus marketing operativo ................................ 27

1.2.1. Dimensión análisis: naturaleza del marketing estratégico ............ 27

1.2.2. Dimensión acción: naturaleza del marketing operativo................. 29

1.2.3. Similitudes y diferencias entre las actividades del marketing estratégico y operativo................................................ 30

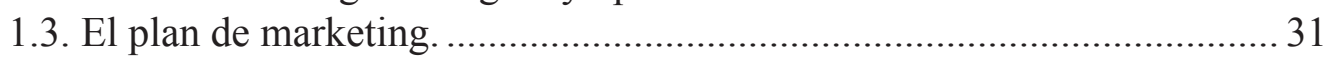

1.3.1. Contenido del plan de marketing................................................. 31

1.3.2. Ejecución de las actividades del plan de marketing...................... 32

1.3.3. El control de las actividades de marketing ..................................... 33

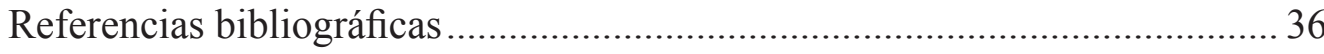

Capítulo 2. Análisis del mercado y la demanda

Ilu Vallet-Bellmunt y Antonio Vallet-Bellmunt ......................................... 37

2.1. Definición y delimitación del mercado de referencia: mercado de referencia, mercado relevante y producto-mercado .............................. 39

2.1.1. Evolución del concepto de mercado............................................. 39

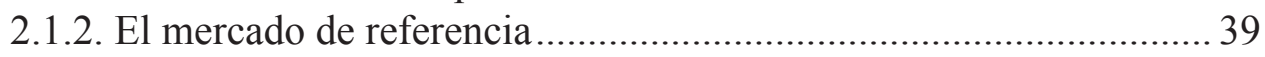

2.1.3. El producto-mercado............................................................... 41

2.1.4. El mercado relevante y estrategias de cobertura. ............................ 42

2.1.5. Ampliaciones del mercado de referencia...................................... 46

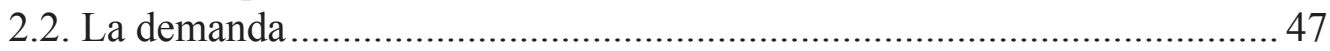

2.2.1. Dimensiones de la demanda de mercado ....................................... 47

2.2.2. Tipos de mercado para el análisis de la demanda........................... 48

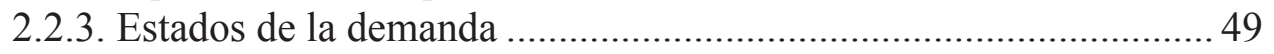

2.2.4. Análisis de la demanda .......................................................................5 50

2.2.5. Cálculo de la demanda actual ........................................................... 50

2.2.6. Algunos métodos para calcular la demanda actual........................ 52 
2.2.6.1. Potencial total del mercado............................................ 52

2.2.6.2. Método de proporciones en cadena................................... 52

2.2.6.3. Potencial de mercado por zonas.......................................... 53

2.2.6.4. Volumen de ventas y cuotas de mercado por sector........... 54

2.2.7. Cálculo de la demanda futura........................................................ 55

2.2.7.1. Análisis de intención de compradores............................... 55

2.2.7.2. Opinión de la fuerza de ventas.......................................... 56

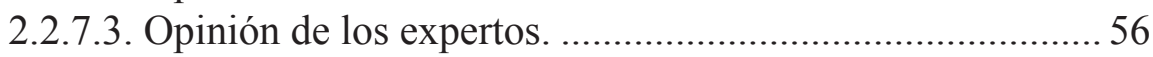

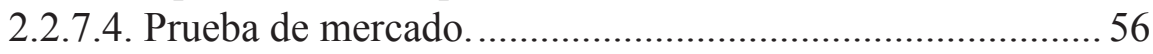

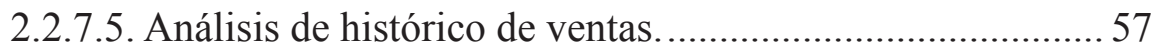

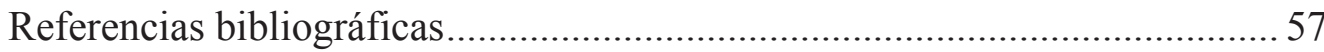

Capítulo 3. Comportamiento de compra de consumidores finales

y de compradores organizacionales

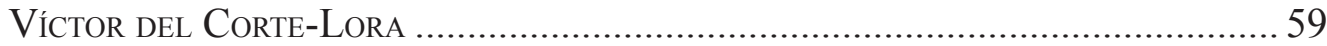

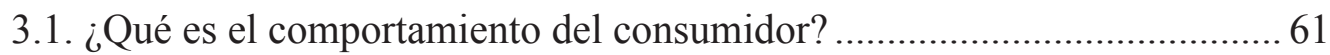

3.2. Modelo de comportamiento estímulo-respuesta..................................... 61

3.3. Características diferenciales del comprador organizacional.................... 62

3.4. Proceso de decisión de compra del consumidor final ............................... 64

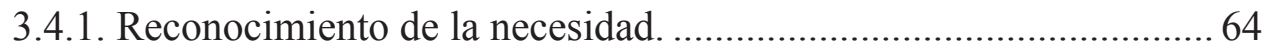

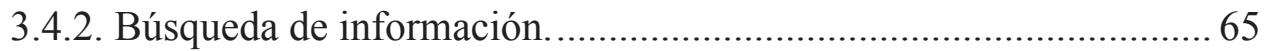

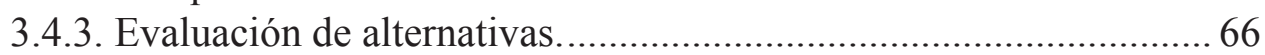

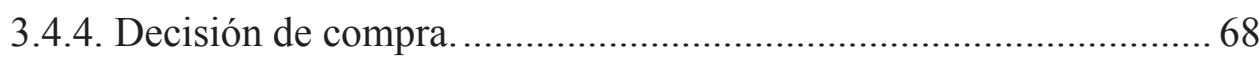

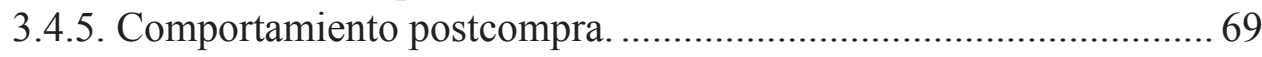

3.5. Proceso de decisión de compra del comprador organizacional ................. 71

3.5.1. Reconocimiento del problema................................................. 72

3.5.2. Descripción de la necesidad y especificaciones del producto......... 72

3.5.3. Búsqueda de proveedores........................................................... 72

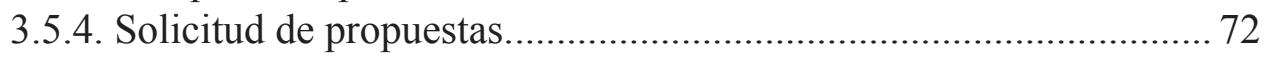

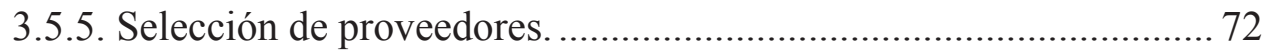

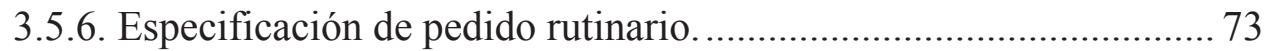

3.5.7. Revisión de la actuación del proveedor........................................ 73

3.6. Factores condicionantes del comportamiento del consumidor final......... 74

3.6.1. Factores culturales................................................................... 74

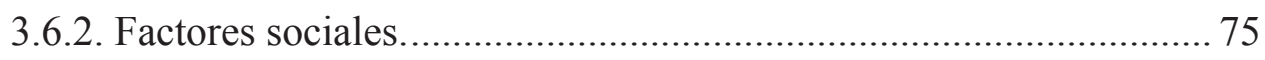

3.6.2.1. Grupos de referencia...................................................... 75

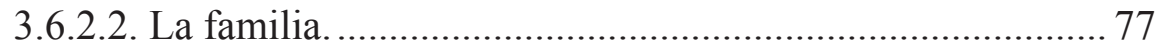

3.6.2.3. Roles y estatus.............................................................. 78

3.6.3. Factores individuales................................................................. 78

3.6.3.1. Edad y etapa del ciclo de vida........................................ 78

3.6.3.2. Ocupación y situación económica. ..................................... 79

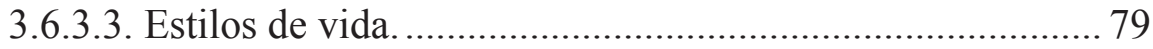

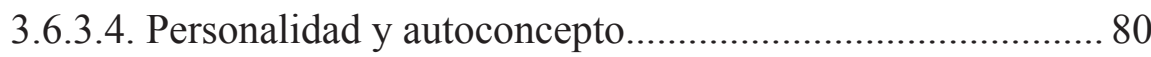

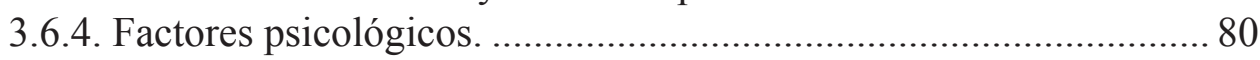

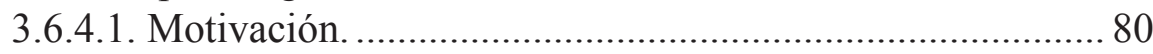

3.6.4.2. Percepción....................................................................... 81

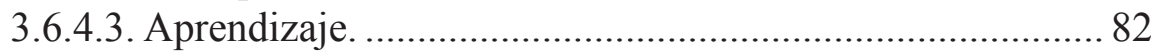

3.6.4.4. Creencias y actitudes........................................................ 83 
3.7. Factores condicionantes del comportamiento del comprador

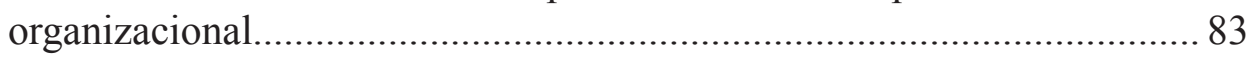

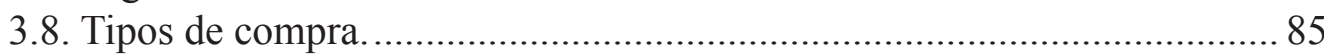

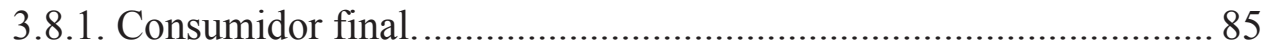

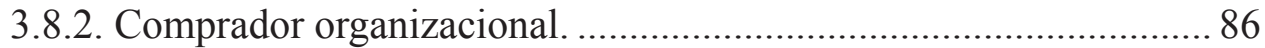

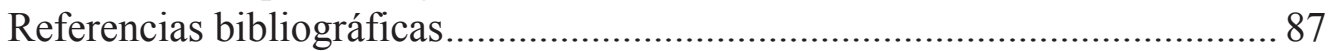

Capítulo 4. Análisis del entorno competitivo

Juan Carlos Fandos-Roig y Marta Estrada-Guillén .................................. 89

4.1. Noción del análisis de la competencia ..................................................... 91

4.1.1. Identificación de la competencia............................................... 91

4.1.2. Evaluación de la competencia...................................................... 92

4.1.3. Selección de competidores para atacar y evitar............................. 92

4.1.4. Niveles de competencia.............................................................. 93

4.1.5. Competencia actual y competencia potencial. .............................. 93

4.1.5.1. Competencia actual...................................................... 93

4.1.5.2. Competencia potencial................................................... 94

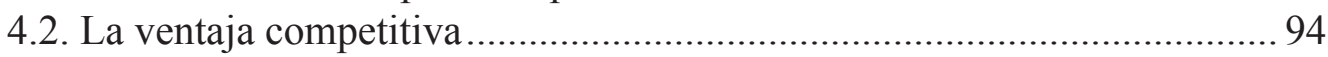

4.3. Métodos de identificación de los competidores...................................... 95

4.3.1. Competidores desde la óptica de la empresa................................ 95

4.3.1.1. Clasificación estándar en función del sector...................... 95

4.3.1.2. Análisis de grupos estratégicos....................................... 95

4.3.2. Competidores desde la óptica del consumidor. ............................ 97

4.3.2.1. Competidores según el comportamiento de compra y consumo del consumidor final......................................... 97

4.3.2.2. Competidores según el juicio u opinión del consumidor final. ........................................................... 98

4.4. Análisis de los competidores. Los sistemas de inteligencia competitiva.. 99

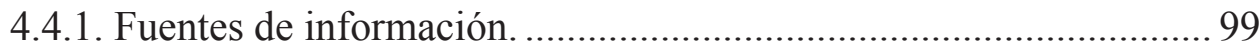

4.4.2. Los sistemas de inteligencia competitiva...................................... 99

4.4.3. Análisis estratégico de los competidores...................................... 100

4.4.4. Análisis de puntos fuertes y débiles. ............................................. 100

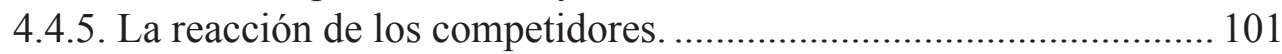

4.5. Nuevas tendencias en el análisis de la competencia: benchmarking....... 102

Referencias bibliográficas..................................................................... 103

Capítulo 5. Identificación y selección del público objetivo

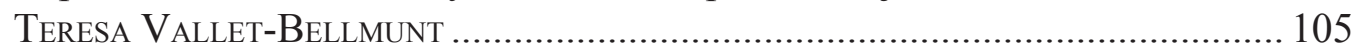

5.1. Proceso de segmentación del producto-mercado.................................... 107

5.1.1. Concepto de segmentación....................................................... 110

5.1.2. ¿Mejora la segmentación la rentabilidad de la empresa? ................. 111

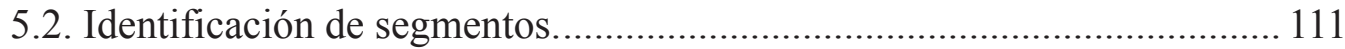

5.2.1. Criterios de segmentación del consumidor final........................... 112

5.2.1.1. Criterios de segmentación según el beneficio buscado...... 114

5.2.1.2. Criterios de segmentación según el comportamiento de compra y consumo....................................................... 115

5.2.1.3. Criterios de segmentación según las características personales. 
5.2.1.4. Criterios de segmentación según las características psicográficas.

5.2.2. Criterios de segmentación del comprador organizacional.

5.2.2.1. Criterios de segmentación según las características de la empresa.

5.2.2.2. Criterios de segmentación según el beneficio buscado...... 120

5.2.2.3. Criterios de segmentación según el comportamiento de compra y consumo.

5.2.3. Procedimientos de segmentación.

5.2.4. Descripción de los perfiles. 123

5.3. Selección del mercado objetivo 123

5.3.1. Evaluación del atractivo de los segmentos.................................... 123

5.3.2. Estrategias de cobertura del producto-mercado. ............................ 124

5.4. Ejemplo de segmentación del producto-mercado de pastas de dientes .... 126 Referencias bibliográficas. 128

Capítulo 6. Posicionamiento

Emilia Casanova-Calatayud 129

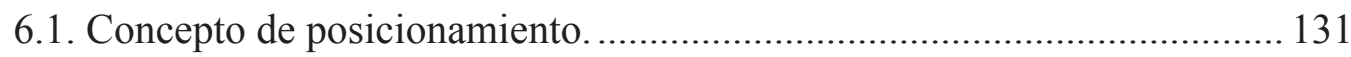

6.1.1. Decisión de posicionamiento estratégico...................................... 131

6.2. Fases para la elección del posicionamiento.......................................... 132

6.3. Identificación de las ventajas competitivas: dimensiones competitivas ... 133 6.3.1. Formas específicas para diferenciar la oferta de mercado.

Tipos de posicionamiento.

6.3.2. ¿Cuántas diferencias debemos promocionar? ................................. 135

6.3.3. ¿Qué diferencias se deben promover?............................................ 136

6.4. Estudio del posicionamiento de los competidores, dimensiones competitivas y posición de los consumidores. ....................................... 136

6.5. Comunicación de la posición elegida. ...................................................... 138

6.5.1. Estrategias para cambiar de posicionamiento: el reposicionamiento.

Referencias bibliográficas

Capítulo 7. Diagnóstico

Antonio Vallet-Bellmunt e Ilu Vallet-Bellmunt ...................................... 141

7.1. El diagnóstico y la toma de decisiones. ................................................... 143

7.2. Cartera de productos: definición y modelos de análisis............................. 143

7.3. Matriz crecimiento-cuota de mercado: enfoque Boston Consulting Group.

7.4. Matriz atractivo del mercado-competitividad de la empresa: enfoque McKinsey-General Electric.

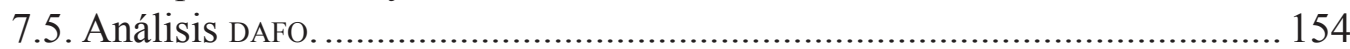

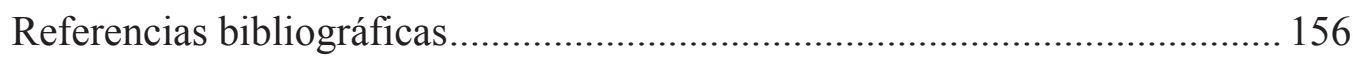

Capítulo 8. Fijación de objetivos y estrategias de marketing

Valentín Gallart-Camahort y Pilar Monte-Collado ................................ 157

8.1. La planificación en la empresa. ............................................................ 159

8.2. La misión de la organización y los objetivos corporativos...................... 159 


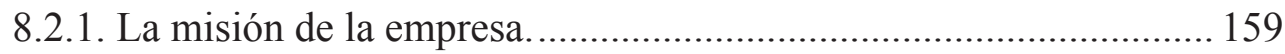

8.2.2. Los objetivos corporativos. ……................................................ 160

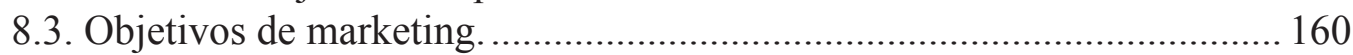

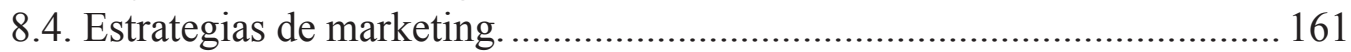

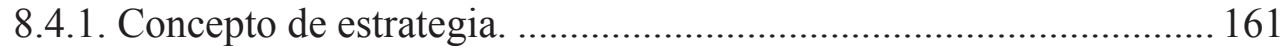

8.4.2. Clasificación de las estrategias de marketing.................................. 162

8.5. Estrategias genéricas de marketing respecto a la ventaja competitiva

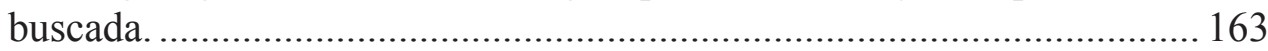

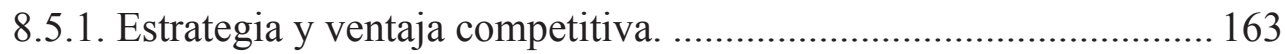

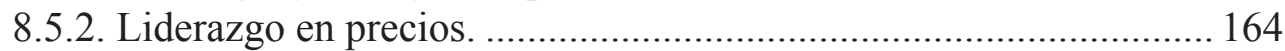

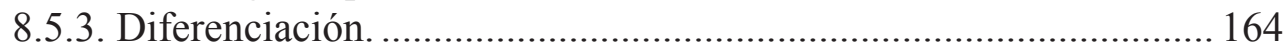

8.5.4. Enfoque o especialización (segmentación). .................................. 166

8.6. Estrategias competitivas en relación al entorno y en relación a los

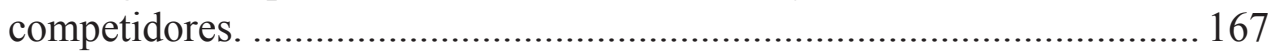

8.6.1. Estrategias competitivas en relación al entorno............................. 167

8.6.1.1. Estrategia prospectora o exploradora................................ 167

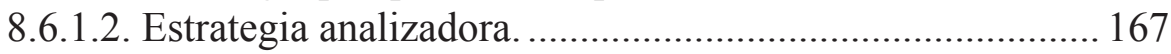

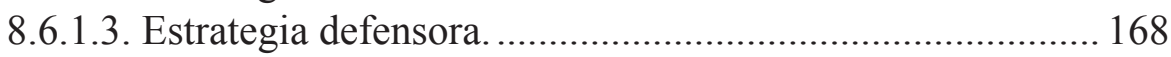

8.6.1.4. Estrategia reactiva.......................................................... 168

8.6.2. Estrategias competitivas en relación a los competidores. ............... 168

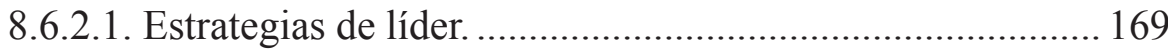

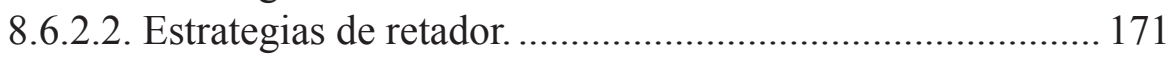

8.6.2.3. Estrategias de seguidor.................................................... 172

8.6.2.4. Estrategia para especialistas en nichos. ............................ 173

8.7. Estrategias de crecimiento o inversión, de mantenimiento y de

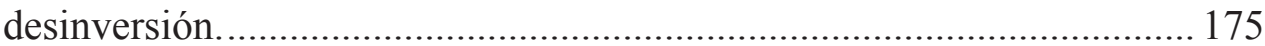

8.7.1. Estrategias de crecimiento o inversión........................................... 175

8.7.1.1. Estrategias de penetración de mercado.............................. 176

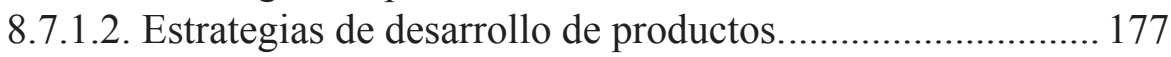

8.7.1.3. Estrategias de desarrollo de nuevos mercados................... 177

8.7.1.4. Estrategias de crecimiento diversificado e integración...... 179

8.7.2. Estrategias de mantenimiento y de desinversión.............................. 180

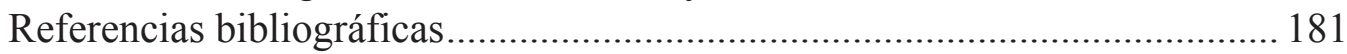

Capítulo 9. El diseño de la oferta de marketing

Marta Estrada-Guillén y Juan Carlos Fandos-Roig ................................... 183

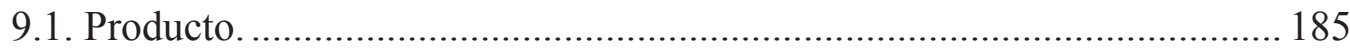

9.1.1. Niveles de productos y servicios................................................. 185

9.1.2. Clasificación de productos y servicios........................................... 185

9.1.2.1. Productos de consumo. .................................................... 185

9.1.2.2. Productos industriales....................................................... 186

9.1.2.3. Organizaciones, personas, lugares e ideas. ......................... 186

9.1.3. Decisiones de productos o servicios individuales.......................... 187

9.1.3.1. Los atributos del producto o servicio............................... 187

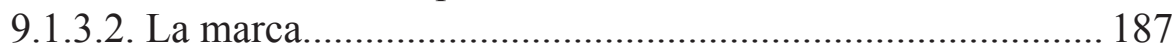

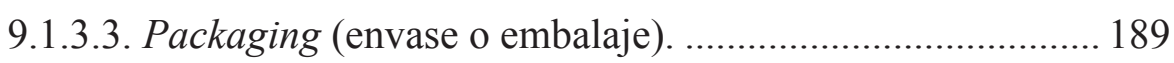

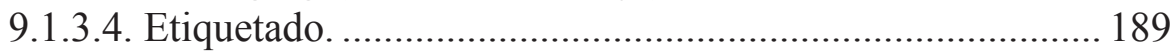

9.1.4. Decisiones sobre la cartera de productos y servicios. .................... 189 
9.2. Precio. 189

9.2.1. Métodos de fijación de precios.

9.2.1.1. Métodos basados en los costes......................................... 190

9.2.1.2. Métodos basados en la competencia.................................. 191

9.2.1.3. Métodos basados en la demanda......................................... 191

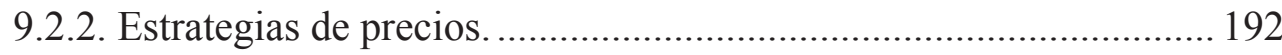

9.2.2.1. Productos nuevos. ........................................................... 192

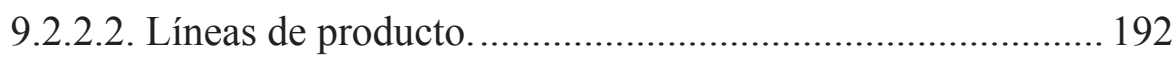

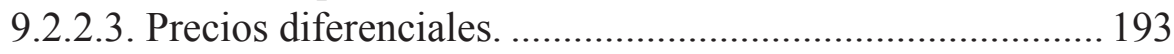

9.2.2.4. Precios psicológicos............................................................ 193

9.2.2.5. Precios geográficos. ....................................................... 194

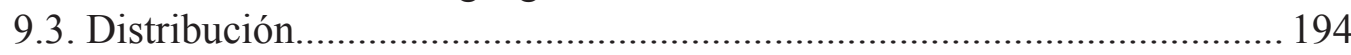

9.3.1. Cómo añaden valor los miembros del canal: Funciones de la

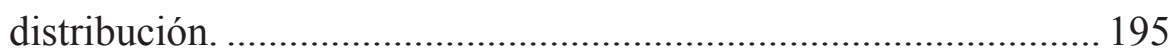

9.3.2. Decisiones en el canal de distribución. .......................................... 195

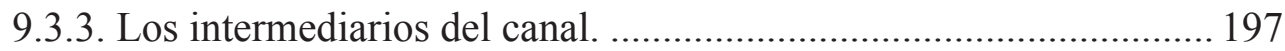

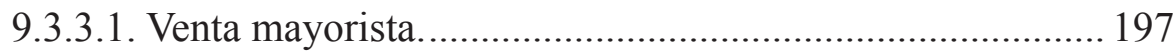

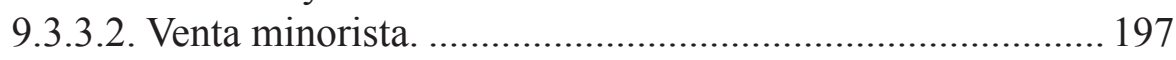

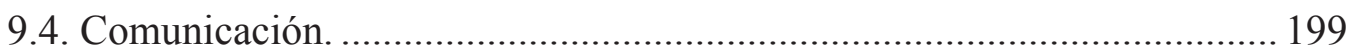

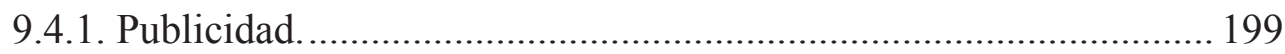

9.4.1.1. Métodos de fijación del presupuesto publicitario.............. 200

9.4.1.2. Desarrollo de la estrategia publicitaria. ........................... 200

9.4.1.3. Evaluación de la eficacia publicitaria............................... 201

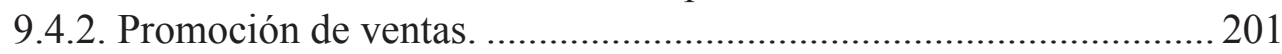

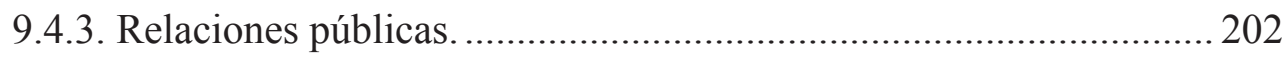

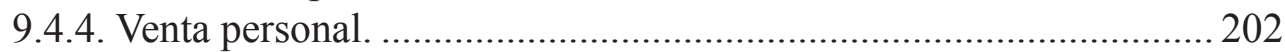

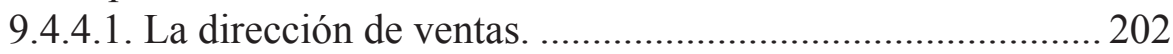

9.4.4.2. El proceso de venta personal........................................... 203

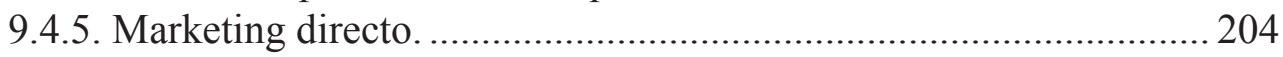

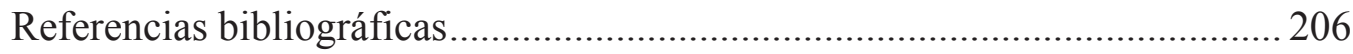

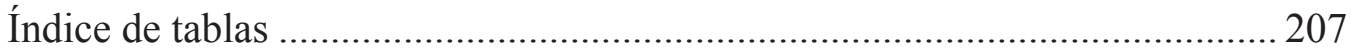

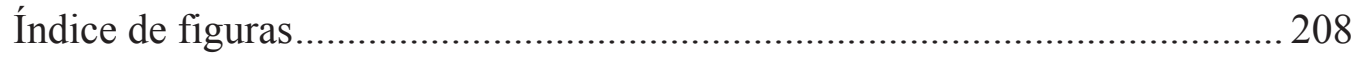




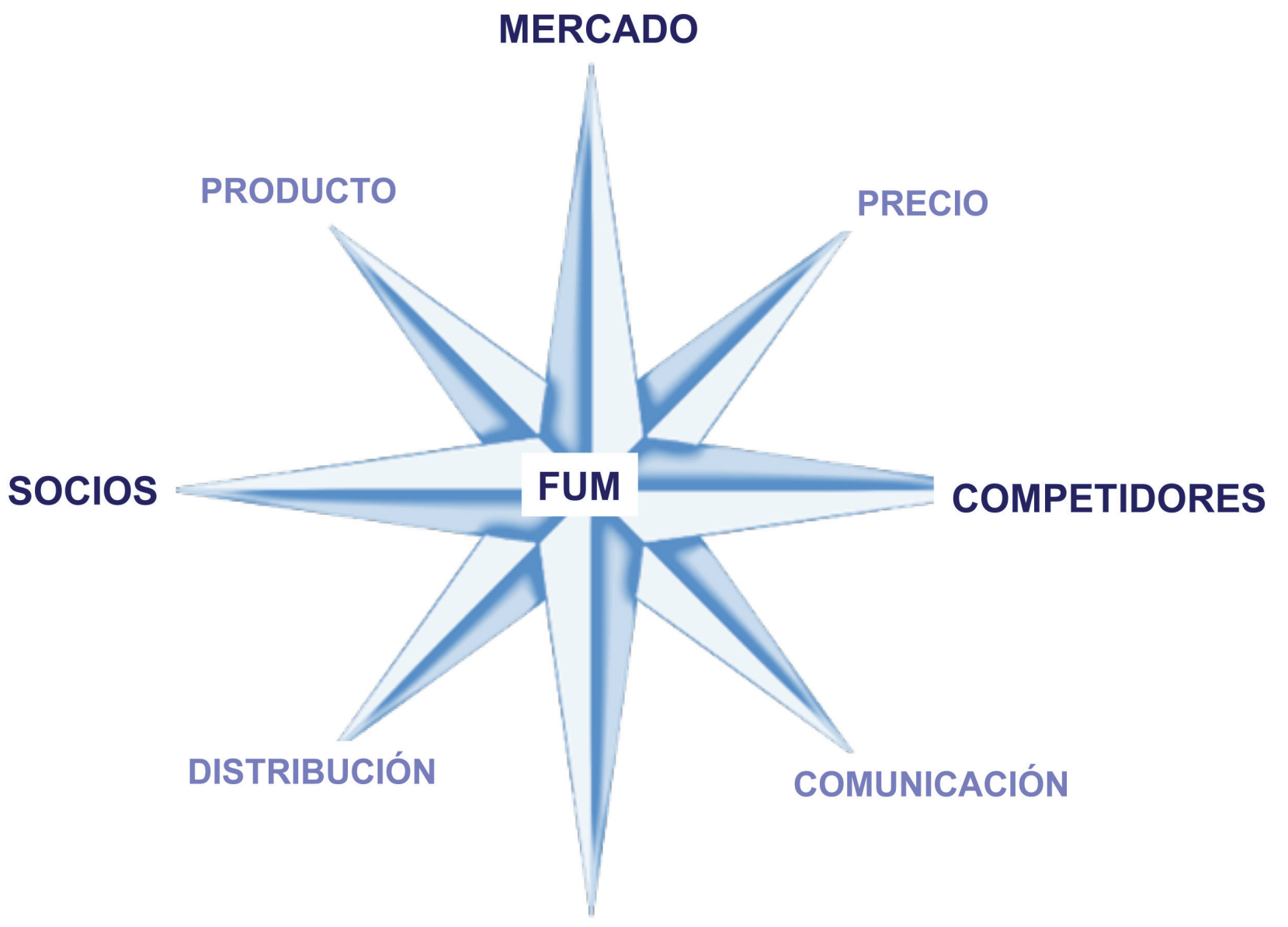

EMPRESA 

INTRODUCCIÓN

La asignatura Fundamentos
de marketing
en la Universitat Jaume I
y los proyectos
de innovación educativa
TERESA VaLLeT-BeLLMUNT 



\section{La asignatura Fundamentos de marketing en la Universitat Jaume I}

Este manual tiene como contexto la enseñanza del marketing en la Universitat Jaume I de Castellón y los planes de estudio de Economía, Finanzas y Contabilidad, y especialmente el Grado en Administración de Empresas. En la Universitat Jaume I, los tres grados se imparten conjuntamente y con las mismas asignaturas durante los dos primeros años. A partir del tercer año empiezan los itinerarios curriculares y se separan.

El estudio del marketing durante estos dos años se limita a una asignatura y media: en el primer curso el cuarenta por ciento de la asignatura «Introducción a la administración de empresas» se dedica al concepto de marketing y la filosofía de marketing en la empresa. En segundo curso se imparte la asignatura «Fundamentos de Marketing», a la que se dedica este manual. Para dotar de contenido a esta asignatura había que tener en cuenta que es la última asignatura de marketing que van a ver los alumnos de los grados de Economía y Finanzas y Contabilidad, pero es realmente la introducción al marketing de los alumnos del grado de Administración de Empresas, por lo que debe incluir los conceptos mínimos de marketing para aquellos que no van a volver a tener una asignatura de marketing, pero no tan avanzados como para solapar materias de cursos superiores para los alumnos de Administración de Empresas.

En la figura 1 puede verse el contenido de marketing en el Plan de estudios del grado de Administración de Empresas en la Universitat Jaume I. En el Plan de estudios no se ha contemplado una asignatura de dirección comercial, aunque sí una de marketing operativo. Teniendo esto en cuenta, se decidió que la asignatura de segundo curso, «Fundamentos de marketing», tuviese el contenido del marketing estratégico, o dimensión análisis del marketing. Por ello se diseñó el programa de la asignatura basándonos en la distinción entre marketing operativo (tercer curso) y estratégico (segundo curso). El hilo conductor de todo el libro es el proceso de marketing en la empresa, centrándose sobre todo en la fase análisis. Como los alumnos de los grados de Economía y Finanzas y Contabilidad no tienen más asignaturas de marketing, se añadió un tema sobre la dimensión acción (el diseño de la oferta comercial o marketing mix), que a su vez, servirá de enlace con la asignatura de tercero «Marketing Operativo» para los alumnos del Grado de Administración de Empresas.

Al decidir que el contenido debía ser marketing estratégico, el siguiente paso fue identificar los manuales más adecuados para cubrir la asignatura. Durante el primer año utilizamos tres manuales a la vez que abordaban el temario desde ángulos distintos y complementarios. Sin embargo, los alumnos tenían problemas en trabajar tanta bibliografía básica, y así nos lo hicieron saber en las encuestas de evaluación. Por ello decidimos hacer este manual, en el que han participado todos los profesores que imparten teoría en esta asignatura. 


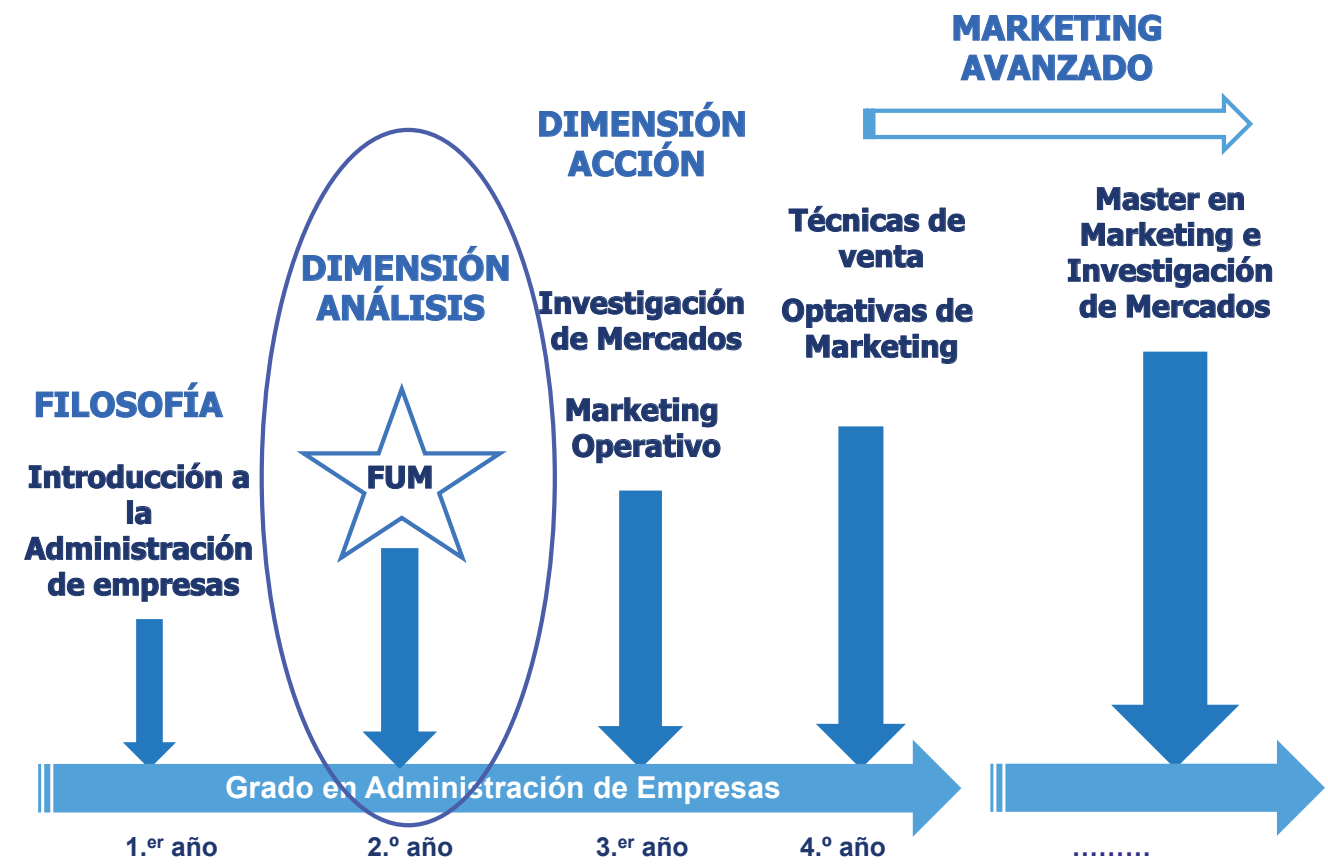

Figura 1. Enseñanza de marketing en la Universitat Jaume I

Fuente: Elaboración propia

Este manual está enfocado a cubrir estos aspectos particulares de la enseñanza de marketing en la Universitat Jaume I. Su característica principal es que incluye toda la teoría que creemos necesaria para lograr los objetivos establecidos en la guía docente de la asignatura «Fundamentos de Marketing», pero no incluye el contenido que se imparte en otras asignaturas del plan de estudios. ${ }^{1}$ Es por ello que el título del manual, Principios de marketing estratégico, se adecua más a su contenido.

Por otro lado, este manual es eminentemente teórico, ya que los ejemplos actualizados y la parte más práctica de la asignatura se dejan para las presentaciones de las clases en el aula. Por último, como nos hemos inspirado en los manuales que tradicionalmente se utilizaban en las clases de Dirección Comercial de la antigua Licenciatura en Administración de Empresas, si algún alumno desea profundizar contenidos en marketing más avanzados, al final de cada capítulo se recomiendan los manuales más adecuados.

Esperamos que este manual ayude a los alumnos a entender las actividades de marketing en la empresa, la importancia de la fase del análisis antes de tomar decisiones y refuerce la necesidad de saber qué es lo que se necesita antes de diseñar una oferta para el mercado.

1. Por ejemplo, la asignatura «Introducción a la administración de empresas», que es el primer contacto de marketing de nuestros estudiantes, incluye en su temario aspectos como: la definición y la filosofía de marketing, la orientación al mercado y el marketing de relaciones, las tendencias actuales del marketing, factores del macro-entorno y el micro-entorno y cómo se analiza el entorno mediante fuentes primarias y secundarias. Por otro lado, ya en el Plan de estudios de Administración de Empresas, la asignatura de tercero «Marketing operativo» desarrolla todos los elementos del marketing mix: producto, precio, distribución y comunicación, y la asignatura «Investigación de mercados» cubre las técnicas y el proceso para realizar investigaciones de marketing en la empresa. 


\section{Los proyectos de innovación educativa}

Para entender mejor las actividades que se realizan en la asignatura y el énfasis que se pone en el trabajo cooperativo, hay que conocer la política de innovación educativa que se está realizando en la Universitat Jaume I. La asignatura «Fundamentos de marketing» se impartió por primera vez durante el curso 2011-2012. Durante ese curso se puso en marcha la primera convocatoria de Grupos de Innovación Educativa (GIE) por parte de la Universitat Jaume I. Algunos de los profesores que iban a impartir la asignatura de «Fundamentos de marketing» solicitaron la creación del GIE TEAM (Grupo de Innovación Educativa: Tecnología, Equipos y Actividades Motivadoras). Estos profesores llevaban varios años compartiendo la asignatura de «Dirección Comercial» en la extinta Licenciatura de Administración de Empresas, donde ya se habían realizado durante los últimos años diversas actuaciones de innovación educativa: los alumnos trabajaban en equipos cuyos componentes eran elegidos en función de la personalidad de sus miembros y su actitud hacia el trabajo en equipo y se puso en marcha durante varios años un concurso como actividad motivadora para el aprendizaje de la asignatura.

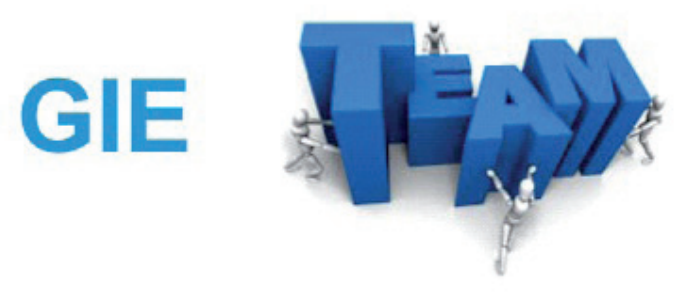

Figura. 2. Logotipo del GIE TEAM (Tecnología, Equipos y Actividades Motivadoras) Fuente: Elaboración propia

El GIE TEAM tiene tres elementos en los que basar su actuación. En primer lugar el trabajo cooperativo. Los componentes del GIE TEAM tienen una gran motivación por el trabajo en equipo. La forma de investigar y trabajar el aprendizaje cooperativo en el aula ha sido a través de la construcción de un modelo sobre los antecedentes y consecuencias del aprendizaje cooperativo, la formación de equipos de carácter heterogéneo por parte de los profesores, mediante la utilización del test de Belbin, y la medida de la actitud hacia el trabajo en equipo. En segundo lugar, las actividades motivadoras para el aprendizaje. En una asignatura de amplio contenido teórico, los alumnos dejaban el estudio de la materia para el final, con el desaprovechamiento de la parte práctica de la asignatura. Para aumentar la motivación de los estudiantes se ideó el instrumento del concurso. En un principio, este juego se enfocó hacia la elaboración por parte de los alumnos, por equipos, de una batería de preguntas tipo test, que posteriormente fue utilizada como cuestiones en el concurso, realizado en dos torneos, y que ellos debían contestar en base a los conocimientos adquiridos en el módulo teórico de la asignatura. En el último curso, las cuestiones las elaboraban los profesores. Por último y en tercer lugar, las nuevas tecnologías aplicadas a la educación. En un primer momento se aplicaron las Google APPS en la docencia y en el aprendizaje cooperativo: Google 
Docs, Sites, Blogger, Google +, Google Reader, etc., enseñando a los alumnos a compartir ficheros y aprovechar el tiempo dedicado al trabajo en equipo. Además, para mejorar la actividad del concurso, durante el curso 2013-2014 se incluyó la utilización de los mandos de respuesta interactiva (Educlick).

Para realizar estas actividades, el GIE TEAM ha contado con la ayuda de la Unitat de Suport Educatiu y del Vicerectorat d'Estudiants, Ocupació i Innovació Educativa de la Universitat Jaume I, a través de las convocatorias anuales de proyectos de innovación educativa. Así, durante los pasados cursos académicos se han conseguido los siguientes proyectos:

- Durante el curso 2012-2013, con la realización del proyecto: «Influencia del aprendizaje cooperativo del marketing estratégico en el rendimiento de los estudiantes», se recogieron datos sobre cómo medir el aprendizaje cooperativo y la relación de este con los resultados objetivos (rendimiento) y resultados subjetivos de aprendizaje (percepciones). Este modelo se aplicó a la asignatura «Fundamentos de marketing» y para dos actividades motivadoras: concurso (TGT: Team-Game-Tournament) y plan de marketing (GI: Group Investigation). Con ello se construyó el modelo teórico del GIE TEAM (véase figura 3 ).

- Durante el curso 2013-2014, con el proyecto «Antecedentes y efectos del aprendizaje cooperativo en marketing. Influencia de las nuevas tecnologías: Educlick», se aplicaron varias mejoras a la asignatura «Fundamentos de marketing». Se volvió a medir el aprendizaje cooperativo y se le relacionó con los resultados objetivos y subjetivos, modificando dos aspectos: se incluyó en el resultado objetivo la evaluación de compañeros y se modificó una de las actividades motivadoras añadiendo nuevas tecnologías (Educlick).

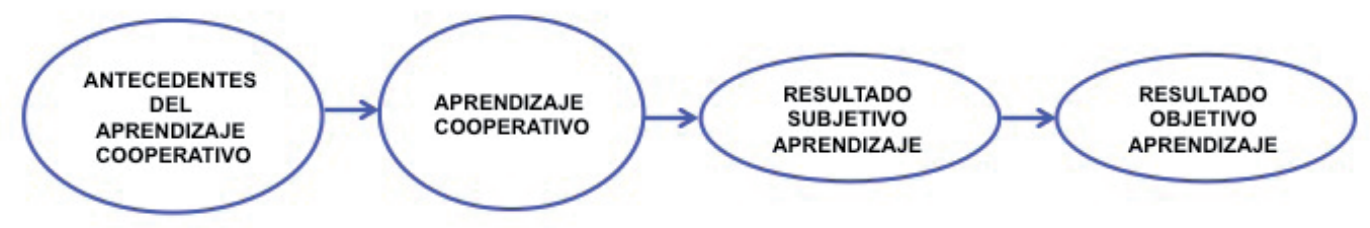

Figura 3. Modelo del GIE TEAM

Fuente: Elaboración propia

- Durante los cursos 2014-2015 y 2015-2016, con el proyecto «Aprendizaje cooperativo: formación de equipos y evaluación entre pares. Una comparación multidisciplinar e internacional», se pretenden estudiar dos de los elementos del modelo del GIE TEAM, concretamente uno de los antecedentes: la formación de equipos, y una de las consecuencias: el resultado objetivo según su forma de evaluación, mediante la evaluación entre alumnos. Aparte de esta mejora, se desea hacer una doble comparativa, en primer lugar entre asignaturas pertenecientes a dos áreas distintas, pero afines: Organización de Empresas y Comercialización e Investigación de Mercados; en segundo 
lugar, entre dos universidades situadas en dos países distintos: Universitat Jaume I (España) y Universidade de Brasilia (Brasil).

Para terminar, comentarermos que el GIE TEAM está formado por los profesores del Área de Comercialización e Investigación de Mercados de la Universitat Jaume I Teresa Vallet, Ilu Vallet, Toni Vallet y Víctor del Corte; así como profesores del Área de Organización de Empresas Teresa Martínez, F. Xavier Molina y Luis Martínez. Además, cuenta con la colaboración de la profesora Pilar Rivera, de la Universidad de Zaragoza y de los profesores de la Universidade de Brasilia Emil Hoffmann, José Marcio Carvalho y Flavio Manoel Coelho Borges. Cualquier aspecto o duda relacionados con el aprendizaje cooperativo lo podréis consultar con cualquiera de ellos. 



\section{CAPÍTULO 1}

\section{El proceso de marketing en la empresa Teresa Vallet-Bellmunt}

\section{Contenido del capítulo}

El punto de partida del proceso de marketing se encuentra en analizar y detectar las necesidades de los compradores potenciales y ofrecer una satisfacción a las mismas con mayor valor que la competencia y con beneficio para la empresa. El alumno entenderá los componentes de la dimensión análisis (marketing estratégico) y los de la dimensión acción (marketing operativo) y su complementariedad para lograr satisfacer dichas necesidades.

A continuación, se trasladará todo el análisis de la información recogida del entorno así como las decisiones tomadas por la empresa en un documento, el plan de marketing, que es el que facilitará la toma de decisiones de marketing en la empresa de una forma eficiente. Los alumnos conocerán sus distintas fases, su ejecución y cómo se llevará el control de su cumplimiento. 
1.1. El proceso de marketing en la empresa

1.1.1. Definición de marketing

1.1.2. El proceso de marketing para crear valor para el cliente

1.1.3. Estructura de este manual

1.2. Marketing estratégico versus marketing operativo

1.2.1. Dimensión análisis: naturaleza del marketng estratégico

1.2.2. Dimensión acción: naturaleza del marketing operativo

1.2.3. Similitudes y diferencias entre las actividades del marketing estratégico y operativo

1.3. El plan de marketing

1.3.1. Fases en el plan de marketing

1.3.2. Ejecución de las actividades del plan de marketing

1.3.3. El control de las actividades de marketing

Referencias bibliográficas 


\subsection{El proceso de marketing en la empresa}

Las actividades de marketing que se realizan dentro de una empresa constituyen el proceso de marketing. El primer paso para entender dicho proceso está en saber qué es marketing, que es una palabra frecuentemente mal entendida, no solo por sus detractores sino también por sus defensores (Lambin et al., 2009). Tres son los significados que se le suele dar:

- Marketing es publicidad, promoción y venta agresiva con el objetivo de penetrar en los mercados, sobre todo en los de consumo masivo.

- Marketing es un conjunto de herramientas de análisis, métodos de previsión de ventas, modelos de simulación y estudios de investigación de mercado, que se usan para realizar un análisis de la demanda y de las necesidades del mercado, que pueden utilizarse solo por las empresas de gran tamaño.

- Marketing es el promotor y arquitecto de la sociedad de consumo, esto es, un sistema de mercado donde los individuos son comercialmente explotados por los vendedores, que les hacen comprar productos que no necesitan. El marketing crea continuamente nuevas necesidades.

Detrás de estas percepciones simplificadas hay tres dimensiones características del concepto de marketing: la dimensión acción, la dimensión análisis y la dimensión filosofía. Esto nos permite dar una definición global del concepto de marketing.

\subsubsection{Definición de marketing}

Marketing es una orientación (filosofía o sistema de pensamiento) de la dirección de la empresa que sostiene que la clave para alcanzar las metas (objetivos) de la organización reside en averiguar las necesidades y deseos del mercado objetivo (dimensión análisis) y en adaptarse para diseñar la oferta (dimensión acción) deseada por el mercado, mejor y más eficiente que la competencia.

Esta definición nos permite destacar las tres dimensiones necesarias que subyacen bajo el concepto de marketing y que permiten obtener una ventaja competitiva de la que depende el resultado de la empresa. Para que la empresa obtenga la ventaja competitiva, es necesario que se den las tres dimensiones. Si una de ellas no está, no se puede decir que la empresa comprenda y aplique el concepto de marketing.

La dimensión filosofía del marketing, denominada actualmente «orientación al mercado», descansa en una teoría de elección individual que se da a través del principio de soberanía del comprador (Lambin et al., 2009). Esta filosofía es totalmente contrapuesta a la idea de que el marketing hace que el mercado acepte cualquier cosa a través de los poderosos medios de comunicación, haciéndola bastante discutible, fundamentalmente por dos motivos: la racionalidad del comprador y el 
índice de fracasos de nuevos productos (más del $40 \%$ ) que indica la capacidad de resistencia del mercado a la seducción de los vendedores. Mediante la orientación al mercado, la empresa tiene claro que la única forma de obtener una ventaja competitiva sostenible en el tiempo y defendible frente a la competencia es analizando cuáles son las necesidades de los compradores y en función de ellas diseñar la oferta más adecuada y de forma más eficaz que la competencia.

La dimensión filosofía se produce en el nivel corporativo de la empresa. El nivel corporativo es el encargado de definir la misión corporativa, identificar las unidades estratégicas de negocio (en adelante UEN), asignar recursos a cada UEN e identificar nuevas oportunidades de negocio (Kotler et al., 2006). Las empresas que tienen la dimensión filosofía de marketing se encargan de transmitir al conjunto de la empresa la necesidad de adoptar la orientación al mercado como fuente sólida de generación de ventaja competitiva basada en el conocimiento del mercado (Munuera y Rodríguez, 2007). La satisfacción de las necesidades se convierte en el objetivo principal de la empresa, dado que de esta forma se alcanzan los otros objetivos de rentabilidad y crecimiento. No es el altruismo, sino el propio interés de la organización el que dicta este curso de acción (Lambin et al., 2009). En la figura 4 se observa el nivel corporativo del Grupo Inditex, junto con el resto de niveles de decisión del grupo.

La dimensión análisis, se ocupa de analizar y comprender el mercado, identificar oportunidades y desarrollar las habilidades y recursos de la empresa para satisfacer las necesidades y deseos de los compradores mejor que la competencia (Munuera y Rodríguez, 1998). La función del marketing que se ocupa de la dimensión análisis se denomina marketing estratégico. Para entender la dimensión análisis es importante saber la diferencia entre necesidad, deseo y demanda (Armstrong et al., 2011). Las necesidades son estados de carencia percibida que incluyen necesidades físicas como alimentos, ropa, calor, seguridad, necesidades sociales de pertenencia y afecto y necesidades individuales de conocimiento y autoexpresión. Las necesidades no son creadas por los expertos de marketing, sino que son inherentes al ser humano. Por otro lado, los deseos son las distintas alternativas entre las que escoge el comprador para satisfacer una necesidad, y pueden influir sobre ellos la cultura, la personalidad del comprador y las acciones de marketing de las empresas oferentes. Cuando los deseos están respaldados por el poder de compra se convierten en demandas. En función de los deseos y de los recursos económicos disponibles, los compradores demandan productos (bienes tangibles, servicios o ideas) para satisfacer sus necesidades. Por ejemplo, imaginemos que la necesidad de estar comunicado de un individuo, puede ser satisfecha con varios teléfonos móviles distintos (deseos) y según su presupuesto, el elegido sería el Modelo A (demanda). Varias empresas de telefonía móvil podrían ampliar su demanda si permiten el pago a plazos del terminal Modelo A. 


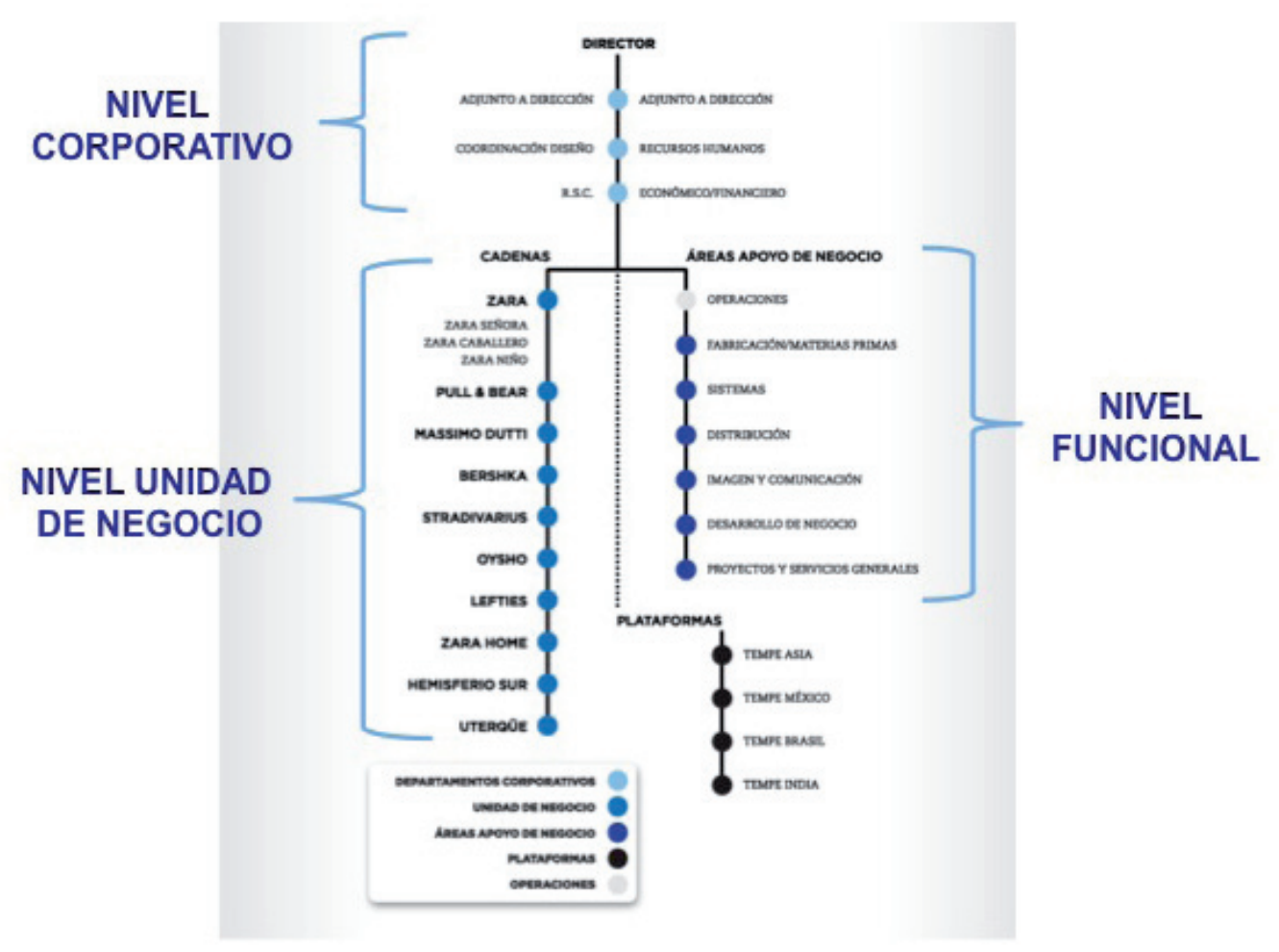

Figura 4. Niveles organizativos de INDITEX

Fuente: Adaptado de http://www.tempe.es/tempe/web/guest/organigrama, Grupo Inditex

La dimensión análisis se produce en el nivel organizativo de UEN o de productomercado. Una unidad estratégica de negocio (UEN) es una unidad u órgano empresarial, compuesta por uno o más productos muy determinados, que tienen un mercado básico común, muy delimitado, al frente de la cual hay un manager o directivo que tiene la responsabilidad de integrar todas las funciones, mediante una estrategia, frente a uno o varios competidores identificables. Las características que se derivan de esta definición son pues: 1) Una misión única y diferenciada, 2) Unos competidores perfectamente identificados, 3) Un mercado totalmente identificado, y 4) Control de sus funciones de negocio. Por ejemplo, Zara sería una unidad de negocio del grupo Inditex (véase figura 4). Un negocio también puede ser definido en torno a tres dimensiones: grupo de clientes, necesidad de los compradores y tecnología (Kotler et al., 2006), por lo que constituirían lo que se denomina producto-mercado, que analizaremos más adelante, en el capítulo 2.

Por último, la dimensión acción se ocupa de poner a disposición del comprador la oferta que la empresa ha diseñado para satisfacer sus necesidades, es decir, desciende al plano de la acción para llevar a cabo las estrategias escogidas en la dimensión análisis. La función del marketing que se ocupa de la dimensión análisis se denomina marketing operativo. El producto, el precio, la distribución y la comunicación serán los instrumentos que la empresa utilizará, formando el marketing mix o las 4 Pes (porque en inglés provienen de las palabras: Product, Price, Place and Promotion). 
La dimensión acción se produce en el nivel funcional, es decir en el departamento de marketing o departamentos que realicen las funciones de marketing. Por ejemplo, en la figura 4 se puede observar que las áreas de distribución y de imagen y comunicación realizan alguna de las funciones de marketing de las distintas unidades de negocio del grupo Inditex.

\subsubsection{El proceso de marketing para crear valor para el cliente}

Una segunda definición de marketing es la que nos proporcionan Armstrong et al., (2011), que establecen que marketing es un proceso mediante el cual las empresas crean valor para los clientes y establecen relaciones sólidas con ellos, obteniendo a cambio el valor de los clientes (ventas y lealtad del cliente a largo plazo). Esta definición se centra en el proceso que se produce en la empresa con la puesta en marcha de la filosofía de marketing y que consta de cinco pasos, como se observa en la figura 5.

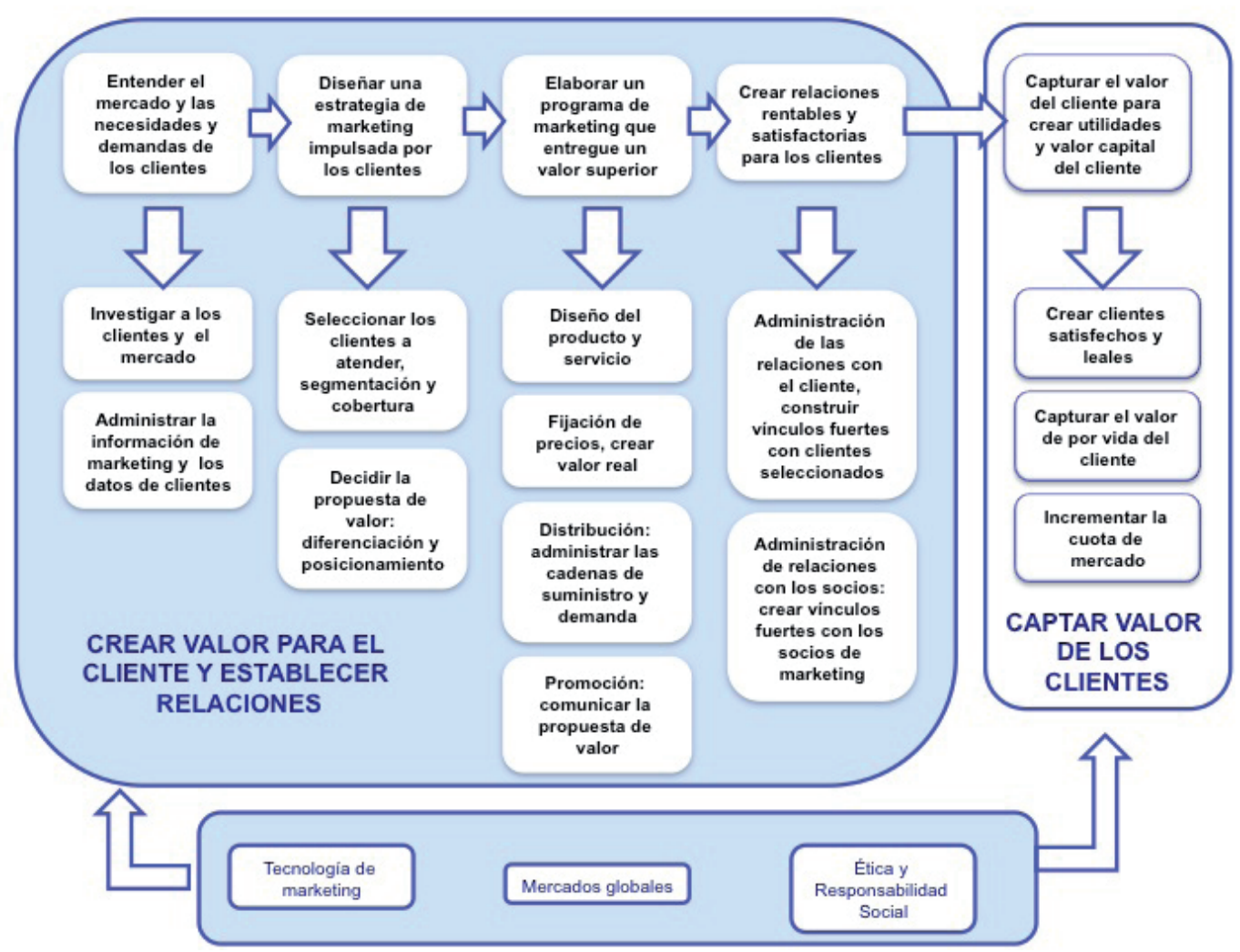

Figura 5. Modelo del proceso de marketing para crear valor al cliente Fuente: Armstrong et al., (2011)

El punto de partida del marketing consiste en entender las necesidades y deseos de los clientes. Para ello la empresa pone en marcha la dimensión análisis e investiga a los clientes y al mercado y crea bases de datos con esa información. Todo el proceso se va a basar en este primer paso, en la identificación de las necesidades, los deseos que prefiere el mercado para satisfacer las necesidades y las demandas efectivas que tiene la competencia y que podría tener la empresa. 
En el segundo paso, la empresa diseña una estrategia de marketing basada en el análisis previo del mercado. Así las dos preguntas básicas en esta fase son: 1) ¿a qué clientes voy a atender, o lo que es lo mismo, cuál va a ser mi público objetivo?, por lo que tendrá que analizar si existen segmentos en el mercado, medir su atractivo y seleccionar los más adecuados para la empresa, porque es muy difícil cubrir todo el mercado (cobertura) y 2) ¿cómo puedo atender mejor a mi público objetivo?, por lo que la empresa tendrá que decidir su propuesta de valor, es decir, su estrategia de diferenciación y posicionamiento para atraer al público objetivo.

En la tercera etapa la empresa debe elaborar un programa de marketing mix que concrete la estrategia de marketing diseñada en la etapa anterior en valor real para los clientes: diseñar el producto, fijar el precio, administrar los canales de distribución y comunicar la propuesta de valor.

El comprador que queda satisfecho, tiene una elevada probabilidad de repetir. Los clientes son compradores que repiten sus compras con la empresa hasta el punto de que la consideran su proveedor en exclusiva para ese tipo de productos. Por ello, en el cuarto paso, la empresa debe construir relaciones rentables y satisfactorias con sus clientes, creando vínculos con ellos y también con las empresas que ayudan a la empresa a mantener e intensificar dichas relaciones: los proveedores y los distribuidores.

Por último, la empresa podrá recoger los frutos derivados del valor creado: captar el valor del cliente, es decir crear clientes satisfechos y leales, crear relaciones a largo plazo con ellos e incrementar la cuota de mercado y las ventas.

Estas cinco fases complementan la definición tridimensional del marketing. El que el punto de partida del proceso se encuentre en las necesidades del mercado (orientación al mercado) está en consonancia con la dimensión filosofía, al igual que el énfasis en construir relaciones rentables y duraderas con los clientes (marketing de relaciones). En segundo lugar, todas las tareas que implican estudiar el mercado, elegir el público objetivo y diseñar la propuesta de valor pertenecen a la dimensión análisis. En tercer lugar, elaborar un programa con las 4 Pes es parte de las tareas asignadas a la dimensión acción. Por último, captar el valor de los clientes es el objetivo principal de marketing, que le va a proporcionar su ventaja competitiva.

\subsubsection{Estructura de este manual}

Teniendo claro lo que se entiende por marketing, este manual va a basar su contenido en la dimensión análisis, o lo que es lo mismo, en la parte del marketing denominada marketing estratégico. En la figura 6 se pueden observar las tres dimensiones del marketing, el nivel organizativo en el que se aplican, y las tareas asignadas a cada dimensión. 


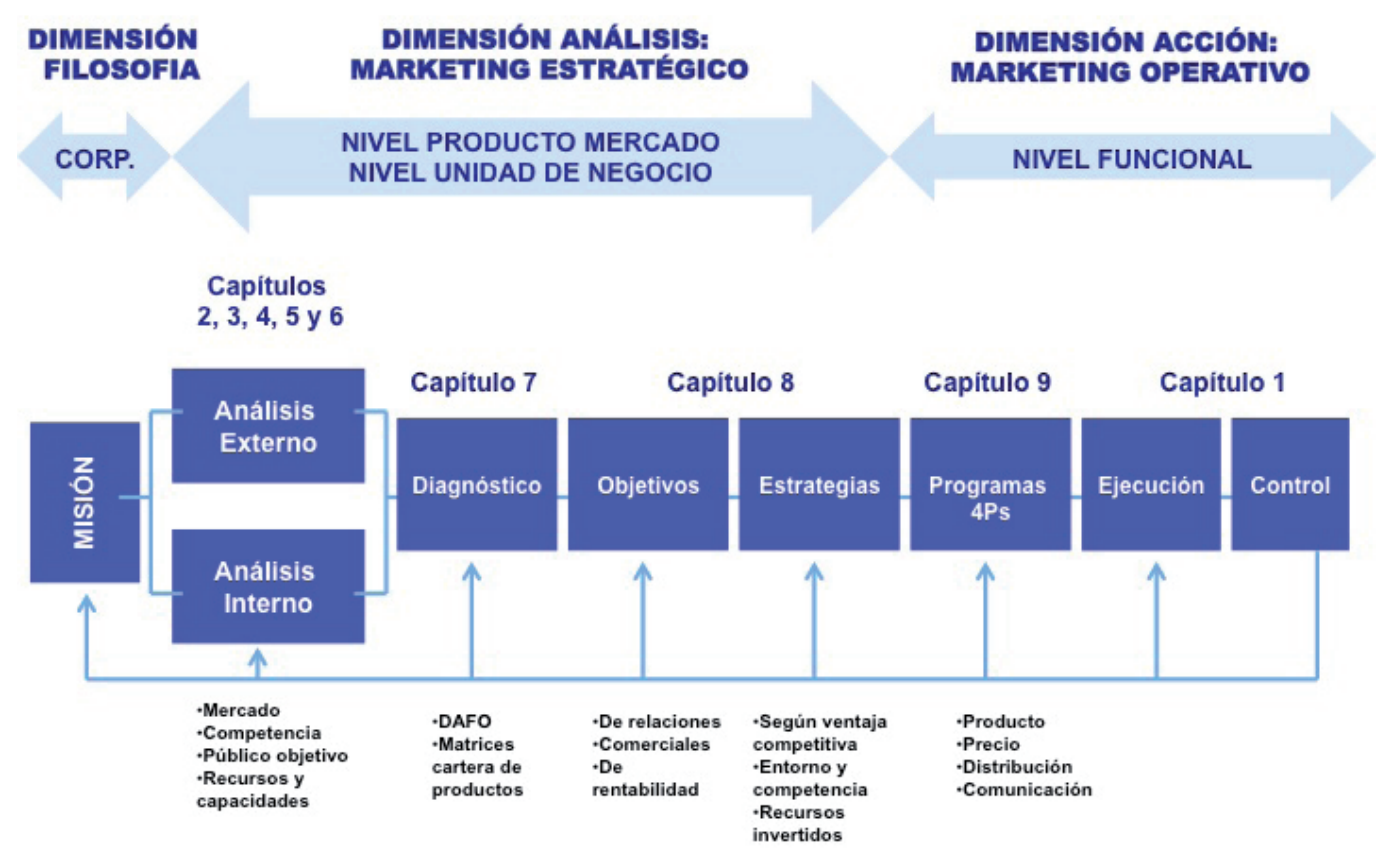

Figura 6. Dimensiones, tareas del marketing y estructura de este manual Fuente: Elaboración propia en base a Kotler et al., (2006) y Lambin et al., (2009) y el contenido de este manual

Respecto al marketing estratégico, en primer lugar vamos a ver un tema introductorio sobre las diferencias entre el marketing estratégico y operativo y las características del plan de marketing (capítulo 1), que es un documento donde se recogen las distintas fases del proceso de análisis, planificación, organización, ejecución y control de las actividades de marketing en la empresa.

A continuación, veremos cómo llevar a cabo el análisis de la situación de marketing de la empresa. Para ello, en primer lugar analizaremos el mercado (capítulo 2) y cómo se comportan los compradores, tanto los individuos como las empresas (capítulo 3). En segundo lugar, cómo se comporta la competencia (capítulo 4). En tercer lugar, elegiremos el público objetivo o segmento/s a los que se va a dirigir la empresa (capítulo 5) y su oferta de valor o posicionamiento (capítulo 6). Para terminar el análisis de situación, tendremos que saber cuáles son los recursos y capacidades de la empresa para poder atender a su público objetivo. Con toda la información analizada en la etapa anterior, la empresa ya es capaz de realizar un diagnóstico (capítulo 7), utilizando instrumentos como el DAFo (Debilidades, Amenazas, Fortalezas y Oportunidades) o las matrices de cartera de productos, lo que le permitirá saber dónde se encuentra.

La siguiente tarea del marketing estratégico es fijar los objetivos que la empresa desea conseguir, es decir, dónde desea ir. Los objetivos de marketing son de tres tipos: de relaciones, de la actividad comercial y de rentabilidad. Una vez se sabe dónde está la empresa y dónde desea ir, existen múltiples caminos para hacer1o. A estas posibilidades se les denomina estrategias. En este manual veremos tres tipologías de estrategias de marketing: en función de la ventaja competitiva 
buscada, en función de cómo la empresa responde al entorno y a la competencia y en función de los recursos que la empresa quiere invertir en la consecución de sus objetivos. Los objetivos y estrategias de marketing los veremos en el capítulo 8 .

Para terminar, se dedica un tema al marketing operativo (capítulo 9), donde brevemente se explican los programas de marketing mix. ${ }^{1}$

A continuación vamos a detallar las características del marketing estratégico y operativo y las diferencias entre ambos.

\subsection{Marketing estratégico versus marketing operativo}

Para entender bien el proceso de marketing en la empresa, se han de conocer las actividades que se realizan tanto en la dimensión análisis como en la dimensión acción. Por ello, en este apartado se explicará en primer lugar la naturaleza del marketing estratégico, a continuación la naturaleza del marketing operativo, para terminar con las similitudes y diferencias que existen entre ambos conceptos.

\subsubsection{Dimensión análisis: naturaleza del marketing estratégico}

Según Lambin et al. (2009), el marketing estratégico es la mente estratégica de la organización. Para Munuera y Rodríguez (1998) se define marketing estratégico como la metodología de análisis que pretende el conocimiento de las necesidades de los consumidores y la estimación del potencial de la empresa y de la competencia para alcanzar una ventaja competitiva sostenible en el tiempo y defendible frente a esta. Esta definición incluye cuatro cuestiones que la empresa debe responder:

- ¿Cuáles son las necesidades y deseos de los compradores? Para responder esta cuestión la empresa debe realizar un análisis estratégico del mercado, es decir analizar el mercado de referencia, el mercado relevante, el productomercado y el mercado objetivo. Toda organización, si desea sobrevivir debe definir la naturaleza de su actividad en términos de las necesidades genéricas del mercado al que se dirige. Esto es el mercado de referencia, que requiere tres dimensiones: la necesidad que la empresa satisface, los grupos de compradores (particulares, empresas y organismos públicos) y las distintas alternativas tecnológicas que satisfacen dicha necesidad. Según las alternativas tecnológicas que posea la empresa y los grupos de compradores escogidos por ella se determina el mercado relevante, es decir el mercado servido por la empresa y en el que va a competir. La unidad mínima de dicho mercado es el producto -mercado. En él la empresa estudiará el comportamiento de

1. Este tema está dirigido a cubrir la asignatura Fundamentos de Marketing, compartida por los Planes de estudio de los grados de Administración de Empresas, Finanzas y Contabilidad y Economía, en segundo curso. Los alumnos del Grado de Administración de Empresas tienen una asignatura de marketing operativo en tercer curso pero los otros dos grados no incluyen ninguna otra asignatura de marketing, y por ello es aconsejable ver el proceso completo. 
compra de los particulares, de las organizaciones o de los organismos públicos y los factores que influyen sobre este. Además identificará las distintas preferencias para satisfacer la misma necesidad, y si estas preferencias están agrupadas, creándose los segmentos. Los segmentos escogidos por la empresa para competir constituirán su mercado objetivo.

- ¿Cómo lo está haciendo la competencia? La empresa debe conocer el grado de rivalidad que existe en los distintos niveles del mercado. Para ello la empresa deberá identificar los competidores y obtener la máxima información sobre ellos para saber cómo lo están haciendo. Aquí la empresa debe tener una idea de competencia amplia para no caer en la «miopía del marketing». Así, desde el enfoque marketing, los competidores son aquellos que satisfacen la misma necesidad que la empresa (y no los que fabrican lo mismo que ella) y que por lo tanto, son el abanico de alternativas entre las que los compradores pueden escoger para satisfacer su necesidad. Por ejemplo, imaginemos la necesidad de poner suelo en una casa para un comprador particular. Las diferentes alternativas tecnológicas podrían ser moqueta, cerámica, madera, hormigón, corcho, etc. Si la empresa fabrica pavimento cerámico, sus competidores no son solo los otros fabricantes de productos cerámicos (esto sería miopía del marketing), sino los fabricantes de todas las alternativas tecnológicas. Analizando la tarea que la competencia está haciendo en los diferentes segmentos identificados en la etapa anterior, la empresa valorará el atractivo de cada segmento.

- ¿Cuál es el potencial de la empresa? La empresa debe hacer un análisis de sus recursos y de sus capacidades para ver si es capaz de aprovechar las distintas oportunidades que está identificando en su entorno. Con el análisis interno y con el análisis del mercado y de la competencia, la empresa realizará un diagnóstico utilizando diversos instrumentos como el análisis DAFO y las matrices de cartera de productos. Con este diagnóstico la empresa puede elegir el segmento o segmentos a los que se va a dirigir (mercado objetivo) y establecer la propuesta de valor que va a ofrecer en cada segmento: el posicionamiento.

- ¿Qué podemos hacer mejor que la competencia para conseguir la ventaja competitiva? Para conseguir una ventaja competitiva, la empresa deberá fijar sus objetivos de marketing y elegir un conjunto de estrategias para alcanzarlos. Los objetivos de marketing son de tres tipos: objetivos de relaciones con los distintos agentes del micro-entorno (compradores, proveedores, distribuidores e incluso competidores), objetivos comerciales (ventas, cuota de mercado o cualquier objetivo de las 4 Pes) y objetivos de rentabilidad de las actividades de marketing (margen comercial, beneficio comercial, costes comerciales). Los análisis del atractivo de mercado y de la competencia, los recursos y capacidades de la empresa y el establecimiento de objetivos posibilitan la elección de la mejor estrategia de marketing para lograrlos. Las múltiples alternativas estratégicas o estrategias que vamos a analizar en este manual son: las estrategias en función de la ventaja competitiva perseguida 
(basada en la tipología de Porter), las estrategias según la respuesta al entorno (basada en la tipología de Miles y Snow) y de respuesta a la competencia (tipología de Kotler y Singh) y las estrategias según los recursos invertidos (crecimiento, mantenimiento y desinversión).

\subsubsection{Dimensión acción: naturaleza del marketing operativo}

El marketing operativo es un proceso orientado a la acción que se extiende sobre un horizonte de planificación a corto y medio plazo. Según Lambin et al. (2009), es el brazo comercial de la empresa. El marketing operativo desciende al plano de la acción (dimensión acción) para hacer frente a la puesta en marcha de las estrategias. Las tres tareas principales del marketing operativo son la elaboración del plan de marketing, la organización y ejecución de las tareas de marketing para llevar a buen puerto el plan de marketing y las actividades de control para verificar si se están obteniendo los objetivos propuestos.

- El plan de marketing. Superada la fase de definición de la estrategia de marketing, la empresa se encuentra en condiciones de diseñar un plan de marketing dirigido a estimular la demanda y a favorecer la aceptación y la compra del producto por el segmento o segmentos de mercado que fueron señalados como mercado objetivo de la empresa. El plan de marketing es un documento en el que se incluye la información principal de la fase de análisis (análisis de situación, diagnóstico, objetivos y estrategias), así como los programas necesarios para concretar las estrategias elegidas, es decir, las 4 Pes: se precisan las características del producto o servicio ofertado, se seleccionan los intermediarios a través de los cuales se ha de llegar al mercado, se fija un precio adecuado y se especifican los medios de comunicación de los que se va a servir la empresa para darlo a conocer y para poner de manifiesto sus cualidades distintivas. También se establece el quién, el cuándo y el cómo, es decir, quién será el responsable de cada acción, con qué medios humanos, materiales y económicos contará y cuál será el cronograma a seguir. En el plan de marketing se establecerá también un análisis comercial y económico-financiero para determinar su viabilidad y las acciones de control a aplicar en el caso en que existan desviaciones.

- Organización y ejecución. Para poner en marcha el plan de marketing, la empresa debe organizar su departamento de marketing de forma que sea fácil la posterior ejecución de las estrategias y programas diseñados por la organización. En el proceso de ejecución comercial se precisa de la coordinación de cuatro elementos interrelacionados: la estructura organizativa, los recursos humanos, los procesos de dirección y la cultura empresarial.

- Control de las actividades de marketing. Ejecutado ya el plan de marketing, es necesario llevar a cabo un control. El control de la estrategia comercial tiene por finalidad asegurar el cumplimiento del plan y comprobar si se están alcanzando los objetivos propuestos en el mismo. Implica medir los 
resultados de las acciones emprendidas, comprobar el grado de consecución de los objetivos previstos y, en su caso, establecer y aplicar medidas correctoras. Existen varios tipos de control de marketing, pero uno de los más completos es la denominada auditoría de marketing, que persigue identificar un plan de marketing mejor al propuesto por la empresa.

\subsubsection{Similitudes y diferencias entre las actividades del marketing estratégico y operativo}

Existen algunas similitudes y diferencias entre el marketing estratégico y el marketing operativo. Empezando por las similitudes, el marketing es una única función en el seno de la empresa. Aunque ambas dimensiones impliquen diferentes actividades, diferentes individuos y diferentes niveles organizativos, esencialmente subyace en ellas un único objetivo final: la necesidad de orientarse al mercado para satisfacer al consumidor mejor que la competencia y así alcanzar los objetivos empresariales. Por ello, las dos dimensiones son complementarias. El proceso empieza con el marketing estratégico (análisis), por lo que un error en esta fase se arrastra por todo el proceso de marketing. Sin embargo, queda también claro que sin opciones estratégicas de marketing no puede haber un marketing operativo rentable. No importa cuán poderoso sea el plan de marketing operativo, porque no puede crear demanda donde no hay necesidad, como tampoco puede mantener vivas actividades condenadas a desaparecer (Lambin et al., 2009). Por lo tanto, para ser rentable, el marketing operativo debe fundamentarse en un diseño estratégico, el cual debe estar basado en las necesidades del mercado y su evolución esperada.

Sobre las diferencias, las decisiones de marketing estratégico involucran a la alta dirección de marketing de la empresa, se producen a nivel de producto-mercado, se trata de decisiones a largo plazo, irregulares en el tiempo, novedosas $\mathrm{y}$, por tanto, no estructuradas, y para las que se cuenta esencialmente con información subjetiva basada generalmente en la experiencia. Existe un elevado riesgo de equivocación en la toma de estas decisiones porque la incertidumbre es elevada. Por el contrario, las actividades de marketing operativo, encaminadas a poner en marcha las anteriores decisiones, están a cargo de los mandos intermedios u operativos del departamento de marketing, son a medio y corto plazo, más repetitivas, frecuentes, objetivas, y, en consecuencia, están más estructuradas. El riesgo de equivocación es menor debido a que la incertidumbre también es menor, respecto al marketing estratégico.

\subsection{El plan de marketing}

El plan de marketing es un documento claro y manejable que ayuda eficazmente a la ejecución de decisiones de marketing y a la optimización de recursos económicos. En él se va a resumir tanto la parte estratégica como la operativa de marketing. 


\subsubsection{Contenido del plan de marketing}

Su contenido se detalla en las siguientes ocho partes (Burk, 2003):

- Resumen ejecutivo. Se realiza al final. Presenta un breve resumen de los principales objetivos y recomendaciones del plan. Ayuda a los altos directivos a encontrar los principales puntos del plan rápidamente. Después del resumen ejecutivo suele figurar un índice o tabla de contenidos.

- Situación actual de marketing. Para saber cuál es la situación actual de la empresa, en primer lugar se analiza el micro-entorno (el mercado, la competencia) y cualquier elemento del macro-entorno que pueda afectar la actividad de marketing. A continuación se realiza un análisis interno que nos muestre los recursos y capacidades de marketing de la empresa para hacer frente a su entorno (productos, resultados anteriores, campañas de marketing previas, influencia de otros departamentos en el marketing de la empresa, etc.). El tercer paso es hacer un diagnóstico, por ejemplo utilizando el DAFO (oportunidades y amenazas del entorno y fortalezas y debilidades de la empresa) lo que ayuda a los gestores a anticipar hechos tanto negativos como positivos que puedan tener impacto en la empresa y en sus estrategias.

- Mercado objetivo. Del análisis del mercado y de la competencia, la empresa escoge el segmento o segmentos en los que va a competir (mercado objetivo) y establece la estrategia de valor para cada segmento (posicionamiento).

- Objetivos. Dónde quiere la empresa ir y qué quiere conseguir. En este apartado se establecen los objetivos de marketing que la empresa quiere obtener en el periodo y analiza los aspectos clave que puedan afectar a su consecución. Existen tres bloques: objetivos de relaciones de marketing (objetivos que intentan atraer, mantener o intensificar relaciones con los clientes $u$ otros agentes del micro-entorno); objetivos comerciales (ventas, cuota de mercado, cualquier objetivo de las 4 Pes) y objetivos de rentabilidad comercial (son ratios que nos miden la rentabilidad, beneficio o margen de las actividades de marketing).

- Estrategias de marketing. La elección de la estrategia muestra los distintos caminos que hay que seguir para pasar de la situación actual a la que queremos conseguir. La empresa elegirá entre las distintas tipologías de estrategias para lograr los objetivos de marketing. Este apartado muestra las estrategias específicas y explica cómo cada una de ellas responde a las amenazas, oportunidades y aspectos críticos detallados anteriormente en el plan.

- Programas de marketing. Detalla cómo las estrategias de marketing se convierten en programas de acción específicos que responden a las siguientes cuestiones: ¿Qué se hará (4 Pes)?, ¿Cuándo se hará (cronograma)?, ¿Quién es el responsable de que se haga?, ¿Cuánto va a costar (presupuesto)?, ¿Con qué medios humanos, económicos y materiales se cuenta? 
- Viabilidad comercial del plan. Consiste en demostrar que el plan que se propone es rentable. Para esto nos hacen falta los objetivos (estimación de los ingresos y la demanda) y los programas de marketing (estimación de los gastos). Si no es rentable se rechaza. Esencialmente es una cuenta de pérdidas y ganancias proyectada. Muestra los ingresos previstos (número de unidades vendidas y precio medio de venta) y los costes esperados (de producción, de distribución y de marketing). La diferencia es el beneficio proyectado. Una vez aprobado por la alta dirección, el presupuesto es la base para la compra de materiales, el programa de producción, la planificación de personal y las operaciones de marketing.

- Control. El plan incluye quién se va a hacer cargo de las medida de resultados, de la comparación con los objetivos y qué acciones correctoras de control hay que introducir en el caso en el que existan desviaciones en los resultados finales. Se decide de antemano cuándo se van a hacer las mediciones (indicador semanal, mensual..., por zonas, productos...), quién lo va a medir y qué margen tiene para actuar. Muestra el control que se utiliza para vigilar el progreso y permite a la alta dirección revisar los resultados de la implementación y detectar aquellos productos que no están cumpliendo sus objetivos.

\subsubsection{Ejecución de las actividades del plan de marketing}

La ejecución significa la puesta en marcha del plan de marketing. Para que esta sea correcta, en primer lugar hay que dar respuesta a cuatro cuestiones, que suelen estar detalladas en el propio plan de marketing: ¿Quién va a poner en marcha el plan de marketing y será responsable de cada programa?, ¿Cuándo se pone en marcha cada acción y por tanto, cuál es el cronograma?, ¿Cómo se va a ejecutar cada programa, o lo que es lo mismo, con qué recursos humanos, materiales y económicos?, y ¿Dónde se llevan a cabo las acciones, por zonas geográficas?.

Por muy perfecto que sea un plan de marketing, si su ejecución no es la adecuada, no producirá los resultados previstos. Por ello, cuando se diseña el plan de marketing, hay que tener en cuenta cuatro elementos interrelacionados entre sí que pueden distorsionar su correcta implantación: la cultura de la empresa, su estructura (organigrama), los recursos humanos y los procesos de dirección (Munuera y Rodríguez, 1998):

- La cultura empresarial es el conjunto de normas, creencias, forma de trabajo, valores aprendidos y compartidos por todos los miembros de la organización, caracterizando el comportamiento de las personas en todos los niveles de la organización e influyendo en la imagen proyectada al exterior. La cultura desempeña un papel invisible y secreto en la organización. Si el plan de marketing es contrario a algún componente de la cultura, este fracasará y habrá que cambiar el plan de marketing. 
- La estructura organizativa u organigrama del departamento de marketing. Los principios fundamentales en los que se asienta la estructura de la organización son la coordinación, la especialización y la formación. La aplicación de los mismos queda condicionada por la estrategia, por el grado de complejidad de la misma y por la estabilidad del entorno en el que se ejecuta. Cuando se plantea un cambio, la estructura organizativa es más dócil y tratable que la cultura; es formal y visible, y puede ser rediseñada, pero habrá que cuantificar dichos cambios. Por ejemplo, si la empresa tiene productos muy heterogéneos por zonas geográficas y su organigrama del departamento de marketing es por funciones, habrá que modificarlo por mercados, y medir cómo afecta el cambio.

- Los recursos humanos. Consiste en saber quién va a llevar cabo la puesta en marcha del plan de marketing y si serán capaces de hacerlo. Eso va a depender de su formación. Para valorar adecuadamente la implicación de los recursos humanos en la ejecución del plan de marketing hay que considerar el grado de cambio de la nueva estrategia respecto a la anterior y del tiempo que se dispone para realizar el cambio. Cuando la ejecución de la nueva estrategia implica pequeños cambios sobre la estrategia existente y es a largo plazo, no requerirá de nuevas habilidades de los empleados, con las existentes será suficiente. En el caso en el que el cambio requerido en la estrategia es importante y se dispone de tiempo, o donde son menores, pero se dispone de poco tiempo, los programas de entrenamiento pueden proporcionar las habilidades necesarias. Por último, cuando el cambio en la estrategia es grande y a corto plazo se aconseja buscar especialistas fuera de la empresa.

- Los procesos de dirección son un aspecto fundamental en la ejecución de la estrategia por los cuales las decisiones son convertidas en acciones. Son mecanismos de autoridad y comunicación que existen entre los miembros de la organización. Significa quién tiene la autoridad para tomar decisiones. Habrá que definir muy bien los flujos de decisión, tanto en horizontal como en vertical así como los flujos de información (horizontales y verticales). La dirección funcional transformará los programas en acciones, en los plazos previstos y bajo los presupuestos acordados.

No hay una solución fácil a las dificultades que se plantean en la ejecución del plan, pero se pueden hacer algunas prescripciones de interés genérico. Es conveniente lograr que todos los objetivos sean entendidos y aceptados, recompensar a la dirección por los buenos resultados, optar por una dirección comunicativa y participativa y comprobar que el personal conoce sus responsabilidades.

\subsubsection{El control de las actividades de marketing}

Se lleva a cabo a fin de asegurar el logro de los objetivos propuestos. Es la medición de los resultados alcanzados, y en su caso, la identificación y análisis de las causas de las desviaciones. Debe incluir el establecimiento de planes y acciones 
correctoras sobre las desviaciones. La efectividad del control depende de la formulación clara, concisa y cuantitativa de los objetivos y de la disposición de información veraz y continua sobre las variables objeto de control.

Ejecutado el plan de marketing, es necesario llevar a cabo un control a fin de asegurar el logro de los objetivos propuestos. Este es el control anual que se realiza sobre el plan de marketing. No se trata de evaluar el grado en que la empresa acertó a la hora de marcar los objetivos y elegir la estrategia para alcanzarlos, sino de estimar en qué medida la estrategia se ha ejecutado o se está ejecutando correctamente. Para ello, la empresa se hace una serie de preguntas que hay que contestar.

- ¿Qué está sucediendo? Para saber qué sucede en la empresa hay que medir los resultados obtenidos que se valoran en las mismas unidades de medida que los objetivos previstos (ventas, rentabilidad o satisfacción) y especificados en cantidad, tiempo y espacio (por ejemplo, en euros, diarios y por municipio).

- ¿Por qué sucede? Esta pregunta se realiza cuando existen desviaciones entre los resultados obtenidos (ventas, rentabilidad o satisfacción) y los objetivos previstos. Para la comparación es preciso establecer el mismo sistema de medida. Cuando los resultados no son los esperados, es necesario identificar las causas de las desviaciones y averiguar en qué parte del proceso de marketing se produjeron: en el análisis de situación, en el diagnóstico, en la fijación de objetivos, en la elección de estrategias, en el diseño de programas o en la ejecución.

- ¿Qué deberíamos hacer? La empresa establece planes y acciones correctoras sobre las desviaciones. Estas pueden ponerse en marcha si la desviación alcanza determinado nivel del indicador o solo si sobrepasa determinado intervalo de acción. La acción correctora se aplicará sobre la parte del proceso de marketing que haya fallado y tendrá repercusiones sobre las partes posteriores del proceso.

Podemos distinguir 4 tipos de control de marketing: control del plan anual (el que se ha detallado en el apartado anterior), control de rentabilidad, control de eficiencia y control estratégico (Kotler et al., 2006).

- Control del plan anual. Su objetivo principal es examinar si los resultados previstos en el plan se han alcanzado. El responsable principal es la alta dirección y la dirección media. Para realizar este control se utilizan diversos métodos en función de los objetivos fijados en el plan de marketing. Si el objetivo se establece en términos de ventas o cuota de mercado se analizan las ventas y la cuota de mercado y se elaboran ratios que relacionan las ventas con la campaña de marketing; si los objetivos eran de rentabilidad, se utilizan diversos ratios financieros y si los objetivos eran relacionales, se analiza la satisfacción del consumidor y de otros agentes, ratios de pérdidas de clientes y ratios de recuperación. 
- Control de rentabilidad. Su objetivo principal es analizar dónde está ganando o perdiendo dinero la empresa. El responsable principal de esta actividad es el controlador de marketing, que va a utilizar diversos análisis para comprobar si existen diferencias en los ingresos, gastos y por tanto en los beneficios obtenidos por tipo de producto, por distintos territorios, por clases de clientes, por segmentos pertenecientes al público objetivo, por canales de distribución o por tamaño de los pedidos.

- Control de eficiencia: Su objetivo es valorar y mejorar la eficiencia e impacto de los gastos de marketing. El responsable es también el controlador de marketing pero pueden realizarlo mandos intermedios del departamento de marketing. Su objetivo es medir la eficiencia (conseguir los objetivos con el mínimo coste) de los gastos realizados en cualquiera de los programas de las 4 Pes, es decir, de la fuerza de ventas, de la publicidad, de las promociones, de la distribución y logística, etc.

- Control estratégico. Tiene como objetivo analizar si la compañía está persiguiendo sus mejores oportunidades en relación con los mercados, productos y canales. Este control debe realizarse fuera del departamento de marketing, ya que se van a cuestionar las decisiones que han tomado los directivos de marketing para buscar la excelencia. Por ello, el responsable principal será la alta dirección (interna a la empresa) o el auditor de marketing (externo a la empresa). El método más utilizado es la auditoría de marketing, pero también se revisará la excelencia de marketing y la responsabilidad ética y social de la empresa.

Una auditoría de marketing es un análisis comprehensivo, sistemático, independiente y periódico del entorno de marketing de la empresa, sus objetivos, estrategias y actividades, con la intención de determinar las áreas que plantean problemas y oportunidades y recomendar un plan de acción que mejore los resultados de marketing de la compañía. Monitorización continua sobre si el plan de marketing es el mejor que la empresa podría tener.

- Comprehensiva: la auditoría del marketing es amplia, cubre todas las actividades del negocio.

- Sistemática: la auditoría del marketing supone una secuencia ordenada de etapas de diagnóstico que cubre desde el análisis del entorno de macro-marketing y de micro-marketing de la organización, al sistema de marketing interno y sus actividades específicas.

- Independiente: las mejores auditorías son las que realizan los consultores externos con la necesaria objetividad e independencia, amplia experiencia en diversas industrias, familiaridad con la empresa concreta y el suficiente tiempo y atención para dedicar a la auditoría. 
- Periódica: las auditorías de marketing no se inician solo cuando las ventas descienden, cuando la moral de los equipos de venta cae o cuando se dan otros problemas en la empresa, sino que se establece que se ha de realizar anualmente o cada determinado periodo de tiempo.

La auditoría de marketing comienza con una reunión entre la empresa y el auditor de marketing para llegar a un acuerdo sobre los objetivos, amplitud, profundidad, fuentes de datos, formato del informe y periodo de tiempo a contemplar por la auditoría. Se prepara un plan detallado. La regla cardinal es no tener información exclusivamente de la compañía en la búsqueda de datos y opiniones; debe entrevistarse también a los clientes, distribuidores y otros grupos externos.

La auditoría de marketing analiza seis principales componentes de la situación de marketing de la empresa:

- Auditoría del entorno de marketing (oportunidades y amenazas).

- Auditoría de la estrategia de marketing (si son las más adecuadas).

- Auditoría de organización de marketing (estructura/organigrama).

- Auditoría de sistemas de marketing (sistemas de información).

- Auditoría de productividad de marketing (estudia gastos, rentabilidad, eficiencia, eficacia).

- Auditoría de funciones de marketing (las 4 Pes).

En Kotler et al. (2006) y en Munuera y Rodríguez (1998) pueden examinarse ejemplos de listas de chequeo que son utilizadas en las auditorías de marketing.

\section{Referencias bibliográficas}

Armstrong, G., Kotler, P., Merino, M. J., Pintado, T. y J. M. Juan (2011): Introducción al marketing, 3. ${ }^{\mathrm{a}}$ ed., Madrid, Pearson Educación.

Burk, M. (2003): El Plan de Marketing, guía de referencia, Madrid, Prentice Hall. Kotler, P., Lane, K., Cámara, D. y A. Mollá (2006): Dirección de Marketing, 12. ${ }^{\text {a }}$ ed., Madrid, Prentice Hall.

Lambin, J. J., Galluci, C. y C. Sicurello (2009): Dirección de marketing, gestión estratégica y operativa del mercado, México, McGraw-Hill.

Munuera, J. L. y A. I. Rodríguez (1998): Marketing estratégico. Teoría y casos, Madrid, Pirámide.

- (2007): Estrategias de marketing, Un enfoque basado en el proceso de dirección, Madrid, ESIC Editorial. 


\section{Análisis del mercado y la demanda Ilu Vallet-Bellmunt y Antonio Vallet-Bellmunt}

\section{Contenido del capítulo}

En este capitulo empezamos a desarrollar la dimensión análisis tal como explicaba el capítulo anterior, identificando la tipología de clientes, las necesidades que satisface la empresa y las alternativas tecnológicas que desarrolla, determinando así el concepto de mercado desde el punto de vista del marketing, y concretamente el mercado de referencia, el mercado relevante y el producto mercado y observaremos los distintos tipos de estrategia de cobertura de mercado que tiene la empresa.

También descubriremos la demanda de mercado, sus tres dimensiones que responden a las preguntas: ¿Qué? ¿Cuándo? y ¿Dónde?, los diferentes estados que posee, en función de los cuales la empresa utilizará diferentes estrategias, así como técnicas para medirla. 
2.1. Definición y delimitación del mercado de referencia: mercado de referencia, mercado relevante y producto-mercado

2.1.1. Evolución del concepto de mercado

2.1.2. El mercado de referencia

2.1.3. El producto mercado

2.1.4. El mercado relevante y estrategias de cobertura

2.1.5. Ampliaciones del mercado de referencia

2.2. La demanda

2.2.1. Dimensiones de la demanda de mercado

2.2.2. Tipos de mercado para el análisis de la demanda

2.2.3. Estados de la demanda

2.2.4. Análisis de la demanda

2.2.5. Cálculo de la demanda actual

2.2.6. Algunos métodos para calcular la demanda actual

2.2.6.1. Potencial total del mercado

2.2.6.2. Método de proporciones en cadena

2.2.6.3. Potencial de mercado por zonas

2.2.6.4. Volumen de ventas y cuotas de mercado por sector

2.2.7. Cálculo de la demanda futura

2.2.7.1. Análisis de intención de compradores

2.2.7.2. Opinión de la fuerza de ventas

2.2.7.3. Opinión de los expertos

2.2.7.4. Prueba de mercado

2.2.7.5. Análisis de histórico de ventas

Referencias bibliográficas 


\subsection{Definición y delimitación del mercado de referencia: mercado de referencia, mercado relevante y producto-mercado}

Muchas han sido las definiciones que se han establecido para el concepto de mercado a lo largo del tiempo, y tal como ha ido evolucionando la sociedad, estas también lo han hecho.

\subsubsection{Evolución del concepto de mercado}

Tradicionalmente se consideraba el mercado solo desde el punto de vista del productor de forma que una popular definición de mercado era aquel lugar físico donde se realizaba un intercambio entre compradores y vendedores. Solo se tenía en cuenta por un lado el conjunto de productos substitutivos y por otro al conjunto de compradores de una misma clase de productos. El problema de esta definición tradicional de mercado es que está hecha desde el punto de vista de la oferta, en este contexto domina una orientación al producto considerado en sí mismo, sin tener en cuenta el beneficio que ese producto genera en quien lo compra, ese beneficio es la satisfacción de una necesidad.

Ahora bien, si definimos el mercado desde el punto de vista del comprador, el mercado de referencia se puede definir en tres dimensiones tal y como señala Abell (1980):

- Funciones o necesidades del cliente: qué necesidades voy a satisfacer.

- El grupo de clientes: a quién se satisface.

- Tecnologías para utilizar: cómo se satisface la necesidad.

\subsubsection{El mercado de referencia}

Definimos el mercado de referencia como el conjunto de productos sustitutivos que satisfacen una necesidad concreta del conjunto total de compradores potenciales (Munuera y Rodríguez, 2007). Con esta definición de mercado de referencia abordamos una tercera dimensión al concepto de mercado, y es la satisfacción de una necesidad por parte del comprador. El mercado de referencia solo mira la satisfacción de una necesidad, y para esta única necesidad analiza todos los posibles compradores y todas las posibles alternativas tecnológicas que se pueden encontrar en la satisfacción de esa necesidad. La figura 7 muestra la relación que guardan las tres dimensiones en la definición de mercado de referencia. 


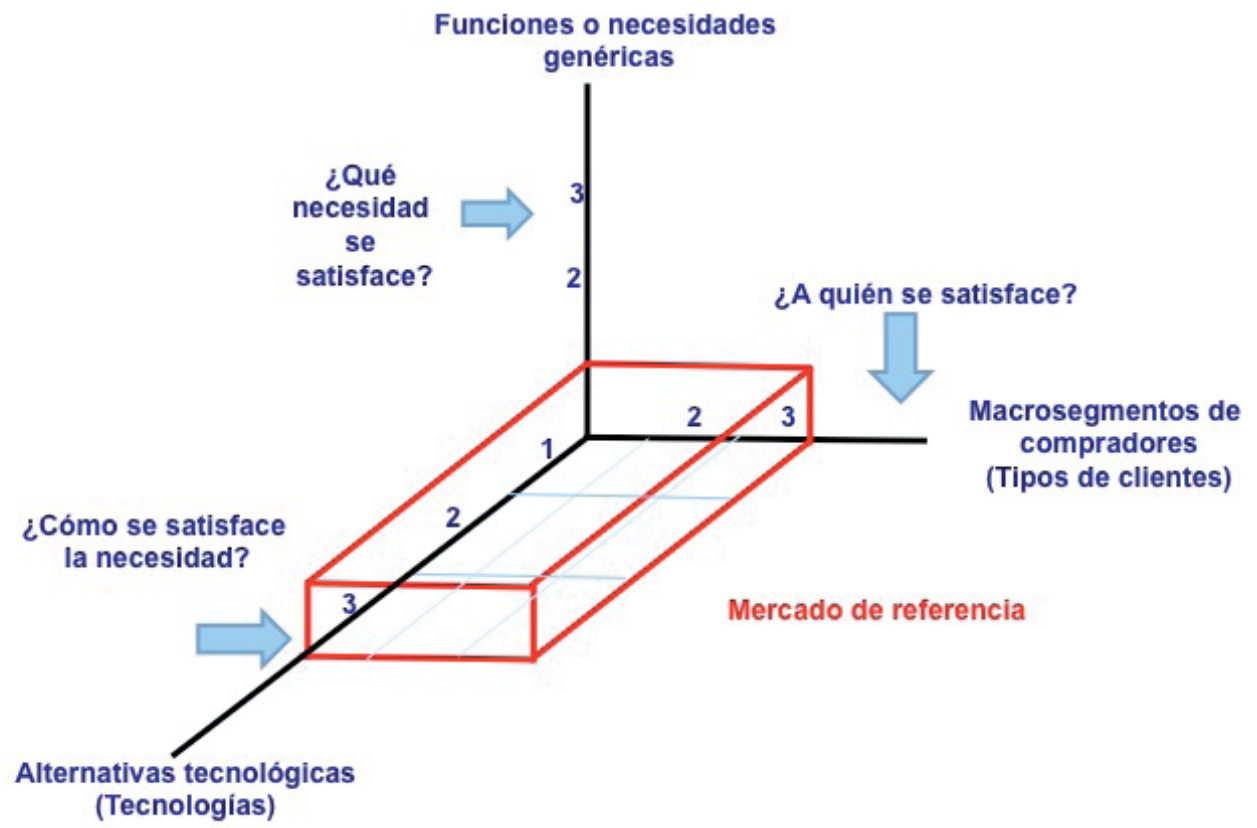

Figura 7. Definición del mercado de referencia Fuente: Elaboración propia basada en Abell (1980)

a) Dimensiones en la definición del mercado de referencia.

La nueva noción de mercado se establece en la intersección de un conjunto de productos sustitutivos que satisfacen una necesidad o función concreta del conjunto de compradores potenciales. A continuación, vamos a precisar el significado de las tres dimensiones y sus posibles desagregaciones:

- Compradores: incluimos a lo largo del eje todos los compradores que buscan satisfacer la misma necesidad genérica. Ahora bien, no todas las empresas pueden competir a este nivel. En ese caso, puede ser necesario dividir a los compradores en grandes segmentos estratégicos de mercado. Son grandes segmentos estratégicos de mercado aquellos grupos de compradores que exigen cambios radicales en los programas de marketing como consecuencia del diferente asentamiento geográfico, tamaño de las operaciones, requerimiento de asistencia técnica y soporte del servicio, etc. Estos tres macrosegmentos son particulares, empresas y administraciones públicas.

- Necesidades o funciones: se deben tener presentes las diferencias entre la función básica o necesidad genérica, que satisface el producto y los atributos o beneficios que el consumidor puede percibir como importantes criterios de elección. A veces, la línea divisoria entre función y beneficio, no está tan clara, por ejemplo la higiene dental es una necesidad básica; el brillo, la blancura, el sabor o forma del envase son atributos añadidos. 
- Alternativas tecnológicas: representan las formas o tecnologías concretas de satisfacer una necesidad genérica del consumidor y se puede asimilar al concepto de producto contemplado desde el lado de la oferta, como un ente con unas determinadas características físicas.

Por ejemplo, las necesidades que satisface un balneario son salud, belleza y relax. Ahora bien, al ser tres las necesidades que cubre, van a ser tres los mercados de referencia y las alternativas tecnológicas van a ser distintas. Por ejemplo, las alternativas para el relax pueden ser: balnearios urbanos, balnearios termales, centros de yoga y taichí, centros de masajes, centros de ocio, centros deportivos, etc. Sin embargo, para la necesidad de belleza las alternativas pueden ser: centros de estética, gimnasios, nutricionistas, productos de belleza, clínicas adelgazamiento, etc.

b) Conceptos relacionados pero distintos: Diferencia entre industria y mercado de referencia.

En relación con la dimensión de alternativa tecnológica, se ha definido tradicionalmente la noción de industria como el conjunto de fabricantes que, bajo una forma tecnológica concreta, responden a cualquier necesidad genérica de los compradores. La industria se centra en tener solo una alternativa tecnológica para cualquier tipo de comprador y cualquier tipo de necesidad. Por lo tanto, la diferencia principal entre industria y mercado de referencia es que el mercado de referencia se centra en la satisfacción de una única necesidad, abarcando a todos los posibles compradores y a todas las alternativas tecnológicas posibles, sin embargo la industria, centrándose en una única alternativa tecnológica trata de satisfacer todas las necesidades existentes abarcando a todos los posibles compradores potenciales. Véase la diferencia en la figura 8.

\subsubsection{El producto-mercado}

Un producto-mercado se define como un grupo de clientes o compradores específicos, que buscan una función específica o un surtido de funciones basadas en una sola tecnología (Lambin, 2003). Es decir, es la intersección entre la necesidad, la tecnología y el grupo de compradores (véase la figura 8). Para seguir con el ejemplo del balneario, un producto-mercado sería la necesidad de belleza, con la alternativa de productos de belleza y dirigidos al macrosegmento de particulares. 


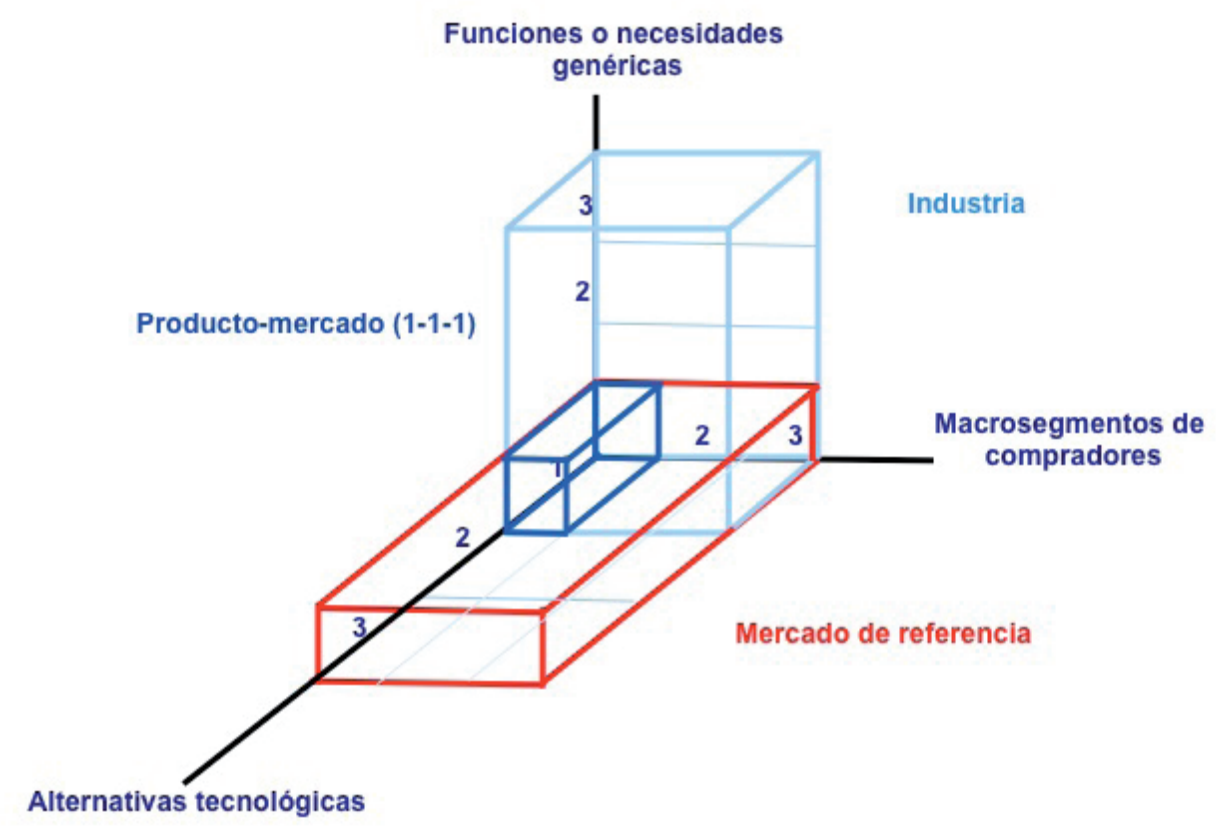

Figura 8. Diferencia entre industria, mercado de referencia y producto-mercado Fuente: Elaboración propia basada en Munuera y Rodríguez (2002) y Lambin (2003)

Dependiendo de la necesidad que se satisfaga, a quién vaya dirigido y la alternativa tecnológica/s en las que se centra, se puede tener más de un productomercado.

\subsubsection{El mercado relevante y estrategias de cobertura}

Es infrecuente que una empresa pueda operar en todos los productos-mercados que resultan de la fragmentación de su mercado de referencia; suele hacerlo en una parcela limitada de él, en la parte del mercado de referencia que denominamos mercado relevante. El mercado relevante es el conjunto de productos-mercados en los que la empresa decide competir en función de sus alternativas tecnológicas y de los macrosegmentos a los que se dirige (Munuera y Rodríguez, 2007). El mercado relevante es el más adecuado referente competitivo para la empresa, el mercado relevante es aquella parte del mercado de referencia en el que la empresa realmente compite.

Existen varias formas de elegir el mercado relevante para la empresa, es decir, las estrategias de cobertura del mercado de referencia (véase figura 9).

- Estrategia del especialista en productos: la empresa elige especializarse sobre una forma tecnológica específica para satisfacer a todos los grupos de compradores que buscan el mismo beneficio básico o necesidad. Las empresas que fabrican componentes intermedios están incluidas en esta categoría. 
- Estrategia del especialista en clientes: la empresa opta por satisfacer una necesidad genérica de un solo grupo de compradores de todas las formas tecnológicas posibles.

- Estrategia de concentración: consiste en especializarse en una única alternativa tecnológica y un único grupo de compradores. Coincide el mercado relevante con el producto-mercado. Es la estrategia del especialista, que busca una alta cuota de mercado en un nicho muy reducido.

- Estrategia de cobertura parcial o mixta: la empresa se especializa en diversos productos-mercados con mayor o menor relación entre sí.

- Estrategia de cobertura total: En esta estrategia la empresa se dirige a todos los productos-mercados, ofreciendo una cobertura a todo el mercado de referencia. Coincide el mercado de referencia con el mercado relevante cuando hay cobertura total.

Es muy importante destacar que las estrategias de segmentación de mercados se llevan a cabo a un nivel de producto-mercado, nunca a un nivel de mercado de referencia, por lo tanto, como ya veremos en el capítulo 5, las estrategias de segmentación se realizan después de haber elegido el mercado relevante (y por tanto la estrategia de cobertura del mercado de referencia) dentro de cada productomercado. Las estrategias de cobertura son superiores a las de segmentación.

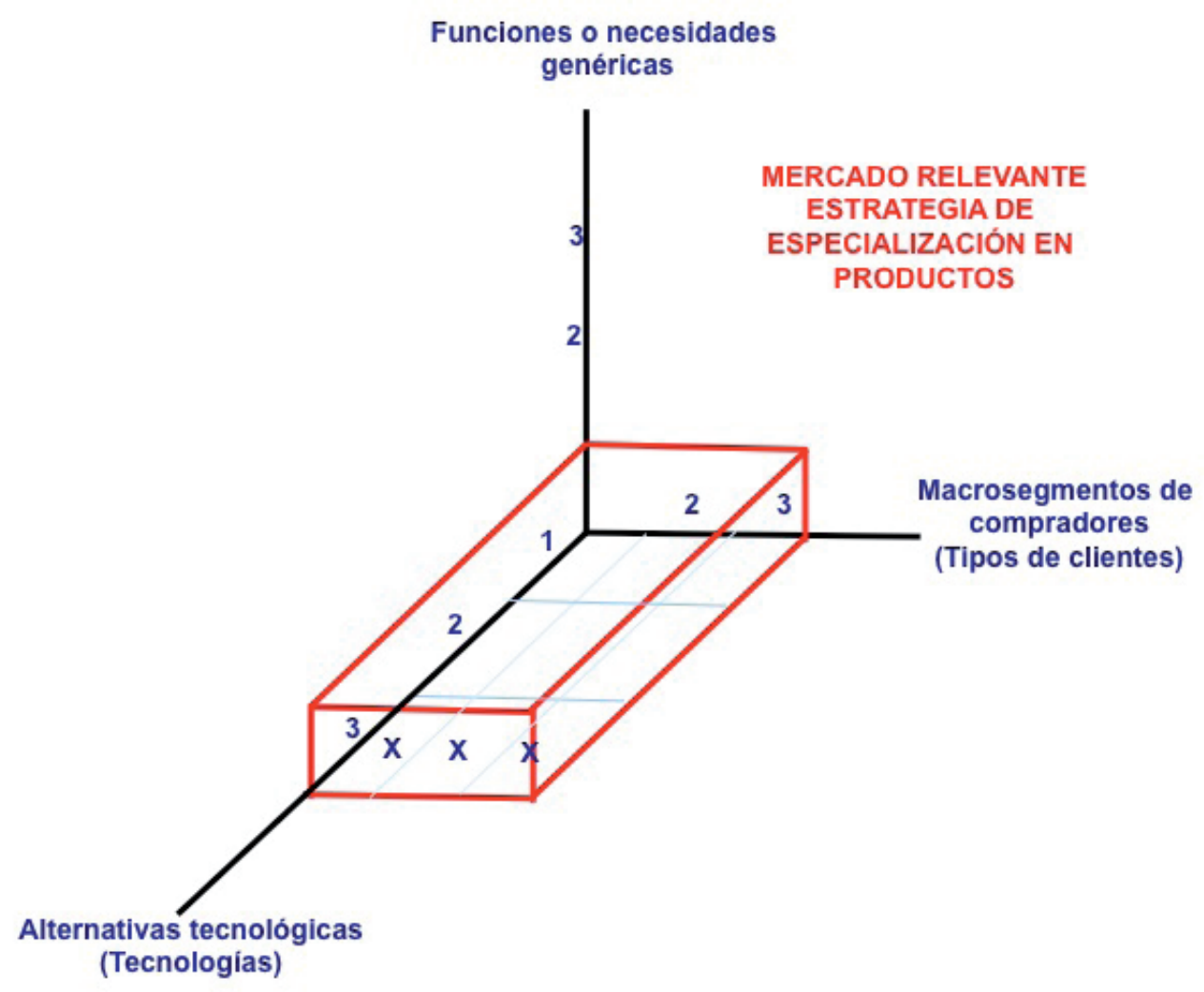



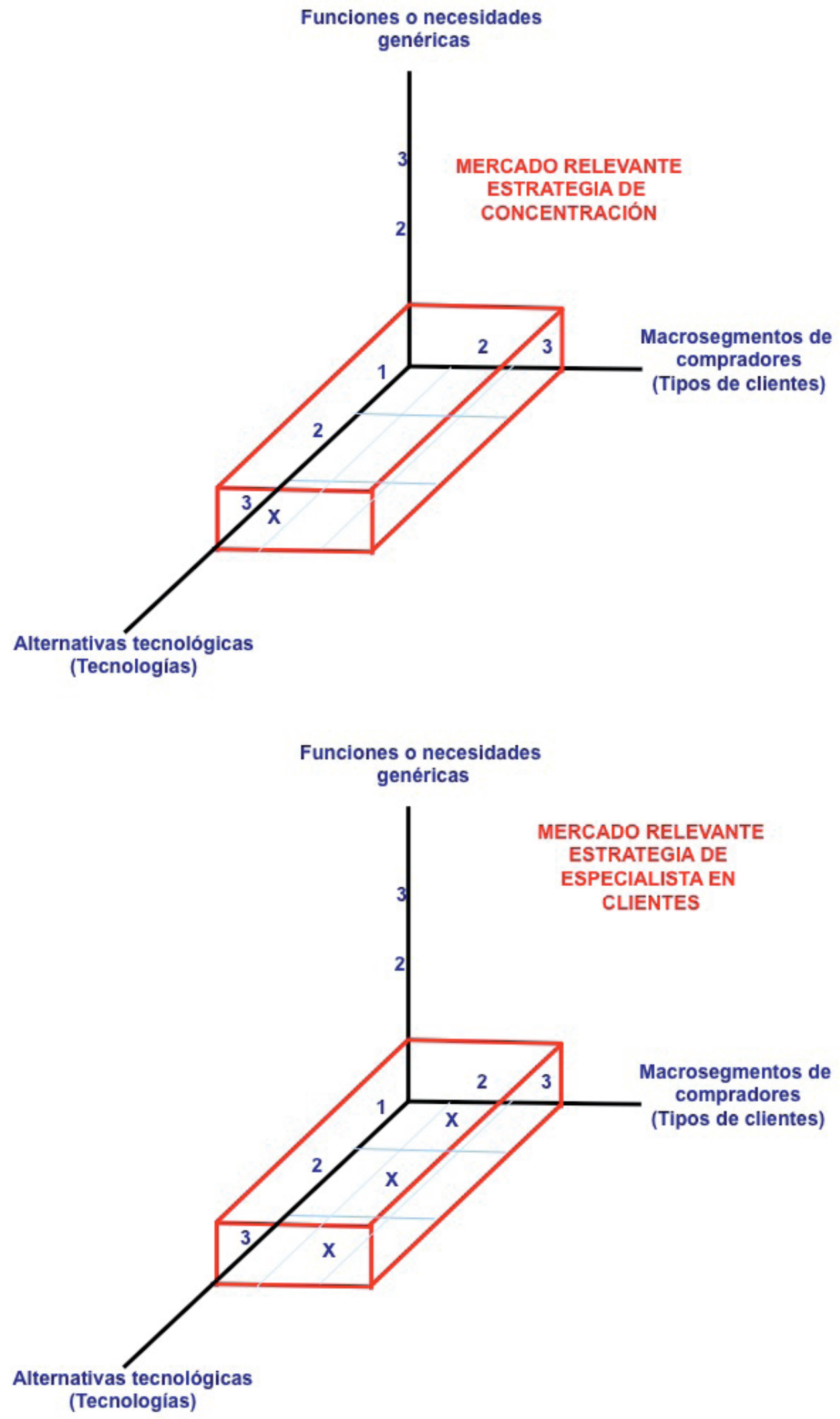

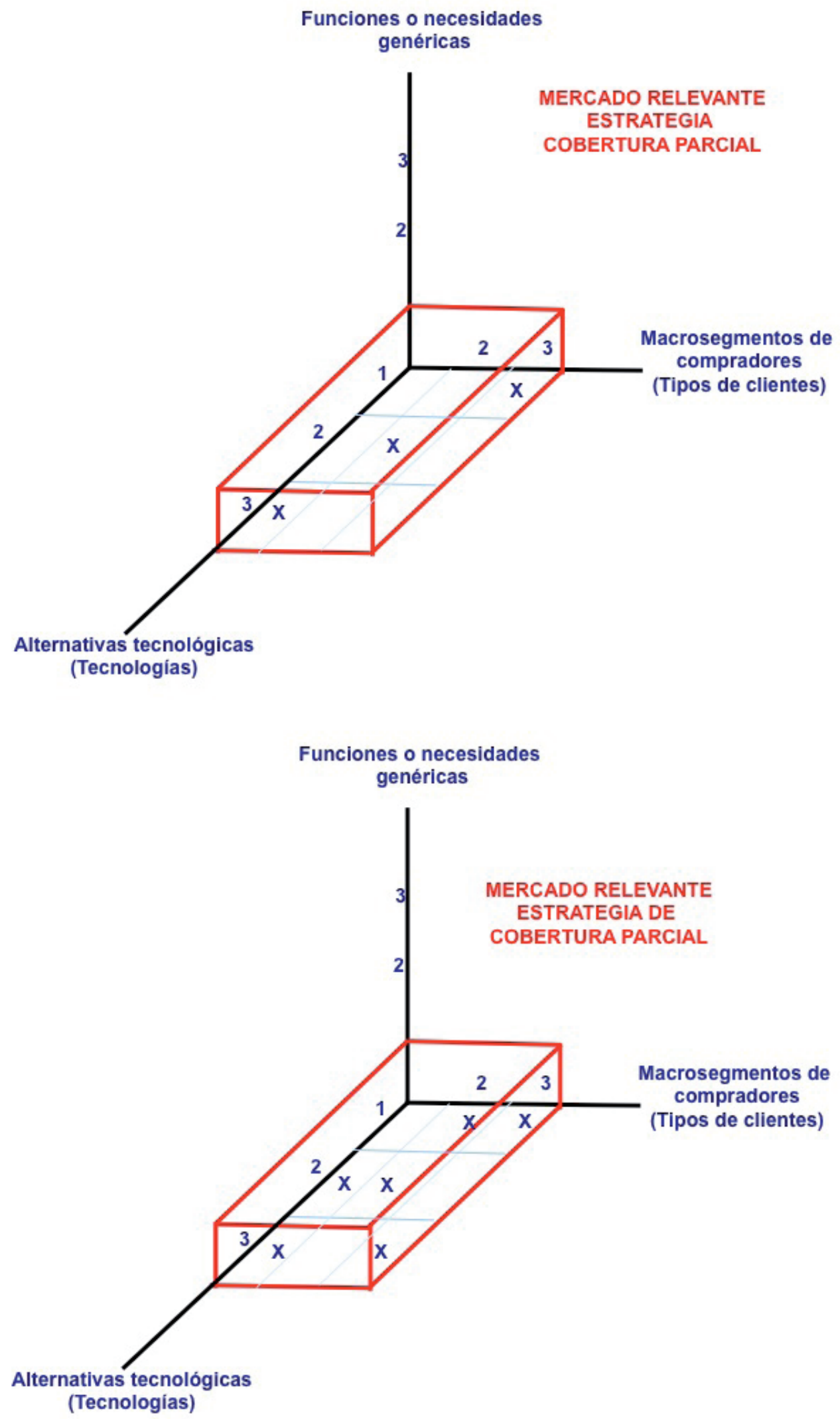


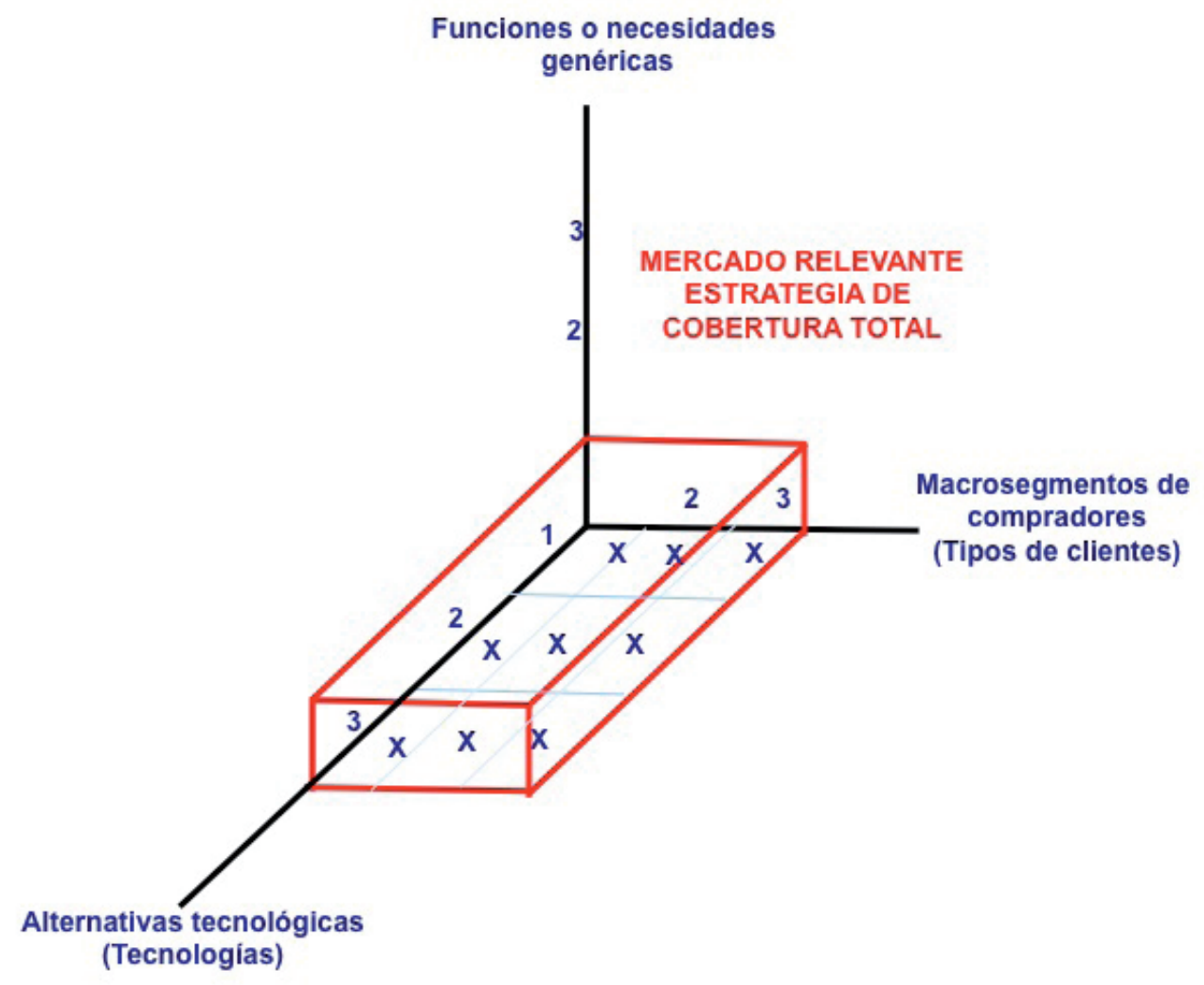

Figura 9. Mercado relevante: Estrategias de cobertura del mercado de referencia Fuente: Elaboración propia basada en Munuera y Rodríguez (2002)

\subsubsection{Ampliaciones del mercado de referencia}

El mercado de referencia puede ampliarse por la entrada de nuevos grupos de consumidores, por la redefinición de la necesidad genérica al aparecer productos que combinan la satisfacción de varias necesidades o a través del surgimiento de nuevas alternativas tecnológicas (Munuera y Rodríguez, 2007). Los tres frentes de ampliación son los siguientes (véase figura 10):
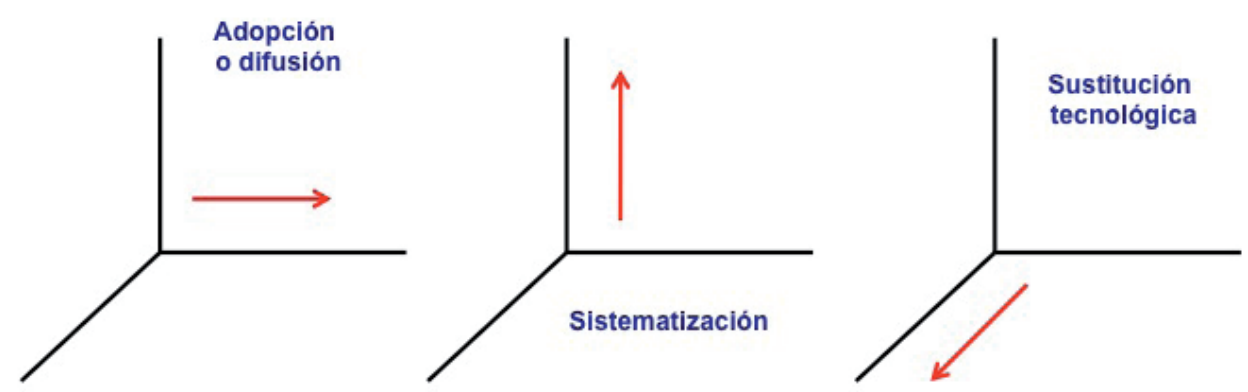

Figura 10. Ampliación del mercado de referencia

Fuente: Elaboración propia basada en Munuera y Rodríguez (2002)

- Ampliación a nuevos grupos de clientes: adopción o difusión hacia nuevos grupos de compradores. Aparecen compradores que hasta ahora no habían deseado el producto, como por ejemplo las cremas corporales para hombres. 
- Ampliación a nuevas necesidades: proceso de sistematización para nuevas necesidades genéricas. Combinan las necesidades. Un ejemplo claro sería el del móvil, cada vez aparecen más características para móviles y se necesitan más instrumentos (cámara, GPS, Wi-fi...).

- Ampliación a nuevas tecnologías: proceso de sustitución o cambio tecnológico o de extensión. Aparecen nuevas tecnologías que complementan o sustituyen a las anteriores. Cuando son nuevas, amplían el mercado de referencia, por ejemplo las nuevas tecnologías para escuchar música (discos de vinilo, CD, MP3, etc.).

\subsection{La demanda}

El departamento de marketing es el responsable de preparar las previsiones de ventas, y estas se basan en cálculos de demanda. Para ello es fundamental definir la demanda de mercado.

\subsubsection{Dimensiones de la demanda de mercado}

Podemos definir la demanda como el volumen total de producto que sería adquirido por un mercado en un lugar y periodo de tiempo fijado, para unas condiciones de entorno y esfuerzo comercial determinado (Kotler et al., 2006).

Destacamos de esta definición las tres dimensiones que posee la demanda:

- Dimensión producto, responde a la pregunta ¿Qué?, y estaría formada por diferentes niveles de producto. Por ejemplo 6 niveles: clase de producto, forma de producto, línea de producto, ventas de la empresa, ventas de la industria y total de ventas.

- Dimensión Temporal, responde a la pregunta ¿Cuándo?, y está formada por distintos niveles de tiempo. Por ejemplo 3 niveles: corto, medio y largo plazo.

- Dimensión Espacial, responde a la pregunta ¿Dónde? y la forman diversos niveles de espacio. Por ejemplo 5 niveles: cliente, territorio, región, país y mundo.

Así pues, según los ejemplos dados, las empresas pueden calcular hasta 90 tipos de medición de demanda: $(6 \times 3 \times 5)$ según se puede observar en la figura 11 . Cada medida de demanda se utilizará para un fin concreto. Por ejemplo, una empresa podría predecir la demanda a corto plazo para realizar los pedidos de materias primas y planificar la producción de un producto, o podría prever la demanda de la línea de producto y decidir si se podría ampliar. Ahora bien, las previsiones dependen del tamaño del mercado, y existen diferentes formas de desglosarlo: 


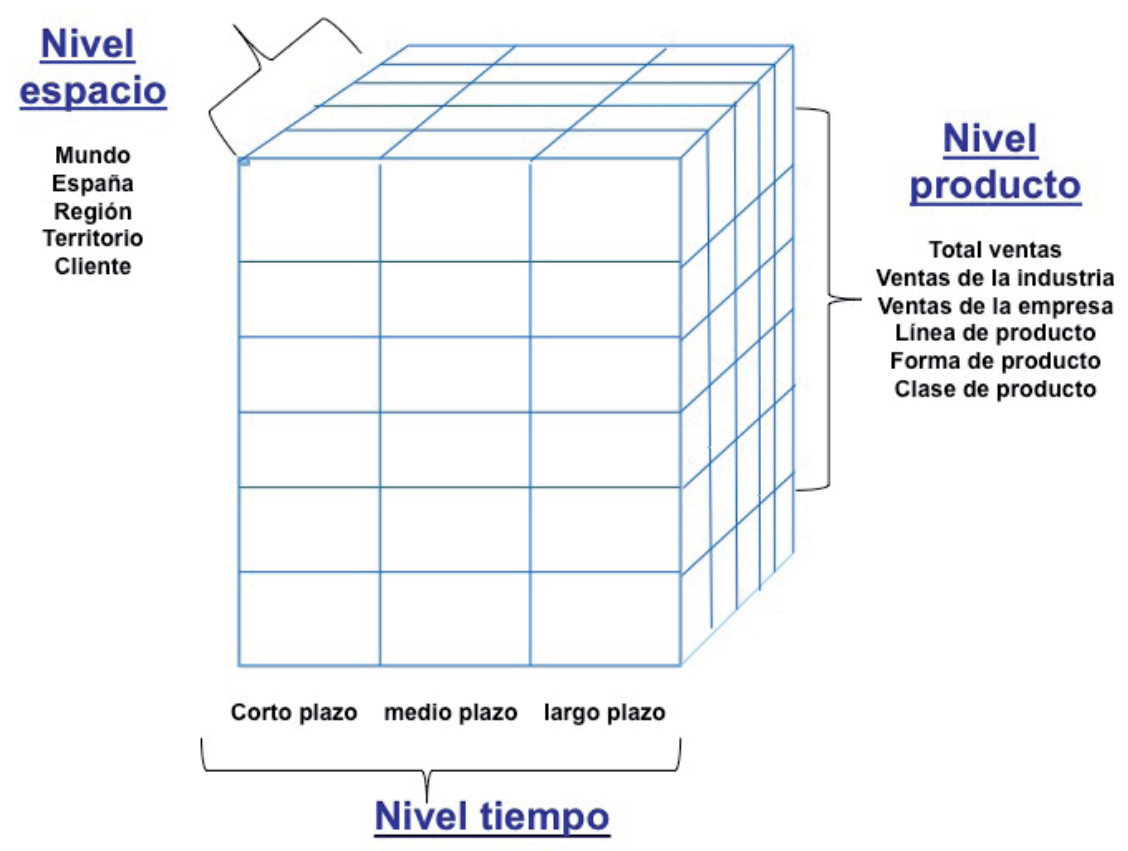

Figura 11. Dimensiones de la demanda de mercado Fuente: Elaboración propia en base a Kotler et al. (2006)

\subsubsection{Tipos de mercado para el análisis de la demanda}

Los tipos de mercado para el análisis de la demanda son cuatro: mercado potencial, mercado disponible, mercado objetivo y mercado penetrado.

- Mercado potencial: es el conjunto de compradores que presentan un nivel de interés suficientemente elevado por la oferta de mercado. Aunque ese interés no es suficiente, ya que los consumidores potenciales deben poseer una renta suficiente y deben poder acceder a esa oferta de mercado.

- Mercado disponible: es el conjunto de consumidores que presentan interés por una oferta de mercado, poseen los recursos económicos necesarios para adquirirla y el acceso a esa oferta de mercado. En determinadas situaciones, la empresa o el gobierno pueden restringir la oferta. Por ejemplo, para poder acceder a una cuenta de Facebook, se debe tener un mínimo de 18 años, en este caso, los mayores de edad constituyen el mercado cualificado disponible, es decir, el conjunto de consumidores que tiene interés por la oferta, dispone de la renta necesaria, puede acceder a ella y además está cualificado para adquirirla.

- El mercado objetivo: es la proporción del mercado disponible cualificado que la empresa decide satisfacer.

- El mercado penetrado: es el conjunto de consumidores que adquieren el producto de la empresa.

A la hora de planificar, la empresa tendrá en cuenta estas definiciones, de forma que pueda atraer a más clientes potenciales y expandir su mercado disponible (disminuyendo precios o ampliando su red de distribución). 


\subsubsection{Estados de la demanda}

La demanda puede presentarse en diferentes estados, y en función de los mismos la dirección de marketing tendrá que responder con una estrategia adecuada. (Kotler et al., 2006), según puede verse en la tabla 1.

\begin{tabular}{|l|l|}
\hline ESTADOS DE LA DEMANDA & \multicolumn{1}{|c|}{ ESTRATEGIAS DE MARKETING } \\
\hline Demanda negativa & Analizar causas y fomentar cambios \\
\hline Demanda inexistente & Motivar al público e incentivar la demanda \\
\hline Demanda latente & Crear el producto que satisfaga la demanda \\
\hline Demanda decreciente & Revitalizar el producto y fomentar su consumo \\
\hline Demanda irregular & Sincronizar la demanda a través de incentivos \\
\hline Demanda en exceso & Reducir la demanda, reorientar el consumo \\
\hline Demanda indeseable & Intentar erradicar la demanda por campañas sociales \\
\hline
\end{tabular}

Tabla 1. Estados de la demanda y sus estrategias de marketing Fuente: Kotler et al., 2006

- Demanda negativa. Una parte importante del mercado no acepta el producto, e incluso le desagrada. Por ejemplo, el cambio de logotipo de una marca o el nombre de un producto. Un caso significativo fue el de Coca-Cola cuando cambió a New Coke, obtuvo un rechazo tan grande por parte de los consumidores, que en menos de tres meses tuvieron que volver a denominar CocaCola Classic. La estrategia de marketing ante esta situación siempre será analizar las causas y fomentar los cambios oportunos.

- Demanda inexistente. El mercado no tiene interés por un producto en ese momento e incluso puede llegar a desconocer la existencia de la oferta del mismo. La estrategia será motivar e incentivar la demanda vinculando el producto con las necesidades e intereses del público.

- Demanda latente. Cuando existen consumidores potenciales de un producto y este no existe todavía en el mercado. La estrategia se basará en la creación de un producto que satisfaga la demanda. Un ejemplo claro de la demanda latente fue la aparición en el mercado de la conocidísima «Viagra».

- Demanda decreciente. En todos los sectores existen situaciones en las que decrece la demanda. En este caso se revitalizará el producto y fomentará su consumo mediante un marketing creativo.

- Demanda irregular. Muchas organizaciones tienen productos estacionales, lo que provoca una demanda variable a lo largo del año. Un clara ejemplo son los helados. En este caso, la empresa debe sincronizar la demanda a través de incentivos. 
- Demanda en exceso. El nivel de demanda de un producto o servicio es más alto del que una organización puede o quiere tener. La estrategia que utilizará la dirección de marketing será la de reducir la demanda y reorientar el consumo de forma temporal o permanente.

- Demanda indeseable. Este caso se da cuando el consumo de un producto o servicio está socialmente mal considerado. Por ejemplo el consumo de tabaco. Se intentará erradicar la demanda por campañas sociales.

Las acciones correctivas que realice la dirección de marketing deberán ser eficientes y eficaces para no malgastar los recursos de la empresa y conseguir en todo momento un equilibrio entre su oferta y demanda.

\subsubsection{Análisis de la demanda}

El análisis de la demanda consiste en tres tareas fundamentales: medir la demanda, explicar la demanda y prever la demanda futura (Kotler et al., 2006).

- Medir la demanda actual, como la cuantificación de la demanda actual o potencial (formada por todos los consumidores que tienen algún interés por un producto o servicio en particular). La cuantificación o medición se puede hacer en términos absolutos o relativos. El indicador de la medición relativa, se denomina cuota de mercado e indica la razón entre las ventas de una empresa o producto y el total del mercado.

- Explicar la demanda, para ello se identificará las variables que influyen en su comportamiento. La localización de estas variables y el cálculo de grado de su influencia sobre la demanda, permitirá cuantificar en qué medida se moverá la demanda ante las variaciones de uno o varios factores que la determinan. Por ejemplo, cómo influye un incremento del $5 \%$ en el precio en la demanda del producto.

- Prever la demanda futura. Una vez conocidas las variables que influyen en la demanda actual y pasada, se puede realizar una previsión de la demanda futura. El cálculo de la demanda futura se desarrolla más extensamente en el último punto de este capítulo.

\subsubsection{Cálculo de la demanda actual}

Para calcular la demanda se deben establecer los conceptos de demanda de mercado y demanda de empresa (Kotler et al., 2006).

- Demanda de mercado: La demanda de mercado para un producto es el volumen total susceptible de ser adquirido por un grupo de consumidores definido en un territorio determinado, durante un periodo de tiempo establecido, 
en un entorno de marketing concreto y bajo un programa de marketing específico. Por todo ello, podemos decir que la demanda de mercado en una función de las variables mencionadas:

$$
\text { Demanda }=f(\text { producto, } \text { tiempo, espacio })
$$

- Demanda de la empresa: Una vez definida la demanda de mercado ya podemos establecer la demanda de la empresa que es la proporción de la demanda de mercado que corresponde a la empresa para los diferentes niveles de esfuerzo de marketing en un periodo concreto. La proporción dependerá de la percepción de los elementos del marketing mix de la empresa respecto a los de la competencia. Si todos lo demás factores son similares, la cuota de mercado de la empresa dependerá del volumen y eficacia de sus inversiones en marketing respecto a sus competidores.

- Previsión de ventas de la empresa. Calculada la demanda de la empresa, se selecciona un nivel de esfuerzo de marketing. Se le denomina previsión de ventas de la empresa al nivel de ventas previstas según un plan de marketing $\mathrm{y}$ en un entorno de marketing determinado.

- La previsión de ventas de una empresa no es la base para decidir qué se debe invertir en marketing sino que es el resultado de un plan de gastos en actividades de marketing.

- La cuota de ventas y el presupuesto de ventas son dos conceptos relacionados con la previsión de ventas. El primero, la cuota de ventas es el objetivo de ventas que marca la empresa para un vendedor, una división o una línea de producto. Es una herramienta de gestión que se utiliza para definir y estimular el esfuerzo de ventas. Generalmente se fijan un poco por encima de la previsión de ventas para exigir un esfuerzo a los vendedores. En relación al presupuesto de ventas, podemos decir que es un cálculo moderado del volumen de ventas, fijado ligeramente por debajo de la previsión de ventas, y utilizado para tomar las correctas decisiones en materia de liquidez, suministros y producción.

- Potencial de ventas de la empresa. El potencial de ventas de la empresa es el límite de ventas al que puede aproximarse la demanda de la empresa a medida que aumentan los esfuerzos de marketing con respecto a los de su competencia. El límite absoluto es el potencial de mercado, que supondría el $100 \%$ del mercado. Obviamente, en la mayoría de las empresas el potencial de ventas es inferior al potencial de mercado aunque sus inversiones en actividades de marketing superen significativamente a sus competidores, y eso es debido a la lealtad que tienen los compradores de cada competidor que no suelen ser receptivos a los esfuerzos de marketing de otras empresas. 


\subsubsection{Algunos métodos para calcular la demanda actual}

Existen diversos métodos prácticos para calcular la demanda de mercado actual. Los directores de marketing desearán calcular el potencial total del mercado, el potencial de mercado por zonas, las ventas totales y las cuotas de mercado del sector.

\subsubsection{Potencial total del mercado}

El potencial total del mercado es el volumen máximo de ventas que podría estar disponible para todas las empresas de un mismo sector durante un periodo de tiempo determinado, con unas condiciones del entorno específicas y un nivel de gasto en actividades de marketing concreto.

Podemos definir las ventas como la multiplicación del número total de compradores por la cantidad media comprada y por precio.

$$
\mathbf{Q}=\mathbf{N} .^{\circ} \text { compradores } \times \text { cantidad media comprada } \times \text { precio }
$$

El elemento más difícil de calcular es el número de compradores de un producto o mercado concreto. Normalmente se comienza con la población total del país, a continuación se eliminarían los grupos que no adquirirían el producto por razones objetivas, La diferencia entre el total de la población y estos grupos descartados suponen los compradores potenciales. A estos clientes potenciales podemos restar otras variables o indicadores, reduciendo así la cifra del mercado.

Por ejemplo: Si 21 millones de personas compran libros cada año en España, el comprador medio adquiere tres libros por año, y el precio medio de un libro son 20 euros, el potencial total del mercado de libros es 1260 millones de euros (21 millones $\times 3$ libros $\times 20 €$ ). En enero de 2012, la población total de España era de 47 millones de habitantes. Si eliminamos los grupos que no adquirirían libros (analfabetos y menores de 12 años), que en este caso representan el $15 \%$ de la población, o 7 millones de personas, significa que el $85 \%$ de la población podrían considerarse compradores potenciales (entorno a los 40 millones de personas). $\mathrm{Si}$ seguimos investigando, podemos descartar también a aquellas personas con bajo nivel de ingresos así como aquellas personas que tienen un nivel bajo de estudios y por tanto no compran libros y representan un $40 \%$ de la población, lo que supondría en torno a 19 millones de personas, que si restamos esta cifra a la anterior, quedaría un total de 21 millones de compradores de libros en España.

\subsubsection{Método de proporciones en cadena}

Este método consiste en multiplicar un número base por una serie de porcentajes. Por ejemplo, un fabricante de zapatillas de montaña, quiere sacar un modelo de montaña para mujer, el cálculo podría ser el siguiente: 
Demanda de nueva zapatilla de montaña para mujer $=$ Población $\times$ renta per cápita $\times$ por porcentaje de renta gastada en calzado $\times$ porcentaje de gasto en calzado deportivo $\times$ porcentaje de gasto en calzado deportivo para mujer.

\subsubsection{Potencial de mercado por zonas}

Evidentemente, el gasto destinado en actividades de marketing no es igual dependiendo de la ciudad, área o país, por lo que desde la dirección de marketing se debe asignar los presupuestos a este fin con la máxima eficacia posible. Para ello se necesita calcular el potencial de mercado por zonas, y se utilizan dos métodos fundamentalmente, en mercados empresariales se utiliza el método de construcción de mercado y en mercados de consumo se utiliza normalmente el método de índice multifactorial.

El método de construcción de mercado, consiste fundamentalmente en identificar el total de compradores potenciales de cada mercado y en calcular sus posibles compras. Con este método se obtienen datos muy precisos siempre que se utilicen una lista de todos los compradores potenciales y un cálculo fiel que lo que adquiriría cada uno. Es en la obtención de estos datos donde está la dificultad de este método. Supongamos una empresa que se dedica a ofrecer servicios de limpieza a empresas, y según su zona de influencia hay 200 empresas que se clasifican por su nivel medio de gasto en limpieza en cuatro tipos, tal y como muestra la tabla 2.

\begin{tabular}{|l|r|r|}
\hline \multicolumn{1}{|c|}{ Tipo de empresa } & Número de empresas & Gasto anual medio en limpieza \\
\hline TIPO A & 52 & $1650 €$ \\
\hline TIPO B & 75 & $1400 €$ \\
\hline TIPO C & 45 & $8700 €$ \\
\hline TIPO D & 28 & $14.500 €$ \\
\hline TOTAL & 200 & \\
\hline
\end{tabular}

Tabla 2. Método de construcción de mercado Fuente: Elaboración propia

Para calcular el mercado potencial de la zona multiplicaríamos el número de empresas de cada tipo por su gasto anual en limpieza y luego las sumaríamos todas, de forma que $(52 \times 1650)+(75 \times 1400)+(45 \times 8700)+(28 \times 14.500)$ daría un resultado de 995.450 euros de gasto anual medio en limpieza, o lo que es lo mismo, nuestro mercado potencial de zona.

El método de índice multifactorial se utiliza en mercados de consumo, y consiste en la identificación de los factores principales que condicionan la demanda y la ponderación de los mismos. Por ejemplo, un fabricante de zapatillas de montaña, podría suponer que el mercado potencial de zapatillas está directamente relacionado con el tamaño de la población. Si la provincia de Castellón supone el 1,22 \% de la población total de España, la empresa podría dar por hecho que Castellón 
constituye el 1,22\% del mercado de zapatillas. Ahora bien, un único factor no representa un indicador fiable de las oportunidades de ventas. Las ventas por área geográfica también dependen de la renta per cápita y de las actividades específicas de montaña que se puedan realizar en la zona, entre otros factores. Por ello, es lógico desarrollar un índice multifactorial, en el que se le asigna una ponderación relativa a cada factor. Supongamos que Castellón posee el 2,2 \% de la renta personal disponible de España, el 1,93 \% de las ventas minoristas y el 1,22 \% de la población española y que las ponderaciones relativas son $0,7,0,5$ y 0,1 respectivamente. El índice de poder de compra para Castellón sería de 2,63 [(0,7 × 2,2) + $(0,5 \times 1,93)+$ $(0,1 \times 1,22)]$, por lo que el $2,63 \%$ de las ventas de España se darían en Castellón.

Ahora bien, estas ponderaciones pueden ser arbitrarias, ya que se podrían utilizar otras si fueran necesarias, y también para ajustar más el potencial de mercado, se añadirían otros factores tales como los costes de promoción local, presencia de otros competidores, factores estacionales, etc.

Otro índice de zona es el índice de desarrollo de marca (IDM), que es la relación existente entre el consumo y la población. Cuanto más alto es este índice, la marca está más desarrollada que la categoría, mientras que si es bajo, la marca está relativamente subdesarrollada y hay más oportunidades de mercado para expandir la marca, aunque algunos expertos opinan que sería mejor realizar los esfuerzos de marketing en aquellas áreas donde la marca está consolidada, y así reforzar la fidelización o conseguir mayor cuota de marca.

\subsubsection{Volumen de ventas y cuotas de mercado por sector}

Para poder calcular el volumen de ventas, las empresas deben identificar a sus competidores y conocer sus ventas. Las ventas por sector, que no de empresas, las suelen recopilar y publicar las confederaciones empresariales, y con esos datos, la empresa puede comparar sus datos con los del sector al que pertenece. Imaginemos que las ventas de una empresa se han incrementado en un $10 \%$, a priori este dato es positivo, pero comparado con las ventas del sector, que para ese mismo año ha sido del $20 \%$, la empresa estaría perdiendo peso específico en ese sector.

También existen empresas de investigación de marketing, como por ejemplo Nielsen Media Research, que auditan el total de ventas y las ventas por marcas de numerosas empresas y que venden estos informes a las empresas interesadas, de forma que no solo la empresa se puede comparar con el sector en el que compite sino que también con sus competidores directos, y analizar si están ganando o perdiendo cuota de mercado.

Para las empresas de bienes industriales es más complicado calcular las cuotas de mercado y ventas por sector porque no existen empresas como Nielsen en las que basarse y los distribuidores no suelen revelar información sobre la venta de productos competidores. 


\subsubsection{Cálculo de la demanda futura}

En la mayoría de los mercados la demanda total y la demanda de la empresa no son estables, muy pocos productos son sencillos de predecir, como los que tienen una evolución de las ventas estable o carecen de competidores (servicios públicos) o cuyos competidores son estables (oligopolios puros).

Las buenas previsiones son un factor clave para el éxito de la empresa. Cuanto más instable sea la demanda, más importante y difícil es la precisión en la previsión. Se suele utilizar un proceso de tres fases para realizar una previsión de ventas: inicialmente se prepara una previsión macroeconómica que requiere la proyección de la inflación, de los tipos de interés, de la tasa de desempleo, del gasto público, del índice de consumo, etc., consiguiendo una previsión del PNB. A continuación, esta previsión del PNB junto con otros indicadores del entorno se utiliza para realizar previsiones de ventas sectoriales para que en último lugar la empresa realice su previsión de ventas considerando las variables del entorno y cuota de mercado que desea conseguir.

La previsión es el arte de anticipar la posible respuesta de los compradores en una serie de condiciones. Las empresas pueden hacer de forma interna estas previsiones o contratando a empresas de investigación de marketing. Todas las previsiones se realizan a partir de una de las tres fuentes de información existentes: lo que la gente dice (análisis de intención de compradores, opinión de la fuerza de ventas y opinión de los expertos), lo que la gente hace (colocar el producto en un mercado de prueba) y lo que la gente ha hecho (análisis de compras y ventas pasadas, e históricos de demanda).

\subsubsection{Análisis de intención de compradores}

Existen diversas empresas que realizan encuestas periódicas de intención de compra. Los fabricantes de bienes de consumo duraderos, pueden utilizar estas encuestas y sus índices para poder anticipar los principales cambios en las intenciones de compra y ajustar así sus planes de producción y marketing. Un ejemplo de pregunta sería como la que aparece en la tabla 3, donde aparece una escala que se conoce como escala de probabilidades de compra.

Para el caso de la compra organizacional, las empresas dedicadas a la investigación, pueden realizar encuestas sobre la intención de compra de materias primas, de plantas de producción, etc. Son especialmente útiles para prever la demanda de productos industriales, y presentan un margen de error en torno al $10 \%$.

\begin{tabular}{|c|c|c|c|c|c|}
\hline 0,00 & 0,20 & 0,40 & 0,60 & 0,80 & 1,00 \\
\hline $\begin{array}{c}\text { No, en } \\
\text { absoluto }\end{array}$ & $\begin{array}{c}\text { Es muy poco } \\
\text { probable }\end{array}$ & Es probable & $\begin{array}{c}\text { Es bastante } \\
\text { probable }\end{array}$ & $\begin{array}{c}\text { Es muy } \\
\text { probable }\end{array}$ & $\begin{array}{c}\text { Sí, } \\
\text { seguro }\end{array}$ \\
\hline
\end{tabular}

Tabla 3. Escala de probabilidades de compra Fuente: Kotler et al. (2006) 
El valor de análisis de intención de los compradores aumenta en la medida en que el coste de llegar a los compradores es limitado, los compradores son pocos, sus intenciones son claras, hacen lo que dicen y revelan sus intenciones de forma clara.

\subsubsection{Opinión de la fuerza de ventas}

A petición de la empresa, los vendedores calculan cuánto comprarán los clientes reales y potenciales. La empresa posteriormente realizará los ajustes oportunos, ya que podrían no disponer de datos macroeconómicos, mostrarse optimistas o pesimistas, ni conocer como influirían los planes de marketing en su zona.

Es muy ventajoso para la empresa solicitar la opinión de la fuerza de ventas en el proceso de previsión de ventas, ya que tras participar en el proceso, los vendedores pueden tener mas confianza en las cuotas de ventas y estar más motivados para conseguirlas, además los resultados de las previsiones pueden ofrecer detalles desglosados por producto, territorio, cliente y vendedor.

\subsubsection{Opinión de los expertos}

Las empresas también pueden solicitar la previsión de ventas a expertos como distribuidores, intermediarios, proveedores, consultores de marketing y asociaciones comerciales. Muchas empresas compran las previsiones económicas y sectoriales a empresas reconocidas especializadas en la materia, ya que son capaces de elaborar mejores previsiones que la propia empresa pues disponen más información y experiencia.

También pueden invitar a un grupo de expertos, donde intercambian opiniones y prepararan la previsión en grupo, o generan previsiones individuales y luego un analista puede combinarlas para llegar a una única previsión (método de agrupación de previsiones individuales) o se siguen realizando rondas de previsión y perfeccionamiento (método Delphi).

\subsubsection{Prueba de mercado}

Las pruebas de mercado son especialmente recomendables para productos nuevos, o un canal de distribución nuevo o en un nuevo mercado geográfico. Es especialmente recomendable cuando los compradores no planifican sus compras o no hay expertos disponibles para las previsiones o estas no son fiables. 


\subsubsection{Análisis de histórico de ventas}

Las previsiones de ventas se pueden basar en ventas pasadas. El alisado exponencial, es una técnica de análisis de series temporales que proyecta las ventas del siguiente periodo a través de la combinación de una media de ventas pasadas y de las ventas más recientes, ponderando más estas últimas. El análisis estadístico de la demanda, mide el impacto de una serie de factores causales (por ejemplo, renta, precio, etc.) sobre el nivel de ventas, y el análisis econométrico consiste en crear conjuntos de ecuaciones que describen un sistema con el fin de ajustar estadísticamente los parámetros, ya que los cambios observados de la demanda se explican por la influencia de otras variables explicativas.

\section{Referencias bibliográficas}

Abell, D. F. (1980): Defining the business: The starting point of strategic planning, Englewood Cliffs (NY), Prentice-Hall.

Kotler, P., Lane, K., Cámara, D. y A. Mollá (2006): Dirección de Marketing, 12. ${ }^{\mathrm{a}}$ ed., Madrid, Prentice Hall.

LAmbin, J. J. (2003): Marketing Estratégico, Madrid, Esic Editorial.

Munuera, J. L. y A. I. Rodríguez (2002): Estrategias de marketing, teoría y casos, Madrid, Pirámide.

- (2007): Estrategias de marketing, Un enfoque basado en el proceso de dirección, Madrid, ESIC Editorial. 



\section{Comportamiento de compra de consumidores finales y de compradores organizacionales Victor del Corte-Lora}

\section{Contenido del capítulo}

En el capítulo anterior hemos visto los diferentes tipos de mercados para la empresa y cómo se calcula la demanda. En este capítulo se aborda el comportamiento del consumidor final y del consumidor organizacional. Entender el porqué de las acciones de los consumidores es indispensable para fijar una estrategia acorde con los objetivos de marketing. Veremos cuál es el proceso de compra que siguen los consumidores para llevar a cabo una determinada compra y cuáles son las influencias que hacen que se decante por un determinado producto en lugar de otro.

El objetivo del estudio del consumidor es comprender tanto las influencias como los procesos mentales que lleva a cabo el consumidor para anticipar e influir en sus decisiones de compra. 
3.1. ¿Qué es el comportamiento del consumidor?

3.2. Modelo de comportamiento estímulo-respuesta

3.3. Características diferenciales del comprador organizacional

3.4. Proceso de decisión de compra del consumidor final

3.4.1. Reconocimiento de la necesidad

3.4.2. Búsqueda de información

3.4.3. Evaluación de alternativas

3.4.4. Decisión de compra

3.4.5. Comportamiento postcompra

3.5. Proceso de decisión de compra del comprador organizacional

3.5.1. Reconocimiento del problema

3.5.2. Descripción de la necesidad y especificaciones del producto

3.5.3. Búsqueda de proveedores

3.5.4. Solicitud de propuestas

3.5.5. Selección de proveedores

3.5.6. Especificación de pedido rutinario

3.5.7. Revisión de la actuación del proveedor

3.6. Factores condicionantes del comportamiento del consumidor final

3.6.1. Factores culturales

3.6.2. Factores sociales

3.6.2.1. Grupos de referencia

3.6.2.2. La familia

3.6.2.3. Roles y estatus

3.6.3. Factores individuales

3.6.3.1. Edad y etapa del ciclo de vida

3.6.3.2. Ocupación y situación económica

3.6.3.3. Estilos de vida

3.6.3.4. Personalidad y autoconcepto

3.6.4. Factores psicológicos

3.6.4.1. Motivación

3.6.4.2. Percepción

3.6.4.3. Aprendizaje

3.6.4.4. Creencias y actitudes

3.7. Factores condicionantes del comportamiento del comprador organizacional

3.8. Tipos de compra

3.8.1. Consumidor final

3.8.2. Comprador organizacional

Referencias bibliográficas 


\section{1. ¿Qué es el comportamiento del consumidor?}

El comportamiento del consumidor engloba todas las actividades que los individuos y organizaciones realizan cuando: seleccionan, compran, evalúan y utilizan los bienes y servicios para satisfacer sus necesidades y deseos.

Los consumidores finales son aquellos que realizan sus compras para su uso final. Los compradores organizacionales, por el contrario, los utilizan en sus actividades dentro de las empresas, bien en la producción de nuevos bienes y servicios, bien revendiéndolos o alquilándolos.

\subsection{Modelo de comportamiento estímulo-respuesta}

Los directores de marketing de las empresas realizan investigaciones para conocer el comportamiento de los consumidores. Quién compra, qué producto, cuándo y dónde lo hace, en qué cantidad y, muy especialmente, por qué.

El objetivo que tienen esas investigaciones es pronosticar, a través del conocimiento de los hábitos de compra y consumo, cómo pueden afectar las futuras acciones de marketing que realice la empresa a la decisión de compra del consumidor.

Los compradores siguen el modelo de comportamiento estímulo-respuesta que se caracteriza por la existencia de unos estímulos (las 4 Pes del marketing y del entorno) que entran en lo que se conoce como la caja negra del comprador, formada por las influencias (externas e internas) y el proceso de decisión de compra, provocando una serie de respuestas de compra como la selección del producto o el momento de la compra.

Son esas respuestas las que buscan conocer el estudio del comportamiento del consumidor, ya que estas ayudan a prever cuál será la conducta de un consumidor, no solo en cuanto a qué producto comprará, sino también el momento en que lo hará, la cantidad o cómo lo hará.

Los modelos de comportamiento del consumidor son distintos cuando se trata de consumidor final (figura 12) y cuando se trata de comprador organizacional (figura 13).

Como se observa comparando los modelos, los estímulos son los mismos en ambos casos. Sin embargo, no sucede lo mismo ni con la caja negra ni con las diferentes respuestas que se dan en ambos casos. En los siguientes apartados veremos las diferencias entre ambos modelos analizando tanto el proceso de decisión de compra, como los factores condicionantes y las respuestas del consumidor final y del comprador organizacional. 


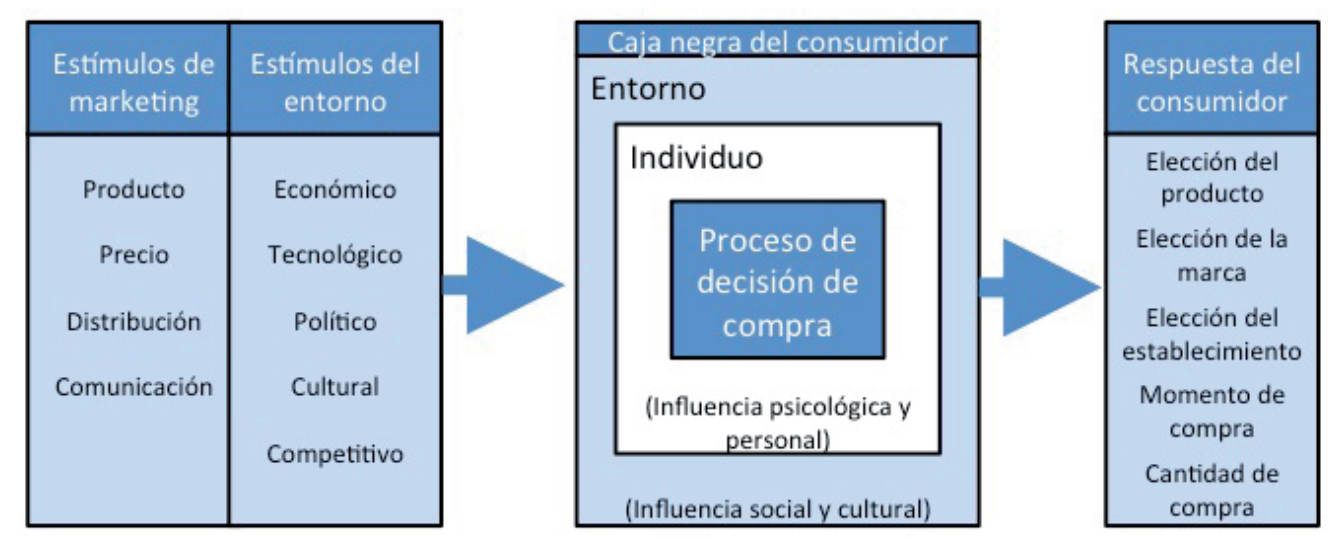

Figura 12. Modelo de comportamiento estímulo-respuesta del consumidor final Fuente: Adaptado de Armstrong et al. (2011)

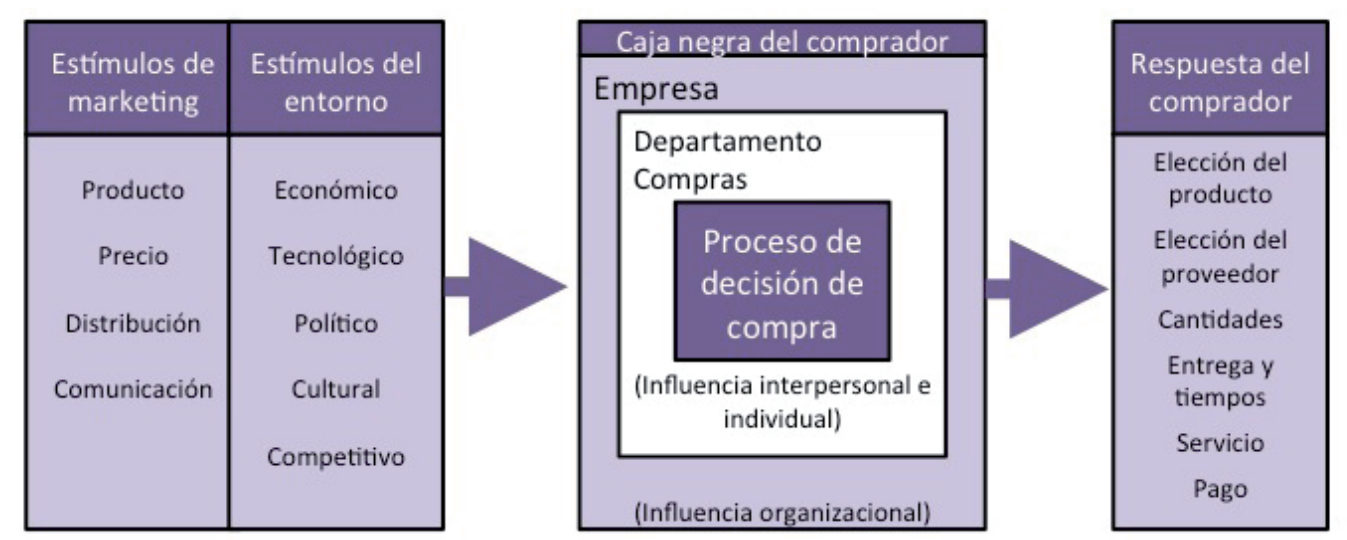

Figura 13. Modelo de comportamiento estímulo-respuesta del comprador organizacional Fuente: Adaptado de Armstrong et al. (2011)

\subsection{Características diferenciales del comprador organizacional}

Los compradores organizacionales son aquéllos que adquieren un producto a otras empresas para su uso en su proceso productivo, porque lo va a revender o alquilar o porque, sin ser una materia prima, lo va a utilizar en sus actividades, es lo que se conoce como B2B (Business to Business). En contraposición, cuando un consumidor final compra un producto o un servicio, lo hace para su consumo inmediato, es lo que se conoce como B2C (Business to Consumer). Esto hace, a su vez, que el dinero que se tiene que mover en el mercado del comprador organizacional sea muy superior al que se mueve en el del consumidor individual y, por otro lado, marca una serie de características en el caso de los compradores organizacionales, que los diferencian de los mercados de consumo individuales (Kotler y Keller, 2012):

- Existen menos compradores y son de mayor tamaño: cuando una empresa vende a otra empresa, tiene menos posibles clientes que cuando vende 
directamente a los consumidores. Además, los compradores van a ser de mucho mayor tamaño, ya que son empresas que utilizan los productos en sus sistemas productivos. Pongamos por ejemplo una empresa que le vende componentes a un fabricante de automóviles, difícilmente el tamaño de la empresa que vende los componentes sea equiparable al fabricante de los vehículos.

- Compradores concentrados geográficamente: es habitual que una determinada industria se encuentre localizada en un mismo territorio geográfico, formando clústeres y distritos industriales, ello implica que mucho de los compradores organizacionales se encuentren concentrados geográficamente. Un ejemplo de clúster industrial, donde muchos compradores se concentran, es el clúster de la cerámica en Castellón.

- Relaciones más estrechas entre clientes y proveedores: proveedores y clientes necesitan mantener una relación más estrecha para poder ofrecer soluciones personalizadas a los clientes.

- Reciprocidad: fruto de las relaciones estrechas, es habitual que los compradores seleccionen proveedores que a su vez sean clientes de su empresa.

- Compradores profesionales: los compradores organizacionales son compradores profesionales que necesitan tener conocimientos sobre las políticas de compra de la empresa y el uso de herramientas de compra que no son utilizados en las compras de los consumidores finales.

- Múltiples influencias de compras: en las compras organizacionales la decisión no la toma únicamente el departamento de compras sino que este tiene que escuchar, en la mayoría de las ocasiones, las opiniones de los técnicos y de los usuarios del producto que se va a adquirir. En función de la importancia de la compra la decisión la puede tomar directamente la dirección de la empresa.

- Múltiples llamadas de ventas: para poder realizar la compra, es necesario que comprador y proveedor entren en contacto en muchas ocasiones con el fin de negociar las condiciones de la compra o mejorar la comprensión de los diferentes puntos de la compra.

- Demanda inelástica: la demanda de la compra organizacional es muy inelástica, no se ve afectada por los cambios de precio. Por más que un proveedor baje el precio de un determinado producto, el consumo de ese determinado producto no variará. Del mismo modo, cuando sube el precio de un producto, la demanda también se mantendrá, salvo que exista un sustitutivo que lo haga más económico.

- Compra directa: los compradores organizacionales prefieren realizar las compras directamente con el fabricante, sin usar intermediarios ni agentes. 


\subsection{Proceso de decisión de compra del consumidor final}

Se debe entender el proceso de compra como un problema que el consumidor debe resolver, y la resolución del problema se puede llevar a cabo mediante la compra o el consumo de un producto o servicio. La figura 14 nos muestra las distintas fases del proceso de decisión de compra del consumidor final:

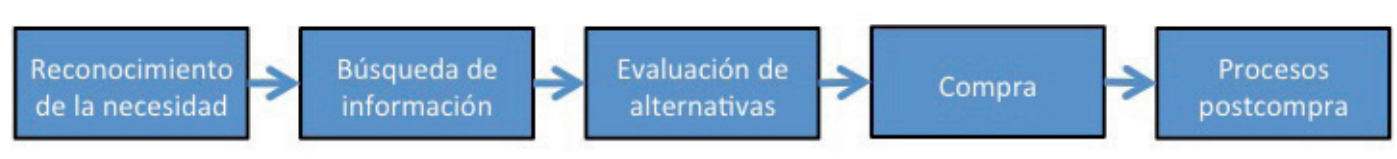

Figura 14. Modelo de cinco fases del comportamiento de compra del consumidor final Fuente: Engel et al. (1990)

Es importante destacar que, aunque el modelo se haya presentado como una secuencia en la que las distintas fases se van sucediendo una detrás de otra, esto no tiene por qué ser así, ya que los pasos pueden darse de forma simultánea. De hecho, es perfectamente plausible que, por ejemplo, un consumidor se salte alguna de las fases. Pensemos en una compra que se realiza de manera habitual, un producto de limpieza, es probable que el consumidor pase directamente del reconocimiento de la necesidad a la compra del producto, sin necesidad de buscar información o evaluar distintas alternativas.

A continuación ahondaremos en cada una de las fases del proceso.

\subsubsection{Reconocimiento de la necesidad}

El inicio que desencadena todo el proceso de compra es el reconocimiento de una necesidad por parte del consumidor. Este identifica que existe una diferencia entre el estado en el que se encuentra y el estado en el que le gustaría estar (expectativa) y esta diferencia se puede recortar mediante la compra de un determinado producto o servicio.

El estímulo que despierta la necesidad puede ser un estímulo interno, por ejemplo el hambre, o puede ser un estímulo externo, como cuando se ve un anuncio de un dispositivo último modelo y surge la necesidad de poseerlo de forma inmediata para estar a la última. De ahí la importancia para los directivos de marketing, que deben ser capaces de activar la necesidad latente del consumidor mediante los estímulos adecuados para dirigirlos hacia sus productos. 


\subsubsection{Búsqueda de información}

Tras reconocer el problema, la necesidad, el consumidor buscará la forma de resolverlo. Para ello recurrirá, en primer lugar, a la búsqueda de información. El principal beneficio que se espera obtener de la búsqueda de información es la reducción del riesgo en la compra, consiguiendo el producto que mejor satisfaga las necesidades. La cantidad y la calidad de la información que el consumidor buscará dependerá en gran medida de la importancia que tenga la compra, el riesgo que asuma, los beneficios que le vaya a aportar y lo accesible que esté la información. Para realizar la búsqueda existen diferentes fuentes a las que el consumidor puede acceder.

En primer lugar, el consumidor recurrirá a fuentes internas: a la experiencia, a su memoria, a las situaciones que ya ha vivido por el hecho de haber realizado otros procesos de selección, haber buscado información y experimentado distintos productos. En ocasiones, si se trata de compras sencillas, es probable que no se recurra a otras fuentes de información. Sin embargo, cuando se trata de compras más complejas, se recurre también a otras fuentes de información externas.

Si el consumidor considera que no tiene suficiente información con la experiencia, es probable que recurra a otras fuentes externas. Las fuentes comerciales, hacen referencia a información que está controlada por la empresa, los vendedores, la publicidad de la marca, la página web, etc. Se trata de información que suele destacar los aspectos positivos de la marca, obviando sus puntos débiles.

Otra fuente de información la componen las fuentes públicas, son fuentes accesibles para todos los consumidores, que en este caso no están controladas por las marcas y por lo tanto no están sesgadas. Son fuentes públicas: las comparativas que se pueden encontrar en internet, las que realizan las organizaciones de consumidores o las que aparecen en los medios de comunicación.

Finalmente encontramos las fuentes personales. Es la información que nos aportan los familiares, amigos, vecinos, etc. Es, generalmente, la información mejor valorada por el consumidor ya que posee un mayor nivel de credibilidad.

A medida que el consumidor va obteniendo información del producto o servicio, va configurando un listado con las distintas marcas y sus atributos. La figura 15 nos muestra los distintos conjuntos que se irán formando y las variaciones que sufrirán según los criterios de evaluación del consumidor. 


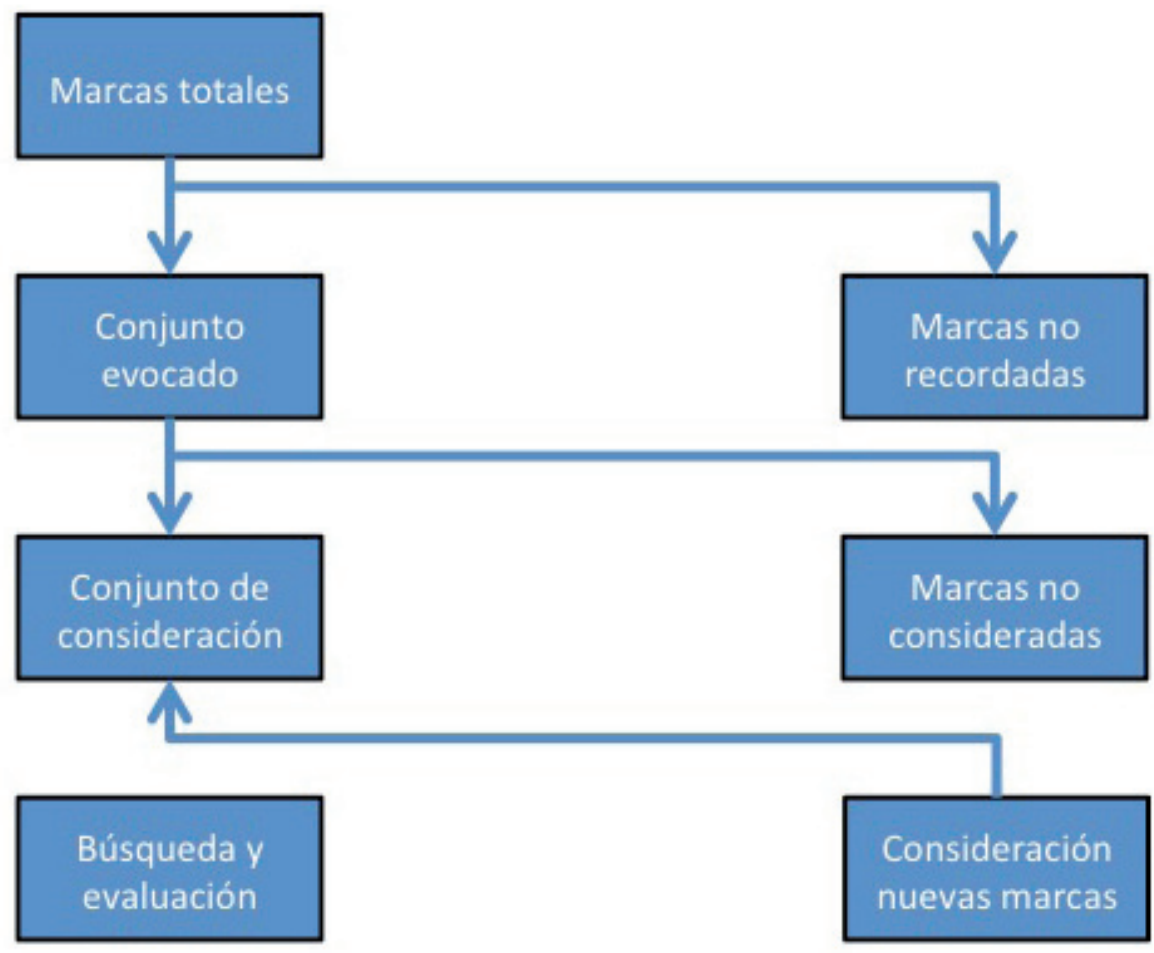

Figura 15. Conjunto de consideración y conjunto evocado Fuente: Mollá et al. (2006)

El conjunto evocado muestra las marcas que el consumidor recuerda en un primer momento, antes de iniciar el proceso de búsqueda de información. Este conjunto es mucho menor que el de marcas totales, ya que hay muchas marcas que el consumidor no recuerda. Este conjunto va a verse modificado, ya que la obtención de información hará que se incluyan nuevas marcas que antes no habían sido consideradas y se excluyan otras que en principio habían sido incluidas en el conjunto evocado pero que ahora se han descartado al no cumplir con los requisitos mínimos. De este nuevo conjunto, el conjunto de consideración, es de donde saldrá la decisión de compra.

\subsubsection{Evaluación de alternativas}

La información que ha obtenido el consumidor le ha dado un mayor conocimiento acerca de los productos y servicios que desea adquirir. Ya durante ese proceso el consumidor está realizando una evaluación tanto de los atributos como de las marcas.

El objetivo del consumidor es satisfacer una necesidad mediante la compra o consumo de un producto o servicio y para ello intentará obtener aquél que mayor satisfacción le aporte. Se debe tener en cuenta que los productos, para el consumidor, son conjuntos de atributos y que la importancia de cada uno de los atributos variará en función del producto que se vaya a adquirir. No es lo mismo comprar 
un coche que un producto de limpieza para el hogar o un viaje. Estos atributos serán los que el consumidor utilizará como criterios para evaluar las distintas alternativas que había obtenido mediante el proceso de búsqueda de información, en función de sus gustos y preferencias.

Para ello, el consumidor aplicará unas reglas de decisión, existiendo diferentes estrategias de decisión, distinguiendo entre modelos compensatorios y modelos no compensatorios.

Los modelos compensatorios consideran que el consumidor es capaz de asignar una valoración a los atributos, algunas de estas valoraciones son negativas, mientras que otras son positivas, compensando de esta forma los valores negativos de algunos atributos con los valores positivos de otros.

El modelo del valor esperado, es un modelo compensatorio en el que el consumidor asigna, en función de sus gustos y preferencias, una importancia relativa para cada atributo de un determinado producto o servicio (que obviamente será la misma para todas las marcas) y una valoración para cada atributo de un producto o servicio que variará en función de la marca. De esta forma obtiene una valoración total para cada una de las marcas.

En la tabla 4 podemos ver un ejemplo de una valoración de un consumidor que desea adquirir un vehículo. Como se observa, el consumidor asigna diferentes valores a la importancia de las características, siendo la más importante la potencia con un $55 \%$. Por otro lado, el consumidor asigna una puntuación para esos atributos a cada una de las marcas. Lo interesante de los modelos compensatorios es, precisamente, la compensación que se hacen entre los distintos atributos. En el ejemplo la característica más importante es la potencia, y la marca con mejor nota en ese atributo es la «A», sin embargo el consumidor elegiría la marca « $\mathrm{B} »$, dado que esta le aporta mayor satisfacción global, pese a tener una nota inferior en potencia.

\begin{tabular}{|c|c|c|c|c|c|c|c|c|c|}
\hline \multirow{2}{*}{$\begin{array}{c}\text { Marca } \\
\text { Vehículo }\end{array}$} & \multicolumn{2}{|c|}{ Comodidad } & \multicolumn{2}{|c|}{ Potencia } & \multicolumn{2}{|c|}{ Accesorios } & \multicolumn{2}{|c|}{ Espacio } & \multirow{2}{*}{$\begin{array}{c}\text { Total } \\
\text { Puntuación }\end{array}$} \\
\hline & Importancia & Valoración & Importancia & Valoración & Importancia & Valoración & Importancia & Valoración & \\
\hline A & $30 \%$ & 3 & $55 \%$ & 6 & $10 \%$ & 8 & $5 \%$ & 8 & 5,40 \\
\hline B & $30 \%$ & 8 & $55 \%$ & 4 & $10 \%$ & 9 & $5 \%$ & 6 & 5,80 \\
\hline C & $30 \%$ & 3 & $55 \%$ & 3 & $10 \%$ & 4 & $5 \%$ & 7 & 3,30 \\
\hline D & $30 \%$ & 5 & $55 \%$ & 5 & $10 \%$ & 5 & $5 \%$ & 5 & 5,00 \\
\hline
\end{tabular}

Tabla 4. Ejemplo de modelo de valor esperado Fuente: Kotler et al. (2006)

Por el contrario, los modelos no compensatorios, parten de la base de que los modelos compensatorios son demasiado complejos y que el consumidor en muchas ocasiones opta por seguir un camino más sencillo, bien porque no puede hacerlo, bien porque requiere excesivo esfuerzo. En estos modelos, los atributos no se compensan, sino que se evalúan de forma aislada, simplificando la toma de decisión. Entre los diferentes métodos no compensatorios encontramos: 
- Modelo conjuntivo, el consumidor fija un mínimo aceptable para las características y rechaza aquellas opciones que no cumplan con los mínimos. Supongamos que en el ejemplo anterior se fijaba un mínimo de 5 para todas las características, la única marca que cumple con ese requisito es la «D»y, por lo tanto, esta debería ser la seleccionada.

- Modelo lexicográfico, el consumidor selecciona el atributo que considera más importante para realizar la criba. La marca que tiene la mejor valoración en este atributo es la seleccionada, en el ejemplo sería la «A», ya que tiene la nota más alta en el atributo más importante, potencia.

- Modelo de eliminación por características, se ordenan los atributos por su importancia y se fija un valor mínimo aceptable para cada una de ellas. Las marcas que no llegan al mínimo en cada atributo, se van eliminando. Supongamos que en el ejemplo de fija un nivel mínimo de 5 para la potencia, 3 para la comodidad, 7 para accesorios y 5 para espacio. En primer lugar se compararía la potencia, eliminando aquéllas opciones que no lleguen a 5, «B»y «C» quedarían por tanto descartadas, ya que no llegan a 5. A continuación se compararía comodidad entre «A» $\mathrm{y}$ «D», como ambas tienen 3 o más, ambas pasarían al siguiente atributo. En este caso en accesorios se pedía un 7, y de las dos marcas que quedan la única que llega a ese valor es «A», por lo tanto sería esta la seleccionada.

\subsubsection{Decisión de compra}

Una vez que se ha seleccionado la mejor opción de compra en la evaluación, se formará la intención de compra y se desencadenará el proceso para ejecutar la compra. Dando respuesta a las siguientes preguntas: comprar o no comprar, qué comprar, cuánto comprar, cuándo comprar y dónde comprar. La ejecución de la compra, sin embargo, no se llevará siempre a cabo, ya que puede haber factores que nos induzcan bien a posponer la compra o incluso a cancelarla. Estos factores pueden ser de dos tipos:

- Actitudes de otras personas que interfieran en la ejecución de la compra, porque muestran una actitud negativa frente a la opción que se ha elegido. Esta objeción será mayor cuanto más intensa sea su actitud negativa, más cercano al consumidor esté y más esté el consumidor dispuesto a complacer a otras personas.

- Factores situacionales imprevistos, que puedan hacer cambiar las necesidades del consumidor. Por ejemplo, una persona puede querer comprar un coche nuevo, pero si se produce una avería importante en el hogar, es posible que decida invertir el dinero en la reparación del hogar en lugar de en el coche. 
La determinación de no comprar o posponer la compra, está muy vinculada a los riesgos asociados a la compra que pueda percibir el consumidor. Los riesgos pueden ser de diferentes tipos (Kotler y Keller, 2012):

- Funcional: el producto no se comporta como se esperaba.

- Físico: puede provocar problemas en la salud.

- Financiero: el producto no vale el precio pagado.

- Social: el producto provoca vergüenza frente a los demás.

- Psicológico: afecta al bienestar mental del usuario.

- Oportunidad: si el producto falla, se tiene un coste de oportunidad, ya que hay que comprar otro que lo sustituya.

El riesgo percibido será mayor cuanto mayor sea la inversión a realizar y menor la confianza del consumidor en sí mismo. Algunas de las maneras en que se puede reducir este riesgo son evitar tomar decisiones sin tener suficiente información, consultar a amistades y familiares, solicitar garantías, etc.

\subsubsection{Comportamiento poscompra}

El proceso de decisión de compra no termina, sin embargo, tras haber ejecutado la compra. El uso del producto y los sentimientos que ello generará aportará información de gran valor para compras futuras.

Tras la compra el consumidor experimenta dudas e inseguridad respecto a la compra que ha realizado. No está seguro de haber realizado la compra correcta. Este estado se conoce como disonancia cognitiva, y será mayor cuanto más compleja sea la compra, más importante para el consumidor o mayor grado de compromiso le suponga.

La satisfacción postcompra se producirá siempre y cuando se haya conseguido cubrir las expectativas con el resultado del producto. Si no solo alcanza esas expectativas, sino que las supera ampliamente, el consumidor estará encantado, facilitando la recompra de la marca así como recomendándola a amigos y familiares.

Por el contrario, el consumidor estará insatisfecho cuando las expectativas no se cumplan y el producto no sea lo esperado. En estos casos se generan sentimientos de decepción, tristeza, frustración y conformismo. Las acciones que puede realizar en este caso el consumidor, son muy diversas.

En primer lugar el consumidor puede decidir no actuar, aunque esta opción no es muy frecuente. Si, por el contrario, el consumidor decide actuar, puede decidirse por ejercer acciones privadas o acciones públicas. 
En el caso de las acciones privadas, la primera de ellas es la más obvia, y se trata de no comprar el bien o utilizar el servicio en el futuro, eliminando la marca de toda consideración posterior. Esta acción suele venir acompañada de una comunicación boca-oído negativa, con la que se advierte a los amigos y familiares de los problemas que se ha tenido con el producto. Es importante destacar en este caso que los consumidores estamos más predispuestos a contar los problemas que hemos tenido cuando estamos insatisfechos, que las bondades de un determinado producto cuando estamos satisfechos.

En cuanto a las acciones públicas, tres son los caminos que se pueden tomar, aunque no son excluyentes entre ellos. El primero de ellos es buscar compensaciones de la empresa. Es decir, quejarse directamente a la empresa con el fin de obtener una recompensa. Por otro lado, se puede también presentar quejas a organismos privados o públicos, como por ejemplo la oficina de consumo o la oCU o, en casos más extremos, emprender acciones legales con el fin de obtener una compensación. El proceso completo lo podemos observar en la figura 16.

Asimismo, los directivos de marketing tienen que tener en cuenta qué uso se le da al producto después de haberlo adquirido el consumidor y especialmente cómo se deshace de él. Cuanto antes se consuma el producto, antes se estará en disposición de adquirirlo de nuevo. Por ejemplo, los consumidores pueden estar utilizando el producto más allá de lo debido, por lo que es importante establecer mecanismos que ayuden a saber si es hora de cambiarlo. Por ejemplo, los neumáticos de los coches incorporan testigos que nos avisan que es necesario sustituirlos.

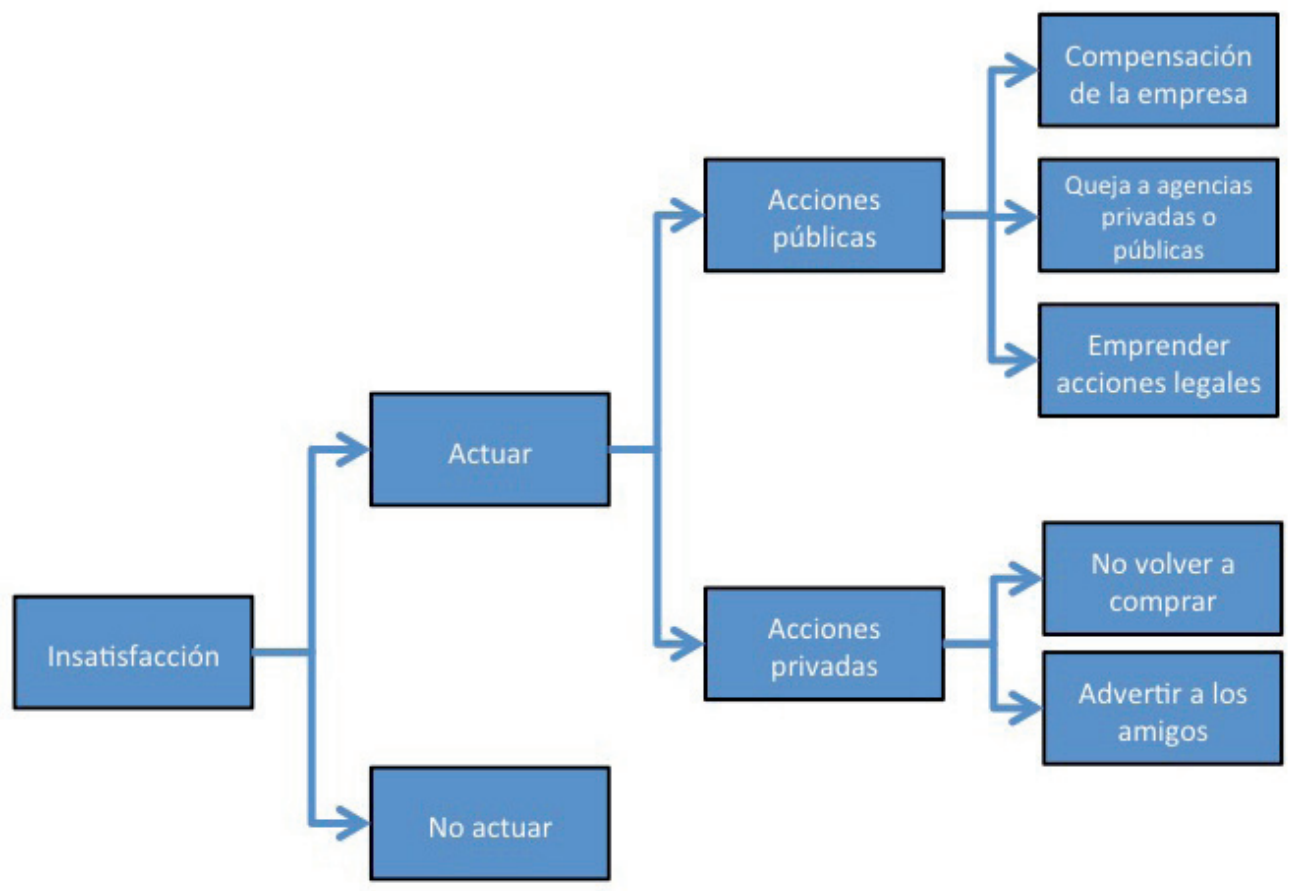

Figura 16. Proceso seguido por el consumidor en caso de insatisfacción Fuente: Elaboración propia a partir de Mollá et al. (2006)

Las acciones que se pueden dar cuando un consumidor agota la vida del producto son las que se muestran en la figura 17. 


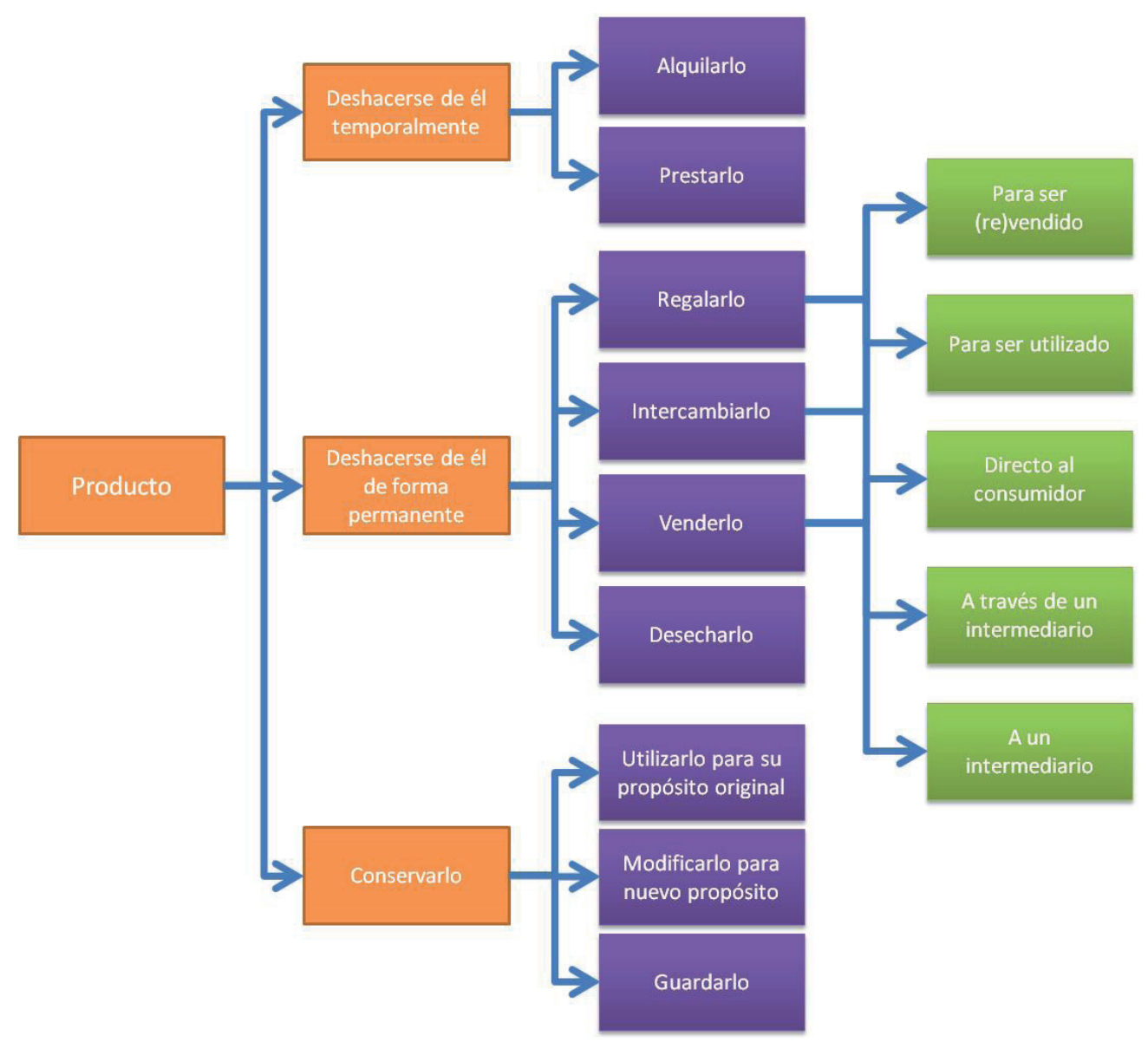

Figura 17. Uso y deshecho de producto poscompra Fuente: Kotler y Keller (2012)

\subsection{Proceso de decisión de compra del comprador organizacional}

El proceso de compra organizacional es el proceso mediante el que las empresas adquieren bienes y servicios para utilizarlos en sus empresas, venderlos o alquilarlos (Kotler y Armstrong, 2013). El proceso lo podemos observar en la figura 18.

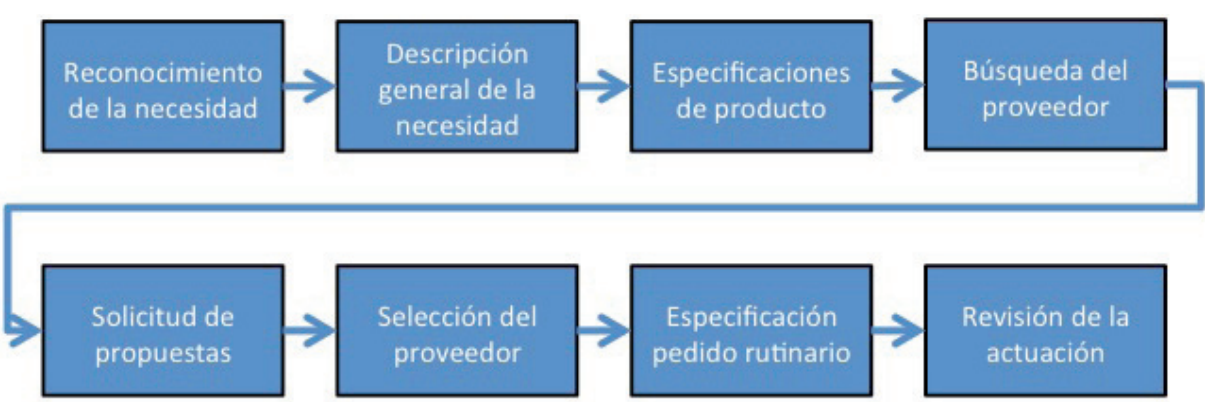

Figura 18. Proceso de decisión de compra comprador organizacional Fuente: Kotler y Armstrong (2013) 


\subsubsection{Reconocimiento del problema}

Al igual que en el caso del consumidor final, el proceso de decisión de compra del comprador organizacional se inicia con el reconocimiento del problema que se puede solucionar mediante la adquisición o consumo de un bien o un servicio. El reconocimiento se puede dar, bien debido a estímulos internos de la organización, por ejemplo si se quiere desarrollar un nuevo producto, o por estímulos externos. Las ideas en este caso, vendrían de fuera: en una feria, por una visita de un comercial, etc.

\subsubsection{Descripción de la necesidad y especificaciones del producto}

El siguiente paso que debe dar el comprador es fijar las especificaciones del producto o servicio que se necesita para resolver el problema. Este proceso puede ser complicado cuando no se trata de un producto de compra habitual, sino que se trata de un producto complejo.

\subsubsection{Búsqueda de proveedores}

Una vez fijadas las características del producto que el comprador está buscando, se deberán buscar los proveedores que se consideren apropiados. Esta búsqueda se puede realizar a través de contactos con otras empresas, directorios de proveedores, ferias comerciales o directorios de internet.

\subsubsection{Solicitud de propuestas}

En esta fase el comprador organizacional solicita a los diferentes proveedores que ha encontrado que le presenten una propuesta de oferta. Hay que tener en cuenta que esta propuesta, para los proveedores, no será únicamente un documento técnico, ya que se trata de una comunicación comercial y, por lo tanto, de un documento de marketing que debe destacar las ventajas sobre sus competidores.

\subsubsection{Selección de proveedores}

Una vez se han recibido todas las propuestas, el comprador realiza un análisis de todas ellas para seleccionar aquélla que mejor se ajusta a sus necesidades. Para ello se utiliza un análisis similar al que utilizaban los consumidores finales. Se hace un listado con los atributos importantes tanto del producto como del proveedor, se asigna una importancia y una valoración a cada uno de los atributos, de esta forma el comprador identificará a los mejores proveedores. 
Los atributos seleccionados para la valoración varían en función del producto o servicio que se desee adquirir. Los más habituales son: precio, plazo de entrega, fiabilidad del proveedor, calidad del producto, reputación del proveedor.

Una vez el comprador tiene identificados a los mejores proveedores, es habitual negociar con ellos de tal forma que se pueda mejorar el precio o las condiciones. Por otro lado, dependiendo del tipo de producto, los compradores no suelen limitarse a tener a un único proveedor, sino que seleccionan a varios proveedores complementarios, con el fin de minimizar el riesgo en caso de tener problemas de suministro o de calidad.

\subsubsection{Especificación de pedido rutinario}

Se trata del pedido que se envía al proveedor (o proveedores) elegidos. En el pedido deben figurar las especificaciones técnicas del producto que se solicita, el precio acordado, la fecha de entrega solicitada, políticas de devolución y garantías, etc.

En numerosas ocasiones, para los suministros habituales de productos, se firma un contrato global, donde se incluye todo lo que se ha mencionado con anterioridad, y cuando se envía el pedido al proveedor se incluye únicamente el producto y la fecha de entrega solicitada, disminuyendo de esta forma la carga administrativa y la posibilidad de errores.

Por otro lado, en los últimos tiempos se están imponiendo nuevas formas de suministro en las que, por ejemplo, el proveedor tiene acceso a los inventarios del comprador y conoce su consumo estimado, siendo responsable de suministrar el producto en los tiempos adecuados evitando la rotura de stock.

\subsubsection{Revisión de la actuación del proveedor}

En esta etapa los compradores revisan la actuación que han tenido los distintos proveedores y la calidad de los productos suministrados, proporcionando retroalimentación a los proveedores. Tres métodos son los habituales a la hora de realizar la evaluación (Kotler y Keller, 2012):

- Mediante un método de puntuación ponderada: prácticamente igual al que se utilizó para realizar la selección de proveedores.

- Agregar el coste de una mala actuación del proveedor al coste de aprovisionamiento del producto.

- Contactar a los usuarios finales, y solicitar sus evaluaciones. Los usuarios finales pueden ser clientes internos de la fábrica en el caso de que se trate de un producto para la fabricación o externos en el caso de que sean productos para la reventa o alquiler. 
En cualquier caso, la evaluación del proveedor debe conducir a: mantener la relación, modificar algunos términos o cancelarla.

\subsection{Factores condicionantes del comportamiento del consumidor final}

Una vez vistos los diferentes procesos de decisión, pasamos a estudiar las diferentes influencias que afectan al proceso de decisión. Estas influencias están agrupadas en los siguientes bloques que se observan en la figura 19. Son factores que no son controlables pero que deben ser tenidos en cuenta por los responsables de marketing para adaptar sus acciones.

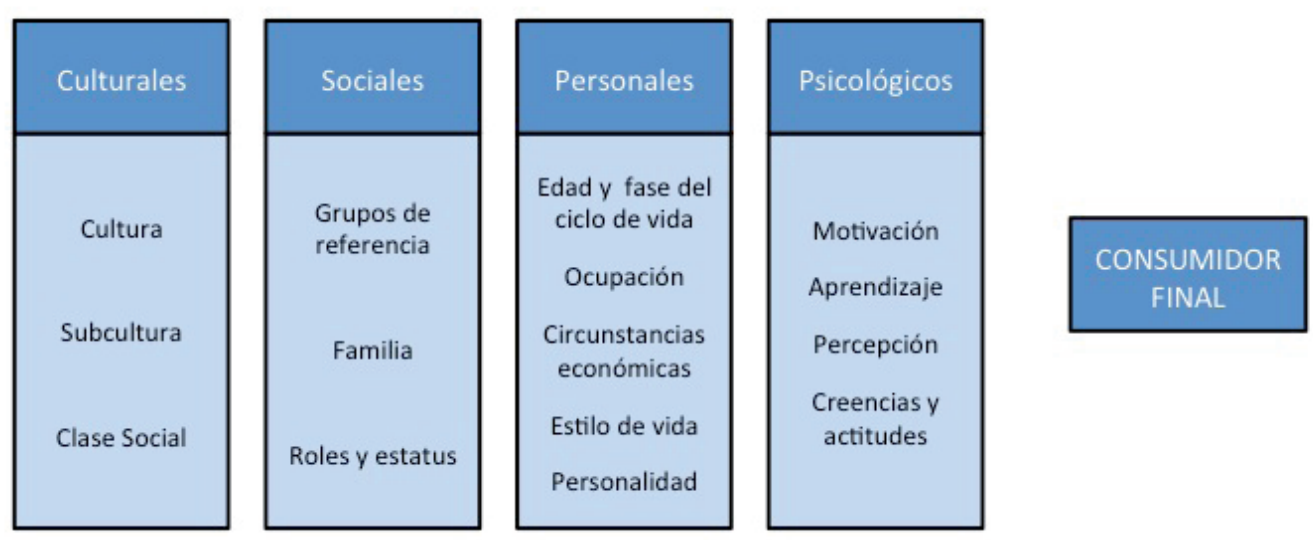

Figura 19. Factores condicionantes de la compra del consumidor final Fuente: Armstrong et al. (2011)

\subsubsection{Factores culturales}

La cultura es un conjunto de conductas aprendidas que se transmite por los miembros de una sociedad. Los valores básicos, los comportamientos, los deseos, etc. Diferencia a los miembros de un grupo humano respecto a otros ya que cada grupo social tiene una cultura y, por tanto, una forma de actuar diferente. Además, la cultura es algo cambiante en el tiempo debido a la interacción social entre los integrantes.

El consumo no es ajeno a estas diferencias en la forma de actuar de cada cultura, por ello es importante que los directivos de marketing se ajusten a los valores culturales de cada cultura, que entiendan su comportamiento para poder ajustar la comercialización de un determinado producto en las diferentes zonas culturales. Por otro lado, dado que la cultura es cambiante, es vital que busquen y encuentren oportunidades en los cambios que se detecten en la cultura. Un ejemplo de cómo los cambios en la cultura pueden suponer nuevas oportunidades es la incorporación de la mujer al mundo laboral, provocando cambios en los patrones de consumo. Los establecimientos de alimentación han puesto nuevos servicios que incluyen el pedido de la compra por internet y la entrega a domicilio. 
Cada cultura está integrada a su vez por diferentes subculturas. Los individuos que integran las diferentes subculturas tienen valores compartidos y experiencias vividas muy similares. Ejemplos de subculturas pueden ser las diferentes nacionalidades de dentro de una cultura, por ejemplo, la cultura europea la integrarían todos los países de Europa, sin embargo, es obvio que existen diferencias entre los diferentes países. Las subculturas son importantes porque conforman segmentos de mercado que pueden necesitar productos específicos. En España, por ejemplo, el aumento de población extranjera facilitó que se instalaran nuevos sistemas de envío de dinero a países extranjeros y la proliferación de locutorios.

Finalmente, el último de estos factores es la clase social. Esta identifica la posición que ocupa un individuo en la sociedad. Contrariamente a lo que se suele creer, los ingresos, aun siendo un elemento importante, no son el único factor que se utiliza para determinar a qué clase social se pertenece. Se deben tener en cuenta también los siguientes factores: ocupación, educación y patrimonio, entre otras. La importancia de la clase social reside en personas que con los mismos hábitos, similar educación e ingresos, son fácilmente segmentables y tienen patrones de consumo muy parecidos.

\subsubsection{Factores sociales}

Los factores sociales incluyen los grupos de referencia, la familia, los roles y el estatus social, todos ellos influyen en el comportamiento del consumidor.

\subsubsection{Grupos de referencia}

«Los grupos de referencia son aquellos que tienen una influencia, que puede ser directa o indirecta, sobre las actitudes y comportamientos de un individuo» (Kotler y Keller, 2012).

Sin embargo, no todos los grupos son iguales, se pueden clasificar en función de diferentes criterios como son: grado de pertenencia, naturaleza de la relación, el grado de formalidad y el grado de atracción.

El grado de pertenencia es una separación básica dado que distingue entre los grupos a los que se pertenece, grupos de pertenencia, y los grupos a los que no se pertenece, grupos de no pertenencia.

Dentro de los grupos de pertenencia, se puede diferenciar nuevamente en cuanto a la naturaleza de la relación entre los grupos primarios, con los que se tiene mucho contacto y mucha relación, por ejemplo familia y amigos, y grupos secundarios, con los que no se tiene tanta relación, por ejemplo asociaciones a las que se pertenece, colegios profesionales, etc. También se pueden separar los grupos de pertenencia en función del nivel de formalidad, los grupos formales tienen normas de acceso claras, los colegios profesionales por ejemplo. Por el contrario, los grupos informales, no tienen normas establecidas y se dan de forma natural, los amigos y la 
familia. Los consumidores tienen más influencias provenientes de grupos primarios que a su vez son informales, como la familia y los amigos.

Por otro lado, en cuanto a los grupos de no pertenencia, estos se pueden separar en disociativos y grupos de aspiración. Los grupos disociativos son grupos a los que no se quiere pertenecer y con los que no se quiere tener nada que ver, poniendo un ejemplo extremo, un extremista de izquierdas no querrá consumir productos que puedan asociarse al consumo de grupos skins. En cuanto a los grupos de aspiración, son grupos con los que el consumidor se identifica y quiere parecerse a ellos. Estos últimos, además se pueden volver a separar entre grupos con contacto directo y grupos sin contacto directo, por ejemplo dentro del trabajo no se pertenece al grupo de directivos pero sí se tiene contacto directo, por el contrario, uno puede sentirse identificado con un determinado club de fútbol sin pertenecer a él.

La importancia de los grupos reside en que establecen modelos de comportamiento para identificarse con el grupo. Se compra en las tiendas y las cosas que aprueba el grupo. La influencia del grupo se da porque para pertenecer al mismo hay que tener una serie de normas comunes, aprobadas previamente por el grupo y este castigará o premiará en función del comportamiento que haya tenido un miembro.

La influencia del grupo dependerá en gran medida del tipo de producto que se consuma, por ejemplo tendrá menos influencia cuando se trate de un producto de consumo habitual que cuando se trate de un producto de lujo. Además, si se trata de un producto cuyo consumo es público, por ejemplo unas zapatillas, también será mucho más influenciable por parte del grupo que cuando se trata de un producto de consumo privado como, por ejemplo, un videojuego. También dependerá de las características tanto del grupo, cuanto más pequeño y más cohesionado esté, la influencia será mayor, como de las características del consumidor, no todos los consumidores tienen la misma personalidad, así el grupo tendrá menos influencia cuando se trate de una persona innovadora que cuando se trate de una persona a la que le gusta ser seguidora de lo que hace el resto.

En la figura 20 se resumen los diferentes tipos de grupos de referencia.
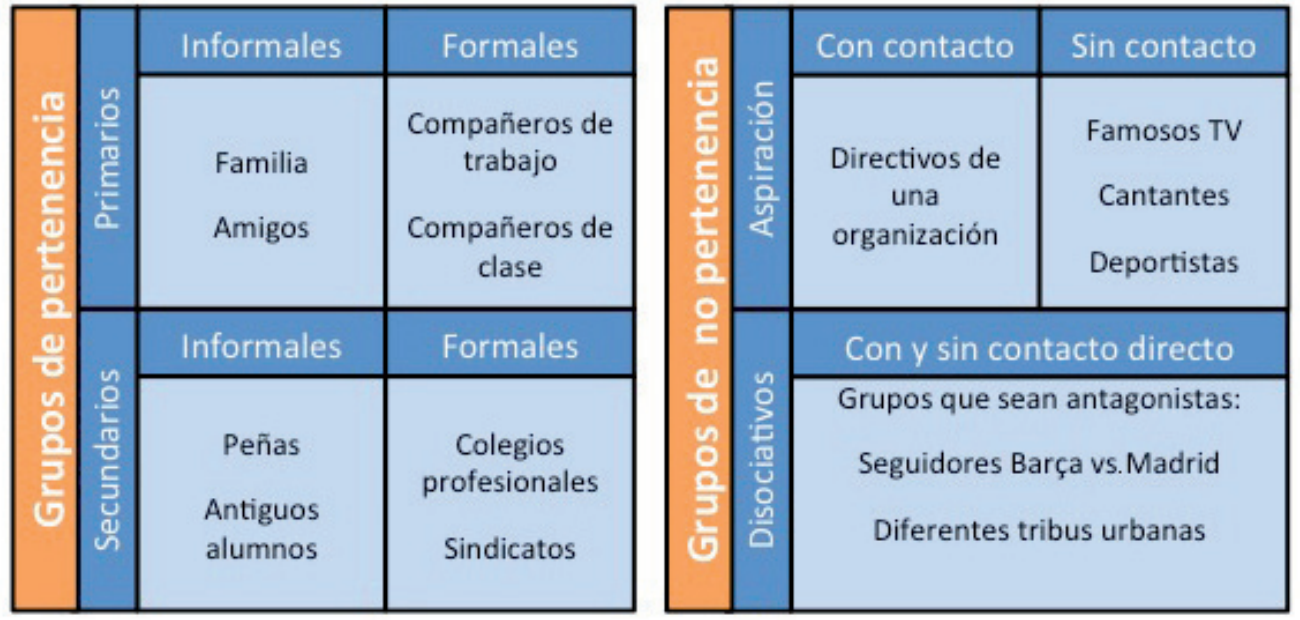

Figura 20. Grupos de referencia

Fuente: Adaptado de Mollá et al. (2006) 
Para el director de marketing cobra mucha importancia poder influenciar directamente a los líderes de los grupos que sean capaces de marcar tendencias influenciando al resto de los miembros del grupo. Esto no solo es válido para los grupos a los que se pertenece, sino que también es básico cuando se habla de los grupos de aspiración, haciendo que los deportistas vistan determinadas marcas de prendas o relojes para que influyan en aquéllos que se sienten identificados con ellos.

\subsubsection{La familia}

La familia es el grupo de referencia más importante, el que mayor influencia tiene sobre el consumidor, se podría asimilar a una organización de compras. La importancia de la familia reside en los siguientes aspectos (Mollá et al., 2006):

- Abundante consumo de productos en el hogar.

- La existencia de lazos afectivos provoca influencias entre los miembros.

- Las prioridades de consumo son familiares en lugar de individuales.

- Existen procesos de socialización y aprendizaje de consumo muy intensos:

a) Transmisión de hábitos de consumo de padres a hijos.

b) Enseñanza de conductas autónomas en la compra (por ejemplo, el control de las compras).

c) Los hijos en ocasiones pueden ser tenidos en cuenta a la hora de realizar las compras.

d) Se enseña a los hijos modelos de consumo y exposición a los medios. Por ejemplo, se fomenta el consumo responsable, se enseña a tolerar la frustración de posponer el consumo, se enseña a juzgar los estímulos de marketing.

A la hora de tomar las decisiones en familia, hay que tener en cuenta que no siempre son tomadas por la misma persona. Hay productos que pueden ser comprados de forma autónoma por cualquiera de los dos cónyuges, sin embargo hay otros productos para los que, de forma habitual, la decisión suele ser tomada por parte de la mujer que es, además, quien ejecuta la compra, por ejemplo los productos de consumo cotidiano, aunque hay que tener en cuenta que hoy en día los roles están cambiando y esto no tiene por qué ser así siempre. Por otro lado, hay productos cuya compra suele realizar el hombre, como pueden ser los seguros. Finalmente, para los productos de mayor coste, automóvil, electrodomésticos, reformas, etc., se suelen negociar conjuntamente antes de llevarlos a cabo. 


\subsubsection{Roles y estatus}

La posición que una persona ocupa dentro de un grupo va determinada por dos factores, su rol y su estatus. En cuanto al rol, se trata del conjunto de actividades que desarrolla. El estatus, por su parte, se refiere a la posición que ocupa esa persona en función de la opinión social. La gente suele elegir productos de acuerdo a su rol y estatus. Una madre trabajadora, que tiene un rol de madre y esposa en su familia y un rol de directiva en su ambiente profesional, seguramente vestirá ropa que ponga de manifiesto su rol y estatus profesional (Armstrong et al., 2011).

En cuanto a los roles a la hora de realizar las compras, existen los siguientes roles:

- Iniciador: es el reconocedor del problema.

- Informador: recoge información para la toma de decisiones de compra.

- Influyente: aporta opiniones y consejos.

- Decisor: tiene capacidad para comprometerse en la compra.

- Comprador: ejecuta físicamente la compra.

- Usuario: utiliza el producto comprado.

\subsubsection{Factores individuales}

Las características personales del comprador influyen también en sus decisiones, entre ellas destacan: la edad y el ciclo de vida, la ocupación y la situación económica, el estilo de vida y la personalidad y el autoconcepto.

\subsubsection{Edad y etapa del ciclo de vida}

Los gustos y las necesidades de los consumidores cambian con la edad y la etapa del ciclo de vida familiar, afectando por tanto al tipo de compra que realizan.

Las etapas del ciclo de vida familiar que tradicionalmente se han identificado son las siguientes:

- Etapa de soltería: individuos jóvenes solteros.

- Etapa de recién casados: jóvenes sin hijos.

- Nido lleno I: matrimonios jóvenes con hijos de menos de 6 años.

- Nido lleno II: matrimonios jóvenes con hijos de más de 6 años. 
- Nido lleno III: matrimonios mayores con hijos dependientes.

- Nido vacío I: matrimonio mayores sin hijos a su cargo y con el cabeza de familia trabajando.

- Nido vacío II: matrimonio mayores sin hijos y jubilados.

- Supervivientes solitarios: personas mayores que viven solas.

Sin embargo, en los últimos años la sociedad ha ido cambiando de tal forma que estas etapas se hacen insuficientes para explicar todos los modelos de familia existentes. Por ejemplo, no aparecen las familias monoparentales, los hijos que regresan al hogar en edad adulta después de haber abandonado el hogar o las parejas que deciden casarse con una avanzada edad.

En cualquier caso, los directores de marketing tienen que seleccionar a qué etapas desean dirigirse y adecuar sus productos y estrategias para cumplir con ese fin.

\subsubsection{Ocupación y situación económica}

La ocupación afecta de dos formas diferentes a las decisiones de consumo. Por un lado, tener una ocupación u otra puede influir a la hora de seleccionar el tipo de producto que se consume debido a las características del trabajo que se desempeña. Un ejemplo puede ser la ropa que se utiliza para el trabajo. Aquellas personas que realizan un trabajo donde la ropa necesita ser más resistente, pondrán esta característica por encima de las demás. Sin embargo, en trabajos donde no sea necesario, por ejemplo un abogado, puede primar más el estilo de la ropa que su durabilidad.

Por otro lado, la ocupación es un factor determinante del nivel de ingresos y afecta en gran medida a la situación económica del individuo, repercutiendo en la manera en la que realizan las compras.

\subsubsection{Estilos de vida}

El estilo de vida podría considerarse como un factor complementario a la clase social. Sintetiza la forma en que los consumidores disfrutan de su tiempo y su dinero, recogiendo el conjunto de actividades (tanto de trabajo como en el tiempo libre), opiniones (acerca de problemas tanto sociales como personales) e intereses (por ejemplo, la moda, la alimentación, tecnología, etc.) de las personas (Mollá et al., 2006).

Los estilos de vida ayudan a realizar segmentaciones de los diferentes grupos de consumidores en función de sus actividades, interés y opiniones lo que da mucha información a los directores de marketing para saber cómo actuar y obtener una 
respuesta positiva de esos consumidores. Entre las diversas segmentaciones, podemos observar, por ejemplo, una realizada para clasificar a los consumidores de tecnología en función de sus deseos y capacidad para consumir tecnología (Armstrong et al., 2011):

- Progresistas: realizan el mayor gasto en tecnología, muy interesados en su carrera profesional, tienen poco tiempo libre y están muy motivados.

- Creadores de la nueva era: gastan mucho en tecnología pero sobre todo para uso doméstico y familiar.

- Adictos a la tecnología: muy interesados por la tecnología y dispuestos a adquirir las últimas novedades.

- Tradicionales: personas que desconfían de la tecnología.

\subsubsection{Personalidad y autoconcepto}

La personalidad es una característica distintiva que también influye en el comportamiento de compra. Son una serie de rasgos individuales que distinguen a cada persona, haciendo que tenga una serie de respuestas que perduran en el entorno individual. Entre los diferentes rasgos que definen la personalidad tenemos: autoconfianza, dominancia, sociabilidad, autonomía, actitud defensiva, adaptabilidad y agresividad (Armstrong et al., 2011).

A las marcas también se les atribuye una personalidad, y cada consumidor busca adquirir marcas que reafirmen la visión que ellos tienen de sí mismos, su autoconcepto, como una manera de reflejar su personalidad a través de la marca.

Algunos ejemplos podrían ser, Apple que está relacionada con la emoción, Red Bull con una persona aventurera, exploradora e inconformista o Ikea con una persona corriente.

\subsubsection{Factores psicológicos}

Hay cuatro factores psicológicos que influyen en la decisión de compra: la motivación, la percepción, el aprendizaje y las actitudes.

\subsubsection{Motivación}

Se trata de un proceso de naturaleza interna que hace que se pase de un estado de inactividad a realizar determinadas conductas y procesos. Como hemos visto anteriormente, el objeto de la conducta de compra del consumidor es satisfacer una necesidad. Las necesidades pueden ser de diferente naturaleza, fisiológicas (saciar 
el hambre) o psicológicas (sentirse seguro). Las necesidades tienen en común que suponen un estado de carencia, sobre el que hay que actuar, convirtiéndose en un motivo.

Hay diferentes teorías sobre la motivación, siendo las más comunes las de Freud y Maslow. Freud sostiene que no somos conscientes de las fuerzas psicológicas que subyacen en las motivaciones. Sugiere que las decisiones de compra se pueden explicar en gran medida por motivos que están enterrados en el subconsciente. Por ejemplo, cuando una persona de mediana edad, padre de varios hijos, decide comprar un deportivo en lugar de un coche familiar, probablemente sea porque le hace sentir joven. Maslow, propone que los consumidores jerarquizan las necesidades, satisfaciendo primero las más importantes y solo cuando estas hayan sido satisfechas se preocupará de las necesidades de los niveles superiores. Así, en la figura 21 solo se prestará atención a las necesidades de seguridad cuando se hayan satisfecho previamente las necesidades fisiológicas.

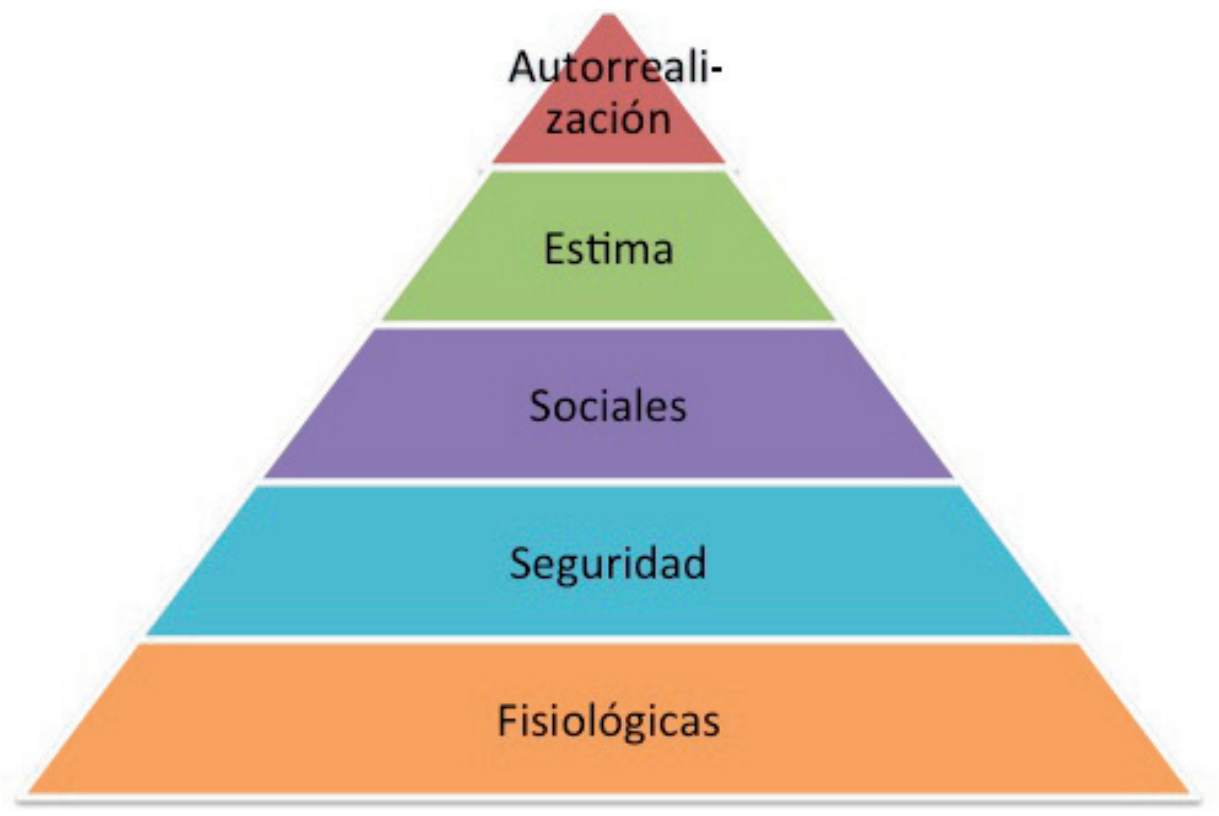

Figura 21. Jerarquía de necesidades de Maslow Fuente: Kotler y Keller (2012), p. 161

\subsubsection{Percepción}

Cuando una persona está motivada, está preparada para actuar. La forma en que lo haga dependerá de la percepción. La percepción es la forma en la que una persona asimila los sucesos del exterior, a los que se expone a través de sus sentidos, y cómo los integra con los conocimientos que ya posee.

La percepción consta de diferentes etapas (Mollá et al., 2006):

- Exposición: es el momento en que consumidor y estímulo se encuentran. Los consumidores estamos expuestos a muchos estímulos a lo largo del día, algunos buscados y otros no. 
- Atención: se trata de focalizar la percepción en el estímulo.

a) Es un proceso activo, tanto cuando se trata de atención voluntaria, hay búsqueda activa de la información, como involuntaria, se captan las características del estímulo.

b) Tiene una amplitud limitada, no podemos prestar atención a todos los estímulos con los que nos encontramos.

c) Es selectiva, dado que no podemos prestar atención a todo lo que nos rodea, seleccionamos a qué estímulos les vamos a prestar atención. Hacemos un filtro de la información que percibimos.

- Sensación: la información es sentida por el organismo y le da un significado.

a) Codificación: se analizan las características de la información sentida y se le dota de coherencia. En la codificación se produce una distorsión selectiva, se interpreta la información apoyando a lo que ya se creía. Si se está viendo un anuncio de una marca con la que se ha tenido una mala experiencia, probablemente no será creído.

b) Integración: el consumidor compara la información que recibe con la que ya tiene almacenada para darle un contexto basado en la experiencia. Cuando inicia el proceso de percepción el consumidor ya tiene en cuenta la información de la que disponía anteriormente por lo que dirige la información hacia los aspectos más importantes. Esto produce lo que se conoce como retención selectiva. Se tiende a recordar lo que confirma las creencias de las personas, por ejemplo, los aspectos positivos de las marcas preferidas, olvidando sus aspectos negativos y olvidando también los positivos de las marcas no preferidas.

\subsubsection{Aprendizaje}

El aprendizaje se produce cuando se experimenta un cambio incremental en la información que se tenía debido a una experiencia vivida. La mayor parte del comportamiento humano es aprendida a través de impulsos, estímulos, señales, respuestas y refuerzos.

Un impulso es un estímulo interno que nos induce a la acción, mientras que las señales son estímulos menores que determinan dónde y cómo responde una persona.

Por ejemplo, si un consumidor desea comprar un ordenador, el estímulo interno determinará que necesita comprar ese ordenador, mientras que las señales le harán elegir la marca del ordenador, cuándo lo comprará y dónde lo comprará.

Posteriormente se producirá una respuesta ante la compra, si esta ha sido positiva producirá un refuerzo que, con mucha probabilidad, le hará repetir en el futuro la compra de un producto de la misma marca. 


\subsubsection{Creencias y actitudes}

La actitud es la predisposición que tiene un consumidor para responder de manera favorable o desfavorable hacia un determinado producto o marca. Las actitudes son muy difíciles de modificar, ya que están relacionadas con las conductas de los consumidores.

La actitud está formada por la combinación de tres elementos: creencias, evaluaciones y comportamiento (Mollá et al., 2006).

Las creencias son las percepciones que los consumidores reciben acerca de las características de los productos de las distintas marcas. Estas percepciones no tienen por qué coincidir con la realidad. Debido a ello, los especialistas de marketing intentan vincular a sus productos beneficios derivados de su consumo que concuerden con las creencias que tienen los consumidores, mejorando la actitud hacia la marca.

Fruto de estas creencias, los consumidores realizan evaluaciones combinando la percepción que ellos tienen de los distintos atributos (las creencias) y la importancia que tienen para ellos. Fruto de ello se generará un comportamiento, la tendencia a actuar hacia un producto, que puede ser la intención de compra. Si un consumidor compra un producto y se evalúa de forma positiva, será un refuerzo positivo.

\subsection{Factores condicionantes del comportamiento del comprador organizacional}

Aunque desde fuera de las empresas puede parecer que los compradores organizacionales se fijan única y exclusivamente en el factor económico para tomar sus decisiones, esto no es así. Si bien los factores económicos son de los más importantes a la hora de tomar la decisión de compra, hay otros factores que influyen de manera significativa.

El departamento de compras no toma las decisiones de una forma aislada, sino que tiene que conjugar distintas necesidades de los distintos departamentos de la empresa de tal forma que todos queden satisfechos. Por un lado, el departamento productivo que vaya a utilizar los productos comprados por el departamento de compras, solicitará que el producto dé pocos problemas y que su uso sea lo más fácil posible con el fin de facilitarle su labor. Por otro lado, los departamentos de ingeniería querrán aquellos productos que maximicen el uso del equipamiento en la fábrica y que vayan a necesitar un mantenimiento menor. También se debe tener en cuenta al departamento financiero que buscará las mejores condiciones económicas del producto en cuanto a las condiciones del contrato y del pago. Finalmente, el departamento de prevención solicitará que el producto sea seguro para su uso. 
Observamos, por lo tanto, que los departamentos de compra no son islas dentro de las fábricas. Además, debemos tener en cuenta que están compuestos por personas y que son estas personas las que toman las decisiones y no la organización como un ente autónomo. Así pues, los compradores reciben influencias de diferentes lugares, como podemos observar en la figura 22, hay múltiples condiciones que afectan a los compradores organizacionales y que deben ser entendidos por los directores de marketing que a ellos se dirijan (Kotler y Armstrong, 2013).

Los elementos que tienen un impacto más amplio son los factores del entorno. Los compradores están especialmente influenciados por la situación económica, pero no únicamente del momento en el que está realizando la compra, sino también del momento futuro. Pero, como se ha mencionado anteriormente, los problemas económicos no son el único aspecto a evaluar por los compradores organizacionales. El número de proveedores que exista en el mercado, ya que estos condicionan la oferta disponible existente, los efectos que los cambios tecnológicos puedan tener tanto en el proceso de producción como en los hábitos de consumo de los clientes, las decisiones y el ambiente político que exista en el país, las acciones de la competencia o la cultura son factores que deben ser tenidos en cuenta a la hora de realizar las compras.

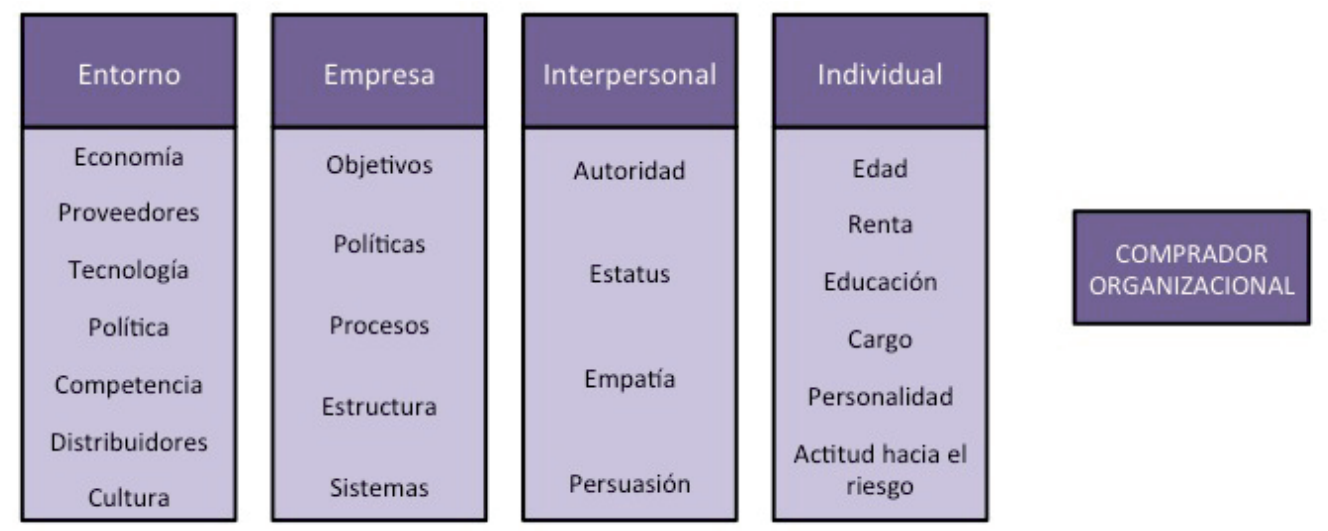

Figura 22. Factores condicionantes de la compra del comprador organizacional Fuente: Adaptado de Kotler y Armstrong (2013)

Los factores de la empresa también influyen de manera significativa en las decisiones del comprador. Hemos comentado anteriormente que las decisiones se realizan por personas, el comprador va a querer obtener recompensas por la forma en la que desarrolla su trabajo, para obtener estas recompensas asumirá como suyos todos los factores del entorno empresarial como las políticas, procesos de decisión, objetivos, estructuras y sistemas.

Ahora bien, las compras no son realizadas únicamente por una persona, sino que en el proceso de decisión de compra influyen varias personas (el departamento de compras), a partir de ahí influirán los factores interpersonales. La persona que influye en mayor medida en la decisión de compra no tiene por qué ser la que tenga una mayor autoridad formal, aunque evidentemente esta es una influencia importante, puede ser aquella persona que tenga un poder de persuasión mayor. Para los directores de marketing de las empresas proveedoras es vital detectar quién es la 
persona con la mayor influencia, y conocer cómo realiza la evaluación para intentar llegar hasta ella. Estos factores no influirán únicamente desde el punto de vista del interior de la empresa, son factores muy importantes también cuando se realiza la negociación inclinando la balanza hacia uno u otro proveedor.

Finalmente, los factores individuales, cada uno de los participantes en el proceso de compra tiene unas características individuales (edad, renta, cargo...) que afectan en la decisión de compra. Por ejemplo, la personalidad de cada uno puede exigir realizar el proceso de compra de una manera diferente. Por ejemplo, una persona muy técnica puede querer realizar un análisis exhaustivo de las propuestas antes de seleccionar un proveedor. Por el contrario, hay compradores de la vieja escuela que se centran más en la intuición y eligen al proveedor sin realizar un análisis tan exhaustivo.

\subsection{Tipos de compra}

\subsubsection{Consumidor final}

Los procesos de compra varían en función de lo que se desee comprar. No es lo mismo comprar servilletas de papel que comprar un coche. Las compras más caras, o en las que existe un mayor riesgo, requieren de un mayor tiempo para tomar la decisión y, probablemente, de un mayor número de personas implicadas en la decisión. Existen dos elementos que van a determinar el tipo de compra que se va a realizar. Por un lado tenemos la implicación, el grado de atención, la importancia que le da el consumidor a las compras. Por otro lado tenemos la diferenciación entre las marcas, la existencia o no de diferencias significativas, percibidas por el consumidor, entre una marca u otra. En función de estos componentes, tenemos los tipos de compra que se observan en la tabla 5:

\begin{tabular}{|l|c|c|}
\hline \multicolumn{1}{|c|}{ Variables } & Alta implicación & Baja implicación \\
\hline $\begin{array}{l}\text { Diferencias significativas } \\
\text { entre marcas }\end{array}$ & $\begin{array}{c}\text { Comportamiento complejo } \\
\text { de compra }\end{array}$ & $\begin{array}{c}\text { Comportamiento } \\
\text { de búsqueda variada }\end{array}$ \\
\hline $\begin{array}{l}\text { Pocas diferencias entre } \\
\text { marcas }\end{array}$ & $\begin{array}{c}\text { Comportamiento de compra } \\
\text { reductor de disonancia }\end{array}$ & $\begin{array}{c}\text { Comportamiento habitual } \\
\text { de compra }\end{array}$ \\
\hline
\end{tabular}

Tabla 5. Tipos de comportamiento de compra Fuente: Rodríguez (2006)

- Comportamiento complejo de compra: los consumidores están muy implicados con la compra y perciben muchas diferencias entre las distintas marcas. Se da con productos de precio elevado y con niveles de riesgo también elevados. Se trata de compras muy poco frecuentes o nuevas, por lo que el consumidor no tiene suficientes conocimientos para tomar la decisión, por lo que intenta buscar toda la información posible. Por ejemplo, una persona que desee adquirir un móvil de alta gama, no conoce todos los atributos del 
producto. Los directivos de marketing deben, esforzarse para que los consumidores puedan comprender y valorar los atributos de sus productos.

- Comportamiento de compra reductor de disonancia: en este caso existe alta implicación pero no se perciben diferencias entre las diferentes marcas. Es una compra en la que el nivel de riesgo es elevado, pero debido a que el cliente no percibe diferencias entre las distintas marcas, es muy probable que la compra sea mucho más rápida, siendo además más fácil que el consumidor tenga en cuenta un buen precio o una buena promoción.

- Comportamiento habitual de compra: los consumidores no perciben grandes diferencias entre las marcas y además están muy poco implicados en la compra, por ejemplo en la compra del azúcar. En estos casos no se da búsqueda de información por parte de los consumidores, sino que directamente hacen la elección en el propio establecimiento en base al precio. Otra estrategia que utilizan los directivos de marketing es asociar alguna característica del producto a algún elemento de mayor implicación, como puede ser la salud, por ejemplo las distintas marcas de agua asocian las características de su producto a beneficios para el cuerpo.

- Comportamiento de búsqueda variada: se da en compras de baja implicación pero con diferencias significativas entre las distintas marcas. Aquí juegan un papel muy importante las creencias previas del consumidor, seleccionando el producto en función de estas, sin realizar un análisis previo. Sin embargo, no será hasta el momento del consumo cuando evalúe la marca. En este tipo de compras se suele dar una variación de marcas mayor de lo habitual, dado que el consumidor desea probar cosas nuevas. Por ejemplo se da en la compra de cereales para el desayuno. En estos casos hay diferencias entre las estrategias que tienen que adoptar las marcas líderes y las seguidoras. Las líderes intentarán mantener una presencia dominante en los lineales, mientras que las segundas deberán ofrecer buenos precios, pruebas en el lugar de venta, promociones, etc.

\subsubsection{Comprador organizacional}

Existen tres tipos de compra a las que se pueden enfrentar los compradores organizacionales en función de la complejidad de la misma, el riesgo que se asume y el número de personas que interviene en la compra (Armstrong et al., 2012):

- Recompra directa: son compras habituales que realiza el comprador de manera rutinaria. El precio no se negocia en cada ocasión ni se cambian las especificaciones. Se llega a un acuerdo con diferentes proveedores a principio de cada año y se envían los pedidos periódicamente directamente desde el departamento de compras. Por ejemplo se da mucho en los suministros de materias primas químicas, ya que sería inviable negociar las condiciones cada vez que se necesita el producto. 
- Recompra modificada: en estos casos sí que se modifican las especificaciones de producto, de precio o de las condiciones de compra. En estos casos intervienen más personas, ya que es probable que afecte a más departamentos. Siguiendo con el ejemplo anterior, imaginemos que se han hecho cambios en el proceso de producción y se necesita el mismo producto que se consumía antes pero con las características modificadas. En este caso será necesario que participe en la decisión en departamento productivo implicado para validar el producto nuevo. Esta compra supone una amenaza para los proveedores ya existentes y una oportunidad para los nuevos proveedores.

- Compra nueva: se trata de una compra que no se ha realizado nunca, cuanto mayor sea el riesgo y el coste, más personas participarán en la compra. Se trata de una oportunidad para la entrada de nuevos proveedores. El comprador deberá tomar decisiones acerca de todos los aspectos de la compra (especificaciones, precio, plazos de entrega, etc.).

\section{Referencias bibliográficas}

Armstrong, G., Kotler, P., Merino, M. J., Pintado, T. y J. M. Juan (2011): Introducción al marketing, 3. ${ }^{\mathrm{a}}$ ed., Madrid, Pearson Educación.

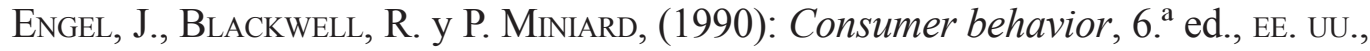
Dryden Press.

Kotler, P. y G. Armstrong (2013): Fundamentos de marketing, 11. a ed., México, Pearson Educación de México.

Kotler, P. y K. L. Keller (2012): Dirección de marketing, México, Pearson Educación de México.

Mollá, A., Berenguer, G., Gómez, M. A. y Quintanilla, I. (2006). Comportamiento del consumidor, Editorial UOC.

Rodríguez Ardura, I. (2006): Principios y estrategias de marketing, Editorial UOC. 



\section{CAPITULO 4}

\section{Análisis del entorno competitivo \\ Juan Carlos Fandos-Roig \\ y Marta Estrada-Guillén}

\section{Contenido del capítulo}

En este capítulo se describirá la importancia de realizar un buen análisis de la competencia de la empresa. Así como en capítulos anteriores se ha estudiado la forma de analizar el mercado, la demanda y el comportamiento de compra de los consumidores, en el presente, se trata de realizar un análisis del entorno competitivo en el que opera la empresa. Es fundamental para la empresa investigar las fortalezas y debilidades de la competencia, distinguiendo entre los diversos niveles de los competidores, anticipando las oportunidades y amenazas que se ciernen sobre la industria para, de este modo, ser capaz de encontrar una ventaja diferencial que le permita ser más competitiva. 
4.1. Noción del análisis de la competencia

4.1.1. Identificación de la competencia

4.1.2. Evaluación de la competencia

4.1.3. Selección de competidores para atacar y evitar

4.1.4. Niveles de competencia

4.1.5. Competencia actual y competencia potencial

4.1.5.1. Competencia actual

4.1.5.2. Competencia potencial

4.2. La ventaja competitiva

4.3. Métodos de identificación de los competidores

4.3.1. Competidores desde la óptica de la empresa

4.3.1.1. Clasificación estándar en función del sector

4.3.1.2. Análisis de grupos estratégicos

4.3.2. Competidores desde la óptica del consumidor

4.3.2.1. Competidores según el comportamiento de compra y consumo del consumidor final

4.3.2.2. Competidores según el juicio u opinión del consumidor final

4.4. Análisis de los competidores. Los sistemas de inteligencia competitiva

4.4.1. Fuentes de información

4.4.2. Los sistemas de inteligencia competitiva

4.4.3. Análisis estratégico de los competidores

4.4.4. Análisis de puntos fuertes y débiles

4.4.5. La reacción de los competidores

4.5. Nuevas tendencias en el análisis de la competencia: benchmarking

Referencias bibliográficas 


\subsection{Noción del análisis de la competencia}

En el contexto de mercado actual no basta con satisfacer las necesidades del consumidor, hay que hacerlo mejor que la competencia. Las empresas deben comparar constantemente sus productos, precios, canales y promociones con los de sus competidores. Este análisis continuo resulta clave en el diseño de una estrategia empresarial efectiva. Su importancia radica en que, al contar la empresa con determinada información, puede sacar un gran provecho de la misma aprendiendo de los aciertos y errores de la competencia, tomando como referencia las estrategias más eficaces. El hecho de tomar decisiones de marketing sin tener en cuenta las circunstancias en que se encuentra (y se puede encontrar en un futuro), no solo la propia empresa, sino también el resto de competidores y demás factores que afectan al entorno competitivo en el que se opera, conduciría a la miopía del marketing. Este hecho podría llevar asociados efectos negativos para la empresa sobre todo en el medio y largo plazo, ya que se pierde perspectiva del mercado y del entorno competitivo en el que se opera.

El análisis de la competencia (véase figura 23) es un proceso que supone la identificación, análisis y selección de los competidores clave. Un buen análisis de la competencia aportará una ventaja competitiva que otorgará cierta superioridad comercial a la empresa sobre el resto del mercado.

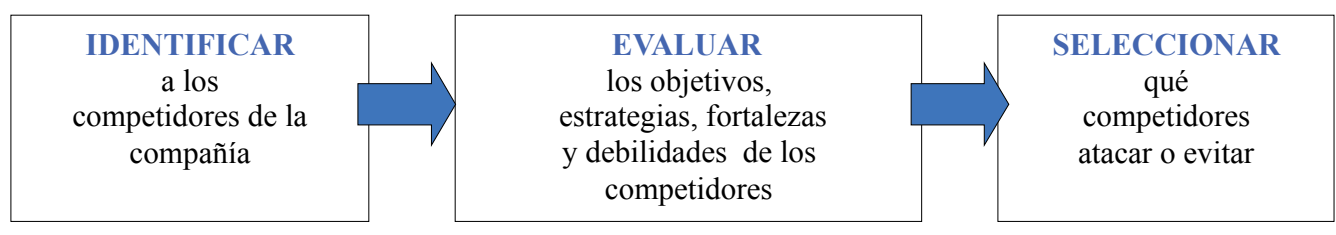

Figura 23. Proceso de análisis de la competencia

Fuente: Elaboración propia

El verdadero «enemigo» de una empresa se encuentra entre las compañías capaces de satisfacer los deseos de los clientes de forma análoga a la propia empresa, las que entregan un valor agregado similar y ostentan ventajas diferenciales difusas de cara al cliente. Cuando se sabe más de los clientes, más se conoce sobre la forma en qué los mismos perciben a cada competidor y, como los atributos propios de cada uno de ellos pueden generar estrategias más competitivas en el mercado. Solo las organizaciones cuyo enfoque empresarial aúne la orientación hacia el consumidor con la orientación hacia la competencia conseguirán la excelencia empresarial.

\subsubsection{Identificación de la competencia}

En la efectiva identificación de la competencia se plantean las siguientes preguntas:

a) ¿Quiénes son los competidores de la empresa/marca?

b) ¿Cómo es de intensa la competencia en el mercado? 
c) ¿Cómo afecta la competencia en la evolución y estructura de mercado?

d) ¿Cómo afectan las acciones competitivas a las decisiones comerciales?

e) ¿Cómo logra y mantiene la competencia la ventaja competitiva?

f) ¿Tienen el resto de compañías habilidades similares a las nuestras?

Respondidas estas y otras cuestiones se procederá a evaluar los objetivos y estrategias de los competidores. En este sentido, resulta fundamental preguntarse: ¿qué busca cada competidor en el mercado?, ¿qué impulsa la conducta de cada uno de ellos? Se debe, en definitiva, valorar la fuerza de la competencia para posteriormente seleccionar aquellas empresas que interesen atacar o evitar.

\subsubsection{Evaluación de la competencia}

Para poder evaluar la competencia resulta fundamental que la empresa reúna la máxima información posible sobre: las ventas, participación en el mercado, margen de utilidad, rendimiento de la inversión, flujo de efectivo, nuevas inversiones y uso de la capacidad del resto del sector. Todos estos datos se obtienen, tal y como veremos posteriormente, a través de la utilización de los sistemas de investigación de inteligencia competitiva. Su uso dará un perfil detallado del nivel en el que se encuentra cada competidor y los patrones de reacción de los mismos y, de este modo, se podrán prever las reacciones y movimientos en el mercado.

\subsubsection{Selección de competidores para atacar y evitar}

La empresa debe decidir contra qué empresa competirá con más energía y su elección estará apoyada por un análisis del valor del cliente que revelará las fuerzas y debilidades de las empresas con respecto a diversos competidores.

- Competidores fuertes contra débiles. Casi todas las empresas enfocan sus energías contra los competidores débiles, ya que estos disponen de menos recursos y tiempo por punto de participación ganado.

- Competidores cercanos contra distantes. Las empresas, en su mayor parte, competirán con quienes se les parezcan más.

- Competidores buenos contra malos. Los competidores buenos juegan con las reglas de la industria, fijan presiones razonables, se limitan a una porción o segmento de la industria. Los competidores malos violan reglas: tratan de comprar participación en lugar de captar, toman grandes riesgos, invierten en capacidad excesiva y trastorna el equilibrio industrial. 


\subsubsection{Niveles de competencia}

Existen 4 niveles de competencia desde la perspectiva del consumidor: la competencia en forma de producto, la competencia de categoría de producto, la competencia genérica y la competencia a nivel de presupuesto (Munuera y Rodríguez, 2002). Describamos los distintos niveles de competencia utilizando como ejemplo del pan de molde sin corteza de la marca Bimbo.

- Competencia en forma de producto. Se refiere a aquellos productos y marcas que proporcionan el mismo servicio o cubren la misma necesidad a los mismos segmentos de mercado. En el caso del Pan Bimbo Sin Corteza, el pan de molde Panrico Sin Corteza supondría una competencia en este nivel. Es función del marketing convencer al consumidor que la marca propia es la mejor entre todas las alternativas posibles. Son productos que se dirigen al mismo segmento.

- Competencia en la categoría del producto. Se trata de aquellos productos y marcas que tienen los mismos atributos pero con diferente presencia de los mismos. En el caso del ejemplo cualquier pan (con corteza, sin corteza, integral, de molde, etc.) supondría una competencia en la categoría del producto. La acciones de marketing tienen que persuadir al consumidor que la forma de producto elegida es la mejor en su categoría. Son productos que tienen la misma alternativa tecnológica.

- Competencia genérica. Agrupa aquellos productos y marcas que resuelven la misma necesidad (alimentación). Este sería el caso del pan tradicional, la bollería y las rosquilletas con respecto a la marca Bimbo, pero también cualquier otro alimento. A través del marketing se debe persuadir al mercado de que la categoría de producto que fabrica la empresa es la mejor para satisfacer determinada necesidad. Son productos que pertenecen al mismo mercado de referencia.

- Competencia a nivel de presupuesto. Productos y marcas que luchan por el mismo presupuesto del consumidor, por ejemplo, la partida de alimentación y bebida. Podríamos citar los refrescos y los yogures en el caso del ejemplo propuesto. Las acciones de marketing deben ir encaminadas hacia el convencimiento que la mejor opción posible para gastarse el dinero es hacerlo en un determinado producto.

\subsubsection{Competencia actual y competencia potencial}

\subsubsection{Competencia actual}

Desde el punto de vista del marketing, los competidores actuales son aquellos que satisfacen la misma necesidad que la empresa, es decir, aquellos que tienen el mismo mercado de referencia que la empresa. Por ello, el concepto de competencia actual se refiere a todas aquellas empresas que operan en la misma industria y 
también a aquellas que fabrican o comercializan productos sustitutivos (otras alternativas tecnológicas). A diferencia de lo mantenido por Porter (1982), desde la óptica del marketing, los productos sustitutivos no son una amenaza competitiva sino una competencia existente en la realidad actual de un determinado mercado. Los productos sustitutivos (por ejemplo: el café y el té) son una amenaza constante y deben formar parte del concepto competencia actual (satisfacen la misma necesidad).

\subsubsection{Competencia potencial}

Identificar a los competidores implica, no solo detectar a los actuales, sino descubrir a los que lo que surgirán en el futuro. La irrupción futura de nuevos competidores puede producirse por varios motivos:

- Expansión del mercado. Cuando se produce una modificación del territorio o la ampliación de usos de un producto. Por ejemplo: un país que entra en la Unión Europea.

- Expansión del producto. Cuando una empresa decide ampliar la oferta de productos a otros distintos de los actuales. Por ejemplo: el Grupo Pascual que produce desde lácteos a zumos pasando por poseer una inmobiliaria.

- Integración hacia atrás. Cuando los clientes deciden intentar controlar las fuentes de abastecimiento. Por ejemplo: Mercadona que está comprando sus frutas y verduras directamente al agricultor.

- Integración hacia delante. Los suministradores deciden hacerse productores. Por ejemplo: un fabricante de papel que decide hacer sus propias libretas.

\subsection{La ventaja competitiva}

La búsqueda de una ventaja competitiva supone alcanzar una diferencia con respecto a los competidores que marca positivamente la situación en el mercado de la empresa. La misma tiene su origen en los diferentes atributos del producto o servicio que la empresa logra convertir en beneficios relevantes. La ventaja competitiva debe poseer alguno o varios de estos atributos (Vicente, 2009):

- Única. La particularidad de la empresa, producto o servicio debe ser diferencial y exclusiva. Esta situación monopolística en cuanto a la ventaja diferencial suele durar poco tiempo ya que la competencia, en cuanto la detecta, suele reaccionar imitando o mejorando la diferencia.

- Percibida. La ventaja debe detectarse como tal por parte del consumidor. En este sentido, la empresa debe ejercer un esfuerzo adicional y, además de generarla, darla a conocer al cliente. 
- Apreciada. Debe responder y satisfacer las expectativas del cliente con respecto al producto o servicio e incluso mejorarlas.

- Sustentable. Debe proporcionar beneficios a la empresa. En este sentido si la ventaja competitiva es fácilmente imitable y en un corto periodo de tiempo apostar por ella deja de ser rentable para la empresa.

El rendimiento que confiere una ventaja competitiva se materializa en la obtención de mayores beneficios y rentabilidad empresarial.

Tradicionalmente la empresa puede basar su ventaja competitiva en los costos y en la diferenciación.

- La ventaja en costo. Implica que la organización tiene capacidad para operar con los costes más bajos del mercado. En este caso el producto o servicio no tiene por qué tener un atributo novedoso ni otra ventaja diferencial a la de un precio bajo. Se trata de poner a disposición del mercado una oferta aceptable al mejor precio.

- La ventaja en diferenciación. La empresa ha generado un atributo diferencial para su producto o servicio por el que el consumidor está dispuesto a pagar más. La clave del éxito está en buscar aquel atributo mejor valorado por el cliente y que perdure la mayor cantidad de tiempo posible.

\subsection{Métodos de identificación de los competidores}

\subsubsection{Competidores desde la óptica de la empresa}

\subsubsection{Clasificación estándar en función del sector}

Existen clasificaciones oficiales como la CNAE (Clasificación Nacional de Actividades Económicas) y la sic (Standard International Classification) que permiten la identificación de la competencia más evidente. Sin embargo, si la empresa solo se basa en estas clasificaciones, obtendrá una información parcial y sesgada sobre su competencia. Dichos índices describen únicamente a la competencia en forma y categoría de producto sin aportar dato alguno sobre la competencia genérica y de presupuesto.

\subsubsection{Análisis de grupos estratégicos}

Los grupos estratégicos son, básicamente, conjuntos de empresas que siguen estrategias similares en algunos sentidos. Resulta muy útil su identificación para analizar una industria, especialmente, cuando hay numerosos competidores. Permitiendo observar sus puntos fuertes y débiles, su capacidad de reacción ante las amenazas y oportunidades. 
Las multinacionales de refrescos de cola, por ejemplo, siguen estrategias similares en cuanto a distribución, precio, publicidad y producto. Todas utilizan embotelladoras con flotas de distribución cautivas y de alcance nacional. Sus precios son similares. Todas tienen elevados niveles de inversión en publicidad y promoción además de líneas de productos que abarcan los principales refrescos. Así, decimos que estas compañías forman parte de un mismo grupo estratégico.

Pero ¿por qué surgen los grupos estratégicos? Los grupos estratégicos surgen porque las empresas que forman parte de ellos tienen:

- Objetivos similares. Por ejemplo, quieren dominar el mercado y ser líderes en innovación.

- Capacidades parecidas. Como el tener conocimientos de marketing y tecnologías similares.

- Supuestos similares sobre el funcionamiento del mercado. Creen, por ejemplo, que el consumidor es fiel a las marcas que conoce.

- Experiencias análogas. Operan aproximadamente en los mismos países y han tenido experiencias parecidas en el negocio.

Por todos estos motivos, la estrategia de todas las empresas dentro del grupo resulta similar en los siguientes aspectos:

- El análisis de los grupos estratégicos permite extraer conclusiones sobre la competencia.

- Evidencia hacia que sectores industriales se están moviendo los competidores.

- Aporta pistas sobre el escenario en que desean ubicarse los grupos estratégicos y qué camino deben recorrer para llegar a esa posición.

- A través de las diferencias en la estrategia nos ayuda a comprender por qué alguna empresa del grupo tiene una rentabilidad distinta de las otras.

Los grupos estratégicos son un concepto sencillo de comprender. Se trata, además, de una herramienta muy gráfica. Es posible confeccionar mapas de grupos estratégicos, donde queda claro cómo están ubicados los distintos grupos en una serie de variables estratégicas y hacia dónde pueden evolucionar. Estos mapas resumen una gran cantidad de información útil para comprender la situación y tomar decisiones. Sin embargo, esta técnica de análisis tiene alguna desventaja como que no contempla, de manera específica, las variables del entorno como las tendencias socioeconómicas, legales, medioambientales, etc. Es un modelo centrado en la oferta, más que en la demanda. Además, algunas de las variables necesarias para la confección de los mapas no son sencillas de obtener. No siempre es posible acceder a información sobre ventas y rentabilidad de las empresas del grupo. Por 
último, son perecederos, tienen validez por un periodo de tiempo limitado y para el sector en el que han sido analizados.

\subsubsection{Competidores desde la óptica del consumidor}

\subsubsection{Competidores según el comportamiento de compra y consumo del consumidor final}

Uno de los mecanismos más usuales para la obtención de información relativa al comportamiento de compra así como del cambio de marca son los paneles de consumidores y/o el escáner de compra. La metodología escáner en el panel de consumidores fue introducida en 1999 en España de la mano de la compañía A. C. Nielsen y al año siguiente es adoptada por la compañía Taylor Nelson Sofres.

Un panel de consumidores es un estudio realizado mediante la recogida de datos de las compras realizadas por una muestra permanente y representativa de consumidores. Existen diferentes tipos de panel de consumidores, sin embargo, en los últimos años se ha impuesto el uso del sistema de escáner doméstico sobre el resto. La utilización de esta técnica supone el suministro a la muestra de ciertos dispositivos (lector óptico, escáner y sistema de conexión) y de las instrucciones para utilizarlos correctamente. Los panelistas, mediante los lápices ópticos que leen códigos de barras, proceden al registro de los productos que han comprado para sus hogares. La información es completada por el panelista con códigos preestablecidos que representan los diferentes precios, puntos de compra, importe total de la compra, forma de pago, personas que han realizado la compra, etc. Toda esta información se recoge en un dispositivo electrónico especial equipado con un lector óptico de códigos de barras y que se coloca en una base conectada telefónicamente con el ordenador central de la empresa que forma el panel. La empresa llama periódicamente a cada uno de los hogares de la muestra y vierte la información almacenada en el dispositivo electrónico a su ordenador central. Una vez que la información llega a la empresa que gestiona el panel se trata mediante un programa informático específico y se obtienen los resultados extrapolados de la muestra al universo. Los datos así recogidos, tal y como podemos ver en la tabla 6 , son útiles para el estudio del cambio de marcas, entre otros. En el ejemplo, los números de la matriz representan la probabilidad de compra del panel en un momento de compra (t) y otro posterior $(\mathrm{t}+1)$ para tres marcas. Los datos del eje de abscisas representan el cambio de marcas. Por ejemplo, la probabilidad que los que compran la marca 1 en el momento $t$ compren la 2 en $(t+1)$ es de 20 por 100 . Un análisis pormenorizado de los datos representados en la matriz permitirá la identificación de los competidores. Además, tal y como hemos comentado anteriormente, a través del panel se obtendrá información de gran valor en el correcto análisis del proceso de compra del cliente. 


\begin{tabular}{|c|c|c|c|c|}
\cline { 2 - 5 } \multicolumn{1}{c|}{} & \multicolumn{4}{|c|}{ Periodo t +1 } \\
\hline \multirow{3}{*}{ Periodo t } & & 1 & 2 & 3 \\
\cline { 2 - 5 } & 1 & 0,6 & 0,2 & 0,2 \\
\cline { 2 - 5 } & 2 & 0,2 & 0,3 & 0,4 \\
\cline { 2 - 5 } & 3 & 0,2 & 0,3 & 0,5 \\
\hline
\end{tabular}

Tabla 6. Matriz panel del consumidor (cambio de marca)

Fuente: Adaptado de Munuera y Rodríguez (2002)

\subsubsection{Competidores según el juicio u opinión del consumidor final}

Una técnica muy extendida de análisis de la competencia desde la óptica del consumidor es el análisis de similitudes. Consiste en crear un mapa perceptual preguntando a los consumidores sobre las similitudes que encuentran entre un conjunto de marcas. Las marcas son representadas en este espacio por puntos y las dimensiones resumen los atributos que los consumidores utilizan para hacer juicios de similitud. Los elementos situados próximos en un mapa perceptual (véase figura 24) son juzgados como similares y, por tanto, forman un conjunto de productos sustitutivos y en régimen de competencia.

Una técnica diferente es la de eliminación de productos. Esta se basa en las reacciones que presentan los consumidores ante la no disponibilidad de un producto. Se trata de preguntar directamente al consumidor que productos o marcas compraría en caso de no encontrar su producto o marca favorita. Esta técnica suele utilizarse para determinar la competencia en forma de producto pero también se puede aplicar al resto de niveles de competencia.

Una alternativa a las técnicas anteriores es la de sustitución en el uso. Esta se basa en una estimación del grado de rivalidad entre varios productos según juicios de similitud en su contexto de uso. Consiste en que un grupo de consumidores identifican en una lista diversos productos y, posteriormente, los clasifican según su uso o aplicación, posteriormente, otro grupo de consumidores juzgarán si la clasificación ha sido más o menos adecuada. Este método suele utilizarse para identificar competidores en el nivel de producto genérico y también para presupuesto.

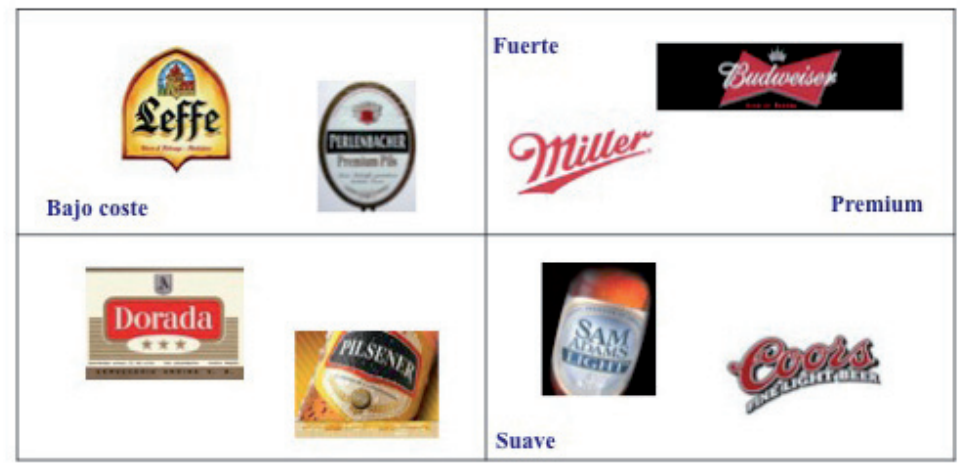

Figura 24. Ejemplo análisis de similitudes a través de un mapa perceptual Fuente: Elaboración propia 


\subsection{Análisis de los competidores. Los sistemas de inteligencia competitiva}

\subsubsection{Fuentes de información}

Para llevar a cabo un estudio de los competidores es necesario obtener información que ayude en primer lugar a tomar conciencia de cuál es la realidad a la que nos enfrentamos. De este modo podremos iniciar un análisis que sea de utilidad tanto en la formulación como en la implementación y control de la estrategia de marketing de la empresa.

Las fuentes de información serán todos los recursos que contienen datos que nos ayudarán a la realización del análisis. Los podemos dividir en dos bloques en función del grado de elaboración. Las fuentes de información primarias contendrán información original que se genera por primera vez con la finalidad de nuestra investigación. Por ello será información muy adaptada a nuestro estudio y muy actualizada, sin embargo, suelen llevar un coste mayor ya que se trata de estudios realizados ad hoc en los que tendremos que soportar todos los gastos generados en la obtención de los datos.

Por otro lado, tenemos las fuentes de información secundarias, que básicamente contienen información que en su día fue primaria, pero sintetizada y organizada en función de los objetivos perseguidos en el momento de su elaboración. Es decir, son estudios realizados para otros fines, que en principio no son los nuestros específicos, pero que nos pueden aportar mucha información. Además, este tipo de fuentes nos supondrán, por norma general, un menor coste de acceso ya que es información ya elaborada con anterioridad. Puede tratarse de estudios realizados y publicados en prensa, informes periódicos de instituciones oficiales o de empresas privadas, estudios sectoriales, etc.

Además, las fuentes de información también pueden clasificarse en función del carácter de obtención. Es decir, pueden ser fuentes de información internas cuando se trate de información obtenida desde dentro de la propia organización (informes contables, comerciales, etc.) o pueden ser fuentes de información externas si la información es generada por terceros o proviene del exterior de la empresa (estadísticas, paneles oficiales, informes económicos, publicaciones y similares).

\subsubsection{Los sistemas de inteligencia competitiva}

Un sistema de inteligencia competitiva ayudará a la empresa a recolectar, interpretar y diseminar información sobre los competidores para controlar la realidad competitiva de su entorno y ser capaz de reaccionar ante situaciones o cambios que puedan ocurrir en el transcurso de su actividad. Una empresa puede conocer mejor su posición frente a la de sus competidores si es capaz de poder entender, intuir y reaccionar a las acciones de la competencia. Por tanto, es conveniente que 
además de los estudios puntuales que sean necesarios para resolver una cuestión concreta, una empresa se encargue de diseñar un sistema de inteligencia que se encargue de mantener informados, de forma continua, a las posiciones encargadas de tomar decisiones, tanto a nivel estratégico como operativo.

\subsubsection{Análisis estratégico de los competidores}

Mediante los estudios y los datos obtenidos de los competidores, es muy importante intentar averiguar los recursos estratégicos de nuestros competidores, para poder establecer comparaciones con la propia empresa y poder entender mejor el sector en el que se opera. Se trata de realizar un análisis de los recursos y capacidades de los competidores para identificar su potencial así como sus principales ventajas competitivas. De este modo, se intentan discernir los distintos tipos de recursos y capacidades con los que cuentan los competidores, haciendo especial hincapié en los recursos intangibles. Además, es fundamental saber interpretar la gestión que se hacen de estos recursos y capacidades, ya que en la mayoría de las ocasiones será la clave de un buen resultado empresarial. En este sentido, y a pesar de la heterogeneidad que suelen mostrar las empresas de la mayoría de los sectores es conveniente realizar un análisis estratégico de la competencia con la siguiente orientación:

- Identificación de los recursos y capacidades. Se trata de averiguar los principales recursos y capacidades de los competidores, así como las rutinas organizativas que aporten valor al cliente y los elementos intangibles como la imagen de marca, reputación, etc.

- Evaluación estratégica de los recursos y capacidades. Se trata de establecer criterios para evaluar los recursos y capacidades de cada empresa, intentando estimar un ideal para las necesidades del sector. De este modo podremos establecer nuestra posición competitiva, y estar en mejores condiciones para la obtención y mantenimiento de ventajas competitivas.

- Gestión de los recursos y capacidades. Tan importante como la dotación de recursos y capacidades con los que cuenta una empresa es la gestión que se realiza de ellos. Por tanto, este es también un campo muy importante en el que poder trabajar para mejorar en la explotación de los recursos actuales y futuros con los que cuenta la empresa.

\subsubsection{Análisis de puntos fuertes y débiles}

Si bien es importante conocer la capacidad y el enfoque estratégico de nuestros competidores, ya que al tener un punto de referencia se pueden mejorar sustancialmente algunos aspectos en los que nos encontrábamos en desventaja, también lo es el estudiar los puntos fuertes y débiles que esto genera sobre todo en relación a lo que demanda el sector. Es importante mantenernos informados de las actuaciones 
de los principales competidores y de los cambios estructurales que vayan aconteciendo en el sector, pero siempre manteniendo la vista en el cliente, que es quien a la postre determinará qué empresa proveedora escoger.

Se trata de averiguar cuáles son los atributos clave en el sector en el que se opera. Estos atributos, aunque se pueden estimar por parte de los miembros de la empresa según su experiencia, es recomendable contrastarlos y completarlos con opiniones de expertos externos (agencias, asociaciones, instituciones, etc.). Incluso, se podría completar con información directa proveniente de clientes (actuales y potenciales) para dar todavía mayor validez a estos atributos, que en principio serán valorados por el cliente, y serán, por tanto, factores claves de éxito.

Se trata de identificar aspectos como calidad del producto, nivel de precio, atención del personal, facilidades de pago, garantías, servicio técnico, etc. y estimar en qué medida cada empresa competidora, y la nuestra misma cumple o no con estas atributos que el cliente valora. Es muy frecuente la realización de tablas donde se pueden resumir las puntuaciones realizadas para cada atributo y para cada empresa. Además, también es usual es realizar representaciones gráficas de estas tablas, con lo cual se obtienen los perfiles competitivos de cada empresa.

También es importante establecer comparativas en función de puntos fuertes y débiles de aspectos que tienen que ver con el nivel actual y la evolución de la cuota de mercado, nivel de ventas, notoriedad, preferencia, etc.

\subsubsection{La reacción de los competidores}

Finalmente es, también, aconsejable establecer algunos criterios o consideraciones que nos ayuden a entender o a intentar predecir cómo responderán los competidores ante nuestras actuaciones. Se trata de incorporar a los estudios estratégicos presentados anteriormente, unas estimaciones de reacciones esperadas de nuestra competencia. Para ello este fin muchas organizaciones se han apoyado en la teoría de los juegos, aunque a menudo esta teoría se vuelva inmanejable en el mundo real, por la heterogeneidad empresarial, la complejidad del entorno y el gran número de variables que influyen en las decisiones. Cuando un competidor dispone de muchas opciones, cuando no está seguro de qué indicadores serán utilizados, o si además se da la existencia de múltiples competidores y cada cual puede reaccionar de forma diferente desencadenando reacciones no esperadas, se plantea realmente complicado realizar cualquier predicción. Sin embargo, se puede realizar una simplificación que nos ayude aunque no sea de forma exacta a realizar algunas estimaciones.

En primer lugar podemos intuir si es previsible la reacción de los competidores, ya que no todas nuestras actuaciones provocarán reacciones. Además, no todos los competidores tienen por qué reaccionar, en principio, por igual ante un hecho común. Se trata, pues, de analizar la probabilidad con que cada empresa del sector reaccione o no ante nuestra actuaciones. 
En segundo lugar, sería conveniente intentar discernir qué opciones de respuesta barajarán los competidores en el caso de que sí reaccionen. Se trata de plantear un reducido número de opciones (tres o cuatro) que creamos que se pueden llegar a tener en cuenta por parte de nuestros competidores como opción de respuesta a nuestras acciones. Los modelos de reacción más comunes entre los competidores son cuatro:

- El competidor rezagado. No reacciona con rapidez ante los cambios en la competencia.

- El competidor selectivo. Reacciona solo ante cierto tipo de ataques.

- El competidor tigre. Reacciona con rapidez ante cualquier intrusión en sus dominios.

- El competidor aleatorio. No tiene un patrón predecible de reacción.

Finalmente, y a partir de la lista de opciones resultante de la etapa anterior, se debe intentar detectar cuál es la que va a elegir cada competidor con mayor nivel de probabilidad. Además, podemos realizar una serie de propuestas de actuación para nuestra empresa en función de las reacciones de los competidores.

En definitiva, parece claro que no es tarea sencilla realizar predicciones de lo que va a ocurrir en el futuro, en relación a las decisiones de los competidores. No se trata de acertar el $100 \%$ de las ocasiones como si de un futurólogo se tratara. Simplemente el análisis de las cuestiones planteadas nos llevarán a un mejor conocimiento del sector y a poder anticipar algunas acciones de la competencia y por tanto poder reaccionar con mayor rapidez y efectividad.

\subsection{Nuevas tendencias en el análisis de la competencia: benchmarking}

En el análisis de la competencia, tanto actual como potencial, requiere tener información constante para poder evaluar sus puntos fuertes y débiles. Las fuentes de información, tal y como hemos descrito anteriormente, pueden ser de distinto tipo. Sin embargo, el análisis de la competencia no debe quedarse en una simple recopilación de datos sobre la situación de la competencia y debe centrarse en obtener la fórmula que consiguió alcanzar estos resultados. Dicha fórmula se denomina benchmarking que es, según Santesmases (2012), «Una técnica de gestión empresarial por la que la organización compara sus niveles de eficiencia con estándares externos y ciertas prácticas internas propias para emular y corregir los posibles desfases existentes y, mediante planes de actuación y de mejora continua, para identificar oportunidades de innovación y realizar cambios efectivos en el negocio, con el fin de tratar de lograr posiciones de liderazgo, alcanzar niveles de excelencia y conseguir los resultados de rentabilidad deseados». 
Tradicionalmente, las empresas medían su efectividad comparándola con su propio desempeño en el pasado. Esto daba una muy buena indicación de la mejora que está logrando. Sin embargo, aunque la empresa esté mejorando, es posible que otras empresas estén mejorando más, por lo que mejorar con respecto a años anteriores, puede no ser suficiente. El benchmarking, en este sentido, ubica el desempeño de la empresa en un contexto amplio, y permite determinar las mejores prácticas. Existen cuatro tipos de benchmarking:

a) Benchmarking interno. Supone un chequeo interno de los estándares de la organización para determinar formas potenciales de mejorar la eficiencia.

b) Benchmarking competitivo. Es la comparación de los estándares de una organización con los de otras empresas competidoras.

c) Benchmarking de la industria. Comparar los estándares de la empresa con los de la industria a la que pertenece.

d) Benchmarking «mejor de su clase». Es la comparación de los niveles de logros de una organización con lo mejor que exista en cualquier parte del mundo sin importar en qué industria o mercado se encuentre.

El proceso de benchmarking supone que las empresas están preparadas y dispuestas para hacer públicas sus mediciones. Esto suele hacerse a través de un tercero que recoge los números de diversas organizaciones y los publican sin identificar a la empresa específica.

\section{Referencias bibliográficas}

Munuera, J. L. y A. I. Rodríguez (2002): Estrategias de marketing, teoría y casos, Madrid, Pirámide.

Porter, M. (1982): Estrategia competitiva, México, cecsa.

Santesmases, M. (2012): Marketing. Concepto y Estrategias, 6. ed., Madrid, Pirámide.

Vicente, M. A. (2009): Marketing y Competitividad. Nuevos Enfoques para Nuevas Realidades, Madrid, Pearson Educación. 



\section{Identificación y selección del público objetivo Teresa Vallet-Bellmunt}

\section{Contenido del capítulo}

En este capítulo los alumnos aprenderán a identificar y a seleccionar al público objetivo de la empresa (mercado objetivo o target) dentro de cada producto-mercado.

Para ello, primero estudiarán las preferencias que se producen en el producto-mercado y que permiten distinguir entre marketing masivo, marketing personalizado y segmentación. Si existen segmentos, el siguiente paso es identificarlos, a través de criterios de segmentación clave, métodos de análisis de datos y estudio de los perfiles de cada segmento.

Con los segmentos identificados, la empresa evaluará su atractivo y seleccionará aquel o aquellos segmentos a los que va a dirigir su actividad, configurando el mercado objetivo, público objetivo o target de la empresa.

A continuación la empresa establecerá las estrategias de cobertura del producto-mercado, determinado el número de segmentos a los que se va a dirigir y la oferta que diseñará para ellos.

El último paso del proceso de segmentación es el posicionamiento, que se verá en el capítulo 6. 
5.1. Proceso de segmentación del producto-mercado

5.1.1. Concepto de segmentación

5.1.2. ¿Mejora la segmentación la rentabilidad de la empresa?

5.2. Identificación de segmentos

5.2.1. Criterios de segmentación del consumidor final

5.2.1.1. Criterios de segmentación según el beneficio buscado

5.2.1.2. Criterios de segmentación según el comportamiento de compra y consumo

5.2.1.3. Criterios de segmentación según las características personales

5.2.1.4. Criterios de segmentación según las características psicográficas

5.2.2. Criterios de segmentación del comprador organizacional

5.2.2.1. Criterios de segmentación según las características de la empresa

5.2.2.2. Criterios de segmentación según el beneficio buscado

5.2.2.3. Criterios de segmentación según el comportamiento de compra y consumo

5.2.3. Procedimientos de segmentación

5.2.4. Descripción de los perfiles

5.3. Selección del mercado objetivo

5.3.1. Evaluación del atractivo de los segmentos

5.3.2. Estrategias de cobertura del producto-mercado

5.4. Ejemplo de segmentación del producto-mercado de pastas de dientes Referencias bibliográficas 


\subsection{Proceso de segmentación del producto-mercado}

El mercado de referencia es el conjunto de compradores que tienen una misma necesidad y que buscan entre las distintas alternativas tecnológicas aquella que más les satisface. Todas las empresas establecen cuál será su mercado de referencia. Como es difícil que una empresa se dirija a todo su mercado de referencia (porque no tiene todas las alternativas tecnológicas que cubrirían la necesidad o no se dirige a todos los macrosegmentos de compradores: consumidores finales o compradores organizacionales), lo lógico es que trabaje sobre el mercado relevante, que es la suma de productos-mercado a los que se va a dirigir.

Cada producto-mercado está formado por una necesidad, una alternativa tecnológica y un macrosegmento de compradores. No todos los compradores tendrán la misma forma de satisfacer la necesidad con la alternativa tecnológica escogida. Por ello, en cada producto-mercado, la empresa analizará cómo es el mapa de preferencias, es decir, qué preferencias tienen los compradores (finales u organizacionales) para satisfacer dicha necesidad con la alternativa tecnológica elegida, porque en función de ellas, la empresa diseñará una estrategia de segmentación distinta. Para entender lo que es un mapa de preferencias vamos a utilizar el ejemplo que aparece en la figura 25. Supongamos que los tres ejes que conforman el producto-mercado son: la necesidad que es la higiene, la alternativa tecnológica que es la pasta de dientes y el macrosegmento de compradores que son los consumidores finales.

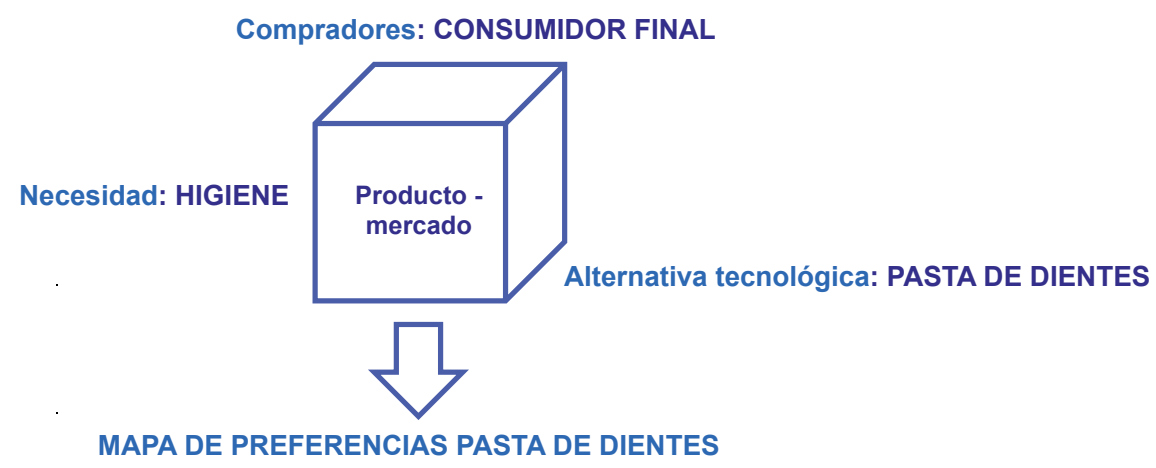

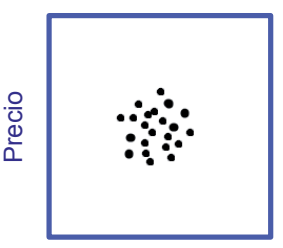

Blancura PREFERENCIAS HOMOGÉNEAS

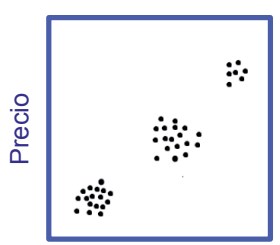

Blancura PREFERENCIAS AGRUPADAS

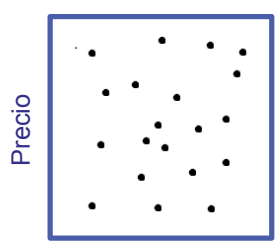

Blancura PREFERENCIAS DISPERSAS

Figura 25. La segmentación se realiza dentro del producto-mercado Fuente: Elaboración propia en base a Kotler et al. (2006) 
Para la empresa es muy importante saber cómo son las preferencias de aquellos consumidores que desean comprar un determinado dentífrico. Suponiendo que los dos criterios por los que se rigen los consumidores fuesen el precio y el nivel de blancura que proporciona la pasta de dientes, la empresa puede encontrarse con tres mapas de preferencias distintos.

En el primero, las preferencias de los consumidores son homogéneas, prácticamente todos los consumidores desean una pasta de dientes medianamente cara y con un nivel mediano de blancura proporcionada, por lo que podemos decir que las preferencias son las mismas. Si sucede esto, la empresa diseñaría un único tipo de pasta, idéntico para todos, que tuviese esas preferencias. Si decidiese diseñar una pasta muy barata pero que no dé blancura, por ejemplo, no tendría mercado para ella. Por tanto, si las preferencias son homogéneas, la empresa realizará una única estrategia de marketing (producto, precio, distribución y comunicación) idéntica para todos los consumidores finales, o lo que es lo mismo, haría marketing de masas, marketing masivo, marketing indiferenciado o contrasegmentación.

En el otro extremo, las preferencias de los consumidores son dispersas, es decir, cada consumidor tiene una preferencia diferente, a cada uno le gusta la pasta de dientes con una combinación distinta de precio y blancura. Si el mapa de preferencias tiene estas características, la empresa que diseñase un único producto con un nivel medio de blancura y precio, no tendría mercado suficiente. La empresa puede entender que la amplitud del área producto-mercado es excesiva si los consumidores que la integran son demasiado numerosos y variados en sus preferencias, pero para satisfacer un producto-mercado con estas características la empresa debería personalizar la pasta de dientes y diseñar tantas combinaciones de precio y blancura como preferencias hubiese. Esto haría que las pastas de dientes fuesen más caras, pero los consumidores que desean un producto a medida, están dispuestos a pagarlo. Por ello, si las preferencias varían considerablemente entre los consumidores, la empresa diseñaría tantas estrategias de marketing como preferencias existen, llevando a cabo un marketing personalizado, marketing ad hoc o hipersegmentación.

En el término medio se encuentran las preferencias agrupadas, es decir, existen tres grupos de consumidores que tienen unas preferencias bajas, medias y altas de la combinación de precio y blancura. Dentro de cada grupo las preferencias son homogéneas, pero entre los grupos son heterogéneas. La empresa que se encuentre con este mapa de preferencias tiene varias opciones. Puede escoger un solo grupo y dirigirse a él con una única estrategia de marketing que cubra las preferencias de ese grupo (por ejemplo un producto barato aunque no blanquee mucho los dientes). También puede elegir dos grupos y diseñar dos estrategias distintas (producto, marca, precio, distribución y comunicación), una para cada grupo (por ejemplo una pasta de dientes cara que blanquee mucho y una intermedia de precio y de blancura). Por último puede elegir los tres grupos y diseñar tres estrategias diferentes, una para cada grupo. Este proceso de identificación, selección y diseño de estrategias de marketing se denomina marketing diferenciado o segmentación. 
El concepto de segmentación se basa en la proposición de que los consumidores son diferentes ya sea en sus preferencias, en sus características demográficas y socioeconómicas, en su personalidad, actitudes o percepciones y que esas diferencias dan lugar a demandas distintas (Santesmases, 2004). Si se quiere satisfacer las necesidades del mercado e incrementar la demanda, debe proponerse una oferta diferenciada a cada uno de los grupos de consumidores que presenta características distintas. El reconocimiento de la heterogeneidad interna de la demanda de cada producto-mercado lleva a poner en marcha el proceso de segmentación del mercado que tiene las siguientes fases:

- Fase 1: Identificación de segmentos. La empresa empieza preguntándose ¿cómo es el mapa de preferencias del producto mercado? Solo en el caso en el que se identifiquen preferencias agrupadas se realizaría la segmentación. Para construir el mapa de preferencias, la empresa tiene que identificar en primer lugar los criterios de segmentación clave que proporcionan grupos de consumidores homogéneos en sí y heterogéneos entre sí. Los consumidores pueden segmentarse considerando distintos factores como indicadores demográficos, estilos de vida, hábitos de consumo o beneficios buscados en el producto. Con solo algunos criterios clave o con la combinación de varios de ellos se identificarían distintos grupos de compradores, que la empresa analizaría buscando un perfil homogéneo dentro de cada grupo, que explicase su comportamiento.

- Fase 2: Selección del mercado meta o público objetivo. La empresa evaluará el atractivo de cada segmento y ello le permitirá jerarquizarlos en importancia para la empresa. El siguiente paso será elegir aquel o aquellos segmentos a los que la empresa se va a dirigir, estableciendo las estrategias de cobertura del producto-mercado. El segmento o segmentos escogidos van a constituir el mercado objetivo, publico objetivo, mercado meta o target de la empresa.

- Fase 3: Posicionamiento en el mercado. Por último, la empresa diseñará tantas estrategias de marketing como segmentos haya escogido. Para ello, establecerá un posicionamiento para cada segmento, es decir, cómo quiere ser percibida la empresa en la mente de su target de acuerdo con las características del producto y el posicionamiento de sus competidores, y se diseñará el marketing mix adecuado para alcanzar dicho posicionamiento (producto, precio, comunicación y distribución) en cada segmento escogido.

Por último, hay que tener en cuenta que las preferencias de los consumidores no son estáticas, sino que se ven influidas por el entorno del comprador, lo que hace que las múltiples variables que afectan su comportamiento (véase capítulo 3) modifiquen estos mapas con el tiempo y la empresa tenga que variar sus estrategias de cobertura del producto-mercado.

En este capítulo se van a desarrollar las dos primeras fases de la segmentación, dejando para el capítulo sexto el concepto de posicionamiento. 


\subsubsection{Concepto de segmentación}

La segmentación puede definirse, pues, como el proceso encaminado a la identificación, dentro del producto-mercado, de aquellos grupos de consumidores con preferencias homogéneas en sí (dentro del grupo) y heterogéneas entre sí (entre grupos), a fin de seleccionar aquellos segmentos más atractivos para la empresa, que constituirán su mercado objetivo, de forma que resulte posible establecer para cada grupo una oferta comercial diferenciada, orientada de un modo específico hacia los intereses y preferencias de los consumidores que componen ese grupo o segmento. Por lo tanto, la segmentación es el proceso dirigido a la identificación de consumidores con preferencias agrupadas con el fin de establecer para cada grupo seleccionado una oferta o programa de marketing diferenciado.

Hay que tener claro que si el mapa de preferencias del producto-mercado nos da un modelo de preferencias homogéneas o dispersas, el proceso de segmentación no tiene sentido.

En el primer caso, si todos los consumidores fuesen iguales (mismos deseos o preferencias, antecedentes, educación y experiencia) el marketing masivo (indiferenciado) sería una estrategia lógica (Schiffman y Kanuk, 2010). Su principal ventaja es que es más barato diseñar una única estrategia de marketing con un producto uniforme y estandarizado, mismo precio, una campaña de comunicación masiva y un mismo canal de distribución. Esta estrategia se suele utilizar en productos manufacturados muy básicos o en mercados en vías de desarrollo, donde los consumidores aún no tienen preferencias definidas. Es la estrategia que utilizó Henry Ford en el lanzamiento de su primer modelo de coche, en el que fabricaba el Ford $T$ en una única línea de montaje, distribuía masivamente mediante concesionarios y promocionaba un único producto con frases como esta: «los consumidores pueden tener un automóvil Ford $T$ de cualquier color que deseen, siempre y cuando sea negro» (Schiffman y Kanuk, 2010; Kotler et al., 2006). También se suele utilizar en épocas de recesión, donde los consumidores están dispuestos a aceptar una menor variedad de productos con tal de que baje el precio. Por ello, las empresas reducen la oferta simplificando el producto, lo que permite rebajar costes y abaratar precios (Santesmases, 2004). Por último, se utiliza en aquellos productos que se encuentran en la última fase de su ciclo de vida y que están condenados a la desaparición.

En el segundo caso, si todos los consumidores son distintos (diferentes deseos o preferencias, antecedentes, educación y experiencia), el marketing personalizado es la estrategia adecuada. Su principal ventaja es que se da al comprador lo que desea, y por lo tanto se produce satisfacción. Pero por otro lado, es una estrategia cara, que implica distintos productos, diferentes canales y precios, así como campañas de comunicación individualizadas, por lo que los costes se disparan. Los consumidores con preferencias dispersas suelen estar dispuestos a pagar un precio superior por una oferta a medida, por eso esta estrategia es de mayor aplicación en periodos de expansión y prosperidad económica, donde el consumidor exige una mayor variedad de productos para encontrar el que mejor se adapte a sus necesidades (Santesmases, 2004). 


\subsection{2. ¿Mejora la segmentación la rentabilidad de la empresa?}

La segmentación incrementa los costes generales de la empresa cuando esta se dirige a dos o más segmentos con estrategias de marketing distintas. Los costes que se disparan porque se rompen las economías de escala y las sinergias son: la modificación de producto, costes de producción, costes de marketing, costes de inventario y costes de comunicación (Kotler et al., 2006).

A pesar de que la segmentación suponga un incremento de los costes, sobre todo si se eligen dos o más segmentos como público objetivo y se diseñan dos o más estrategias de marketing, puede ser una estrategia rentable, por varias razones (Santesmases, 2004).

En primer lugar ayuda a identificar oportunidades de mercado. Se evalúa en la medida en que las preferencias de cada segmento están cubiertas. El proceso de segmentación puede dejar al descubierto algunos segmentos que no son atendidos por ningún competidor y que después de ser analizados podrían ser atractivos para la empresa, que podría atenderlos diseñando nuevos productos o extendiendo la línea de los actuales, y así satisfacer las nuevas preferencias de los compradores.

En segundo lugar, en productos-mercados maduros o en declive cabe la posibilidad de identificar segmentos específicos todavía en fase de crecimiento que podrían ser atendidos por la empresa.

En tercer lugar permite establecer un orden de prioridad entre los segmentos, lo que contribuye a una mejor asignación de recursos. Los criterios que puede utilizar la empresa son: el potencial de compra del segmento, la facilidad de acceso, la complementariedad con otros mercados servidos o la facilidad de adaptación a sus demandas. La empresa primero se dirigirá a los más atractivos, luego al resto.

En cuarto lugar, permite una mejor evaluación de la competencia, ya que pueden identificarse mejor quiénes son los competidores más inmediatos, es decir, los que están actuando sobre los mismos segmentos que la empresa, y así, esta puede concentrarse mejor en anticipar sus movimientos o en contraatacarlos.

Por último, y esto es la esencia del marketing, la segmentación permite una mejor adecuación de los productos ofrecidos y de las acciones promocionales a llevar a cabo, adaptándose la empresa a las necesidades del mercado.

\subsection{Identificación de segmentos}

La primera fase del proceso de segmentación es la identificación de segmentos. Para llevarla a cabo la empresa debe encontrar primero los criterios de segmentación que permitan agrupar las preferencias de los compradores (finales u organizacionales). Generalmente esta información se recoge mediante fuentes primarias, es decir, a través de un cuestionario, en el que se les pregunta a los compradores 
potenciales información sobre beneficios buscados, comportamiento de compra, estilos de vida, datos sociodemográficos y económicos. Con toda esa información, se realiza el análisis de datos aplicando una serie de técnicas multivariables que permiten identificar grupos de compradores. Se analiza cada grupo y construye su perfil. Con los grupos identificados se pasaría a la segunda fase, la selección de segmentos.

A continuación vamos a especificar los criterios más utilizados para la segmentación de los mercados de consumo (consumidor final) y los mercados industriales (comprador organizacional), los métodos más utilizados para el análisis de datos y la definición de los perfiles.

\subsubsection{Criterios de segmentación del consumidor final}

No hay un criterio óptimo de segmentación. Para que el criterio sea útil tiene que implicar diferencias en el comportamiento y en las preferencias del comprador (Munuera y Rodríguez, 2007).

Diferentes autores han realizado una clasificación de criterios según las características de los mismos. La propuesta que expondremos sugiere la clasificación de los criterios en cuatro grandes grupos: características personales, comportamiento de compra y consumo, características psicográficas y beneficio buscado, por la combinación de dos variables, a las que los autores han denominado de diversas formas. En la tabla 7 se observa nuestra clasificación.

\begin{tabular}{|c|c|c|}
\hline & CRITERIOS PRIMARIOS & CRITERIOS SECUNDARIOS \\
\hline OBSERVABLE & $\begin{array}{l}\text { COMPORTAMIENTO DE COMPRA } \\
\text { Y CONSUMO } \\
\text { - Situación de Uso del producto } \\
\text { - Nivel de consumo } \\
\text { - Fidelización a la marca }\end{array}$ & $\begin{array}{l}\text { Características Personales } \\
\text { • C. Demográficos } \\
\text { •C. Socioeconómicos } \\
\text { • C. Geográficos }\end{array}$ \\
\hline LATENTE & $\begin{array}{l}\text { BENEFICIO BUSCADO } \\
\text { - Beneficios buscados } \\
\text { - Preferencias } \\
\text { - Actitudes } \\
\text { - Percepciones }\end{array}$ & $\begin{array}{l}\text { CARACTERÍsTICAS PSICOGRÁFICAS } \\
\text { - Personalidad } \\
\text { - Estilos de vida } \\
\text { - Valores y Creencias } \\
\text { socioculturales }\end{array}$ \\
\hline
\end{tabular}

Tabla 7. Clasificación de criterios de segmentación de mercados de consumo Fuente: Elaboración propia basada en Santesmases (2004), Schiffman y Kanuk (2010), Munuera y Rodríguez (2007) y Kotler y Keller (2012)

En las filas se distingue cómo se obtiene la información, es decir si el criterio de segmentación puede ser observado desde fuera (observable) o necesitamos información que nos proporcione el individuo (latente). Santesmases (2004) divide esta variable en criterios objetivos y subjetivos, mientras que Schiffman y Kanuk (2010) la denominan hechos y cogniciones del individuo. 
Los criterios observables recogen información que puede ser obtenida por fuentes secundarias (estadísticas oficiales, anuarios, monografías) o por fuentes primarias (como paneles de consumidores, escáneres y tarjetas de fidelización de clientes). Incluyen los criterios sobre el comportamiento de compra y consumo y las características personales de los consumidores (demográficas, socioeconómicas y geográficas).

Los criterios latentes recogen información que no se puede observar directamente y que por lo tanto hay que preguntar al consumidor final. Se utilizan encuestas en las que al consumidor se le pregunta por estas variables y también por las observables para poder cruzar los datos. Recoge los criterios según el beneficio buscado y las características psicográficas del comprador (estilos de vida, personalidad, creencias y valores).

En las columnas se clasifican los criterios en dos grupos en función de si están directamente relacionados con la elección del producto por parte del consumidor y por lo tanto generan segmentos altamente homogéneos en sí (primarios) o son más generales y sirven para describir segmentos más que para crearlos (secundarios).

Los criterios primarios son conocidos como criterios de primer orden o segmentación directa (Munuera y Rodríguez, 2007), porque son muy apropiados para hacer grupos de consumidores homogéneos en sí y maximizan las diferencias intergrupos. Santesmases (2004) les denomina criterios específicos porque están relacionados con el producto a adquirir, Schiffman y Kanuk (2009) les llaman específicos de consumo, y Kotler y Keller (2012) criterios conductuales. Pueden ser de dos tipos: 1) según el beneficio buscado: por qué compran productos los consumidores, y 2) según el comportamiento de compra y consumo: cómo y dónde compran los productos los consumidores.

Los criterios secundarios son conocidos como criterios de segundo orden o de segmentación indirecta (Munuera y Rodríguez, 2007), porque sirven más para describir el perfil de grupos formados por los criterios primarios (¿quiénes son los consumidores?) que para generar nuevos grupos (aunque se pueden encontrar excepciones). Santesmases (2004) les denomina criterios generales porque no están relacionados con el producto a adquirir, Schiffman y Kanuk (2009) les llaman arraigados en el consumidor, y Kotler y Keller (2012) criterios descriptivos. Se incluyen en este grupo las características demográficas y socioeconómicas, estilo de vida y personalidad.

A continuación se van a desarrollar cada uno de estos cuatro grupos de criterios: beneficio buscado, comportamiento de compra, características personales y características psicográficas. 


\subsubsection{Criterios de segmentación según el beneficio buscado}

Los beneficios que los consumidores buscan en los productos y servicios son la esencia y el eje de la segmentación (Schiffman y Kanuk, 2009).

- Los beneficios buscados representan necesidades no satisfechas del consumidor. La segmentación por beneficio buscado (¿qué quiere el comprador?) se centra directamente en aquellas razones por las cuales el consumidor es atraído hacia un producto (Munuera y Rodríguez, 2007). Lo que distingue los segmentos es la importancia relativa otorgada a los atributos (beneficios) cuando los compradores son inducidos a hacer elecciones entre ellos. El valor del beneficio que se busca cuando se compra un producto determinado es el principal factor que se necesita identificar. El objetivo de la segmentación por beneficio buscado es explicar las diferencias en las preferencias y no simplemente proporcionar una descripción del comportamiento de compra. Son criterios útiles para encontrar potenciales nuevos productos (Munuera y Rodríguez, 2007).

- La existencia de motivaciones distintas en la compra de productos o servicios genera distintos grupos. Por ejemplo, la compra de un automóvil se puede hacer por diferentes motivos: transporte, estatus, precio, ocio, trabajo, etc.

- Por otro lado, las actitudes que puede exhibir un consumidor en relación con un producto son: entusiasta, positiva, indiferente, negativa y hostil. Por ejemplo, quienes trabajan en campañas políticas haciendo visitas a domicilio utilizan la actitud para determinar cuánto tiempo deben pasar con cada votante potencial. Agradecen a los votantes entusiastas y les recuerdan que voten, refuerzan a los que tienen una disposición positiva, intentan obtener los votos de los electores indiferentes y no desperdician su tiempo tratando de cambiar la actitud de los votantes negativos y hostiles (Kotler y Keller, 2012). La empresa debe identificar las actitudes hacia el producto y ver si se generan grupos lo suficientemente homogéneos para diseñar estrategias de marketing distintas para ellos.

La ventaja de la utilización de estos criterios es que discriminan mucho las preferencias de los compradores dando lugar a segmentos bastante homogéneos en sí. Por otro lado, la mayor dificultad a la hora de aplicar este enfoque se centra en la selección de beneficios a resaltar, especialmente en los mercados de consumo. Cuando los analistas preguntan a los consumidores qué beneficios buscan en un producto, es probable que muchas veces no los sepan. Si el análisis directo del mercado se complementa con información relacionada con los problemas de los consumidores, se pueden obtener nuevas percepciones. Además, su implementación requiere información primaria de una muestra representativa de clientes objetivo (incrementa los costes), a los que se les suele preguntar la lista de beneficios asociados a una categoría de producto y una evaluación de la importancia relativa asignada a cada beneficio: con ello se reagrupan los consumidores con patrones de puntuación similares (técnicas multivariables) y se evalúa la dimensión y perfil de cada segmento identificado (Lambin, 2003). 
La segmentación por comportamiento de compra y consumo (¿qué hace el comprador?) clasifica a los consumidores según su forma de comprar y de consumir. Son utilizados por aquellas empresas que tienen su interés puesto en el desarrollo de estrategias para las marcas y productos ya existentes y en la determinación de su política de marketing (Munuera y Rodríguez, 2007). Tanto el comportamiento de compra como el de consumo y las diferentes respuestas a los elementos de marketing son criterios de segmentación incluidos en este grupo (dónde compra, qué compra, cuánto paga, cuándo compra, cómo compra). Para identificar estos segmentos, la empresa puede utilizar la tarjeta de cliente y los escáneres de las cajas registradoras. Los criterios más utilizados son el uso del producto, el volumen comprado y el estatus de fidelidad (Lambin, 2003).

- Situación de uso: las ocasiones marcan un momento del día, la semana, el mes, el año u otros aspectos temporales bien definidos en la vida de un consumidor (Kotler y Keller, 2012). Algunos factores situacionales que influyen en la elección de compra o consumo incluyen si es un día entre semana (ir al cine), si hay tiempo suficiente disponible (utilizar el correo regular o el urgente), si se trata de un obsequio para un novio, uno de los padres, un compañero de trabajo o uno mismo (Schiffman y Kanuk, 2009). Muchos productos se promueven para utilizarlos en ocasiones especiales: tarjetas de felicitación, flores, dulces, etc.

- Nivel de consumo: estos criterios diferencian entre los usuarios frecuentes, medios y ocasionales, y los no usuarios (Schiffman y Kanuk, 2009). En muchos mercados una pequeña proporción de clientes representa un alto porcentaje de las ventas. Las empresas suelen aplicar la «Ley de Pareto» o «Ley $20 / 80 »$, en la que el $20 \%$ de los compradores suponen el $80 \%$ de las ventas. Por ejemplo, aproximadamente el $25 \%$ de los consumidores de cerveza consumen el $75 \%$ del total de cerveza. Por ello, se pueden identificar dos grupos, los clientes principales y los ocasionales y diseñar estrategias distintas para cada segmento. También se podría utilizar la frecuencia de compra como variable, distinguiendo usuarios expertos o aprendices. Las empresas líderes tienden a centrarse en atraer a usuarios potenciales (no usuarios) porque tienen más que ganar, mientras que las empresas más pequeñas se concentran en conservar o retener a sus usuarios actuales, alejándolos del líder (Kotler y Keller, 2012).

- Segmentación por fidelidad: la lealtad hacia la marca tiene dos componentes: 1) el comportamiento o la frecuencia y consistencia con que se adquiere una marca dada, y 2) actitud o sentimiento de compromiso del consumidor hacia la marca (Schiffman y Kanuk, 2009). Se puede hacer una distinción entre los clientes fieles incondicionales, los no exclusivamente fieles y los que cambian de marca (Kotler y Armstrong, 2012). Por ejemplo, los mercados de tabaco, cerveza y pasta de dientes (véase ejemplo del final del capítulo) generalmente generan fidelidad. Se pueden diseñar estrategias para atraer 
clientes de la competencia o fidelizar a los que cambian de marca. Los usos más comunes de la lealtad hacia la marca son los programas de recompensas por uso frecuente que las empresas ofrecen a sus clientes más leales (Schiffman y Kanuk, 2009).

\subsubsection{Criterios de segmentación según las características personales}

Las características personales del consumidor (¿quién y cómo es?) son un método indirecto de segmentación, es decir, es de segundo orden porque por sí solas, aunque con excepciones, no generan grupos, sirven para describirlos. Incluimos en este grupo las características demográficas, geográficas y socioeconómicas de los consumidores. Las variables más utilizadas son: edad, ingresos, ubicación geográfica, educación, profesión, clase social y tamaño de la familia.

Para que un rasgo personal (demográfico, socioeconómico, geográfico) sea útil a los propósitos de la segmentación tiene que implicar diferencias en el comportamiento y, en última instancia, diferencias en el beneficio buscado y en las necesidades y deseos del consumidor.

La ventaja de la segmentación por características personales es su bajo coste y la facilidad con la que se pone en práctica. En la mayoría de los mercados, la información relacionada con variables demográficas y socioeconómicas se puede obtener con facilidad a través de preguntas, observación y fuentes secundarias como estadísticas oficiales, monografías y los paneles de consumidores, que publican estos criterios en sus informes mensuales o bimensuales de forma similar en varios países europeos (Lambin, 2003). Además permiten una clasificación precisa de cada entrevistado dentro de una categoría dada (Schiffman y Kanuk, 2010). Los datos sociodemográficos se utilizan con diversos fines, como por ejemplo: para describir y comprender mejor a los clientes existentes, para conseguir un perfil del segmento objetivo, para seleccionar los medios de comunicación que tengan una mayor probabilidad de llegar a un grupo objetivo, y para identificar a los compradores potenciales de un nuevo producto (Lambin, 2003).

Sin embargo, la segmentación sociodemográfica también tiene sus limitaciones (Lambin, 2003). Es un análisis que se centra en la descripción de las características de los segmentos en lugar de intentar conocer lo que provoca que estos segmentos se desarrollen. Por otro lado, en la actualidad personas de la misma edad, misma estructura familiar y mismos ingresos tienen actitudes y comportamientos totalmente diferentes, lo que se refleja en sus preferencias. La segmentación sociodemográfica debe complementarse con otros criterios para entender y predecir el comportamiento del consumidor.

Tres son los tipos de criterios según las características personales: las variables demográficas, las variables socioeconómicas y las variables geográficas.

Las variables demográficas, como la edad, género, estado civil, ciclo de vida de la familia y tamaño del hogar, son fáciles de utilizar pero no siempre se consigue 
una segmentación en la que los comportamientos de los grupos estén claramente diferenciados, y además se producen variaciones en el tiempo.

- Por género. A medida que los derechos y deberes de hombres y mujeres se igualen, será difícil encontrar ejemplos de segmentación por género (Santesmases, 2004), aunque sigue siendo un buen criterio en algunos casos, porque muchos productos se diseñan de forma concreta para hombres o mujeres. Por ejemplo, Multicentrum es un complejo vitamínico, que modifica el contenido de vitaminas según si va dirigido al hombre o a la mujer, dando lugar a dos productos: Multicentrum hombre y Multicentrum mujer. ${ }^{1}$ Otros productos que distinguen por género podrían ser artículos para afeitar, cremas cosméticas, tintes para el cabello, revistas y herramientas. Algunos mercados que se dirigían tradicionalmente a los hombres han descubierto nuevos segmentos en las mujeres. Por ejemplo, ellas utilizan criterios distintos a los hombres a la hora de comprar un coche (impacto ambiental, diseño interior, seguridad) lo que ha generado que los fabricantes de automóviles cambien la manera en que diseñan y venden coches (Kotler y Keller, 2012).

- La edad es también un buen diferenciador de comportamientos (por ejemplo Multicentrum adultos y Multicentrum junior). Los deseos de los consumidores cambian con la edad (véase el ejemplo del final del capítulo).

- El hogar o la familia sigue siendo la unidad de consumo esencial para muchos bienes y servicios. Las empresas estudian el número de hogares y su tamaño y qué productos adquieren. El estado civil es una variable que sirve para medir el número de hogares (Schiffman y Kanuk, 2010). Por ejemplo, a medida que aumentan los hogares con un único individuo, las empresas de alimentación se dirigen a ellos y empaquetan sus productos en unidades con menos producto (raciones individuales).

- Una variable que combina la edad y tipo de familia es el ciclo de vida familiar. Muchas familias atraviesan fases similares en su formación, crecimiento y disolución final, y cada etapa representa segmentos-meta relevantes para las empresas. Los solteros jóvenes necesitan mobiliario para su primer apartamento, mientras que sus padres, ahora liberados, desean renovar sus muebles por otros de mayor calidad (Schiffman y Kanuk, 2010). Las empresas de equipamiento de hogar y fabricantes de automóvil segmentan a sus clientes por las fases del ciclo de vida en la que se encuentran.

Las variables socioeconómicas, como la renta (ingresos), ocupación y nivel de estudios (educación) proporcionan una buena base para segmentar mercados.

- Los ingresos se han utilizado mucho en la segmentación de mercados para la compra de automóviles, ropa, cosméticos, servicios financieros y viajes, sin embargo, no siempre predicen el mejor grupo de clientes para un producto.

$\overline{\text { 1. http://www.multicentrum.es }}$ 
Por ejemplo, los obreros constituyen el principal grupo de compradores de televisores a color, porque para ellos es más barato adquirir esos aparatos que ir al cine o a restaurantes (Kotler y Keller, 2012). En muchas economías, las empresas tienen claro que sus mercados tienen forma de reloj de arena, y que sus consumidores de clase media migran hacia los productos de descuento o hacia los de lujo, lo que implica cambios en el diseño de sus productos.

- La combinación de los ingresos (cantidad de dinero ganado en un año), educación (número de años que se requieren para obtener cierto título académico) y ocupación (calificaciones numéricas según la función desempeñada en la economía) da lugar a la clase social. El concepto de clase social implica una jerarquía donde los individuos de la misma clase social poseen el mismo nivel de estatus, en tanto que los miembros de otras clases tienen mayor o menor nivel. Los estudios han demostrado que los consumidores de diferentes clases sociales varían en términos de valores, preferencias hacia los productos y hábitos de compra (Schiffman y Kanuk, 2010).

Las variables geográficas como nación, región y hábitat también generan diferencias entre los grupos de consumidores finales. El lugar donde vive el consumidor determina alguno de sus comportamientos de consumo (Schiffman y Kanuk, 2010). Algunos ejemplos son los siguientes. En Francia, Italia y España se consume vino, en Alemania la cerveza y en el Reino Unido el té (Santesmases, 2004). Las diferencias climáticas hacen que en los suelos se utilicen en el Reino Unido las moquetas, en los países nórdicos la madera y en España los azulejos. El clima también determina el tipo de ropa que usa la mayoría de gente, y las modas varían también de las ciudades grandes a las áreas rurales (Schiffman y Kanuk, 2010). Dentro de cada nación las diferencias también son importantes (por ejemplo la gastronomía). La segmentación de mercados por criterios geográficos junto con la utilización de bases de datos ha dado lugar al geomarketing, ${ }^{2}$ que consiste en el diseño de acciones comerciales directas dirigidas a segmentos de compradores mediante la utilización de sistemas de información geográfica (Santesmases, 2004). Se basa en la premisa de que es muy probable que la gente que vive cerca entre sí tenga medios financieros, gustos, preferencias, estilos de vida y hábitos de consumo similares (Schiffman y Kanuk, 2010). El código postal es también otra información clave para saber si hay clientes agrupados geográficamente en una ciudad.

\subsubsection{Criterios de segmentación según las características psicográficas}

Los criterios de características personales van perdiendo valor predictivo en las sociedades desarrolladas, a medida que los patrones de consumo se van personalizando. El objetivo de los criterios psicográficos es complementar los datos demográficos añadiendo elementos como actividades, actitudes, intereses, opiniones, percepciones y preferencias para obtener un perfil más completo del comprador

2. Ejemplos de la aplicación comercial del geomarketing son la clasificación PRIZM NE (un producto de NIELSEN) que divide a la población de EE. UU. en 66 segmentos (http://www.claritas.com/MyBestSegments/Default.jsp). 
(Lambin, 2003). El objetivo es relacionar variables del tipo de personalidad con comportamiento de compra. Estos criterios son difíciles de aplicar porque son subjetivos o latentes.

Son criterios de este tipo: los estilos de vida, las variables de personalidad y los valores y creencias.

El estilo de vida de una persona se puede medir y describir de diversas maneras. Hace referencia a la forma en que las personas viven, gastan su dinero y pasan su tiempo. Los grupos generados por estilos de vida tienden a comportarse de una manera definida e imponen normas sobre qué productos comprar y cómo y dónde adquirirlos (Santesmases, 2004). La gran mayoría de estudios empíricos sobre estilos de vida recogen información sobre actividades, intereses y opiniones (AIO), en los cuales la investigación mide (Lambin, 2003):

- Las actividades de las personas en términos de cómo pasan el tiempo: trabajo, hobbies, eventos sociales, vacaciones, entretenimiento, comunidad, compras, etc.

- Sus intereses: a lo que otorgan importancia en su entorno más cercano. Por ejemplo la familia, hogar, trabajo, comunidad, recreo, moda, alimentos, logros, etc.

- Sus opiniones en términos de su visión sobre ellos mismos y sobre el mundo que les rodea, como por ejemplo, opinión sobre política, negocios, economía, cultura, futuro, etc.

- A esta información se le añade otra sobre datos demográficos (edad, educación, ingresos, ocupación, dimensión de la familia, residencia, tamaño de la ciudad, ciclo de vida) y sobre el producto a estudio.

Con estos datos se elaboran los perfiles de usuario. Las clasificaciones sobre estilo de vida más conocidas son vals (VAlues and Life Styles) ${ }^{3}$ desarrollado por la empresa SRI International, con ocho segmentos según estilos de vida o MOSAIC desarrollado por Experian. Estos datos se recogen en diversos países (muestras amplias y representativas) y se actualizan cada tiempo, lo que permite ver la evolución de los distintos estereotipos y de las motivaciones de los distintos subgrupos sociales. La utilidad de estos criterios (Lambin, 2003) es doble, por un lado identifica las tendencias y sensibilidades en la sociedad y evalúa las oportunidades y amenazas asociadas con esos cambios (aspecto dinámico). Por otro lado, determina si un subgrupo determinado va por delante o está atrasado con respecto a una tendencia sociocultural (aspecto estático). Los problemas asociados a los estilos de vida son dos: son estudios causales, por lo que no siempre se diseña adecuadamente el experimento para obtener la información y que la fiabilidad del instrumento de recogida (un cuestionario demasiado amplio) se pone en duda.

3. VALs: http://www.strategicbusinessinsights.com/vals/ustypes.shtml

MOSAIC: http://www.experian.com/marketing-services/consumer-segmentation.html 
Los criterios de personalidad también nos dan grupos con comportamientos y preferencias distintos. Ejemplos de tipos de personalidad son el introvertido, el extrovertido, el emotivo, el flemático, el líder, el gregario, el entusiasta, etc. Sin embargo, si se les pregunta a los consumidores de forma directa es poco probable que revelen sus rasgos de personalidad porque son reservados o porque no los reconocen de manera consciente, por lo que hay que utilizar otros métodos de recogida de información (pruebas de personalidad).

Los criterios según valores y creencias agrupan cogniciones abstractas del individuo que se pueden obtener a través de instrumentos psicológicos y actitudinales (Schiffman y Kanuk, 2009). Las empresas segmentan a sus mercados considerando su herencia cultural, ya que los miembros de una misma cultura suelen compartir valores, creencias y costumbres (Kotler y Keller, 2012).

\subsubsection{Criterios de segmentación del comprador organizacional}

En teoría no existe ninguna diferencia entre la segmentación de los mercados industriales y los mercados de consumo, pero los criterios pueden variar sustancialmente (Lambin, 2003). Para segmentar mercados industriales se utilizan fundamentalmente criterios objetivos (Santesmases, 2004), ya sean primarios o secundarios. En la tabla 8 se observan los criterios más comunes a la hora de segmentar mercados industriales. La segmentación es más sencilla de realizar en los mercados industriales que en los de consumo, porque los usuarios son profesionales que tienen menos reparo en expresar sus preferencias y calificar la importancia relativa de los atributos del producto (Lambin, 2003). Por ello, todos los criterios pueden ser observados con el trato habitual entre vendedor y comprador, por lo que la clasificación de criterios da lugar a dos bloques: los criterios primarios y los criterios secundarios.

\subsubsection{Criterios de segmentación según las características de la empresa}

La segmentación según las características de la empresa (criterios descriptivos) se basa en criterios que describen el perfil del cliente industrial (Lambin, 2003). Estos criterios están relacionados con la actividad, ubicación geográfica, tamaño, etc. Uno de los criterios más utilizado es el del volumen de ventas de la empresa cliente, de forma que la empresa escoge como clientes a las empresas grandes (elevado volumen de ventas) y deja para los distribuidores las pequeñas (pequeño volumen de ventas).

\subsubsection{Criterios de segmentación según el beneficio buscado}

Los criterios según el beneficio buscado implican clasificar a las empresas según el tipo de industria o por el uso final que le dan al producto. Los productos industriales tienen una elevada gama de aplicaciones, por lo que la clasificación por tipo 
de industria indica las necesidades prioritarias y su importancia relativa (Lambin, 2003). La información sobre la clasificación nacional de actividades económicas (CNAE) es fácil de obtener, ya que este tipo de datos lo proporciona la Administración pública o Bases de datos privadas (tipo $\mathrm{SABI}^{4}$ ) y nos permite clasificar a los clientes según la industria en la que trabajan.

\begin{tabular}{|c|c|}
\hline CRITERIOS PRIMARIOS & CRITERIOS SECUNDARIOS \\
\hline $\begin{array}{l}\text { COMPORTAMIENTO DE COMPRA } \\
\text { Y CONSUMO } \\
\text { - Funcionamiento del centro de compras } \\
\text { - Productos comprados } \\
\text { - Volumen y frecuencia de compra } \\
\text { - Relación comprador-vendedor } \\
\text { BENEFICIO BuSCADo } \\
\text { - Beneficios buscados: tipo de industria } \\
\text { (CNAE) } \\
\text { - Preferencias } \\
\text { - Actitudes }\end{array}$ & $\begin{array}{l}\text { CARACTERíSTICAS DE LA EMPRESA } \\
\text { - Tamaño: número de empleados, } \\
\text { facturación, número de plantas } \\
\text { - Localización geográfica } \\
\text { - Antigüedad } \\
\text { - Capacidad técnica y financiera } \\
\text { - Variables estratégicas y de gestión }\end{array}$ \\
\hline
\end{tabular}

Tabla 8. Clasificación de criterios de segmentación de mercados organizacionales Fuente: Elaboración propia

\subsubsection{Criterios de segmentación según el comportamiento de compra y consumo}

La segmentación por comportamiento de compra es muy importante en los mercados industriales. Su propósito es desarrollar una estrategia para contactar con los clientes industriales según la forma en que funciona su centro de compras. En algunas empresas la compra está centralizada y las decisiones se toman con normas muy precisas mientras que en otras compañías se descentralizan. El funcionamiento interno del centro de compras no se puede observar directamente, pero el responsable de ventas pronto aprende cómo funcionan los centros de compra de sus clientes.

Otro criterio muy utilizado en la segmentación según el comportamiento de compra es la ley de Pareto que divide a los clientes entre buenos (20\% de clientes que producen el $80 \%$ de la facturación de la empresa) y malos ( $80 \%$ de clientes que solo producen el $20 \%$ de la facturación de la empresa) y los criterios ABC, que dividen a los clientes en tres grupos en función de las compras que realizan a la empresa (buenos, medios, malos). La empresa se dirigirá a cada uno de estos grupos con estrategias de marketing distintas.

4. Sistema de Análisis de Balances Ibéricos (https://sabi.bvdinfo.com). 
Debido a la complejidad y variedad de las posibles bases para segmentar los mercados industriales algunos autores (Shapiro y Bonoma, 1984; Wind y Cardozo, 1974) han propuesto realizar la segmentación en varias etapas, primero utilizando los factores más amplios y generales (características de la empresa) y en un segundo paso los más específicos (beneficios buscados y comportamiento de compra).

Por último, en los mercados organizacionales es común encontrarnos con marketing personalizado porque en muchos sectores industriales las ventas se basan en pedidos con unas especificaciones muy detalladas (producto especializado a medida), por lo que el producto se ajustará a esas necesidades específicas del cliente (Lambin, 2003). También se puede encontrar el marketing masivo cuando la empresa se dirige a mercados poco desarrollados, donde un producto genérico sirve a la gran mayoría de compradores (productos estándar). Algunos expertos del B2B proponen realizar «ofertas flexibles» a todo el segmento: un parte común a todos ellos y otra parte con opciones en función de sus preferencias (Kotler y Keller, 2012).

\subsubsection{Procedimientos de segmentación}

Tras recoger la información necesaria para llevar a cabo la segmentación, generalmente a través de encuestas al público objetivo, en las que se les pregunta sobre motivaciones, comportamientos de compra y consumo, y características personales, es necesario acudir a métodos estadísticos que permitan la división del mercado en grupos homogéneos de consumidores. Los métodos que posibilitan la segmentación del mercado son los siguientes:

- Diseños de segmentación a priori, según los cuales el investigador selecciona una variable a explicar (el criterio de segmentación clave) antes de realizar el análisis y un conjunto de variables explicativas de la misma. Para tratar los datos se utilizan diversas técnicas. Las más empleadas son las tabulaciones cruzadas, el análisis Chi-cuadrado, análisis de varianzas y análisis discriminante (Santesmases, 2004).

- Diseños de segmentación a posteriori, según los cuales los consumidores son agrupados de acuerdo a la similitud de sus perfiles multivariables, sin hacer distinción entre variables explicativas y variables explicadas. Para el análisis de datos se utiliza entre otros el análisis de clasificación o análisis cluster que permite obtener una división entre los grupos de modo que internamente sean lo más homogéneos posible y que a la vez, las diferencias entre los grupos sean las máximas posibles (Santesmases, 2004).

Lo óptimo sería disponer de una técnica que simultáneamente permitiera la identificación (característica de los diseños a priori) y la descripción (ventaja de los diseños a posteriori). 


\subsubsection{Descripción de los perfiles}

Una vez se tienen identificados los grupos de consumidores, la empresa analizará las características diferenciales de cada grupo. Esto se lleva a cabo mediante el análisis de los datos que proporciona el procedimiento de segmentación. Las características diferenciadas de cada grupo permitirán a la empresa establecer un perfil y elegir un nombre que «bautice» al segmento. A saber, independientes, sensoriales, precavidos y sociables en el ejemplo disponible al final del capítulo.

\subsection{Selección del mercado objetivo}

La selección del mercado objetivo es un proceso en dos fases, en el que se evalúa el atractivo para la empresa de cada segmento identificado, y se selecciona el segmento o los segmentos a los que la empresa desea dirigirse (público objetivo, mercado-meta o target) mediante las estrategias de cobertura del producto-mercado.

\subsubsection{Evaluación del atractivo de los segmentos}

La empresa valorará el atractivo de cada segmento en base a unos criterios. Según Lambin (2003) para que se dé una segmentación eficaz, los segmentos deberían cumplir los criterios de: respuesta diferenciada, tamaño adecuado, accesibilidad y mensurabilidad. Según Kotler y Keller (2012) cada segmento obtenido debe ser: medible, rentable (sustancial), accesible, diferenciable y accionable. A continuación vamos a desarrollar estos criterios:

- Respuesta diferenciada a las acciones de marketing o «diferenciable». Los segmentos identificados deben ser diferentes en términos de su sensibilidad hacia una o varias variables de marketing controladas por la compañía, es decir, que sean más sensibles a una de las 4 Pes que al resto para poder llegar a ellos (Lambin, 2003). El criterio de segmentación elegido tiene que maximizar las diferencias entre segmentos (criterio de heterogeneidad) y minimizar las diferencias entre compradores en el seno del mismo segmento (criterio de homogeneidad). Si todos responden por igual, no hace falta segmentar.

- Tamaño adecuado o segmento «sustancial»: los segmentos deben representar a suficientes clientes potenciales y proporcionar suficientes ingresos por ventas para justificar la creación de una estrategia de marketing para cada segmento, es decir, lo suficientemente grandes (tamaño por gasto medio) como para justificar que la empresa diseñe una estrategia de marketing para ellos. Esta condición no solo afecta al volumen de ventas y frecuencia de compra sino también a su estabilidad o ciclo de vida del segmento (Lambin, 2003). Es fundamental averiguar que el segmento es estable y no temporal. Por tanto, este criterio está relacionado con la rentabilidad que va a proporcionar el segmento, por lo que coincidiría con el criterio de rentabilidad o segmento sustancial de Kotler y Keller (2012). 
- Mensurabilidad o segmento «medible»: tenemos que poder cuantificar cuantas personas forman el segmento y cuál es su gasto medio o poder de compra y sus principales hábitos y comportamientos de compra (Lambin, 2003). Por ello es importante que entre los criterios utilizados para la segmentación aparezcan criterios secundarios que nos proporcionarán información muy útil sobre los componentes del segmento y cómo cuantificarlos.

- Accesibilidad o segmento «accesible»: es la facilidad de llegar a un segmento mediante un solo programa de marketing. Existen dos formas de llegar a los clientes: 1) la autoselección del cliente (estos consumidores se autoseleccionan prestando atención a los mensajes publicitarios que van dirigidos a un público más general), y 2) la cobertura controlada (la empresa llega a los clientes objetivo directamente utilizando medios de comunicación asociados al perfil del segmento). Los criterios secundarios ayudan a adaptar el segmento a los perfiles de audiencia de los distintos medios y soportes de comunicación (Lambin, 2003).

- Accionabilidad o segmento «accionable»: que la empresa sea capaz con sus recursos y capacidades de diseñar una estrategia para cada segmento de forma efectiva y rentable, teniendo en cuenta la compatibilidad (por imagen) para atender ese segmento. Cualquier segmento atractivo del mercado puede no serlo para una empresa concreta si esta no cuenta con los recursos para hacerle frente. Antes de la elección de un segmento como mercado objetivo la empresa debe estimar los recursos y capacidades de que dispone para conquistarlo.

\subsubsection{Estrategias de cobertura del producto-mercado}

Evaluados los segmentos previamente identificados, la siguiente fase en el proceso de segmentación es la elección de un mercado objetivo, público objetivo, mercado meta o target al que se va a dirigir la empresa. La forma de dirigirse al mercado objetivo se llama estrategia de cobertura. Dentro de cada producto-mercado la empresa escoge los segmentos para formar el mercado objetivo y decide con cuántos productos va a cubrir cada segmento (Kotler et al., 2006). Fruto del cruce de estas alternativas (uno o más segmentos y uno o más productos) surgen las estrategias de cobertura del producto-mercado (véase figura 26).

- Estrategia de concentración en un único segmento: la empresa se dirige a un solo segmento con un solo producto. Esta estrategia es característica de pequeñas empresas especialistas con recursos limitados. Mediante ella, la empresa llega a conocer mejor las necesidades de su público objetivo, alcanza una fuerte presencia en el mercado y puede conseguir una reducción de costes debido a la especialización de la distribución, producción y promoción (Kotler et al., 2006). Por otro lado, concentrar todos los esfuerzos en un único segmento es muy arriesgado, sobre todo si atrae a competidores que pueden eliminar a la empresa de dicho segmento. 
- Estrategia de expansión a varios segmentos (o de especialista en productos): consiste en especializarse en un producto y atender con él a diversos segmentos. El riesgo de esta estrategia estriba en la obsolescencia del producto con la aparición de nuevas tecnologías (Kotler et al., 2006).

- Estrategia de expansión de la línea de productos (o especialista en mercado): la empresa se dirige con varios productos a un único segmento, lo suficientemente grande y rentable. En este caso la empresa se esfuerza por satisfacer un buen número de deseos del mismo segmento de mercado. El riesgo radica en que el segmento podría ver limitada su capacidad de gasto de repente o disminuir su tamaño progresivamente (Kotler et al., 2006).

- Estrategias de diferenciación: consiste en diferenciar la oferta de productos con objeto de satisfacer los deseos de dos o más segmentos del mercado con dos o más productos. Puede que la sinergia entre los segmentos sea escasa o nula, pero cada uno de ellos por separado debe ser rentable (Kotler et al., 2006). Esta estrategia de cobertura diversifica los riesgos. La cobertura puede ser parcial o total. En el primer caso el riesgo es considerable, dada la dispersión de esfuerzos e incremento de costes. En el segundo caso, donde se cubren todos los segmentos con todos los posibles productos, pueden existir sinergias que disminuyan los costes y los riesgos. La cobertura total solo se puede adoptar por grandes empresas multinacionales.
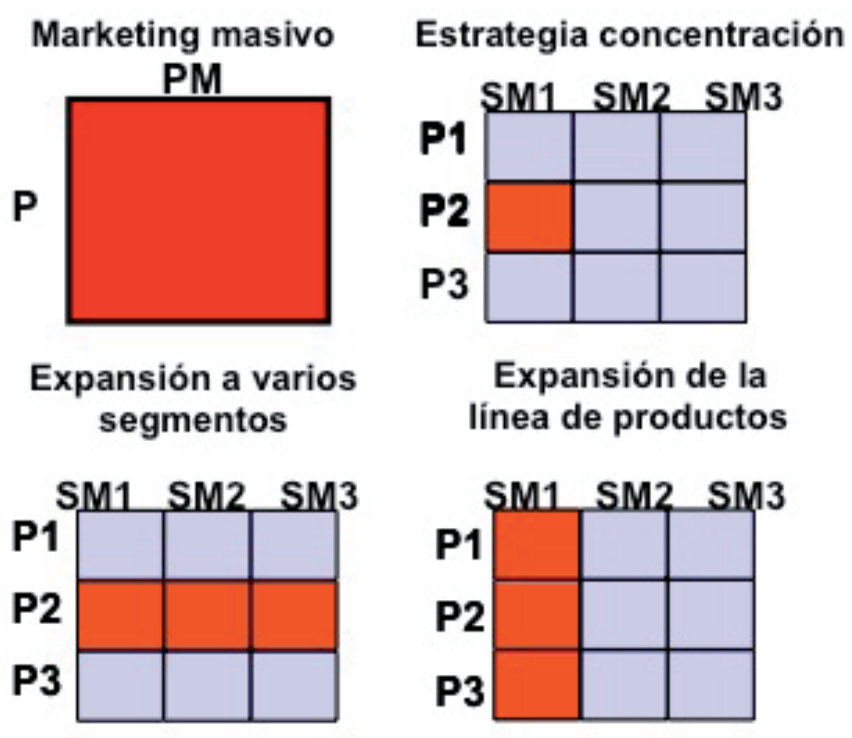

Estrategias de diferenciación

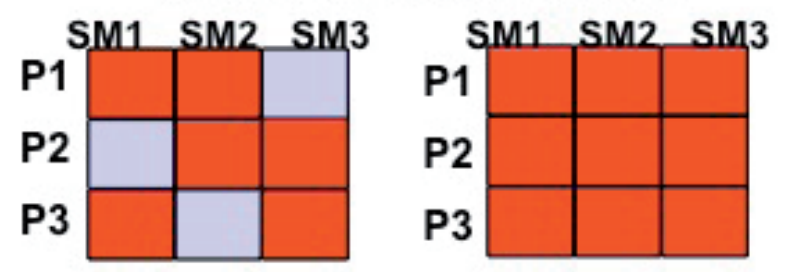

Figura 26. Estrategias de cobertura del producto-mercado Fuente: Kotler et al. (2006) 
Por otro lado, no hay que confundir la cobertura total del producto-mercado (existen segmentos y la empresa diseña una estrategia de marketing distinta para cada uno de ellos) con el marketing de masas (no existen segmentos y la empresa solo diseña una estrategia de marketing idéntica para todo el producto-mercado).

Por último, las estrategias de cobertura son dinámicas, y las empresas van modificándolas en función de los segmentos que desean cubrir.

\subsection{Ejemplo de segmentación del producto-mercado de pastas de dientes}

Como ejemplo de segmentación vamos a utilizar los trabajos de Haley (1968) y Cohen (1986), ambos enfocados a la segmentación en el producto-mercado de la pasta de dientes.

La primera fase es la identificación de segmentos. En este trabajo, Haley (1968) utilizó los criterios de beneficio buscado como criterio clave de segmentación y lo complementó con el resto de criterios. Tras la recogida de datos, aplicó técnicas multivariables que le proporcionaron cuatro grupos de consumidores. Estudiando las características personales, el comportamiento de compra y consumo, los criterios psicográficos y sobre todo los beneficios buscados de cada grupo, Haley estableció los perfiles de cada grupo y bautizó los cuatro segmentos como independientes, sociables, precavidos y sensoriales.

En el producto-mercado de la pasta de dientes (véase figura 25), los beneficios buscados que se identificaron fueron los siguientes: blancura, frescor, buen sabor, presencia del producto, prevención de la caries, protección de las encías y economía. A continuación se les pidió a los entrevistados que repartiesen 100 puntos entre cada uno de los beneficios según su importancia en la elección del producto (pasta de dientes), así como información suplementaria sobre características personales, psicográficas y de comportamiento de compra y consumo. Se identificaron cuatro grupos (véase tabla 9).

El segmento precavido incluye a un elevado número de familias con niños. Están preocupados porque sus hijos tengan ese problema y muestran una preferencia por marcas de pasta de dientes con flúor.

El segmento sociable, que incluye a personas que se preocupan por la blancura de sus dientes integra a un elevado número de jóvenes recién casados. Fuman por encima de la media y tienen una vida social muy activa.

El segmento sensorial se preocupa más del sabor y de la presencia del producto. Un número muy elevado de usuarios son niños y su uso de la pasta de dientes con sabor a menta está muy por encima de la media. 


\begin{tabular}{|c|c|c|c|c|c|}
\hline $\begin{array}{c}\text { BENEFI- } \\
\text { CIO BUS- } \\
\text { CADO }\end{array}$ & $\begin{array}{c}\text { DEMO- } \\
\text { GRÁFI- } \\
\text { CAS }\end{array}$ & $\begin{array}{c}\text { COMPORTAMIEN- } \\
\text { TO DE COMPRA } \\
\text { Y CONSUMO }\end{array}$ & $\begin{array}{c}\text { PSICO- } \\
\text { GRÁFICAS }\end{array}$ & $\begin{array}{c}\text { MARCAS } \\
\text { ELEGIDAS }\end{array}$ & $\begin{array}{c}\text { NOMBRE } \\
\text { SEGMEN- } \\
\text { TO }\end{array}$ \\
\hline $\begin{array}{c}\text { Economía } \\
\text { (Bajo precio) }\end{array}$ & Hombres & Grandes compradores & $\begin{array}{c}\text { Alta autono- } \\
\text { mía, orienta- } \\
\text { dos al valor }\end{array}$ & $\begin{array}{c}\text { Marcas en } \\
\text { oferta }\end{array}$ & $\begin{array}{c}\text { Indepen- } \\
\text { dientes }\end{array}$ \\
\hline $\begin{array}{c}\text { Medicinal } \\
\text { (Prevención } \\
\text { caries) }\end{array}$ & $\begin{array}{c}\text { Familias } \\
\text { amplias }\end{array}$ & Grandes compradores & $\begin{array}{c}\text { Hipocon-dría- } \\
\text { cos, conserva- } \\
\text { dores }\end{array}$ & Crest & Precavidos \\
\hline $\begin{array}{c}\text { Cosmético } \\
\text { (Dientes } \\
\text { brillantes) }\end{array}$ & $\begin{array}{c}\text { Jóvenes } \\
\text { Jóvenes }\end{array}$ & Fumadores & $\begin{array}{c}\text { Sociabilidad } \\
\text { alta, activos }\end{array}$ & $\begin{array}{c}\text { MaClean's } \\
\text { Ultrabrite }\end{array}$ & Sociables \\
\hline $\begin{array}{c}\text { Sabor } \\
\text { (Buen sabor) }\end{array}$ & Niños & Les gusta la menta & $\begin{array}{c}\text { Hedonistas, } \\
\text { les gusta } \\
\text { comprome- } \\
\text { terse }\end{array}$ & Colgate \\
Aim & Sensoriales \\
\hline
\end{tabular}

Tabla 9. Segmentación por beneficios del producto-mercado de pasta de dientes Fuente: Haley (1968)

El segmento independiente está orientado al precio y compuesto principalmente por hombres. El consumo de la pasta de dientes está por encima de la media.

Una vez identificados los segmentos, el siguiente paso consistirá en evaluarlos y elegir la estrategia de cobertura más adecuada. Por la recogida de datos primarios, se puede saber cuántos usuarios hay en cada segmento y su gasto medio en el producto. Suponiendo que los datos son los que aparecen en la tabla 10, la empresa evaluaría, cuál o cuáles de los segmentos son más atractivos para ella y establecería las estrategias de cobertura.

En tabla 11 se observan las estrategias de cobertura seguidas por algunas empresas competidoras de la industria de la pasta dental. Tres son los segmentos que identifica Cohen (1986), basados en las características personales, concretamente la edad. Se identifican cinco empresas competidoras, con distintas estrategias de cobertura.

El último paso consiste en el posicionamiento en cada segmento utilizando las 4 Pes: diseño del producto, fijación del precio, comunicación y canales de distribución (véase capítulo 6).

\begin{tabular}{|c|c|c|c|c|}
\cline { 2 - 5 } \multicolumn{1}{c|}{} & TAMAÑO & $\begin{array}{c}\text { GASTO ME- } \\
\text { DIO ANUAL } \\
\text { (EUROS) }\end{array}$ & TOTAL & $\%$ \\
\hline INDEPENDIENTES & 40 & 100 & 4000 & 38,5 \\
\hline PRECAVIDOS & 15 & 150 & 2250 & 21,6 \\
\hline SOCIABLES & 20 & 120 & 2400 & 23,1 \\
\hline SENSORIALES & 25 & 70 & 1750 & 16,8 \\
\hline Total & 100 & & 10.400 & 100,0 \\
\hline
\end{tabular}

Tabla 10. Evaluación de los segmentos del producto-mercado de pasta de dientes Fuente: Elaboración propia. Datos hipotéticos 


\begin{tabular}{|c|c|c|c|}
\hline & Niños y adolescentes & 19- 35 años & Más 36 años \\
\hline Pasta dientes lisa & $\begin{array}{c}\text { Colgate-Palmolive } \\
\text { Procter \& Gamble }\end{array}$ & $\begin{array}{c}\text { Colgate-Palmolive } \\
\text { Procter \& Gamble }\end{array}$ & $\begin{array}{c}\text { Colgate-Palmolive } \\
\text { Procter \& Gamble }\end{array}$ \\
\hline $\begin{array}{c}\text { Pasta de dientes lisa } \\
\text { con flúor }\end{array}$ & $\begin{array}{c}\text { Colgate-Palmolive } \\
\text { Procter \& Gamble }\end{array}$ & $\begin{array}{c}\text { Colgate-Palmolive } \\
\text { Procter \& Gamble }\end{array}$ & $\begin{array}{c}\text { Colgate-Palmolive } \\
\text { Procter \& Gamble }\end{array}$ \\
\hline $\begin{array}{c}\text { Pasta de dientes en gel } \\
\text { Procter \& Gamble } \\
\text { Lever Bros }\end{array}$ & $\begin{array}{c}\text { Colgate-Palmolive } \\
\text { Procter \& Gamble } \\
\text { Lever Bros }\end{array}$ & $\begin{array}{c}\text { Colgate-Palmolive } \\
\text { Procter \& Gamble } \\
\text { Lever Bros }\end{array}$ \\
\hline $\begin{array}{c}\text { Pasta de dientes rayada } \\
\text { Pasta de dientes para } \\
\text { fumadores }\end{array}$ & Beecham & Beecham & Topol \\
\hline
\end{tabular}

Tabla 11. Estrategias de cobertura del producto-mercado de pasta de dientes ${ }^{5}$ Fuente: Cohen (1986)

\section{Referencias bibliográficas}

Armstrong, G., Kotler, P., Merino, M. J., Pintado, T. y J. M. Juan (2011): Introducción al marketing, 3. ${ }^{\mathrm{a}}$ ed., Madrid, Pearson Educación.

Conen, W. A. (1986): Winning on the Marketing Front: The Corporate Manager's Game, New York, John Wiley.

Haley, R. I. (1968): «Benefit Segmentation: A Decision-Oriented Research Tool», Journal of Marketing, Vol. 32 (3), 30-35.

Kotler, P. y K. L. Keller (2012): Dirección de marketing, México, Pearson Educación de México.

Kotler, P., Lane, K., Cámara, D. y A. Mollá (2006): Dirección de Marketing, 12. ${ }^{\mathrm{a}}$ ed., Madrid, Prentice Hall.

LAMBIn, J. J (2003): Marketing Estratégico, Madrid, ESIC Editorial.

Munuera, J. L. y A. I. Rodríguez (2007): Estrategias de marketing, Un enfoque basado en el proceso de dirección, Madrid, Esic Editorial.

Santesmases, M. (2004): Marketing, Conceptos y Estrategias, 5. a ed., Madrid, Pirámide.

Schiffman, L. G. y L. L. KanuK (2010): Comportamiento del consumidor, 10. a ed., México, Pearson Educación de México.

Shapiro, B. y T. V. Bonoma (1984): «How to segment industrial markets», Harvard Business Review, 62: 104-110.

Wind, Y. y R. CARDOzo (1974): «Industrial market segmentation», Industrial Marketing Management, 3: 153-166.

5. Nota: Procter \& Gamble tiene en España las marcas Oral B y Fluocaril; Lever Bross (Unilever) tiene en España las marcas Signal y Close Up; Colgate-Palmolive tiene en España la marca Colgate total; Beecham (ahora GSK) tiene las marcas Aquafresh, Sensodine y Binaca; y Topol no existe en España. 


\section{CAPÍTULO 6}

\section{Posicionamiento \\ Emilia Casanova-Calatayud}

\section{Contenido del capítulo}

Tal y como hemos visto en el capítulo anterior, dentro del proceso de segmentación, el posicionamiento representa la última fase. En este capítulo, se desarrolla este concepto y su importancia, dentro de la sociedad actual, dado el gran volumen de información al que se ven expuestos los consumidores y la alta rivalidad competitiva en todos los sectores en general.

El posicionamiento será el colofón para una estrategia de diferenciación exitosa, para ello, debemos saber elegir aquellos atributos y características de nuestra oferta que permitirán posicionar el producto en la mente del consumidor.

El alumno podrá identificar qué fases se han de desarrollar para poder llevar a cabo un buen posicionamiento, así como los objetivos y distintas herramientas, que nos ayudarán a ello. 
6.1. Concepto de posicionamiento

6.1.1. Decisión de posicionamiento estratégico

6.2. Fases para la elección del posicionamiento

6.3. Identificación de las ventajas competitivas: dimensiones competitivas 6.3.1. Formas específicas para diferenciar la oferta de mercado. Tipos de posicionamiento

6.3.2. ¿Cuántas diferencias debemos promocionar?

6.3.3. ¿Qué diferencias se deben promover?

6.4. Estudio del posicionamiento de los competidores, dimensiones competitivas y posición de los consumidores

6.5. Comunicación de la posición elegida

6.5.1. Estrategias para cambiar de posicionamiento: el reposicionamiento

Referencias bibliográficas 


\subsection{Concepto de posicionamiento}

El concepto de posicionamiento aparece dentro del proceso de segmentación, en último lugar. Una vez la empresa ha identificado los segmentos del mercado, los ha valorado y finalmente seleccionado, es el momento de posicionarse en los segmentos elegidos, pero, ¿a qué nos referimos cuando hablamos de posicionamiento?

Definimos el posicionamiento como la imagen (conjunto de atributos) relativa (respecto a la competencia) que un producto ocupa en la mente los clientes (Kotler et al., 2006).

El término posicionamiento puede venir referido:

- A la localización del producto en función de sus características físicas.

- A la posición que ocupa el producto en función de las percepciones de los consumidores.

En el primer caso hablamos de posicionamiento objetivo. Ahora bien, este tipo de posicionamiento no es útil, a menos que las características del producto coincidan con las percepciones que los consumidores poseen de los productos o marcas.

Así pues, el posicionamiento basado en las características físicas solo es significativo si se extiende al campo de las percepciones de los consumidores (Wind et al., 1982).

\subsubsection{Decisión de posicionamiento estratégico}

Pero ¿por qué debemos llevarlo a cabo en nuestro producto, marca...? La sociedad de hoy en día está sobrecomunicada, y los expertos señalan que los consumidores establecemos con las marcas, una especie de escala de productos en nuestra mente, así, cuando piensas en refrescos, en el primero que pensamos es Coca-Cola, es el líder, las empresas lo saben, y por ello intentan conseguir esa posición. Si alguien de la competencia quiere su participación en el mercado, debe desalojar a la marca ubicada más arriba, o bien, relacionar la suya con la posición lograda por la otra empresa.

De hecho, los consumidores posicionan los productos con o sin la ayuda del marketing. Será pues, tarea de los gestores y especialistas de marketing desarrollar aquel posicionamiento estratégico que dé a sus productos la mayor ventaja competitiva dentro del mercado objetivo al que se dirigen.

Definimos la estrategia de posicionamiento como: La acción de diseñar la oferta y la imagen de una empresa/producto o marca de tal modo que ocupen un lugar distintivo en la mente de los consumidores (Kotler et al., 2006). 
Lo primero que debemos destacar de este concepto, es que no se realiza sobre el producto en si, es lo que la empresa debe construir en la mente de las personas que pertenecen a su público objetivo.

El posicionamiento facilitará el diseño y posterior desarrollo de las estrategias de marketing en cuanto a qué necesidades y deseos de los clientes se deben intentar satisfacer. De esta forma, se establecen las directrices para el diseño de un plan de marketing mix, donde cada una de las herramientas utilizadas (producto, precio, distribución y comunicación) nos acercarán a conseguir nuestro objetivo.

La selección de la estrategia de posicionamiento proporciona el elemento unificador del desarrollo del programa de marketing. Será uno de los pasos más importantes en la implementación del marketing estratégico, ya que la empresa debe decidir cómo diferenciar su marca de la competencia.

\subsection{Fases para la elección del posicionamiento}

Ya hemos señalado que estamos en una era de gran «bombardeo» informativo, la mente del consumidor como defensa ante tal volumen de información, rechaza gran parte de ella, y solo acepta aquello que encaja con sus conocimientos y experiencias anteriores.

La solución a este problema estará en centrarse en el receptor de nuestro mensaje, es decir, concentrarnos en la manera que tiene de percibir nuestro público objetivo.

Así pues, para elegir un buen posicionamiento de mercado, partiremos del estudio de las actitudes del consumidor hacia los productos que compiten en él, con la finalidad de aportar los atributos más afines a las necesidades del segmento en el que queremos situarlo.

No debemos olvidar llevar a cabo un análisis interno de las debilidades y fortalezas de nuestra empresa, determinar el conjunto de posibles ventajas competitivas para posicionar el producto, y saber en qué medida estamos capacitados, para ofrecer los atributos y características que nuestro mercado objetivo valora.

El posicionamiento toma como punto de partida, un análisis interno de nuestra empresa y posteriormente desarrollamos dos fuentes de análisis (Munuera y Rodríguez, 2007):

- El segmento del público objetivo

- La competencia

Nuestro objetivo será servir a un mercado, con un programa de marketing específicamente adaptado a los intereses y expectativas del público objetivo, y hacerlo antes y mejor que nuestros competidores. 
Para llegar a esta situación, es decir, para lograr ese posicionamiento en la mente del consumidor es necesario recorrer las siguientes fases:

- Identificación de la competencia o del conjunto relevante de productos y marcas con los que vamos a entrar en competencia directa.

- Determinación de las posiciones de los competidores mediante mapas de percepción y preferencias.

- Determinación de las dimensiones competitivas, es decir debemos estudiar cómo el consumidor percibe y evalúa nuestros productos, los productos competidores y en base a qué atributos.

- Análisis de las posiciones/preferencias de los consumidores (esta fase está relacionada con el proceso de segmentación que nos identifica los segmentos y sus preferencias).

\subsection{Identificación de las ventajas competitivas: dimensiones competitivas}

Para que las empresas, puedan llevar a cabo marketing relacional, es decir, crear relaciones rentables a largo plazo con sus clientes, la primera tarea será entender sus necesidades mejor que la competencia, y entregarles un mayor valor. En la medida que la empresa se pueda posicionar a sí misma como proveedor de mayor valor, obtendrá una ventaja competitiva.

El posicionamiento empezará con una diferenciación real de la oferta de marketing de la empresa, de modo que se proporcione a los consumidores un mayor valor.

\subsubsection{Formas específicas para diferenciar la oferta de mercado. Tipos de posicionamiento}

Se puede diferenciar de acuerdo con las líneas de producto, los servicios, los canales, las personas o la imagen.

En los productos, se desarrolla a través de una línea continua. En un extremo, encontramos productos físicos que casi no permiten variación: ternera, hierro, agua embotellada. Incluso en estos casos puede haber cierta diferenciación significativa; cuando Font Vella sacó al mercado su envase Font Vella Go, o si un agricultor cultiva de forma ecológica, puede poner el precio de su cosecha más alto.

En el otro extremo están los productos que pueden tener una alta diferenciación, como automóviles, la ropa o los muebles. Estos productos se pueden diferenciar según sus características, sus funciones, su rendimiento, su estilo, diseño, etc. Por 
ejemplo, Volvo ofrece nuevas y mejores características de seguridad. La empresa Fujitsu aporta el silencio, como una característica básica en sus aparatos de aire acondicionado.

Además de trabajar sobre los productos físicos, las empresas también pueden diferenciar los servicios que acompañan al producto. Podemos hacerlo llevando a cabo una entrega rápida, por añadir facilidades de pago, entrega a domicilio etc. Los supermercados están ofreciendo ya la posibilidad de realizar la compra por Internet, o por teléfono. Muchos compradores están dispuestos a pagar un poco más si el producto lleva incluidos esta serie de servicios. El Corte Inglés, - «si no queda satisfecho le devolvemos su dinero»- se basa en la premisa de la satisfacción de sus clientes, y se compromete a ello ofertando todo un catálogo de servicios que añaden valor a sus productos, como: financiación, tarjetas regalo, devolución de la compra, tarjeta de cliente y un largo etcétera.

Las empresas pueden conseguir una fuerte ventaja competitiva a través de sus recursos humanos, es decir, de las personas que forman el staff de la empresa, contratar y capacitar al personal mejor que nuestros competidores, puede también resultar un punto clave. Esta ventaja competitiva adquiere una gran importancia cuando la oferta de nuestra empresa se basa en un servicio: cadenas hoteleras, aerolíneas, hospitales, etc., ya que como estudiaremos en el tema oportuno, una de las características de los servicios es su variabilidad, es decir, dependen en total medida de quién ofrezca el servicio, no es lo mismo cortarse el pelo en Llongueras que en la peluquería del barrio.

Incluso, cuando las ofertas competidoras parecen iguales, los compradores pueden percibir alguna diferenciación basada en la imagen de la empresa, o la marca. En muchos sectores las marcas pueden no estar diferenciadas sobre una base de características tangibles. Una cierta imagen diferenciará la marca frente a su competencia, siempre teniendo en cuenta que una imagen de marca debe transmitir los beneficios y el posicionamiento distintivos del producto.

Cuando se procede a un posicionamiento centrado en el consumidor se parte del estudio de las actitudes del consumidor hacia los productos que compiten en el mercado, a fin de dotar al producto de la empresa de aquellos atributos más adecuados a las necesidades del segmento en el que deseamos situarlo.

Pero, además del posicionamiento del producto centrado en el consumidor, también tiene cabida el posicionamiento centrado en la competencia. Este consiste en poner el énfasis sobre las ventajas que posee el producto respecto a sus competidores directos, para proporcionar un punto de referencia que permita diferenciar la marca, por ejemplo, algunas empresas pueden utilizar el precio como una forma de posicionarse frente a la competencia.

Existen diferentes categorías de precio: el precio más alto en su categoría Gucci en perfumes, Cartier en joyas, el mayor valor del dinero Nivea en el sector cosmético, y el menor precio de la categoría Ryanair en el sector de las aerolíneas, Aldi para el mercado alimentario minorista, etc. 
Algunas ideas de posicionamiento pueden ser:

- Posicionamiento basado en los atributos del producto.

- Posicionamiento basado en los beneficios del producto.

- Posicionamiento basado en el uso/aplicaciones del producto.

- Posicionamiento basado en la tipología de las personas.

- Posicionamiento frente a la competencia.

- Posicionamiento basado en la definición de una categoría de producto.

\subsection{2. ¿Cuántas diferencias debemos promocionar?}

Los gestores de marketing, deberán identificar un beneficio o atributo, diferenciar el producto, y que así quede reflejado en la mente del consumidor, pero ¿cuántas beneficios o atributos debemos promocionar hacia nuestro público objetivo?

Algunos especialistas consideran que las empresas deben promover una única propuesta de marca, y centrarse en ella. Cada marca debe elegir un atributo e intentar ser el número uno basándose en él. Mercadona eligió su filosofía de calidad total, desarrollando la estrategia comercial de SPB, «siempre precios bajos», o ING Direct su $0 \%$ de comisiones.

Otros especialistas consideran que las empresas se deben posicionar basándose en más de un factor de diferenciación. Hoy en día las empresas tratan de ampliar sus estrategias de posicionamiento con el fin de ser atractivas al mayor número de segmentos, pero a medida que se incrementan las características elegidas corren el riesgo de no ser creídas o de perder un posicionamiento claro. El desafío es, convencer al público objetivo de que la marca ofrece todos los beneficios que estamos comunicando. Si la empresa decide varias propuestas de valor para sus marcas, debe tratar de no incurrir en los siguientes errores.

- Infraposicionamiento: cuando los consumidores, tienen una vaga idea de la declaración distintiva de la marca, los consumidores no observan nada especial en ella.

- Sobreposicionamiento: en este caso los consumidores, tienen una idea demasiado concreta de la marca, demasiado estrecha, porque la perciben como demasiado especializada o no accesible; esto puede «ahuyentar» a posibles clientes.

- Posicionamiento confuso: los consumidores tienen una imagen confusa de la marca, consecuencia de promocionar demasiados beneficios, de que sean 
incompatibles entre sí o se intente cambiar de posicionamiento con demasiada frecuencia.

- Posicionamiento dudoso: los consumidores encuentran «poco fiable» las asociaciones buscadas por la marca, a la vista de las características del producto, su precio, canal de distribución o fabricante.

\subsection{3. ¿Qué diferencias se deben promover?}

Hemos estudiado el número de beneficios o atributos sobre los que debemos posicionar nuestra marca, pero ¿qué características deben reunir cada una de esas diferencias? Vale la pena establecer una diferencia, siempre que satisfaga los siguientes criterios:

- Importante: la diferencia ha de percibirse como algo valorado por los consumidores.

- Distintiva: podemos ofrecer algo diferenciado de la competencia, bien porque ellos esa característica no la tienen, bien porque la de la empresa es mejor.

- Superior: la diferencia es superior a otras formas en que los clientes podrían obtener el mismo beneficio.

- Comunicable: la diferencia se puede comunicar para que así lo perciban los consumidores.

- Exclusiva: debe ser lo más difícil posible de copiar por la competencia.

- Asequible: los compradores pueden pagar por esa diferencia.

- Rentable: la introducción de la diferencia redunda en un incremento de rentabilidad para la empresa.

\subsection{Estudio del posicionamiento de los competidores, dimensiones competitivas y posición de los consumidores}

Existen dos razones por las cuales la identificación de los diferentes niveles de competencia es el primer paso del proceso de posicionamiento. La primera está relacionada con la recogida de información. Debemos delimitar el número de marcas consideradas a estudio, para que este proceso no sea rechazado por los entrevistados, ya que muchas de las técnicas multivariantes usadas para el análisis del posicionamiento requieren de la comparación entre pares de marcas. La segunda 
razón es el impacto distorsionador que puede tener, la inclusión de competidores lejanos o indirectos en los resultados que se persiguen.

Una vez identificados los competidores directos, se debe proceder a la determinación de las posiciones de los competidores, de las dimensiones competitivas y de la posición de los consumidores.

Para planificar sus estrategias de posicionamiento, los especialistas de marketing, suelen preparar mapas de posicionamiento perceptual que muestran la percepción que los consumidores tienen sobre sus marcas, en comparación con los productos de la competencia para algunas dimensiones o atributos de compra importantes. Precio, calidad, diseño, surtido, embalaje son ejemplos de dimensiones a estudio.

Para buscar el posicionamiento del producto se utilizan técnicas como los análisis factoriales, en los que realizamos el estudio sobre dos variables (precio y calidad, por ejemplo); análisis de correspondencias con más de dos variables, y el análisis multidimensional, que nos identifica varias dimensiones y además las preferencias de los segmentos de compradores. En los análisis factoriales y de correspondencias, los consumidores son encuestados sobre un producto desglosado en una lista de atributos, por tanto, son especialmente adecuados cuando se conocen con precisión los beneficios que los consumidores buscan en un producto. Por el contrario, los análisis multidimensionales se usan cuando los beneficios son difíciles de especificar exactamente.

Para realizar un mapa perceptual la forma de proceder es la siguiente: en primer lugar, hay que seleccionar el producto-mercado que se va a segmentar, y decidir cuáles son las marcas que compiten en el mismo. En segundo lugar, hay que recoger las percepciones de una muestra de consumidores acerca de los atributos de las marcas existentes. El mapa perceptual de la figura 27 ilustra cómo hacerlo. Este mapa se basa en dos atributos o dimensiones: calidad y precio, que se representan mediante los dos ejes. Las marcas identificadas como competencia directa aparecen en los distintos cuadrantes. Utilizando la jerarquía de las preferencias hacia las marcas de los entrevistados podemos situar a los consumidores en aquellos lugares que representan sus posiciones ideales en cuanto a preferencia, es decir, estarán más cerca de la marca más preferida y más alejados de aquellas menos deseadas.

En el ejemplo que estamos trabajando (figura 27) los segmentos detectados son cuatro y contienen los grupos de consumidores según sus preferencias respecto a las variables que permiten diferenciar las marcas del mercado que hemos decidido estudiar. Por ejemplo, el segmento más grande (el tamaño del círculo mide el tamaño del segmento) prefiere calidad media y precio bajo y las marcas más cercanas son la E y la A. La marca D, por otro lado, es percibida como cara y de baja calidad, por lo que no hay un segmento de compradores cercano.

Una vez interpretados los datos y detectados los segmentos potenciales de ser público objetivo, se arbitrarán los programas de marketing adecuados para ubicar la marca o producto en la posición ideal deseada. Si se intenta modificar un posicionamiento anterior, a dicha estrategia se le denomina reposicionamiento. 


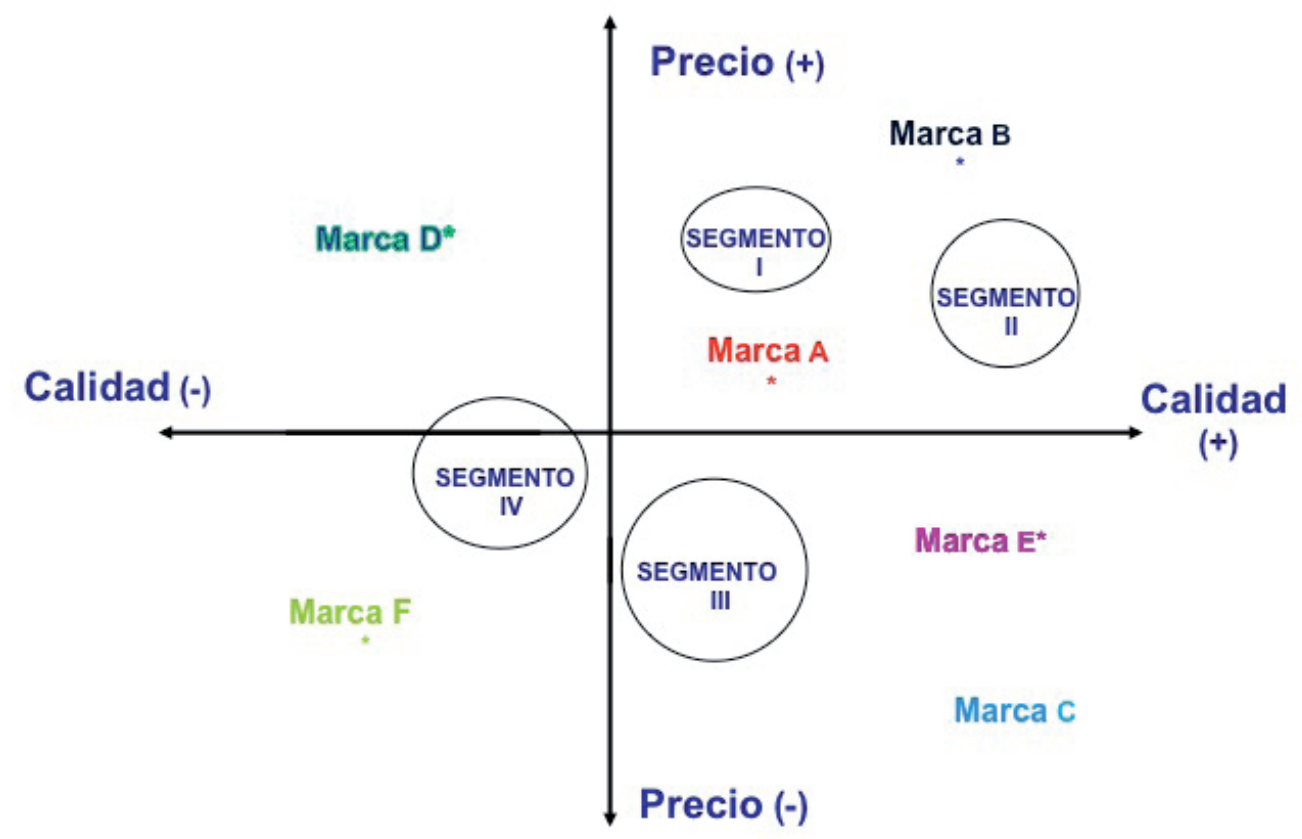

Figura 27. Mapa de percepción elaborado con el análisis factorial Fuente: Elaboración propia

\subsection{Comunicación de la posición elegida}

Cuando la empresa tenga decidida cuál va ser su idea de posicionamiento, será el momento de tomar las medidas oportunas para comunicarlo a nuestro público objetivo, ya que como sabemos, este, se forma en la mente del consumidor, Para ello, debemos utilizar las herramientas del marketing mix: producto, precio distribución y promoción. Todas las actividades del mix de la empresa, deben ir encaminadas a apoyar la estrategia de posicionamiento que hayamos establecido.

Pasaremos a llevar a cabo acciones concretas, si la empresa decide basar su posicionamiento en mejor calidad y salud, como Leche Pascual, lo primero que debemos ofertar es un producto que cumpla esos requisitos, cobrando un precio alto, teniendo una buena distribución, y por supuesto, todas las herramientas del mix de comunicación irán encaminadas a difundir esa idea. Deberá contratar y formar a buen personal de servicio, encontrar detallistas que tengan una buena reputación y crear mensajes de venta y publicidad que transmitan esa superioridad - «la calidad y la salud, nuestra razón de ser»».

Establecer un posicionamiento, suele llevar mucho tiempo, pero se puede perder rápidamente, por ello, las empresas deben tener cuidado para mantenerlo a través de una actuación y comunicación consistentes, adaptarlo al paso del tiempo, para adecuarlo a los cambios que se producen en los deseos y necesidades del consumidor, sin olvidar a la siempre temida competencia, aparición de productos sustitutivos, etc. 
Sin embargo, la empresa debe evitar introducir cambios bruscos que puedan confundir a los consumidores, el posicionamiento de un producto debe evolucionar gradualmente.

\subsubsection{Estrategias para cambiar de posicionamiento: el reposicionamiento}

Conocer el modo en que los consumidores perciben los productos de la competencia es determinante en la estrategia que se quiere adoptar para modificar un posicionamiento desfavorable. Podemos considerar seis estrategias diferentes (Body et al., 1972):

- Modificar el producto: podemos modificar el producto reforzando alguna característica en la que tengamos alguna desventaja.

- Modificar el peso de los atributos: comunicar al mercado la importancia de alguna característica que exhibe nuestra marca.

- Modificar las creencias sobre una marca: el mercado puede estar mal informado, debemos en este caso hacer un reposicionamiento.

- Modificar las creencias sobre las marcas competidoras: la llevaremos a cabo cuando el mercado sobrestime algunas características de nuestros competidores.

- Atraer la atención sobre atributos negados: implica la creación de un nuevo beneficio que aún no ha sido considerado por el segmento objetivo.

- Modificar el nivel requerido del atributo: podemos encontrar que ofrecemos al mercado un mayor nivel de calidad del requerido. En este caso, debemos convencer al segmento de mercado de que el nivel ofertado es el adecuado.

\section{Referencias bibliográficas}

Body, H. W., RAY, M. L. y T. Strong (1972): «An Attitudinal Framework for Advertising Strategy», Journal of Marketing, 36, 27-33.

Kotler, P. y G. Armstrong (2013): Fundamentos de marketing, 11. ed., México, Pearson Educación de México.

Munuera, J. L. y A. I. RodríGuez (2007): Estrategias de marketing, Un enfoque basado en el proceso de dirección, Madrid, ESIC Editorial.

Wind, Y. y V. Mahajan (1982): «An Integrated Approach to Portofolio Analysis», Working Paper, The Warton School, University of Pennsylvania. 



\section{CAPÍTULO 7}

\section{Diagnóstico \\ Antonio José Vallet-Bellmunt \\ e llu Vallet-Bellmunt}

\section{Contenido del capítulo}

El diagnóstico estratégico cierra la fase de análisis de todo plan de marketing. Tras un sistemático estudio de las potencialidades, riesgos y atractivo del mercado de referencia en el que la empresa quiere ubicarse, incluyendo a sus competidores principales, y sopesando los recursos y capacidades que la empresa dispone, esta podrá establecer sus objetivos y estrategias en el medio y largo plazo.

En este capítulo se explican distintas herramientas que ayudan a establecer un diagnóstico estratégico. Inicialmente veremos distintos modelos de análisis de la cartera de productos de una empresa, que permiten a los directivos enfocar sus decisiones para optimizar las inversiones en cada una de sus unidades de negocio. Finalmente, se describirá el análisis DAFO, que confronta dimensión interna y externa de la empresa, y permite de un modo muy gráfico tener una visión de los retos a los que esta se enfrenta y los frentes que deberá tener en cuenta en la toma de decisiones futuras. 
7.1. El diagnóstico y la toma de decisiones

7.2. Cartera de productos: definición y modelos de análisis

7.3. Matriz crecimiento-cuota de mercado: enfoque Boston Consulting Group

7.4. Matriz atractivo del mercado-competitividad de la empresa: enfoque McKinsey-General Electric

7.5. Análisis DAFO

Referencias bibliográficas 


\subsection{El diagnóstico y la toma de decisiones}

En un entorno cambiante y altamente competitivo los responsables de las empresas han de tomar constantemente decisiones que van a afectar, tanto en el corto como en el medio o largo plazo, a los resultados de la empresa.

Una de las principales decisiones por tomar es la que se refiere a las políticas de inversión de la compañía en referencia a los productos o servicios que fabrica, comercializa u ofrece al mercado y la posición estratégica que quiere establecer para cada uno de ellos.

Para facilitar estas decisiones las empresas se sirven de distintas metodologías que permiten establecer un diagnóstico de la situación actual que explique la idiosincrasia del mercado en general y de la posición de la empresa en él en particular.

En este capítulo abordaremos dos herramientas que se utilizan para dicho diagnóstico estratégico, a saber, los modelos de análisis de la cartera de productos de la empresa y el análisis DAFO.

\subsection{Cartera de productos: definición y modelos de análisis}

En general las empresas no se dedican a la comercialización, fabricación o prestación de un único producto o servicio. Tienen un surtido de distintos productos cuya gestión conjunta se hace necesaria en términos tanto de política comercial como financiera.

Toda decisión que se adopte con respecto a un producto afecta directamente al resto de los productos de la empresa. A partir de ahí surge el concepto de cartera de productos, que hace referencia al conjunto de bienes que una empresa comercializa. El análisis de dicha cartera de productos busca la consecución de un equilibrio entre los distintos tipos de inversiones asociadas a los mismos, y la rentabilidad y el riesgo que implican dichas decisiones de inversión.

Las decisiones referentes a la incorporación de nuevos productos, modificación de los existentes o incluso la eliminación de algunos productos de la cartera deberán estar basadas en un diagnóstico objetivo que case la situación del mercado de referencia de la empresa con la situación actual y potencial de la misma.

Los modelos de análisis de cartera de productos se basan en la observación de diversas dimensiones que pueden asociarse a los productos, a los mercados en que se comercializan y a las posiciones competitivas de las empresas que en ellos operan.

Existe una amplia variedad de modelos de análisis de cartera de productos. Los más utilizados son los denominados modelos de matrices, que generalmente son 
bidimensionales donde se compara una dimensión relativa al atractivo del mercado frente a una dimensión de la fuerza competitiva de la empresa en cada uno de sus productos.

Estos modelos siguen un proceso compuesto básicamente por cuatro fases:

- Definición de las dimensiones de análisis que se va a estudiar, tanto en lo referente al conjunto de la oferta de la empresa (producto, forma de producto, línea de producto, etc.) como al atractivo del mercado (ventas, crecimiento, etc.) y la competitividad de la empresa (cuota de mercado, por ejemplo). La decisión sobre producto a analizar busca que las comparaciones con otros productos de la competencia puedan ser homogéneas, por lo que generalmente se suele utilizar el nivel de la forma de producto.

- Medición y evaluación de las dimensiones de análisis: ventas, cuota de mercado, crecimiento, etc.

- Estudio de las interrelaciones entre las variables del modelo que deriva en un análisis integrado de todas ellas.

- Toma de decisiones u estrategias recomendables respecto a los productos que forman parte de la cartera.

Por otra parte, a la hora de utilizar un modelo u otro hemos de tener en cuenta que la dimensión mercado ha de estar enfocada con la perspectiva de la atención a los gustos y percepción de los consumidores y su visión de los productos de la empresa, así como que hemos de tener en cuenta la cartera de productos de los competidores. Del mismo modo no se puede obviar la dimensión temporal de cada una de las variables que se utilicen en dicho modelo, lo cual incide directamente a la hora de plantearse decisiones tanto en el corto como en el medio plazo respecto a la cartera de productos.

Por todo ello, las recomendaciones estratégicas resultantes de un análisis de cartera han de tomarse como orientaciones que guíen a la empresa en la toma de decisiones pero no como cuestiones de absoluto cumplimiento, pues como hemos visto, hay que contemplar otros elementos en el análisis definitivo.

\subsection{Matriz crecimiento-cuota de mercado: enfoque Boston Consulting Group}

El análisis de la cartera de productos mediante la matriz crecimiento /cuota de mercado, también llamado modelo de cartera del Boston Consulting Group o matriz BCG, ya que fue desarrollada por la firma de consultoría norteamericana Boston Consulting Group, enfoca el análisis en las dimensiones nivel de crecimiento del mercado y posición competitiva que ostenta la empresa y sus productos. 
El objetivo de la matriz puede resumirse en intentar determinar la asignación más adecuada de recursos entre los distintos negocios de la empresa, identificando aquellos que son generadores de recursos y aquellos otros que absorben recursos.

Los fundamentos de este modelo se basan en la identificación de los flujos de caja que generan los productos como un indicador del éxito de los mismos, y además se considera que dichos flujos de caja pueden ser estimados a partir de las dos variables mencionadas.

Se trata de una matriz de doble entrada en la que el eje vertical representa el grado de atractivo del mercado para una empresa, medido mediante la variable tasa de crecimiento del mercado, y en el horizontal la competitividad, medido a través de la variable cuota de mercado.

La primera variable representa el atractivo actual y futuro de la industria, así como la necesidad de fondos por parte de la empresa para financiar inversiones que permitan mantener el ritmo de crecimiento de un negocio. En la matriz se distinguen dos zonas en función de esta dimensión según que se considere alta o baja la tasa de crecimiento, entendida esta como el crecimiento en volumen de ventas del mercado en el que opera la empresa. Aunque la línea divisoria entre ambas zonas no es fija y depende de la industria en la que se opere, suele establecerse el umbral según las tasas de crecimiento de dicho mercado sean inferiores o superiores al $10 \%$ anual. El modelo asume que aquellos mercados que crecen por encima de la media son atractivos pero a su vez requieren de la empresa gran cantidad de recursos para que la empresa mantenga su posición y por tanto la empresa necesitará de liquidez y flujos de caja constantes para proceder a dichas inversiones.

La segunda variable, representada en el eje horizontal, hace referencia a la posición competitiva de nuestros productos en el mercado así como la capacidad de estos para generar recursos. Se utiliza la variable cuota de mercado entendida como el valor de la participación en el mercado respecto al competidor más importante en unidades monetarias. Para ello se lleva a cabo un cálculo relativo que consiste en obtener el cociente entre nuestras ventas y las ventas de nuestro principal competidor para cada uno de nuestros productos. Es más sencillo y práctico calcular este índice de cuota de mercado relativa que la cuota de mercado global de nuestros productos. El análisis diferencia entre posiciones favorables y desfavorables. Se considera que una empresa consigue dominar el mercado si tiene una cuota de mercado superior al menos en un $50 \%$ al más grande competidor directo. En la matriz se considerará que un producto tiene una posición competitiva favorable o desfavorable si la ratio obtenida es mayor o menor de 1,5, o dicho de otro modo, será favorable cuando se vende al menos 1,5 veces las ventas de nuestro principal competidor. El modelo asume que los productos con mayores cuotas de mercado relativas respecto a sus principales competidores alcanzan una ventaja competitiva en términos de coste y por ende de rentabilidad debido al efecto experiencia y de la obtención de economías de escala y de un mayor poder de negociación frente a proveedores y clientes, y ello se reflejará en una mayor obtención de liquidez y flujos de caja. Se produciría el efecto contrario en caso de tener una cuota de mercado relativa baja. 
Una vez definidos los ejes se construye la matriz (véase figura 28) que estará compuesta por cuatro cuadrantes, y cada uno de los productos de la empresa deberá identificarse en alguno de ellos en función de si pertenece a un mercado con tasa de crecimiento alta o baja por un lado, y si su cuota de mercado relativa respecto a su principal competidor es alta o baja. En la tabla 12 y en la figura 29 se observa un ejemplo con datos cuantitativos.

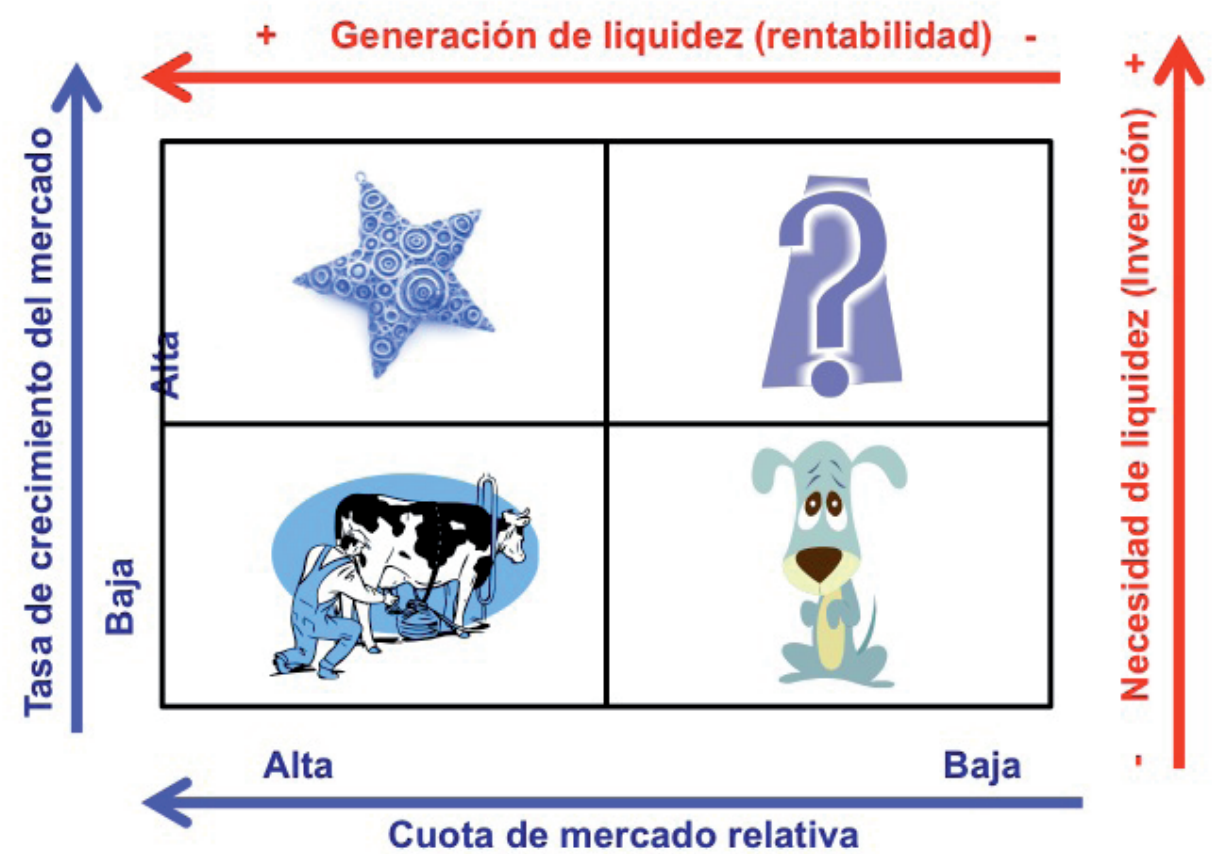

Figura 28. Matriz BCG

Fuente: Elaboración propia

Cada uno de los cuadrantes representa una tipología de productos:

- Los productos estrella son aquellos presentes en un mercado de alto crecimiento y con elevada participación en su mercado. Al objeto de mantener su posición, precisan de importantes cantidades de flujos monetarios. Por otro lado su elevada cuota de mercado, en virtud del efecto experiencia, les convierte en buenos generadores de liquidez. Representan las mejores oportunidades de inversión disponibles para la empresa; por ello todos los esfuerzos deberían ir dirigidos, al menos, a mantener y consolidar su posición actual. Combinan una posición competitiva fuerte con una expectativa de crecimiento alta. La primera dimensión hace que generen recursos, pero la segunda exige inversiones fuertes. De este modo el resultado neto suele ser equilibrado, ligeramente positivo o ligeramente negativo. Entre las inversiones destacan aquellas para proteger la cuota de mercado: reinversión de beneficios en forma de reducción de precios, mejoras de la calidad de producto, incremento de la cobertura de mercado, énfasis en la comunicación, etc. 
- Productos generadores de caja o vacas lecheras. Se caracterizan por un bajo crecimiento de su mercado y una alta cuota de participación relativa. Por tanto, poseen una sólida posición en el mercado y unas necesidades de inversión relativamente bajas merced a su débil crecimiento. Por este motivo estos productos son básicamente generadores de recursos, los cuales pueden desviarse hacia otros productos necesitados de inversiones, para el desarrollo de nuevos productos o para retribuir al capital propio y ajeno. Las inversiones a realizar en estos productos básicamente son para mantener su dominio de mercado, como por ejemplo inversiones en tecnología necesarias para mantener su liderazgo. La tendencia natural en este tipo de productos con el tiempo será el estancamiento de las ventas en el mercado, e incluso, los posibles incrementos de los costes, de modo que las reducidas inversiones realizadas sobre estos productos, pueden generar la pérdida de la posición competitiva dominante.

- Productos desastre, también llamados perro. Estos productos no generan recursos aunque tampoco los absorben por lo que pueden mantenerse en una situación de equilibrio financiero. Sin embargo, son productos con muy escasas perspectivas futuras, por lo que a pesar de que la empresa no requiera de excesivos flujos de caja para mantenerlos no es menos cierto que hay una inmovilización de recursos con su correspondiente coste de oportunidad al no poder utilizar esos recursos en actividades o productos que aporten mayor rendimiento. Con el tiempo la empresa tiende a deshacerse de ellos canalizando recursos de la desinversión hacia otros productos más prometedores. Las mejores estrategias para estos productos de bajo crecimiento y escasa participación son: $a$ ) centrarse en un segmento concreto del mercado que pueda ser dominado y a la vez protegido de una competencia más dura; $b$ ) seguir una estrategia de minimización de los costes y maximización de los flujos de caja hasta que muera el producto; $c$ ) desinvertir, vender marcas a otras empresas, $\mathrm{y} d$ ) eliminar el producto.

- Los productos interrogantes o dilemas son aquellos que están en mercados con elevado crecimiento y que tienen una débil participación en ellos. Al estar instalados en mercados de alto crecimiento sus necesidades financieras son elevadas puesto que la empresa se ve obligada en invertir en ellos para alcanzar una posición importante. Sin embargo, la correspondiente generación de flujos de caja es aún baja debido a su escasa participación relativa en el mercado. Ello implica que los flujos de caja netos generalmente sean negativos. Estos productos pueden ser necesarios para la empresa por ser complementarios a otros que se encuentren en otros cuadrantes. Dependiendo de la evolución de este tipo de productos la empresa debe elegir aquellos que tengan posibilidades de futuro y de mejora de su posición competitiva de modo que siga invirtiendo en ellos para convertirlos en productos estrellas, o bien plantearse la eliminación de los productos cuya expectativa sea negativa, y retirarlos del mercado para no malgastar más recursos en ellos. 


\begin{tabular}{|c|c|c|c|c|c|c|c|c|c|}
\hline $\begin{array}{l}\text { CARTERA } \\
\text { PRODUCTOS } \\
\text { DE LA EM- } \\
\text { PRESA }\end{array}$ & $\begin{array}{l}\text { VENTAS } \\
\text { PRODUC- } \\
\text { TO DE LA } \\
\text { EMPRESA }\end{array}$ & $\begin{array}{l}\% \text { VTAS. } \\
\text { SOBRE } \\
\text { CARTERA } \\
\text { NEGOCIO }\end{array}$ & $\begin{array}{c}\text { VENTAS } \\
\text { PRODUC- } \\
\text { TO COM- } \\
\text { PETIDOR } \\
\text { PRINCIPAL }\end{array}$ & $\begin{array}{l}\text { VENTAS } \\
\text { SECTOR } \\
\text { AÑO } \\
\text { ACTUAL }\end{array}$ & $\begin{array}{c}\text { VENTAS } \\
\text { SECTOR } \\
\text { AÑO AN- } \\
\text { TERIOR }\end{array}$ & $\begin{array}{c}\text { TASA CTO. } \\
\text { MDO. }\end{array}$ & $\begin{array}{l}\text { CUOTA } \\
\text { MDO. } \\
\text { RELATIVA }\end{array}$ & $\begin{array}{l}\text { CTO./ } \\
\text { MEDIA }\end{array}$ & $\begin{array}{c}\text { CASILLAS } \\
\text { MATRIZ } \\
\text { BCG }\end{array}$ \\
\hline & a & & $\mathrm{b}$ & $\mathrm{t}$ & $\mathrm{t}-1$ & $=(\mathrm{t}-\mathrm{t}-1) / \mathrm{t}-1$ & $=\mathrm{a} / \mathrm{b}$ & & \\
\hline PRODUCTO A & 130.000 & $31 \%$ & 60.000 & 300.000 & 260.000 & 15,38 & 2,17 & 2,52 & ESTRELLA \\
\hline PRODUCTO B & 200.000 & $48 \%$ & 350.000 & 700.000 & 680.000 & 2,94 & 0,57 & $-9,93$ & PERRO \\
\hline PRODUCTO C & 67.000 & $16 \%$ & 40.000 & 200.000 & 198.000 & 1,01 & 1,68 & $-11,86$ & VACA \\
\hline PRODUCTO D & 15.000 & $4 \%$ & 34.000 & 60.000 & 50.000 & 20,00 & 0,44 & 7,13 & DILEMA \\
\hline PRODUCTO E & 5.000 & $1 \%$ & 10.000 & 15.000 & 12.000 & 25,00 & 0,50 & 12,13 & DILEMA \\
\hline TOTALES & 417.000 & $100 \%$ & 494.000 & 1.275 .000 & 1.200 .000 & 12,87 & & & \\
\hline
\end{tabular}

Tabla 12. ¿Qué datos necesitamos para construir la matriz BCG?

Fuente: http://www.economia-excel.com/2010/08/bcg-boston-consulting-group.html

La matriz $\mathrm{BCG}$, en definitiva, permite una visión gráfica de todos los productos de la empresa y sirve para de una forma resumida obtener una valoración de la situación actual de la cartera de productos. Las empresas deben tender a manejar una cartera de productos equilibrada, habida cuenta que con el tiempo hay una tendencia a la evolución de los productos a lo largo de los distintos cuadrantes. Una descompensación de esta estructura, aunque momentáneamente pueda suponer una posición muy favorable de la cartera de productos, a medio y largo plazo presenta unos elevados riesgos para la empresa.

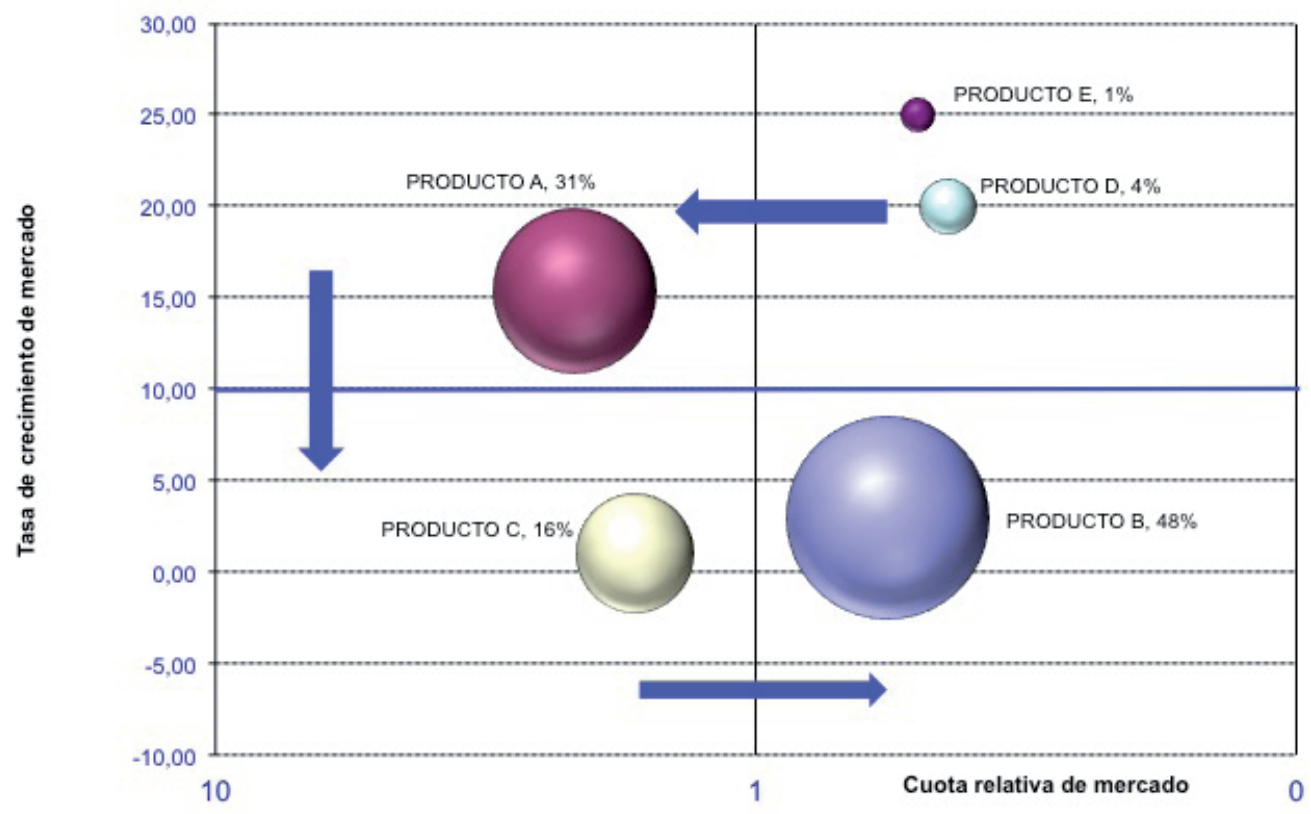

Figura 29. Ejemplo aplicado de la matriz BCG

Fuente: http://www.economia-excel.com/2010/08/bcg-boston-consulting-group.html

Finalmente, destacar que este modelo tiene la ventaja de su sencillez pero también tiene sus inconvenientes y limitaciones, a saber:

- En mercados donde el efecto experiencia no es muy destacado una mayor cuota de mercado no implica necesariamente la obtención de mayores flujos de caja. 
- Los productos desastre, a pesar de tener una baja cuota de mercado, en determinados mercados sí pueden ser rentables, fruto de la especialización o diferenciación del producto respecto a la competencia directa.

- Las unidades de medida cuota de mercado relativa y tasa de crecimiento de mercado no explican por sí solas la complejidad de un mercado concreto.

- El modelo basa su fundamentación básicamente en una perspectiva financiera de flujos de caja, obviando otras interrelaciones con otros aspectos de la empresa como distribución, compras, atención al cliente, etc.

\subsection{Matriz atractivo del mercado-competitividad de la empresa: enfoque McKinsey-General Electric}

El análisis de la cartera de productos mediante la matriz atractivo-competitividad, también llamado modelo de cartera de productos de McKinsey-General Electric o matriz GE, fruto de la colaboración entre la consultora norteamericana McKinsey y la empresa General Electric es también bidimensional. Enfoca el análisis en el atractivo de la industria y la fortaleza competitiva de la empresa, respectivamente.

Las dos dimensiones de la matriz GE pueden considerarse como variables multicriterio. La evaluación de las mismas se basa tanto en criterios cuantitativos como en otros de carácter cualitativo. Dicho de otro modo, la medición y evaluación de las dimensiones atractivo de la industria y fortaleza competitiva de la empresa engloba el estudio previo de un conjunto de variables de mercado, financieras, económica, tecnológicas y del entorno que afectan a la empresa y su mercado.

La construcción de la matriz atractivo-competitividad requiere de 4 fases diferenciadas:

- Identificación de los factores relevantes externos e internos que expliquen cada una de las dos dimensiones (véase tabla 13). No existe un listado rígido de factores. Cada empresa debe establecer cuáles explican mejor su mercado y su posición en él. La dimensión de atractivo de la industria se obtiene a través del análisis del tamaño de la industria o sector, del nivel de crecimiento del mercado, de los niveles de evolución de los precios, de la diversidad de oferentes, de la estructura competitiva que existe en el mercado, de la rentabilidad del mismo, y de otros factores como puede ser el papel desarrollado por la innovación tecnológica. Por el otro lado, la dimensión de fortaleza de la empresa se establece en base a unas variables internas, entre las que destacan: el tamaño de la empresa, el nivel de crecimiento propio de la empresa, la cuota de mercado ostentada por la empresa para la categoría de producto, la posición competitiva de la empresa, la rentabilidad del producto, los márgenes aplicados sobre el mismo, la tecnología utilizada en su producción, la imagen del producto en el mercado, y como no, las fortalezas y debilidades que el producto presenta. 
- La evaluación y ponderación de estos factores (véase tabla 14): normalmente se realiza una evaluación en una escala del 1 al 5 para expresar valores mínimo y máximo de cada uno de los factores tanto para el atractivo como para la competitividad, y se establece una ponderación de cada uno de los factores para obtener un resultado final. De esta forma se pueden tener unos criterios muy claros sobre el atractivo de la industria y la fortaleza de la empresa sumando los valores de cada uno de los ítems analizados. Cada una de las dimensiones se clasifica en tres niveles: alto, medio y bajo para la variable Atractivo del mercado, y fuerte, media o débil para la variable Posición competitiva de los productos de la empresa.

\section{FACTORES DETERMINANTES DEL ATRACTIVO DEL MERCADO Y LA POSICIÓN COMPETITIVA DE LA CARTERA DE PRODUCTOS ATRACTIVO DE MERCADO POSICIÓN COMPETITIVA}

\section{Factores de mercado}

- Tamaño (euros o unidades)
- Tasa de crecimiento anual
- Poder de negociación de los proveedores
y clientes

- Cuota de mercado

- Cuota de mercado en los segmentos

- Poder de negociación de sus clientes y de sus proveedores

\section{Factores competitivos}

- Grado de concentración

- Tasa de cambio de su cuota de mercado

- Entradas y salidas

- Vulnerabilidad ante la nueva tecnología

- Sustitución por nueva tecnología

- Niveles y tipos de integración

- Niveles y tipos de integración

- Segmentos en los que trabaja

\section{Factores financieros y económicos}

- Márgenes de contribución

- Barreras de entrada y salida

- Utilización de la capacidad de producción del sector
- Sus márgenes

- Economías de la empresa

- Utilización de la capacidad de la producción de la empresa

\section{Factores tecnológicos}

- Madurez y volatilidad

- Habilidades tecnológicas

- Complejidad

- Protección de patentes

- Tecnología de producción necesaria

- Nivel de destreza

\section{Factores políticos del entorno}

- Leyes y normativas

- Factores humanos
- Nivel de adaptación

- Relaciones sociales interempresas

Tabla 13. Ejemplo de factores explicativos del atractivo del mercado y la posición competitiva de la empresa

Fuente: Abell y Hammond (1979) 
- El posicionamiento de los negocios en la matriz (véase figura 30): cada uno de los productos de la empresa se identifica dentro de los 9 cuadrantes posibles de la matriz en función de los valores obtenidos. Cada círculo representa un artículo de la empresa, el tamaño el volumen del mercado de un producto, y las porciones la cuota de mercado del producto. El producto A estaría en una posición media.

\begin{tabular}{|c|c|c|c|}
\hline \multicolumn{4}{|c|}{$\begin{array}{c}\text { EVALUACIÓN Y PONDERACIÓN DE LOS FACTORES INTERNOS } \\
\text { Y EXTERNOS PARA UN PRODUCTO «A» }\end{array}$} \\
\hline ATRACTIVO DE MERCADO & PONDERACIÓN & $\begin{array}{l}\text { VALOR } \\
\text { (DE } 1 \text { A 5) }\end{array}$ & TOTAL \\
\hline - Tamaño del mercado & 25 & 3 & 75 \\
\hline - Grado de concentración & 15 & 1 & 15 \\
\hline - Márgenes de contribución & 15 & 4 & 60 \\
\hline - Barreras de entrada & 10 & 3 & 30 \\
\hline $\begin{array}{l}\text { - Tecnología e innovación } \\
\text { necesaria }\end{array}$ & 20 & 2 & 40 \\
\hline - Complejidad de la legislación & 15 & 4 & 60 \\
\hline TOTAL & 100 & & 280 \\
\hline POSICIÓN COMPETITIVA & PONDERACIÓN & $\begin{array}{l}\text { VALOR } \\
\text { (DE } 1 \text { A 5) }\end{array}$ & TOTAL \\
\hline - Cuota de mercado relativa & 25 & 2 & 50 \\
\hline $\begin{array}{l}\text { - Poder negociación frente a } \\
\text { proveedores }\end{array}$ & 15 & 2 & 30 \\
\hline - Coste unitario & 10 & 3 & 30 \\
\hline - Márgenes & 10 & 3 & 30 \\
\hline - Notoriedad e imagen de marca & 15 & 3 & 45 \\
\hline - Protección de patentes & 20 & 2 & 40 \\
\hline $\begin{array}{l}\text { - Relaciones sociales } \\
\text { interempresa }\end{array}$ & 5 & 4 & 20 \\
\hline TOTAL & 100 & & 245 \\
\hline
\end{tabular}

Tabla 14. Ejemplo de evaluación y ponderación de los factores que miden el atractivo del mercado y la posición competitiva para elaborar una matriz GE

Fuente: Elaboración propia

- Recomendaciones estratégicas (véase figura 31): en función del área de la matriz donde se encuentra el negocio. La matriz de General Electric nos muestra las opciones estratégicas más adecuadas para cada una de las nueve posibles situaciones. 


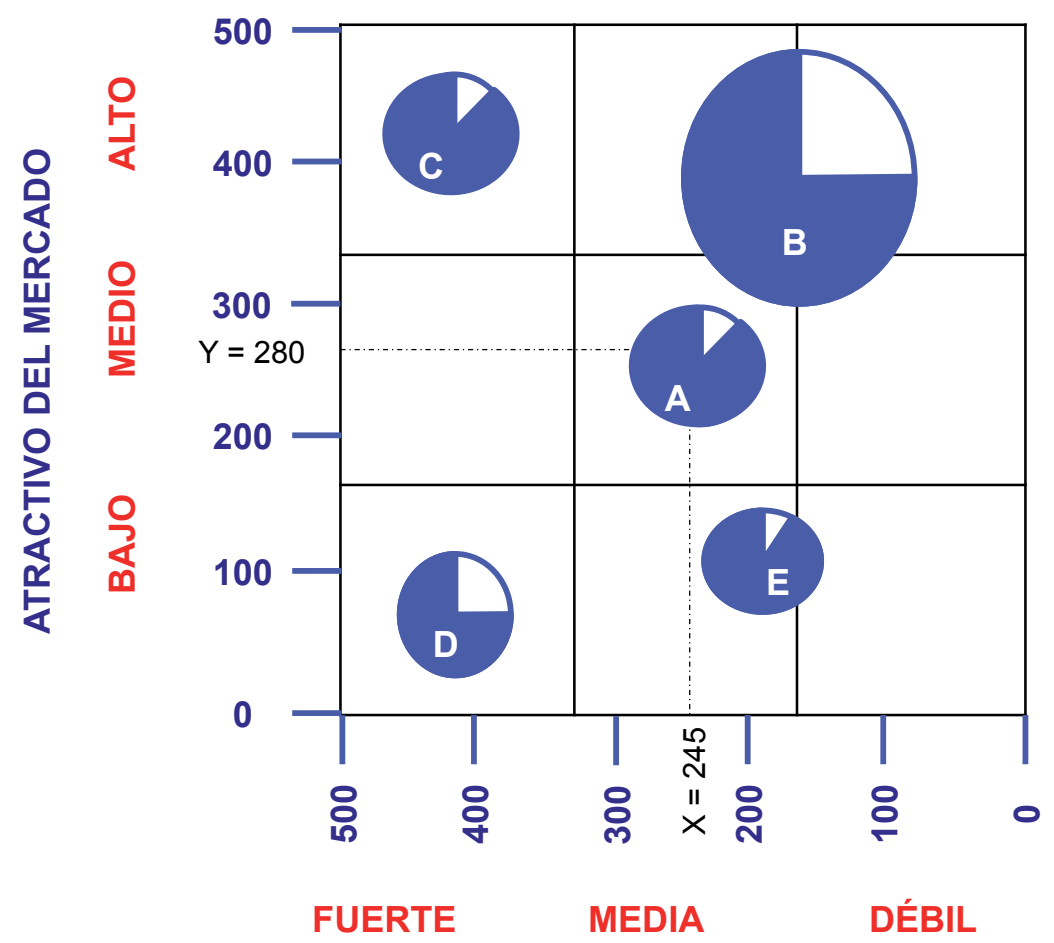

POSICIÓN COMPETITIVA DE LOS PRODUCTOS DE LA EMPRESA

Figura 30. Ejemplo del posicionamiento de los productos de una empresa en la matriz GE Fuente: Elaboración propia

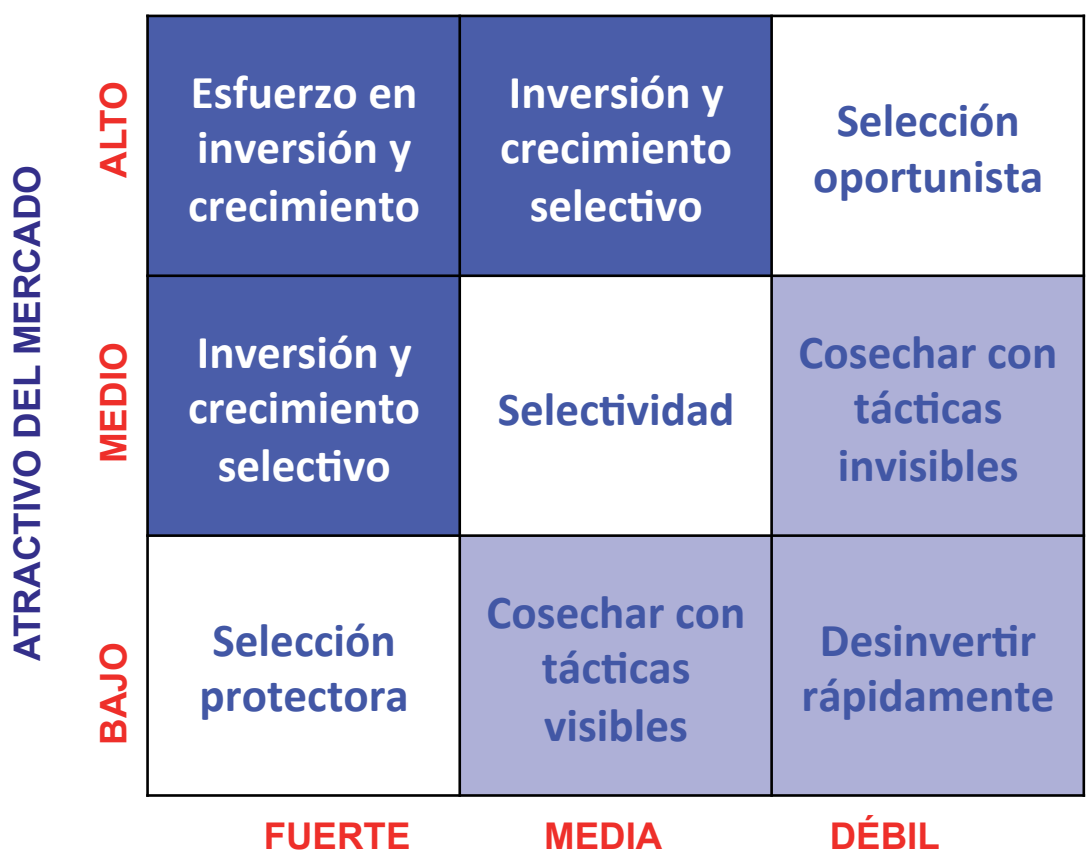

\section{POSICIÓN COMPETITIVA DE LOS PRODUCTOS DE LA EMPRESA}

Figura 31. Matriz GE: Recomendaciones estratégicas

Fuente: Elaboración propia en base a Kotler et al. (2006) 
En la diagonal con las situaciones intermedias, se caracteriza por la estrategia común de Selectividad en las inversiones, buscando la consecución de ahorro en recursos de modo que se aconseja invertir selectivamente y especializarse solo en mercados que estén al menos estabilizados o en aquellos en los que aún se pueda obtener alguna rentabilidad. La Selección protectora hace referencia a la decisión de tratar de sacar el máximo rendimiento ante mercados que claramente van a la baja mientras que la Selección oportunista implica que se priorizarán aquellos negocios que posean un potencial de crecimiento mayor para invertir y mejorar su posición renunciado a aquellos en lo que no tiene previsto crecer en el futuro.

Los productos que se encuentren en la matriz por debajo de la diagonal, debemos seguir una estrategia centrada en la consecución de beneficios, asociados a una retirada más o menos rápida del mercado, en función de la situación concreta. Se habla de Cosechar cuando hay desinversión controlada y se mantiene el producto en los niveles mínimos de coste con la esperanza de obtener la mayor rentabilidad a corto plazo protegiendo la posición de aquellos productos ubicados en segmentos rentables, diferenciando en el uso de tácticas invisibles o visibles dependiendo si se disimula o disfraza la salida del mercado o bien si se anuncia esta explícitamente. Finalmente, se habla de una Desinversión rápida cuando se procede bien a la venta o eliminación del producto, lo cual deberá hacerse de modo que se perjudique lo menos posible a la cartera de la empresa y a su imagen frente a sus actuales consumidores en caso de venta.

Las posiciones que se encuentran por encima de la diagonal nos presentan las situaciones favorables, que conllevan realizar una mayor inversión. Los productos que están en el primer cuadrante requieren de un Esfuerzo en inversión y crecimiento puesto que ostentan la posición de liderazgo en un mercado muy atractivo. Deben tener prioridad en cuanto a la asignación de recursos con el fin de maximizar las inmejorables perspectivas que poseen y sostener sus puntos fuertes. Por otro lado, los productos que estén situados en una posición media requerirán de una Inversión y crecimiento selectivo de modo que se debe proceder a la identificación de los segmentos con más alto crecimiento y a la inversión de recursos suficientes para mantener al menos la posición actual y solventar los puntos débiles.

Como se ha visto, la matriz atractivo del mercado- competitividad (Mckinsey-G. E.) es más completa que la matriz crecimiento-cuota de mercado (BCG) porque se ciñe más a la idiosincrasia del mercado que se estudia al tener en cuenta más variables. Sin embargo, también tiene sus inconvenientes y limitaciones, a saber:

- La selección de las variables y factores que explican tanto el atractivo del mercado como los puntos fuertes y débiles de la empresa son difíciles de establecer y se corre el riesgo de caer en subjetividad de criterio por parte de los dirigentes de la empresa al seleccionarlos y cuantificarlos.

- Al manejar tanta información hay unos costes de obtención, estudio y selección de los datos tanto desde la perspectiva económica como en términos de tiempo. 


\subsection{Análisis DAFO}

Aparte de los modelos de análisis de la cartera de productos existen otras herramientas que sirven a los dirigentes de las empresas para establecer un diagnóstico de la situación de la empresa y del mercado donde opera y que podrán utilizar para establecer sus decisiones estratégicas.

El método más comúnmente utilizado es el denominado Análisis DAFO (sigla de Debilidades, Amenazas, Fortalezas, Oportunidades).

Se trata de identificar todos aquellos elementos o factores que influyen directamente en la empresa, tanto desde una perspectiva externa como interna (véase figura 32). Dada su sencillez es la herramienta estratégica por excelencia más utilizada para conocer la situación real en que se encuentra la organización.

En la fase de análisis de todo plan de marketing hay una identificación de los factores externos o del entorno que pueden afectar a una compañía, también llamado análisis externo. Aquí se engloban tanto aspectos del Macroentorno o entorno general como por ejemplo la evolución económica, la regulación o la situación sociopolítica del país, como elementos del Microentorno o entorno específico más cercanos al sector donde radica la empresa como gustos de los consumidores, nivel de competencia, tipos de distribuidores, etc.

Todos esos factores vienen de fuera de la empresa y van a incidir positiva o negativamente en la misma, dependiendo de la capacidad de adaptación de la empresa o de sus circunstancias. Se dice que la empresa se encuentra ante una Oportunidad del entorno cuando algún factor que le viene dado de fuera le va a resultar favorable si lo sabe aprovechar. Ejemplo de oportunidades del entorno: cambio de hábitos de consumo favorable a los productos/servicios del sector, decreciente poder negociador de los clientes, crecimiento dinámico del mercado, políticas fiscales favorables, etc.

Por otro lado, hablaremos de Amenaza del entorno cuando un elemento exógeno a la empresa le pueda influir negativamente. Ejemplo de amenazas del entorno: aparición de nuevos competidores, aumento de la demanda de productos sustitutivos, nuevos costes relacionados con políticas medioambientales, recesión económica, etc.

Tanto las oportunidades como las amenazas inciden en todas las empresas del sector en el que trabaja la empresa, si bien no afectará a todas por igual habida cuenta que cada una de las empresas tiene su propia idiosincrasia.

Del mismo modo que el análisis externo, las empresas a la hora de establecer sus objetivos y estrategias han de proceder a realizar un análisis interno, es decir, identificar, valorar y evaluar todos aquellos factores de dentro de la empresa que le supongan tener una ventaja o una desventaja competitiva frente a los competidores en el medio y corto plazo. De este modo hablaremos de Fortaleza o punto fuerte de una empresa cuando nos refiramos a una característica o factor diferencial de la 
empresa con respecto a sus competidores especialmente valorada por los consumidores. Ejemplos de fortalezas: cualificación y experiencia del equipo directivo, aumento de la participación en el mercado, marca reconocida y posicionada en los clientes, costes de estructura bajos, etc.

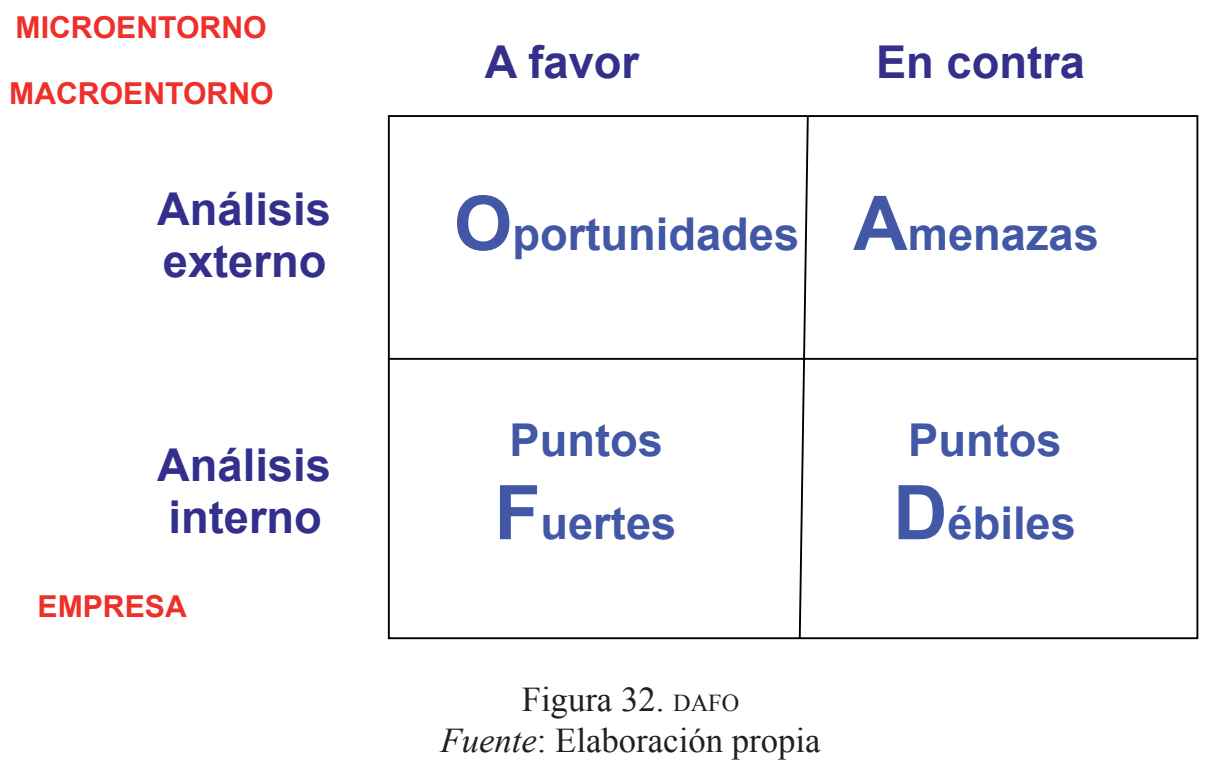

En contraposición define una Debilidad o punto débil de una empresa como aquella carencia o rasgo negativo diferencial que la empresa mantenga con relación a la competencia. Ejemplos de debilidades: dificultades para el acceso a la financiación, elevados costes de estructura, red de distribución débil, falta de innovación, baja cualificación del personal, etc.

Las fortalezas y debilidades son dos factores controlables por la empresa dado que tiene capacidad de influir sobre ellos. En cambio, las oportunidades y amenazas son factores no controlables en el sentido que le vienen dados a la empresa desde el exterior.

Una vez identificados los factores que influyen en la empresa se construye lo que se denomina matriz DAFO (véase figura 32) que incluye en una tabla tanto los elementos externos (amenazas y oportunidades) como los internos (fortalezas y debilidades).

Por último, los dirigentes han de plantearse las siguientes cuestiones: ¿Cómo se pueden explotar y mantener las fortalezas? ¿Cómo se puede aprovechar cada oportunidad? ¿Cómo se puede detener o reducir cada debilidad? ¿Cómo se puede defender de cada amenaza?

Un análisis DAFO se puede aplicar a todo tipo de niveles de agregación. Puede hacerse de una empresa, de un departamento, de un grupo de empresas, de un sector o incluso de un organismo público. 


\section{Referencias bibliográficas}

Abell, D. F. y J. S. Hammond (1979): Strategic Market Planning: problems and analytical approaches, Englewood Cliffs (NY), Prentice-Hall.

Armstrong, G., Kotler, P., Merino, M. J., Pintado, T. y J. M. Juan (2011): Introducción al marketing, 3. ${ }^{\mathrm{a}}$ ed., Madrid, Pearson Educación.

LAmbin, J. J. (2003): Marketing Estratégico, Madrid, ESIC Editorial.

Munuera, J. L. y A. I. Rodríguez (2007): Estrategias de marketing, Un enfoque basado en el proceso de dirección, Madrid, ESIC Editorial. 


\section{Fijación de objetivos y estrategias de marketing Valentín Gallart-Camahort y Pilar Monte-Collado}

\section{Contenido del capítulo}

Una vez analizada la situación en la que se encuentra la empresa, llega el momento de planificar la estrategia de marketing. Para ello se verán las distintas fases del proceso de planificación, empezando por la definición de la misión de la empresa, pasando por el establecimiento de objetivos hasta llegar a las estrategias de marketing que se ofrecen a la empresa para alcanzar sus metas. Se detallarán, de esta manera, las posibilidades estratégicas existentes en base a la ventaja competitiva buscada, las estrategias en relación a los competidores y al entorno, para acabar analizando las estrategias de crecimiento, las de mantenimiento y las de desinversión. 
8.1. La planificación en la empresa

8.2. La misión de la organización y los objetivos corporativos

8.2.1. La misión de la empresa

8.2.2. Los objetivos corporativos

8.3. Objetivos de marketing

8.4. Estrategias de marketing

8.4.1. Concepto de estrategia

8.4.2. Clasificación de las estrategias de marketing

8.5. Estrategias genéricas de marketing respecto a la ventaja competitiva buscada

8.5.1. Estrategia y ventaja competitiva

8.5.2. Liderazgo en precios

8.5.3. Diferenciación

8.5.4. Enfoque o especialización

8.6. Estrategias competitivas en relación al entorno y en relación a los competidores

8.6.1. Estrategias competitivas en relación al entorno

8.6.1.1. Estrategia prospectora o exploradora

8.6.1.2. Estrategia analizadora

8.6.1.3. Estrategia defensora

8.6.1.4. Estrategia reactiva

8.6.2. Estrategias competitivas en relación a los competidores

8.6.2.1. Estrategias de líder

8.6.2.2. Estrategias de retador

8.6.2.3. Estrategias de seguidor

8.6.2.4. Estrategia para especialistas en nichos

8.7. Estrategias de crecimiento o inversión, de mantenimiento y de desinversión

8.7.1. Estrategias de crecimiento o inversión

8.7.1.1. Estrategias de penetración de mercado

8.7.1.2. Estrategias de desarrollo de productos

8.7.1.3. Estrategias de desarrollo de nuevos mercados

8.7.1.4. Estrategias de crecimiento diversificado e integración

8.7.2. Estrategias de mantenimiento y de desinversión

Referencias bibliográficas 


\subsection{La planificación en la empresa}

En el mundo de los negocios se suele decir que hay tres tipos de empresas: las que hacen que las cosas ocurran, las que miran cómo ocurren y las que se preguntan qué ha ocurrido. La empresa que quiera tener éxito deberá saber cómo adaptarse a los cambios del mercado y cómo responder a ellos.

Como la evolución de los mercados es constante, la empresa tendrá que realizar una planificación estratégica orientada hacia el mercado. Una vez establecidos los objetivos, es decir, la meta que quiera alcanzar la empresa, se deberá desarrollar una estrategia o un plan de juego adecuado para tener éxito en la consecución a largo plazo de dichos objetivos.

En el presente capítulo veremos el establecimiento de objetivos y las distintas estrategias de marketing que una empresa puede seguir a fin de alcanzarlos.

\subsection{La misión de la organización y los objetivos corporativos}

\subsubsection{La misión de la empresa}

La misión es una declaración formal del propósito general de la empresa, es decir, qué desea esta conseguir en el tiempo y en el espacio. Es el punto de partida del proceso de planificación estratégica. Siguiendo a Navas y Guerras (2001): «La misión representa la identidad y personalidad de la empresa, en el momento actual y de cara al futuro, desde un punto de vista muy general». Así pues, la misión debe dar respuesta a la pregunta de por qué se ha creado la empresa, en qué negocio se está, quiénes son sus clientes, etc. Tal y como apunta Kotler (1992), en el momento de la creación, la misión suele estar clara, pero con el tiempo puede ocurrir que la empresa crezca, que añada nuevos productos, que se dirija a nuevos mercados, etc. Así, cuando la dirección sienta que la organización está cambiando, habrá llegado el momento de renovar su misión.

Siguiendo con la opinión de Kotler (1992), la definición de la misión de la empresa debe observar cinco elementos. En primer lugar, debe tener en cuenta la historia de la propia empresa, de sus objetivos, políticas y progresos. El segundo aspecto son las preferencias, es decir, los objetivos y visiones personales de sus dirigentes y propietarios. También deberá observar su entorno, las amenazas y oportunidades que este le puede presentar. Otro aspecto importante son los recursos de los que se dispone, ya que estos determinarán qué logros son posibles y cuáles hay que desechar. Por último, la empresa deberá basar su misión en sus ventajas competitivas.

Por otra parte, una correcta definición de la misión se da cuando en ella se establecen un número limitado de objetivos, se definen los campos más importantes en los cuales va a competir la empresa (ubicación, público objetivo, área geográfica, 
etc.), es motivadora, se define la política de la misma y cómo se deben comportar los empleados en sus relaciones con el entorno y se proporciona una visión y dirección a seguir durante los próximos años.

\subsubsection{Los objetivos corporativos}

Después de que la empresa haya establecido cuál es su misión, deberá definir unos objetivos de carácter amplio que contemplen el largo y medio plazo y que estén enfocados a alcanzar dicha misión. Estas metas, en principio, no deben tener un contenido cuantificable o bien lo tendrán únicamente de manera muy amplia. Además, se deberán tener en cuenta distintos propósitos como pueden ser la rentabilidad, el crecimiento de las ventas, la mejora de la cuota de mercado, la innovación, etc., ya que, como es lógico, una empresa no se constituye con el fin de alcanzar solo un objetivo. Estas metas corporativas han de servir de guía y orientación para las actuaciones de la empresa.

Para alcanzar los objetivos a largo plazo la empresa tendrá que establecer otros más específicos a corto plazo, que se verán reflejados en el plan de empresa. Este tipo de objetivos, a diferencia de los anteriores, deberán ser cuantificables y deberán contemplar su alcance, así como el periodo de tiempo en el que se deben alcanzar.

Los objetivos a corto plazo son más concretos y, por tanto, esta concreción hace que sean más fáciles de gestionar y de controlar, puesto que estarán definidos cuantitativamente. Así, por ejemplo, un objetivo general del Banco de Santander Central Hispano puede ser el convertirse en un banco de referencia en Europa, mientras que uno más concreto y a un plazo más inmediato puede ser el aumentar la cobertura en determinados países europeos, para lo que se establecerán concretamente para esos países: cuotas de mercado, número de oficinas, cifras de ventas por productos, servicios, etc.

\subsection{Objetivos de marketing}

Los objetivos de marketing tienen un carácter más funcional y se establecen a menor plazo que los corporativos. Su importancia radica, entre otras cosas, en que de ellos dependerá que la estrategia se implante con éxito. Deberán ser cuantificables y no contradecir lo establecido en la misión de la empresa y en sus objetivos corporativos, puesto que su finalidad es que estos se lleven a la práctica. Son, por tanto, aspiraciones concretas para el corto plazo.

A la hora de establecerlos, tal como indica Burk (2003), se deberán tener en cuenta algunos requisitos:

- Cuantificables: los objetivos de marketing deben ser concretos y cuantificables, de manera que se pueda realizar el control de los mismos. 
- Periodo de tiempo y lugar: deberán estar definidos claramente para un plazo de tiempo determinado y para unos mercados concretos.

- Realistas: deberán tener en cuenta tanto los factores externos como los recursos de la empresa de forma que sean asequibles y, por tanto, estimulantes.

- Consistentes: siempre deberán estar alineados y nunca contradecir lo establecido por la misión y por los objetivos corporativos, es decir, serán coherentes con ellos.

- Ambiciosos: deberán tener ambición, pero dentro de lo que es asequible para la empresa.

Así pues, los objetivos de marketing estarán estrechamente ligados al propósito general de la empresa y coordinados con los objetivos corporativos.

Se pueden distinguir distintos objetivos:

- De relaciones. Son los que hacen referencia a la relación de la empresa con su entorno más próximo. Así, se podrán establecer metas relativas a la creación de relaciones con los clientes, mantenimiento e intensificación de las mismas, cuántos clientes se deben captar en un periodo determinado de tiempo, fidelización de los mismos, cómo debe mejorar la tasa de mantenimiento de clientes, satisfacción de los consumidores, relaciones con proveedores, con distribuidores, etc.

- Comerciales. Son los relacionados con la gestión del producto, precio, distribución y comunicación. Pueden venir referidos a las ventas por periodo de tiempo, por mercados, por línea de productos, cuotas de mercado, gestión de la cartera, gestión de pedidos, aumento del reconocimiento de marca, etc.

- Económicos de marketing. Están relacionados con la actividad comercial y se centran en beneficios, rentabilidades y márgenes por productos y mercados, rentabilidad de la inversión en actividades de marketing, etc.

\subsection{Estrategias de marketing}

\subsubsection{Concepto de estrategia}

Una vez se han identificado los competidores y se ha hecho una evaluación de cómo son, cuáles son sus características, cómo actúan en el mercado, etc., la empresa deberá diseñar sus estrategias de marketing dirigidas a aumentar su ventaja competitiva ofreciendo más valor al cliente que el resto de empresas participantes. Esta ventaja tendrá que ser sostenible en el tiempo, por lo que se deberá tener en cuenta que la empresa tenga capacidad suficiente para defenderla. 
Como se verá a lo largo de este capítulo, no hay una única estrategia que pueda considerarse válida o que garantice el éxito para todas las empresas, sino que, más bien al contrario, cada una de ellas deberá tener en cuenta cuál es su posición en el mercado, cuáles son sus características, qué objetivos se pretenden alcanzar, qué oportunidades se le presentan y con qué recursos cuenta para llevar adelante su estrategia. Es más, incluso se puede decir que una misma empresa puede utilizar diferentes estrategias en función de sus distintos negocios o productos.

De acuerdo con la definición de Navas y Guerras (2001) «La estrategia competitiva es la forma mediante la cual una empresa se enfrenta a sus competidores para intentar obtener un rendimiento superior al de ellos». Así pues, la empresa que quiera tener éxito, tendrá que definir correctamente cuál es la estrategia más adecuada para alcanzar sus objetivos.

Munuera y Rodríguez (2007) definen la estrategia empresarial como «Un conjunto de acciones encaminadas a la consecución de una ventaja competitiva sostenible en el tiempo y defendible frente a la competencia, mediante la adecuación entre los recursos y capacidades de la empresa y el entorno en el cual opera, y a fin de satisfacer los objetivos de los múltiples grupos participantes en ella».

\subsubsection{Clasificación de las estrategias de marketing}

Las diferentes estrategias por las que puede optar una empresa podrían agruparse en diferentes ejes, en función de la propuesta de Lambin, Gallucci y Sicurello (2009). Según estos autores, en primer lugar, se debería proceder a la elección de una estrategia que tenga en cuenta la ventaja competitiva que pueda defender la empresa. Por otra parte, se debe considerar el aspecto de crecimiento empresarial, presente en la mayor parte de las estrategias de las empresas. Y, por último, definir la posición y el comportamiento de la empresa en relación con los competidores. Así, las primeras estrategias que se van a plantear se fundamentan en la clasificación realizada por Porter (1982) y se basan en la ventaja competitiva que la empresa pretende conseguir. Se verán, así, estrategias basadas en el coste (traducidas en estrategias de liderazgo en precio para el mercado), en la diferenciación y en el enfoque o especialización.

En el segundo bloque se verán las estrategias definidas por Miles y Snow (1978) en función de la actitud de la empresa ante su entorno y las de Kotler y Sighn (1981) que tienen en cuenta el comportamiento de la empresa con respecto a su competencia (líder, retador, seguidor o especialista).

Por último, se analizarán las estrategias de Ansoff (1965) basadas en las distintas opciones de crecimiento que puede adoptar la empresa en función de si se dirige a nuevos mercados o se mantiene en los que ya actúa y si, además, lo hace con sus productos actuales o si, por el contrario, opta por el desarrollo de nuevos productos. También se verán las estrategias de sostenimiento, cosecha y eliminación que puede seguir la empresa según los recursos que destine a la inversión. 


\subsection{Estrategias genéricas de marketing respecto a la ventaja competitiva buscada}

\subsubsection{Estrategia y ventaja competitiva}

De acuerdo con lo visto en los puntos anteriores, podemos decir que la estrategia genérica es el conjunto de acciones que la empresa realiza para obtener una ventaja competitiva.

Por su parte, diremos que una ventaja competitiva está constituida por aquellas características de las marcas o de los productos de la empresa que hacen que esta tenga algún tipo de superioridad sobre el resto de empresas del mercado, principalmente, sobre su competencia más directa. Además, esta ventaja deberá ser sostenible en el tiempo para que resulte interesante para la empresa.

Así, a pesar de que las ventajas competitivas pueden ser de muchos tipos, se pueden agrupar en las que provienen del ámbito interno de la empresa y las que tienen su origen en factores externos a la misma.

Las ventajas competitivas internas provienen de los procesos de compra y aprovisionamiento, de la fabricación, de la gestión o de la distribución del producto. Todo esto puede llevar a que el producto tenga un coste de fabricación unitario menor que el de la competencia.

Por su parte, las ventajas competitivas externas se originan gracias a que el producto tenga una cualidad propia que lo diferencie de la competencia y que sea identificado y apreciado por parte del consumidor por aportarle valor.

Porter (1982) definió tres estrategias competitivas básicas que podían adoptar las empresas en su participación en el mercado. Estas estrategias las consideró como ganadoras: estrategia de líder en costes, diferenciación de producto y enfoque; mientras que el quedarse a medio camino entre ellas es considerada como una opción perdedora para la empresa, ya que supone, más bien, ausencia de una estrategia competitiva clara. En este último caso, las empresas intentan ser buenas en todos los aspectos y acaban no consiguiendo su objetivo en ninguno de ellos. En los siguientes epígrafes vamos a ver las tres estrategias competitivas básicas definidas por este autor y su aplicación en el campo del marketing.

\subsubsection{Liderazgo en precios}

Con la estrategia de bajo coste definida por Porter (1982) la empresa persigue fabricar sus productos a un coste inferior al de la competencia. Esta estrategia se traslada al ámbito del marketing como estrategia de liderazgo en precios, ya que tener una ventaja en costes supondrá el poder rebajar los precios, sin llegar al extremo de no tener beneficios, pero dejando sin margen a sus competidores. Esto 
supone que si los costes de la empresa son bajos, los beneficios podrán ser mayores, lo que permitirá un margen para llevar a cabo una buena política de precios.

Para llevar a cabo esta estrategia la empresa deberá alcanzar costes de producción y distribución más bajos que los de la competencia, de manera que esto le permita bajar sus precios y aumentar, a la vez, su cuota de mercado, es decir, aumentar las ventas de sus productos. Aplicar esta estrategia supondrá conseguir una estructura de costes lo más reducida, sencilla y ligera posible en una empresa, lo que en ocasiones puede llevar a una reconfiguración de la forma de desarrollar todas sus actividades que permita soportar estos costes reducidos.

Por tanto, para conseguir aplicar esta estrategia con éxito, la empresa deberá ser buena en ingeniería, compras, fabricación y distribución, ya que estos son los principales campos en los que puede conseguir la reducción de costes. La curva de experiencia de la propia empresa en la fabricación y las economías de escala también pueden contribuir en gran manera a la perseguida disminución de costes, así como la fabricación de productos estándar para facilitar la producción, tener una cartera de productos relacionados de forma que los costes se distribuyan entre ellos, atender a grandes segmentos del mercado para generar grandes volúmenes de ventas, lograr la implantación de una cultura de reducción de costes entre el personal de la empresa, reducir costes en ventas, marketing y publicidad, etc.

El liderazgo en precios puede llevar a la empresa a obtener una mayor participación en el mercado, incrementando sus ventas. Llegados a esta situación, si algún competidor opta por entrar en una guerra de precios, la empresa siempre estará en mejor disposición para salir victoriosa de la misma.

Esta estrategia puede ser la adecuada para situaciones en las que no haya una gran diferencia entre las diversas opciones disponibles en el mercado o cuando el consumidor presente una elevada sensibilidad hacia el factor precio.

Un riesgo de poner en práctica una estrategia de costes es que en un momento determinado, el precio puede dejar de ser el único factor o el más importante por el cual se rige el consumidor, optando por otras características del producto diferentes al precio.

Algunos ejemplos de esta estrategia los vemos en empresas como Max Descuento o Zailand en mobiliario y decoración para el hogar; El Corte Chino en bazar; Media Markt en electrodomésticos y electrónica; Aldi, Dia o Lidl en alimentación; Ryanair o Easy Jet en aerolíneas...

\subsubsection{Diferenciación}

Como se ha dicho, las ventajas competitivas externas pueden conducir a una estrategia de diferenciación mediante la cual la empresa comercialice un producto que sea percibido por los consumidores como único, especial o superior gracias a 
sus características. En mayor o menor medida, cualquier producto es susceptible de diferenciación. Solo tenemos que pensar en un producto como el agua mineral y la cantidad de marcas que ofrecen este tipo de producto embotellado. En el otro extremo tenemos productos como los automóviles, los relojes, los instrumentos musicales, etc., que permiten una mayor diferenciación con respecto a los de la competencia.

La empresa se concentra en la creación de una tipología de producto altamente diferenciada, desarrollando un programa de marketing adecuado a la misma. Si la diferencia del producto es apreciada de manera especial por los clientes, la empresa podrá cobrar por ellos un precio más alto.

Siguiendo la clasificación realizada por Kotler (1992) hay diversas maneras por las cuales una empresa puede diferenciar su oferta:

- Diferenciación a través del producto: si bien existen productos muy estandarizados que permiten menores posibilidades de diferenciación, hay otros en los cuales es posible encontrar grandes diferencias, tales como automóviles, muebles, vinos, etc. Una forma de conseguir la diferenciación es a través de las distintas versiones que se pueden ofrecer de un producto, añadiéndole características extras, tal y como hacen los fabricantes de automóviles. Otra opción para la diferenciación viene dada por el nivel de calidad, ya que si se consigue fabricar un producto de una alta calidad se podrá vender a precios más altos, lo que supondrá mayor rentabilidad para la empresa. Esta opción es la seguida por determinadas marcas que gozan de un reconocido prestigio en el mercado, tales como Jaguar en automóviles, los hoteles Ritz, Loewe en bolsos y complementos, etc. La fiabilidad y la duración intentan aumentar la confianza que el consumidor tiene en determinados productos, incrementando la seguridad en su uso. Un ejemplo son las maletas y bolsos de viaje de Samsonite que se ha sabido diferenciar ofreciendo una durabilidad, fuerza y robustez por encima de sus competidores, acompañado de un diseño moderno y actual. El estilo, la innovación o el diseño son otros aspectos a tener en cuenta para conseguir la diferenciación del producto.

- Diferenciación a través de los servicios. En ocasiones no es fácil diferenciar un producto por su aspecto físico y las empresas acuden a la diferenciación aumentando el valor a través de los servicios añadidos. De esta manera, la puntualidad y la precisión en la entrega, la instalación o la puesta en funcionamiento del producto, un buen servicio de atención al cliente, garantías, la asesoría técnica adecuada o incluso el mantenimiento y reparación de los productos adquiridos, pueden ser, junto a muchos otros, motivo de diferenciación para una empresa. Un ejemplo de esta diferenciación lo tenemos en El Corte Inglés que ofrece al cliente numerosos servicios periféricos.

- Diferenciación a través de la imagen. La imagen de la empresa, que es la forma en la que el público percibe a esta o a sus productos, puede ser un factor clave para la diferenciación. En este punto, la marca, el nombre y el logotipo 
de la empresa pueden constituir una ventaja competitiva clara y sostenible. En el campo de equipamiento deportivo encontramos claros ejemplos como son Nike y Adidas y en el de las motocicletas Harley-Davidson Motor Company. La estrategia de estas empresas se basa en la creación de una imagen de marca sólida que les permite unos precios superiores a los de la competencia. Los mensajes de sus campañas de comunicación son singulares y están asociados a unos estilos y formas de vida determinados.

- Diferenciación a través de las personas. Algunas empresas centran sus esfuerzos de diferenciación en la formación y preparación de sus empleados. $\mathrm{Su}$ personal se distingue, principalmente, por las siguientes características: competencia (capacidad y conocimiento necesarios), cortesía (amabilidad, respeto y consideración), credibilidad, confianza, responsabilidad (responden rápidamente a las peticiones y a los problemas de los clientes) y comunicación (se esfuerzan por comprender al cliente y por comunicarse con él con claridad).

- Diferenciación a través de los canales de distribución, centrada en la explotación de un canal de distribución que no es utilizado por el resto de competidores. La empresa de ordenadores personales Dell se caracterizó desde sus inicios por vender sus productos únicamente a través de Internet. Eligiendo, por tanto, un canal directo para la realización de sus ventas. Un ejemplo en el sector de la alimentación lo encontramos en Naranjas Lola, que se dedica a la venta de naranjas únicamente a través de Internet.

Cabe decir que estas estrategias no tienen por qué ser incompatibles unas con otras. Algunas empresas han logrado la diferenciación gracias a la combinación de varias de ellas. Por ejemplo, Dell además de vender por Internet, también permite la personalización del producto y Naranjas Lola combina la distribución on line con una alta calidad de las naranjas, recogidas del árbol bajo unas determinadas condiciones y enviadas directamente a casa del cliente. Tal y como indican Lambin, Gallucci y Sicurello (2009): «La diferenciación permite a las empresas fijar un precio más alto que el mercado está dispuesto a aceptar». Además, para llevar a cabo esta estrategia normalmente se necesita hacer grandes inversiones en publicidad para hacer llegar al mercado las cualidades distintivas del producto.

\subsubsection{Enfoque o especialización (segmentación)}

La estrategia de enfoque o especialización se da cuando la empresa centra su esfuerzo en servir a pocos o incluso a un único segmento (un grupo de compradores o un mercado geográfico) en lugar de intentar abarcar el mercado completo. De esta manera se podrá conocer a estos segmentos con mayor profundidad que la competencia y se intentará ser líder en costes o en diferenciación dentro del segmento o segmentos elegidos. Un ejemplo de enfoque lo encontramos en la empresa italiana Ducati que fabrica únicamente motocicletas deportivas de gran cilindrada para motociclistas con un espíritu deportivo muy marcado, es decir, se centra en un único segmento, dejando de lado otros como el de los scooters, motos de campo, motos de trial, customs, etc. 


\subsection{Estrategias competitivas en relación al entorno y en relación a los competidores}

A la hora de definir su estrategia la empresa deberá tener en cuenta en qué posición se encuentra en el mercado, con respecto a los competidores y cuál es la forma de actuar de estos. Así pues, analizaremos en este apartado las diferentes estrategias que pueden seguir las empresas en función de su situación con respecto al entorno y a los competidores.

\subsubsection{Estrategias competitivas en relación al entorno}

Miles y Snow (1978) definen cuatro estrategias competitivas diferentes en función de cómo puede actuar una empresa ante la evolución del mercado. Los autores parten de que las empresas con éxito son capaces de adaptarse sistemáticamente al entorno con el paso del tiempo. Estas estrategias son las de explorador, analizador, defensor y reactivo. Así, la primera de ellas se caracteriza por un espíritu innovador muy alto que va decreciendo en el resto, hasta llegar a la reactiva, en la que la actitud emprendedora es prácticamente inexistente.

\subsubsection{Estrategia prospectora o exploradora}

Se caracteriza por una actitud orientada constantemente hacia la búsqueda de nuevas oportunidades. Estas empresas asumen riesgos y son innovadoras, intentando anticiparse a las necesidades de los clientes. Es por ello que no dudan en desarrollar nuevos productos y servicios en la búsqueda de esa oportunidad de negocio, siendo la rapidez de reacción una de sus características principales. Suelen ser empresas descentralizadas y con un grado de flexibilidad importante. El entorno más favorable para estas empresas es el que sufre cambios continuos, por lo que si para el futuro se plantea una situación similar a la actual, estas empresas correrán el riesgo de volverse poco eficientes, ya que sus características de flexibilidad, rapidez, etc. no serán tan importantes en un entorno más estable.

Es el caso de algunas empresas como Apple con sus tablets o con los iPhone que continuamente están sacando al mercado nuevos productos que en poco tiempo dejan obsoletos a sus propios productos anteriores y, por supuesto, a los de la competencia.

\subsubsection{Estrategia analizadora}

La adopción de esta estrategia supone que la empresa tiene claro cuál es su negocio fundamental y adopta las acciones necesarias para protegerlo. En un entorno estable es capaz de comportarse de manera eficiente. A pesar de esto, no pierde de vista el mercado y es por ello que no renuncia a un cierto nivel de innovación, 
intentando identificar las oportunidades que se presentan, lanzando nuevos productos o incluso dirigiéndose a nuevos mercados. Así, si el entorno es más incierto o cambiante, se comportarán como seguidores de las empresas prospectoras. Normalmente, pues, no será la primera en entrar en los nuevos negocios.

Por tanto, este tipo de empresas se defiende de las amenazas que se puedan presentar para su negocio principal o básico, pero sin dejar de lado la identificación de nuevas oportunidades de negocio. La empresa L'Oreal, con sus diversas marcas, sigue una estrategia analizadora, ya que por una parte mantiene y protege su actividad, pero también lanza nuevos productos, intentando situarse en nuevos mercados, como los productos que comercializa bajo la marca Innéov.

\subsubsection{Estrategia defensora}

Al contrario que las dos estrategias vistas anteriormente, la empresa que adopta una estrategia defensora apenas muestra interés por las nuevas oportunidades de negocio que se puedan plantear en el mercado. Su análisis del entorno en busca de esas nuevas oportunidades es prácticamente inexistente. Estas empresas no se caracterizan por ser innovadoras y su máxima preocupación es sobrevivir en su mercado en el largo plazo. Es por esto que no tendrán en cuenta los cambios que se produzcan en el entorno a no ser que afecten directamente y de manera clara a su negocio. Normalmente su cartera de productos no será amplia, ya que pretenden alcanzar la estabilidad limitándose a unos productos que ya conocen. Cuando detectan una amenaza de algún competidor suelen actuar con agresividad para mantener su posición en el mercado.

\subsubsection{Estrategia reactiva}

Podríamos decir que las empresas reactivas son las que prácticamente carecen de estrategia, no tienen una estrategia genérica consistente y no responden con efectividad a los cambios que puedan producirse en su entorno competitivo: su respuesta llegará tarde, no será, por tanto, adecuada y sus resultados no serán positivos. Esto es así porque su forma de actuar significa que carecen de la mínima predisposición de cara al descubrimiento de nuevas oportunidades de negocio y cuando toma sus decisiones lo hace porque se ve obligada a ello por las presiones del entorno.

\subsubsection{Estrategias competitivas en relación a los competidores}

«Las estrategias competitivas indican la opción de la empresa según la posición relativa que esta ocupa en el mercado en relación con su competencia» (Kotler, 1992). Así, lo normal es que en un mercado haya una empresa líder que posea una cuota elevada del mismo, una o varias empresas retadoras del líder (con cuotas de mercado menores que las de este), varias empresas seguidoras y otro grupo 
de empresas especialistas en nichos que se centran en pequeños segmentos del mercado a los que las grandes empresas apenas prestan atención. En el presente apartado se van a analizar las estrategias competitivas definidas por Kotler y Sighn (1981).

\subsubsection{Estrategias de líder}

La empresa líder ocupa una posición destacada, tiene la mayor cuota de mercado y normalmente marca los cambios y las tendencias en lo que se refiere a nuevos productos, precios, distribución y comunicación. Tal y como indica Kotler (1992): «Su dominio es reconocido por las otras empresas; es un punto de referencia para la competencia». Algunas empresas líderes son Coca-Cola en el mercado de las bebidas refrescantes, Microsoft en software, McDonald's en restauración de comida rápida o Danone en yogures y postres lácteos. Normalmente, otras empresas intentarán atacar a la empresa líder, buscando y aprovechándose de sus debilidades.

Siempre de acuerdo con Kotler y Sighn (1981), la empresa líder, para seguir manteniendo su posición, puede actuar en tres frentes diferentes:

- Expansión de la demanda total del mercado. Cuando aumenta la demanda total del mercado, lo normal es que la empresa líder sea la que más se beneficie de esa expansión. Así, si crece la demanda de productos lácteos es lógico pensar que Danone se verá beneficiada por dicho incremento. Para llevar a cabo esta expansión de la demanda, la empresa líder deberá intentar conseguir nuevos usuarios: los que estarían dispuestos a utilizarlo pero todavía no lo hacen (penetración de mercado), los que nunca lo han utilizado (nuevo mercado) y los que viven en otras zonas (expansión geográfica). El líder también puede promover nuevos usos del producto o intentar aumentar el uso de sus productos, como hizo Danone con su producto dirigido a los niños, Petit Suisse (actual Danonino) cuando lanzó la campaña de comunicación A mí me daban dos, para potenciar el consumo entre los ya consumidores.

- Defensa de su cuota de mercado. La empresa líder debe estar atenta en todo momento y dispuesta a defenderse de los ataques de su competencia. Para ello, una de las mejores respuestas es la innovación constante, aunque también puede intentar reducir costes, mejorar los servicios y la distribución buscando aumentar su valor para los clientes, realizar campañas de comunicación, etc. El líder puede utilizar diferentes estrategias a la hora de defenderse:

a) Defensa de la posición. El líder no puede limitarse a defender la posición de sus productos actuales, ya que esto podría hacerle caer en la miopía de marketing. Su actitud debe ir dirigida a ocupar el espacio de mercado más deseado en la mente del consumidor. Esto es lo que hizo Sanex con el gel dermoprotector o Colgate con la prevención de la caries. 
b) Defensa de flancos. La empresa líder también debe organizar flancos o defensas que la protejan en sus puntos más débiles o incluso que le sirvan para, a partir de ellos, contraatacar. Así, cuando Smirnoff (marca perteneciente a Heublein) se vio atacada por competidores de bajo precio, la empresa lanzó al mercado la marca Relska para competir con sus atacantes y fue más allá con la marca Popov para vender a un precio incluso inferior al de sus competidores.

c) Defensa preventiva. Aquí el líder adopta un papel más agresivo, ya que ataca al enemigo antes de que sea este quien inicie el ataque. La utilización de esta estrategia puede tener efectos psicológicos importantes sobre los competidores, ya que se les está enviando un mensaje de fuerza que les puede hacer desistir de su intención de atacarle. Un ejemplo de esta estrategia lo vemos con los nuevos modelos de iPhone que Apple lanza al mercado, mejorados y con nuevas características, cuando otros competidores todavía están tratando de sacar productos similares a las anteriores versiones.

d) Defensa de contraofensiva. Cuando alguna empresa ataca al líder, lo normal es que este contraataque. Puede hacerlo mediante una disminución del precio del producto atacado, realizando promociones agresivas o anunciando mejoras de su producto a fin de disuadir a los posibles compradores de la competencia.

e) Defensa móvil. El líder defiende su territorio e intenta aumentar su dominio, ampliando o diversificando sus mercados. Algunas empresas tabacaleras, como Philip Morris, ante el aumento de restricciones sobre el tabaco y su consumo, optaron por invertir recursos en industrias como la cervecera, alimentación, bebidas o licores.

f) Defensa de contracción. Si la empresa no es capaz de defender correctamente todos los campos en los que actúa debería optar por una retirada estratégica, abandonando los territorios en los que es más débil y asignando esos recursos a los puntos clave de la empresa. La empresa Heinz ha llevado a cabo, en diferentes ocasiones, una reducción de su cartera de productos para concentrarse en aquellos considerados como cruciales para su negocio.

- Expansión de la cuota de mercado. Las empresas que ocupan una posición de líder pueden optar por aumentar su cuota de mercado para buscar el incremento de su rentabilidad. El aumento de un punto porcentual en la cuota puede suponer un incremento importante de ingresos. Sin embargo, se debe evitar que el coste de conseguir ese aumento de cuota sea mayor que el aumento de los ingresos obtenidos. Este problema no suele darse cuando se crece a costa de la competencia en el mercado atendido (competencia más directa). Por ejemplo, Mercedes tiene una buena rentabilidad, ya que, a pesar de no tener una cuota alta en el mercado total de automóviles, tiene una 
cuota alta en el segmento de mercado al que se dirige. Véase detalle de esta estrategia en las opciones del retador (apartado 8.6.2.2).

\subsubsection{Estrategias de retador}

La empresa retadora tiene dos alternativas estratégicas: expansión de la cuota de mercado o defensa de esa cuota.

- Expansión de la cuota de mercado. Las empresas retadoras intentan expandir su cuota de mercado actuando de manera agresiva contra el líder o contra otras empresas similares o incluso menores que ellas. Este tipo de empresa, como indica Kotler (1992), puede plantearse un ataque al líder para arrebatarle parte de su cuota de mercado. Si bien esta opción puede conllevar peligros, se han dado casos de éxito en los que empresas retadoras como Airbus han atacado al líder Boeing, consiguiendo vender más aviones que este. $\mathrm{O}$ como Toyota, que en la actualidad fabrica más automóviles que General Motors. Otra opción es atacar a empresas de su mismo tamaño que no atienden bien a su mercado y/o que tengan problemas financieros. Normalmente este tipo de empresas se caracterizan por no ser claramente innovadoras, por tener unos precios demasiado altos o por no ser capaces de satisfacer correctamente las necesidades de sus clientes. La tercera posibilidad para el retador es llevar a cabo un ataque a pequeñas empresas locales y regionales. Este sería el caso de muchas grandes empresas del sector cervecero español que han crecido gracias a la absorción de empresas más pequeñas que actuaban únicamente en ámbitos regionales, como es el caso de la adquisición de cervezas Alhambra por parte del grupo Mahou-San Miguel. Una vez se tenga claro a quién se va a atacar y con qué finalidad, se tendrá que decidir cómo hacerlo. Para ello hay unas estrategias generales de ataque que se citan a continuación:

a) Ataque frontal. El retador une todos sus esfuerzos y recursos para atacar directamente a su oponente en los puntos fuertes de este. Para ello deberá, como mínimo, alcanzar el mismo nivel que su competidor en las distintas acciones de marketing que realice o, incluso, modificarlas con reducciones de precios. El atacante deberá ser consciente de que tiene suficiente capacidad como para enfrentarse al líder, ya que, de lo contrario, puede correr un riesgo elevado.

b) Ataque de flancos. Cuando el atacante tiene menos recursos que su competidor, tiene que analizar bien cuáles pueden ser los puntos débiles de su enemigo y golpear sobre ellos, bien sea en mercados geográficos que este tenga poco atendidos o en segmentos del mercado en los que el competidor no sea tan fuerte o tenga algo menos cubiertos. Esta estrategia, tal y como apunta Kotler (1992), fue la seguida por los fabricantes de coches alemanes y japoneses cuando entraron en el mercado americano con vehículos más reducidos y de menor consumo. 
c) Ataque envolvente. Si el retador dispone de más recursos que el líder puede optar por intentar conseguir parte de su cuota mediante un ataque relámpago dirigido a diversos frentes. El agresor deberá ofrecer al mercado más de lo que ofrece el oponente.

d) Ataque en «bypass». No es tan directo como los anteriores, ya que no pretende dirigirse directamente contra el adversario, sino más bien dejarlo inicialmente de lado, atacando mercados más accesibles. Para ello se puede intentar una diversificación hacia productos no relacionados o hacia nuevos mercados geográficos o incluso adoptando nuevas tecnologías. Un ataque con estas características fue el que realizó Pepsi con la adquisición de Quaker Oats, propietaria de Gatorade, con una cuota de mercado en bebidas isotónicas muy superior a la de Powerade de Coca-Cola.

e) Ataque de guerrillas. Consiste en lanzar de manera intermitente pequeños ataques a diferentes puntos del oponente. Normalmente el ataque de guerrillas los emplean las empresas pequeñas contra las más grandes, intentando conseguir pequeños avances. Se puede contemplar la reducción selectiva de precios o ataques promocionales intensos y fugaces con el objetivo de debilitar al oponente. Para tener éxito es recomendable hacerlos en una zona concreta que no sea demasiado amplia.

Más allá de estas estrategias, la empresa retadora debería desarrollar otras más concretas como pueden ser descuentos de precios, productos de menor calidad a precio inferior, productos baratos pero de calidad para intentar restar cuota de mercado a los líderes, estrategia basada en productos de prestigio, lanzando al mercado productos de mayor calidad con precios superiores a los del líder, ofrecer mayor variedad de productos que el líder, innovar en producto, mejorar los servicios, desarrollar nuevos canales de distribución, etc.

- Defensa de su cuota de mercado (véase Estrategias del líder, apartado 8.6.2.1).

\subsubsection{Estrategias de seguidor}

No todas las empresas aspiran a retar o a alcanzar al líder: algunas prefieren seguirlo. La empresa seguidora ocupa una posición inferior a la del líder y un ataque frontal a este podría suponer un daño más que aportar algún beneficio. A pesar de esto, las empresas seguidoras deben tener sus propias estrategias, ya que tendrán que intentar, como mínimo, mantener su cuota de mercado actual y, cuando sea posible, aumentarla poco a poco. Para ello necesitarán ofrecer algún tipo de ventaja a su mercado objetivo: ubicación, servicios, etc. Las empresas seguidoras pueden ser objetivo de los ataques de las empresas retadoras. Por ello tienen que intentar mantener un nivel de costes bajos y una calidad al mayor nivel posible. La empresa seguidora deberá establecer sus propias vías de crecimiento, pero de manera más bien discreta para evitar ataques de las empresas más grandes. 
Theodore Levitt (1996) apuntó en su momento que una estrategia de imitación de productos puede ser tan rentable como una de innovación. Si bien, dice este autor, la empresa innovadora suele obtener como recompensa el ser líder de su mercado, esto conlleva importantes inversiones en desarrollo de productos, distribución y comunicación. En el caso de las empresas que copian o incluso mejoran el producto, a pesar de no alcanzar al líder, se pueden obtener altos beneficios, ya que no se tendrán gran parte de esos gastos.

Se pueden destacar cuatro estrategias específicas para las empresas seguidoras:

- Estrategia de falsificación. La empresa copia el producto y el envase y lo vende en el mercado negro. Empresas del sector discográfico y cinematográfico o de otros sectores como Rolex, Lacoste, etc. han sido objeto de este tipo de falsificaciones. Es ilegal.

- Estrategia de clonación. La empresa reproduce el producto del líder, el nombre y el envasado, pero con ligeras variaciones.

- Estrategia de imitación. La empresa copia algunos de los aspectos del líder, pero se diferencia en características como el envase, la publicidad, el precio, etc.

- Estrategia de adaptación. La empresa se basa en los productos del líder, pero los adapta y, en ocasiones, incluso los mejora. Muchas veces el adaptador acaba convirtiéndose en una empresa retadora.

\subsubsection{Estrategia para especialistas en nichos}

Hay empresas que evitan el enfrentamiento directo con los grandes competidores, pero que tampoco pueden ser consideradas como seguidoras. Son empresas que seleccionan segmentos reducidos (nichos de mercado) en los cuales el líder del mercado o los seguidores muestran poco interés. Gracias al conocimiento profundo que tiene del cliente, el especialista en nichos suele ofrecer a su mercado un producto con mayor valor que el de la competencia, lo que le da la posibilidad de conseguir una cuota de mercado importante dentro del segmento en el que se ha especializado. Como indica Kotler (1992): «El especialista en nichos acaba conociendo tan bien a su público objetivo, que es capaz de satisfacer las necesidades del mismo mejor que las empresas que atienden a este nicho por casualidad. El especialista puede establecer un precio muy superior al coste, debido al gran valor añadido de sus productos, consiguiendo obtener un gran margen».

Puesto que los nichos pueden debilitarse con el paso del tiempo (por la entrada de nuevos competidores, por cambios en los gustos y preferencias de los consumidores, etc.) la empresa puede especializarse en varios de ellos simultáneamente para no depender de una sola fuente de recursos. 
Lógicamente el éxito de la empresa que se centra en nichos de mercado pasa por su especialización y esta puede conseguirse a distintos niveles, según Kotler (1992):

- Especialista en consumidores finales. Se especializa en atender a un perfil de consumidor final con unas características y necesidades concretas. Un ejemplo de este tipo de especialización es la seguida por la empresa Imaginarium.

- Especialista a nivel vertical. La empresa se especializa en alguno de los niveles del ciclo producción-distribución.

- Especialista en clientes de un determinado tamaño. Se da una especialización en atender a clientes pequeños, medianos o grandes. Normalmente, las grandes empresas dejan más desatendidos a los pequeños clientes.

- Especialista en clientes específicos. La empresa se centra en vender su producción a uno o a unos pocos clientes, como puede ser el caso de algunos proveedores de Mercadona o de El Corte Inglés.

- Especialista en zonas geográficas. Se centra en vender sus productos en una única región o área. Este es el caso de la empresa cervecera Moritz que, prácticamente, solo comercializa sus cervezas en la provincia de Barcelona y algunas zonas más de Cataluña.

- Especialista en un producto o línea de productos. La empresa vende únicamente un producto o una sola línea de productos. Es el caso de la empresa de alimentación Fartons Polo o de los productos de limpieza KH Lloreda.

- Especialista en un solo atributo del producto. Se ofrece al mercado únicamente un único tipo de producto o una característica particular del mismo. Este es el caso de la empresa Avancar Carsharing, dedicada al uso compartido de coches.

- Especialista en productos a medida. Los productos que se comercializan son personalizados en función de los deseos del cliente individual.

- Especialista calidad/precio. Especialización en el segmento de alta o bien de baja calidad del mercado. Así, la empresa española Farggi está especializada en helados de alto precio.

- Especialista en servicios. Se centra en ofrecer uno o varios servicios que no ofrecen el resto de empresas.

- Especialista en canal. La empresa se especializa en un único canal de distribución. Este puede ser el caso de Spotify que comercializa música únicamente a través de Internet. 


\subsection{Estrategias de crecimiento o inversión, de mantenimiento y de desinversión}

Si bien las estrategias vistas con anterioridad hacían referencia a la ventaja competitiva buscada o a la forma de actuar en el mercado en función de la competencia y el entorno, el grupo de estrategias que se van a estudiar en este apartado viene referido a la actuación de la empresa en función de los productos y mercados en los que esta se mueve, así como del atractivo que el mercado puede presentar.

\subsubsection{Estrategias de crecimiento o inversión}

Ansoff (1976) definió las estrategias básicas de crecimiento o desarrollo, que hacen referencia a la relación entre la situación existente en la empresa y la posibilidad de desarrollo, tanto de productos como de mercados.

Las dos estrategias básicas son la de crecimiento intensivo o expansión y la de diversificación. La primera supone que la empresa actuará dentro de ámbitos relacionados con su negocio actual, bien sea porque comercialice los mismos productos que hasta ahora, o bien porque desarrolle nuevos productos para los mercados en los que actúa. La segunda, es decir, la diversificación supone una cierta ruptura con la situación actual, ya que se intentará comercializar nuevos productos en nuevos mercados, tal y como apuntan Navas y Guerras (2001). Son estrategias de crecimiento intensivo las estrategias de penetración, desarrollo de mercado, desarrollo de producto y desarrollo conjunto de producto y mercado. Son estrategias de diversificación las de diversificación concéntrica y la diversificación pura (véase figura 33).

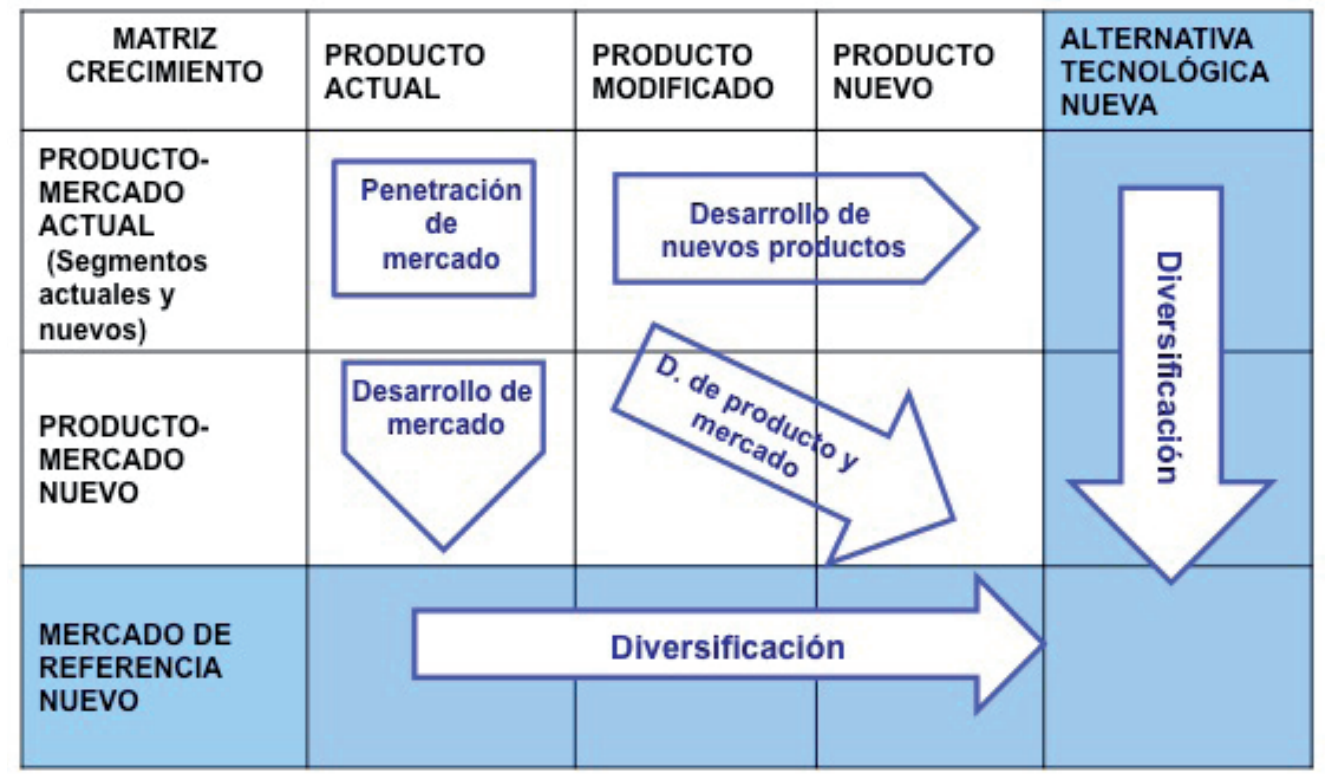

Figura 33. Matriz de crecimiento

Fuente: Elaboración propia basada en Ansoff (1976) 


\subsubsection{Estrategias de penetración de mercado}

Estas estrategias persiguen la potenciación de las actuales actividades que está llevando a cabo la empresa, sin realizar cambios importantes. Como dicen Navas y Guerras (2001), se intenta aumentar las ventas de los productos que ya se están comercializando dirigiéndose a sus clientes actuales o bien atrayendo a nuevos usuarios para los productos actuales de la empresa. Si se trata de mercados maduros será más difícil conseguir el éxito con esta estrategia, que sería más adecuada para mercados en crecimiento o para productos que se encuentren en fases iniciales de su ciclo de vida.

Esta estrategia presenta la ventaja de que la empresa conoce el terreno en el que se mueve, ya que conoce a fondo sus mercados, las características de los consumidores, su competencia, etc. Sin embargo, con ella, se limita la detección de nuevas oportunidades de negocio.

Tal y como afirman Munuera y Rodríguez (2007), algunas formas de llevar a cabo la penetración de mercado por parte de las empresas son:

- Incrementar la cuota de mercado, aumentando las actividades de marketing, realizando promociones, incrementando su presupuesto de comunicación y publicidad, reduciendo el precio, etc., o bien ofreciendo un producto diferenciado del de la competencia.

- Aumentar la frecuencia de uso. Esto puede conseguirse aumentando la publicidad para recordar el uso del producto, posicionando el producto como de uso frecuente o incluso haciendo el uso del producto más fácil.

- Promover nuevos usos. La empresa puede proponer a los consumidores nuevos usos de sus productos, o bien son los propios consumidores los que utilizan los productos para nuevos usos. Así, por ejemplo, Gallina Blanca realizó una campaña de comunicación de su crema de pollo Sopinstant en la que se mostraba a consumidores bebiendo el producto en una taza, como merienda. La misma estrategia es la utilizada por Kellog's cuando anuncia sus cereales Special K como producto ideal para cenar.

- Aumentar los niveles de uso por ocasión, convenciendo a la gente para que consuma más cantidad de producto en cada ocasión. Un claro ejemplo fue la campaña de comunicación lanzada por Danone para su Petit Suisse en la que el eslogan era $A$ mí me daban dos.

- Búsqueda y atracción de nuevos usuarios. Se trata de ampliar el número de consumidores o usuarios atrayendo a los no consumidores o a consumidores de productos sustitutivos. Por ejemplo, los yogures Activia de Danone intentan, con las últimas campañas de comunicación, promocionar su consumo entre todas las mujeres de un determinado perfil y no solo entre las que tienen problemas de tránsito intestinal, como hacía en un principio. 


\subsubsection{Estrategias de desarrollo de productos}

A fin de seguir siendo competitiva, cualquier empresa, en mayor o menor medida, tendrá que adaptar sus productos a las necesidades del mercado y a la evolución de las preferencias de los consumidores. Deberá, para ello, estar atenta a las tendencias del mercado.

Según Lambin, Gallucci y Sicurello (2009), esta estrategia supone el aumento de las ventas de la empresa, «desarrollando productos nuevos o mejorados que apunten a los mercados existentes». Para estos autores hay diferentes posibilidades para llevar a cabo esta estrategia:

- Crear un nuevo producto o servicio que represente cambios en los beneficios que se ofrecen a los clientes y que pueden ser compatibles con los productos actuales, aprovechando el conocimiento del mercado y la imagen de marca de la empresa.

- Incorporación de nuevas funciones, atributos o características para atraer a nuevos consumidores.

- Ampliación de la gama de productos con, por ejemplo, nuevos modelos, nuevos envases y tamaños, nuevos sabores, etc.

- Rejuvenecer la gama de productos es otra posibilidad que supone actualizar productos obsoletos para continuar siendo competitivos.

- Mejorar la calidad del producto y sus prestaciones, lo que permitirá crecer dentro del mercado en el que se está actuando.

\subsubsection{Estrategias de desarrollo de nuevos mercados}

Cuando el mercado en el que actúa habitualmente se satura la empresa puede aprovechar su experiencia y el conocimiento que tiene sobre sus productos para crecer hacia otros mercados.

La primera opción que se le presenta para desarrollar esta estrategia, tal y como apuntan Lambin, Gallucci y Sicurello (2009), es la expansión hacia nuevos segmentos del mercado. Se trataría, en este caso, de intentar llegar a nuevos grupos de clientes, a los cuales la empresa no atendía hasta ahora, dentro del mismo mercado geográfico. Así, especializándose en un producto, se puede atender con él a distintos segmentos del mercado. En este caso no se debe olvidar que el dirigirse a un nuevo segmento no debería debilitar la posición de la empresa en el segmento anterior. Un ejemplo lo tenemos en la empresa Tau Cerámica que no se limita a comercializar su producto únicamente como revestimiento de suelos y paredes de interior, sino que se dirige a nuevos segmentos con grandes formatos para revestir edificios con su sistema de fachadas ventiladas. 
Una segunda posibilidad es la expansión geográfica, ya sea a nivel local, regional o internacional. El dirigirse a distintos mercados puede favorecer la estabilidad en el tiempo, ya que no se estará dependiendo de una única fuente de recursos. Este es el caso de Mercadona que, teniendo sus orígenes en la Comunidad Valenciana, ha ido ampliando sus puntos de venta hasta estar presente en la mayoría de provincias españolas. Otras empresas, como Cola Cao o Chupa Chups están presentes en distintos países como China o Rusia, buscando nuevas posibilidades de negocio.

- El primer paso para la expansión geográfica es decidir cómo se van a abordar los nuevos mercados. La forma más normal, tal y como indica Kotler (1992), sería la exportación indirecta, es decir, contactar con un exportador especializado que será el que se encargue de vender el producto en otros mercados y realice la exportación propiamente dicha. Con esta fórmula la empresa apenas tiene control sobre las ventas, ya que no es ella quien se dirige a los canales de distribución, pierde la posibilidad de establecer los precios y las promociones y no tiene contacto con el consumidor final.

- En segundo lugar está la exportación directa en la que la propia empresa gestiona la venta de sus productos a clientes de mercados exteriores. Aquí la empresa tampoco tiene gran control sobre los elementos del marketing, ya que no es ella quien decide los precios finales, promociones, etc., si bien, si que gestionará las condiciones de entrega o los medios de pago.

- La posibilidad de la exportación concertada supone llevar acciones para la entrada en mercados exteriores tales como joint-ventures, franquicias o alianzas con empresas de los mercados a abordar.

- Munuera y Rodríguez (2007) también apuntan que el establecimiento de subsidiarias comerciales puede ser una opción adecuada cuando la empresa tiene un nivel de ventas importante en el mercado y tiene ya una cierta experiencia en él. Para ello puede abrir filiales o delegaciones en el país extranjero.

- Por último, la empresa puede establecer subsidiarias de producción en distintas partes del mundo. De esta manera puede evitar aranceles o cuotas a la importación, a la vez que puede obtener ventajas en costes de producción y reducir los gastos de transporte.

Otras estrategias para desarrollar nuevos mercados que apuntan Lambin, Gallucci y Sicurello (2009), pasarían por la proposición de soluciones a necesidades de los clientes aún no percibidas o expresadas, así como por la utilización de nuevos canales de distribución, complementarios a los actuales. 


\subsubsection{Estrategias de crecimiento diversificado e integración}

La diversificación supone para la empresa la decisión de ampliar su ámbito de actuación, ya que se basa en dirigirse a mercados nuevos con nuevos productos. Es, por tanto, una decisión más arriesgada que la expansión, tal y como indican Navas y Guerra (2001).

A pesar de este nivel de riesgo, hay una serie de razones que pueden animar a la empresa a diversificar (Bueno, 1996), ya que con estas estrategias se reduce el riesgo global puesto que es difícil pensar que todas las actividades a las que se dedica la empresa van a ir mal simultáneamente. Por otra parte, la saturación del mercado en el que habitualmente se mueve la empresa también puede conducir a la diversificación si ve que con sus mercados tradicionales no puede alcanzar sus objetivos de crecimiento. Otra razón importante para diversificar se da cuando se dispone de excedentes financieros que se pueden invertir en nuevas oportunidades de negocio. La búsqueda de sinergias para reforzar la posición competitiva puede ser también una razón para seguir estas estrategias, ya que la empresa puede aprovechar sus recursos infrautilizados y reforzar su posición competitiva a través de las sinergias en ventas, operativas, financieras y de dirección.

Así pues, las estrategias de diversificación suponen la ampliación del ámbito de actuación de la empresa hacia otros tipos de negocio, lo cual comporta un nivel de riesgo elevado, ya que la empresa se va a dirigir a nuevos mercados con nuevos productos. La diversificación puede adoptar dos formas: la diversificación relacionada o concéntrica y la no relacionada o pura. La primera de ellas supone que la empresa pretende agregar nuevas actividades relacionadas con las que desarrolla en la actualidad y que antes no tenía. Este sería el caso de las nuevas Yogurterías de Danone, ya que son heladerías en las que se vende yogur helado, con lo que guarda cierta relación con el negocio principal (fabricación de yogures), pero se da un paso hacia adelante para tener una distribución propia. Por su parte, la diversificación pura se da cuando la empresa decide entrar en una serie de actividades que no guardan relación con las que ejerce habitualmente, dirigiéndose de esta manera a nuevos campos de actuación. Un ejemplo lo encontramos en la empresa japonesa Yamaha que produce y comercializa una serie de productos tan diferentes como motocicletas e instrumentos musicales.

Por su parte, las estrategias de integración suponen una extensión en el plano vertical o en el plano horizontal. Cuando la empresa lleva a cabo una integración en el plano vertical es porque asume la realización de actividades que están en otros niveles de producción o de distribución. Tal y como apuntan Navas y Guerra (2001): «La empresa se convierte en su propio proveedor o cliente emprendiendo actividades que antes eran cubiertas con operaciones de mercado». Si es una integración vertical hacia arriba, se intentará asumir el control de fuentes de suministro (funciones propias de los proveedores). Por el contrario, si es hacia abajo se dirigirá hacia la realización de actividades de producción situadas en niveles inferiores de la cadena, o bien, hacia las actividades de distribución, buscando, en este caso, el control de la comercialización de los productos en el mercado. Un 
ejemplo de esta estrategia es el de la firma Porcelanosa que, además de dedicarse a la producción de cerámica, está abriendo sus propias tiendas para llegar mediante ellas a su público objetivo. Por su parte, la integración horizontal conlleva la absorción de competidores con la finalidad conseguir una mejor posición en un mercado determinado. Ejemplos de integración horizontal los encontramos en el sector bancario con fusiones y absorciones como la llevada en su día por el Banco de Bilbao, Banco de Vizcaya y Argentaria o por el Banco de Santander con el Banco Central Hispano.

\subsubsection{Estrategias de mantenimiento y de desinversión}

En mercados en crecimiento es más sencillo ganar cuota de mercado atrayendo a clientes potenciales. Ahora bien, a medida que el mercado se va saturando, el crecimiento de la empresa y la consecución de sus objetivos se hacen más difíciles. Como indica Best (2007): «En algunos mercados maduros o en declive se puede conseguir una gestión atractiva de la tesorería a través de una estrategia defensiva de monetización. En otras situaciones, la mejor estrategia defensiva es una salida lenta del mercado (estrategia de cosecha) o una salida rápida del mercado (estrategia de desinversión)». Así pues, la empresa deberá proponerse como objetivo defender y mantener su participación en el mercado o llegado el momento, incluso, desinvertir en determinados productos.

- Estrategia de sostenimiento. Como apuntan Munuera y Rodríguez (2007), si la empresa se encuentra en un mercado con un atractivo medio y su posición competitiva también es media, puede optar por mantener su situación en espera de ver cómo evoluciona el mercado y a partir de ahí tomar sus decisiones en función de si este crece o decrece. Esta estrategia, por tanto, no puede considerarse como de desinversión, puesto que en ningún caso la empresa ha tomado la decisión de abandonar el mercado.

- Estrategia de cosecha. Es adecuada para situaciones no del todo desfavorables para la empresa. Como indica Best (2007), si los mercados no son atractivos y la posición de la empresa tampoco es favorable con respecto a sus competidores, se dará una posición débil de la misma en el mercado, con pocas posibilidades de beneficio. Aun así, en ocasiones no se debería abandonar rápidamente el mercado, ya que podrían existir posibilidades de generar beneficios a corto plazo. Esta estrategia también podría ser adecuada cuando, a pesar de estar en un mercado con un bajo atractivo, la empresa tenga una posición competitiva relativamente buena. La empresa ha decidido retirarse del mercado, pero todavía puede recuperar parte de las inversiones que ha realizado en él.

- Estrategia de eliminación. Si la posición de la empresa o de algunos de sus productos no es buena y, además, se encuentra con un mercado que tampoco presenta un nivel alto de atractivo, una opción que se debe plantear es la eliminación de esos productos para ese mercado. La disminución continuada de las 
ventas o de los beneficios suele conducir a la eliminación de los productos del catálogo de la empresa. Otras causas que pueden llevar a la eliminación son los cambios en los gustos de los consumidores, el crecimiento de la competencia, problemas de aprovisionamiento de materias primas, reducción de la cartera de productos, etc.

\section{Referencias bibliográficas}

Ansoff, H. I. (1976): La estrategia de la empresa, Pamplona, Universidad de Navarra.

Best, R. (2007): Marketing Estratégico, 5. a ed., Madrid, Pearson Educación.

Bueno, E. (1996): Dirección Estratégica de la Empresa. Metodología, técnicas y casos, 5. ${ }^{\mathrm{a}}$ ed., Madrid, Pirámide.

Burk, M. (2003): El Plan de marketing, guía de referencia, Madrid, Prantice Hall.

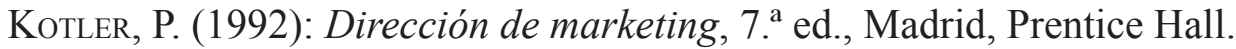

Kotler, P. y R. Sighn, (1981): «Marketing Warfare in the 1980», Journal of Business Strategy, Winter.

Lambin, J. J., Galluci, C. y C. Sicurello (2009): Dirección de marketing, gestión estratégica y operativa del mercado, México, McGraw-Hill.

LevitT, T. (1996): «Innovative imitation», Harvard Business Review.

MiLes, R. y C. SNOw (1978): Organizational strategy, structure and process, Nueva York, McGraw-Hill.

Munuera, J. L. y A. I. Rodríguez (2007): Estrategias de marketing, Un enfoque basado en el proceso de dirección, Madrid, EsIC Editorial.

Navas, J. E. y L. A. Guerras (2001): La dirección estratégica de la empresa. Teoría y aplicaciones, 2. ${ }^{\text {a }}$ ed., Madrid, Civitas Ediciones.

Porter, M. (1982): Estrategia competitiva, México, CECSA. 



\section{CAPÍTULO 9}

\section{El diseño de la oferta de marketing \\ Marta Estrada-Guillén \\ y Juan Carlos Fandos-Roig}

\section{Contenido del capítulo}

En este capítulo se describirá brevemente el denominado marketing mix, también conocido como las 4 Pes de marketing: producto, precio, distribución y comunicación. Definidos los objetivos y estrategias de marketing, es necesario planificar y ejecutar un conjunto de acciones sobre las políticas de producto, precio, distribución y comunicación de la empresa.

En este capítulo, el alumno aprenderá la necesidad de establecer coherentemente las acciones operativas de acuerdo con los objetivos y estrategias propuestos por el plan de marketing. Progresivamente, a lo largo de los diferentes apartados, se describirán los elementos que definirán las decisiones del marketing operativo, elementos que supondrán la realización y ejecución efectiva del plan de marketing y la asunción con éxito de los objetivos propuestos. 


\subsection{Producto}

9.1.1. Niveles de productos y servicios

9.1.2. Clasificación de productos y servicios

9.1.2.1. Productos de consumo

9.1.2.2. Productos industriales

9.1.2.3. Organizaciones, personas, lugares e ideas

9.1.3. Decisiones de productos o servicios individuales

9.1.3.1. Los atributos del producto o servicio

9.1.3.2. La marca

9.1.3.3. Packaging (envase o embalaje)

9.1.3.4. Etiquetado

9.1.4. Decisiones sobre la cartera de productos y servicios

9.2. Precio

9.2.1. Métodos de fijación de precios

9.2.1.1. Métodos basados en los costes

9.2.1.2. Métodos basados en la competencia

9.2.1.3. Métodos basados en la demanda

9.2.2. Estrategias de precios

9.2.2.1. Productos nuevos

9.2.2.2. Líneas de producto

9.2.2.3. Precios diferenciales

9.2.2.4. Precios psicológicos

9.2.2.5. Precios geográficos

9.3. Distribución

9.3.1. Cómo añaden valor los miembros del canal: funciones de la distribución

9.3.2. Decisiones en el canal de distribución

9.3.3. Los intermediarios del canal

9.3.3.1. Venta mayorista

9.3.3.2. Venta minorista

9.4. Comunicación

9.4.1. Publicidad

9.4.1.1. Métodos de fijación del presupuesto publicitario

9.4.1.2. Desarrollo de la estrategia publicitaria

9.4.1.3. Evaluación de la eficacia publicitaria

9.4.2. Promoción de ventas

9.4.3. Relaciones públicas

9.4.4. Venta personal

9.4.4.1. La dirección de ventas

9.4.4.2. El proceso de venta personal

9.4.5. Marketing directo

Referencias bibliográficas 


\subsection{Producto}

«Un producto es cualquier cosa que se puede ofrecer a un mercado para su atención, adquisición, uso o consumo, y que puede satisfacer un deseo o una necesidad» (Armstrong et al., 2011). Los productos incluyen objetos físicos, servicios, eventos, personas, lugares, organizaciones, ideas, etc.

\subsubsection{Niveles de productos y servicios}

El producto está configurado no solo por los beneficios básicos que aporta sino también por aspectos formales como la calidad, la marca, el packaging y aspectos adicionales como el servicio postventa, la garantía, entrega, financiación, etc. Levitt (1980) hace referencia al término producto total para referirse a la existencia de diferentes niveles en la formación de este constructo: producto genérico, producto esperado, producto aumentado y producto potencial.

- Producto genérico. El producto en sí mismo. Manifiesta las características básicas (técnicas) del mismo.

- Producto esperado. Responde al conjunto de prestaciones que el comprador espera encontrar en el producto.

- Producto aumentado. Supera las expectativas del cliente añadiendo valor al producto (mejores condiciones de entrega, pago, etc.).

- Producto potencial. Se refiere a todas las innovaciones que el producto podrá incorporar a lo largo de su ciclo de vida.

\subsubsection{Clasificación de productos y servicios}

De acuerdo a las características de los consumidores, los productos y servicios se pueden clasificar en tres categorías: productos de consumo, productos industriales y otros, como organizaciones, personas e ideas.

\subsubsection{Productos de consumo}

Son aquellos dirigidos a los consumidores finales. Dentro de los mismos se incluyen los productos de conveniencia, los productos de comparación, los productos de especialidad y los productos no buscados.

- Los productos de conveniencia (o de oportunidad). Son aquellos que se adquieren con regularidad y son conocidos. Su compra no requiere esfuerzo o atención. No suelen ser caros, se distribuyen en muchos sitios y la promoción es masiva. Por ejemplo: la leche, el gel de ducha, el pan, etc. 
- Los productos de comparación. Son aquellos en los que el comprador potencial puede comprobar distintas ventajas o condiciones en otros establecimientos. Su compra requiere un mayor esfuerzo y tiempo para obtener información y realizar las comparaciones oportunas. Se distribuyen a través de menos puntos de venta y la fuerza de ventas resulta una pieza clave en la estrategia de marketing. Por ejemplo: electrodomésticos, servicios bancarios, etc.

- Los productos de especialidad. Son productos o servicios con unas características especiales que provocan una fuerte preferencia y lealtad hacia la marca. Los clientes están dispuestos a realizar un esfuerzo especial de compra. El precio es alto, su distribución es exclusiva y la promoción se dirige tanto al distribuidor como al comprador. Como ejemplos podemos citar artículos de lujo como la porcelana Lladró, los relojes Cartier, etc.

- Los productos no buscados. Son aquellos que todavía no son conocidos por ser novedosos en el mercado, o que, siendo conocidos, no se piensa en adquirirlos. Su precio al igual que la distribución varía. Necesitan de una publicidad agresiva y de un equipo de ventas formado en venta personal. Algunos productos de este tipo son: los seguros para servicios funerarios, planes de pensiones, etc.

\subsubsection{Productos industriales}

Los productos industriales son los que se compran para su procesamiento posterior. Si un consumidor compra un secador para su uso doméstico es un producto de consumo pero si lo compra para su negocio de peluquería es un producto industrial. Dentro de los productos industriales se incluyen los materiales y componentes, bienes de capital, suministros y servicios.

- Los materiales y componentes. Están formados por materias primas (trigo, algodón...), materiales (hierros, cementos, alambres...) y componentes (partes integrantes de otros productos como motores pequeños, baterías...).

- Los bienes de capital. Son productos industriales que ayudan en la producción, incluyen, pues, instalaciones (como la compra de naves industriales, oficinas...) y equipamiento (como equipos informáticos, muebles archivadores...).

- Los suministros y servicios. Incluyen suministros ordinarios (papel, lápices...) y artículos para el mantenimiento y reparación (pintura, calvos, escobas...).

\subsubsection{Organizaciones, personas, lugares e ideas}

En marketing se considera que las organizaciones, personas y servicios son productos. El marketing de las organizaciones trata de crear, mantener o modificar las actitudes y comportamientos de los consumidores con respecto a la organización. 
La práctica de este tipo de marketing es frecuente tanto en organizaciones lucrativas como no lucrativas. Un ejemplo de ello lo tenemos en las campañas de relaciones públicas y de publicidad corporativa realizadas por la Universitat Jaume I.

- Las personas también pueden verse como un producto y ser objeto de marketing. El marketing de las personas consiste en actividades cuyo objetivo es crear, mantener o modificar las actitudes o comportamientos hacia determinados individuos. Esto explicaría la irrupción, entre otros, del marketing político o el marketing de las celebrities. Como ejemplo podemos citar la campaña para las elecciones presidenciales norteamericanas con su famoso eslogan «Yes we can» o el auge de las redes sociales como recurso para promocionar a personajes famosos.

- El marketing de lugares implica actividades que se efectúan para crear, mantener o modificar actitudes o comportamiento hacia lugares y sitios concretos. Sirva como ejemplo las acciones promocionales llevadas a cabo por el Patronato de Turismo de la Diputación de Castellón para fomentar, no solo el turismo de sol y playa, sino también el del interior de la provincia.

- El marketing de ideas o marketing social pretende influir en las personas para mejorar su bienestar y el de la sociedad. Como ejemplo citaremos las campañas de salud pública en contra de consumo del tabaco y del alcohol.

\subsubsection{Decisiones de productos o servicios individuales}

Durante el desarrollo y comercialización de productos se toman una serie de decisiones sobre los atributos que tiene que tener el producto, la marca, el packaging y el etiquetado de forma individual para cada producto.

\subsubsection{Los atributos del producto o servicio}

Implica definir los beneficios a ofrecer, características, la calidad, el estilo y diseño del producto.

\subsubsection{La marca}

«La marca es un nombre, un símbolo, un diseño o una combinación de estos que identifica al fabricante o al vendedor de un producto o servicio» (Armstrong et al., 2011). Sirve para identificar, distinguir y proteger.

En la marca distinguimos:

- El nombre que es la parte de la marca que se puede pronunciar, como Lancaster, Adolfo Domínguez... 
- El logotipo que es un grafismo para distinguir la marca. Logo significa 'palabra' y tipo, 'letra'. Su objetivo es identificar y recordar la marca con facilidad y rapidez.

En la selección del nombre de marca se debe:

- Comprobar que el nombre no está registrado en el Registro de la Propiedad Industrial.

- Sugerir algo sobre los beneficios y cualidades del producto.

- Debe ser fácil de pronunciar, recordar y reconocer.

- Ser distintivo.

- Debe extenderse a otros productos.

- Fácil de traducir a otros idiomas.

Con respecto a las estrategias de marca utilizadas por las organizaciones, se distingue entre la estrategia de marca única, la de marcas múltiples, la de segundas marcas y la de alianzas de marca.

- Marca única. La totalidad de lo que la empresa produce o comercializa aparece en el mercado bajo una única marca. Esta estrategia la siguen Nike, Sanyo, entre otras. Tiene como ventaja ofrecer una imagen fuerte al cliente, sin embargo, tiene el inconveniente de que, si un producto nuevo no satisface las expectativas del cliente, puede perjudicar a la imagen corporativa de la empresa y afectar a todos los productos.

- Marcas múltiples. Es la alternativa a la opción anterior. Implica mayores costes de promoción aunque permite una mayor segmentación. Sería el caso de las marcas Opel, Chevrolet de la General Motors.

- Segundas marcas. Con esta estrategia se intenta alcanzar a nuevos segmentos de consumidores. Las segundas marcas se utilizan para aquellos productos con una calidad y precio distinto al de las primeras marcas.

- Alianzas de marcas. Suponen un acuerdo entre diferentes marcas para facilitar la entrada en otros mercados, beneficiarse del prestigio de la otra marca, etc. El co-branding supone un tipo de alianza en la que se juntan las fuerzas de dos marcas para ofrecer un producto o servicio en conjunto. Normalmente los productos de cada una de las marcas son complementarios y en este caso se ofrecen como un paquete conjunto. Un ejemplo de co-branding lo tenemos en la marca Ron Bacardi Coca-Cola.

- Marcas del distribuidor. Son aquellas marcas privadas propiedad del distribuidor. Su utilización supone un mayor control del mercado por parte del 
distribuidor. En sus orígenes fueron asociadas a una baja calidad, sin embargo, en la actualidad, pueden competir tanto en precio como en calidad con el resto de marcas comerciales. Como ejemplo citaremos la marca Hacendado de los supermercados Mercadona.

\subsubsection{Packaging (envase o embalaje)}

Implica diseñar y producir el recipiente o envoltura de un producto. Sirve para contener, proteger, identificar, diferenciar y comunicar el producto. El packaging en la actualidad se está convirtiendo por sí mismo en un medio de venta, sirva como ejemplo los productos cosméticos que miman hasta el extremo sus envases.

\subsubsection{Etiquetado}

La etiqueta puede servir para promocionar el producto, lo que se denomina etiqueta de marca. Si informa de las características del producto se trata de una etiqueta informativa.

\subsubsection{Decisiones sobre la cartera de productos y servicios}

Además de las decisiones sobre los productos o servicios individuales también hay que tomar decisiones de carácter más global, sobre la cartera y las distintas líneas de productos que tiene la empresa.

Una empresa casi siempre ofrece más de un producto o servicio; es lo que se conoce como cartera de productos de la empresa. Esta, a su vez, está compuesta por una o varias líneas de productos o, lo que es lo mismo, un grupo de productos dentro de la misma categoría que están relacionados estrechamente porque funcionan de manera similar, se venden al mismo tipo de clientes, se comercializan a través de los mismos establecimientos, etc. La empresa Adidas, por ejemplo, produce varias líneas de zapatos y ropa deportiva. Cuantas más líneas de producto tenga una empresa más amplia será la cartera de productos que ofrezca, $\mathrm{y}$, según los modelos o las variaciones que presente, hablaremos de una mayor o menor profundidad en la línea de productos. Por otra parte, el número de productos vendidos determina la longitud de la línea.

\subsection{Precio}

«El precio es la cantidad de dinero que se cobra por un producto o servicio, o la suma de todos los valores que los consumidores intercambian por el beneficio de poseer o utilizar productos o servicios» (Kotler y Armstrong, 2000). El precio es el elemento más flexible del mix de marketing ya que puede ser modificado rápidamente. Los errores más frecuentes a la hora de fijar el precio en marketing son: 
- El precio está demasiado basado en los costes.

- No se revisa con la suficiente frecuencia para tener en cuenta los cambios del mercado.

- Se fija independientemente del resto de variables del marketing mix.

- No varía suficientemente para los distintos productos, segmentos del mercado y circunstancias de compra.

\subsubsection{Métodos de fijación de precios}

El método de fijación de precios es un conjunto de reglas a aplicar para la obtención del nivel de precio final de un producto o servicio. Existen varios métodos, entre los que destacamos: los basados en los costes, los basados en la competencia y los basados en la demanda.

\subsubsection{Métodos basados en los costes}

Estos métodos se centran en los datos de costes para la consecución de los niveles de precios finales de los productos. Su facilidad de aplicación provoca que sea uno de los métodos más utilizados por las empresas. Entre estos métodos destacan: los de coste más margen, los del margen en precio y los de beneficio objetivo.

- Coste más margen. Se calculan los costes unitarios de los productos y sobre estos costes se aplica un margen (normalmente de forma porcentual) para obtener el precio de venta final. Este método tiene una gran carga de subjetividad ya que, si la empresa debe calcular el coste total unitario de un producto, solo lo podrá calcular cuando haya establecido una cantidad de producción para el periodo entre el cual repartirá los costes fijos. Si la empresa solo tiene en cuenta los costes variables entonces asumirá la incertidumbre de saber cuál es la contribución unitaria al margen de la organización de cada uno de los productos vendidos.

- Margen en el precio. En este método el precio se tiene en cuenta que una parte del mismo debe ser el margen. El margen no se calcula sobre los costes sino como un porcentaje del precio.

- Beneficio objetivo. Este método parte de unos costes y de una cantidad de actividad (producción planificada) a partir de la que se establecen los distintos costes, y fijando una cantidad de beneficio a obtener (beneficio objetivo) se plantea el cálculo del precio que posibilita la obtención del mismo. 


\subsubsection{Métodos basados en la competencia}

Estos métodos son más realistas que los anteriores y solo tienen en cuenta los costes como límite inferior al precio. Se utilizan en mercados donde la competitividad es elevada, en los que los productos están en su fase de madurez y también cuando las empresas tienen excedentes productivos. Los más frecuentes son los de licitación o propuesta sellada y los que obtienen el precio a partir del nivel actual de precios.

- Licitación o propuesta sellada. Se basa en varias ofertas que realizan distintos productores a una demanda especificada de antemano (pedidos ad hoc, concursos de suministros...) en los que el cliente especifica las características y condiciones del producto o servicio y las hace públicas. Los encargados deben tener en cuenta que solo conseguirán hacer efectiva la venta si su oferta presenta la mejor relación calidad-precio. La forma de calcular el precio es a través de la esperanza matemática de ganancia, es decir, se buscará el precio que maximice el producto entre beneficios que proporciona el nivel precio y la probabilidad de que dicha oferta resulte elegida.

- Método a partir del nivel actual de precios. Este método se basa en la situación actual de los precios y en cómo reaccionarán los competidores ante un aumento o disminución de nuestro precio. Se puede aplicar de forma intuitiva o mediante la aplicación científica.

\subsubsection{Métodos basados en la demanda}

La demanda de un producto dependerá del precio al que el producto puede ser encontrado en el mercado, del valor o utilidad que asociemos al producto, las posibilidades económicas de los compradores, etc. Estos métodos son los más realistas pero presentan ciertas dificultades como la de obtención de información ya que parten de ciertas premisas como el conocimiento de las preferencias de los consumidores sobre los atributos del producto o servicio. Entre estos métodos encontramos el análisis marginalista y el del valor percibido.

- Análisis marginalista. Se puede aplicar en el caso de aquellas empresas que tengan información sobre la curva de demanda que tienen sus productos y servicios en el mercado. Las empresas según la evolución que tenga la demanda en función del precio pueden averiguar el beneficio proporcionado por cada unidad adicional vendida. Así se fijarán los precios para obtener el máximo beneficio.

- Valor percibido. El precio se fija de acuerdo al valor que el comprador otorga a los atributos del producto y al producto en general. Este método muestra cómo es percibido nuestro producto frente al de la competencia, pudiendo evidenciarse que, en ocasiones, los consumidores valoran poco los atributos que nos diferencian. Si somos capaces de hacer que el consumidor valore más positivamente los atributos diferenciales podremos subir los precios sin alterar la relación precio/valor percibido. 


\subsubsection{Estrategias de precios}

En función de los distintos objetivos de la organización existen diversas estrategias para la fijación de precios. Destacamos: las de productos nuevos, las de línea de producto, las de precios diferenciales, las de precios psicológicos y las basadas en criterios geográficos.

\subsubsection{Productos nuevos}

La estrategia de productos nuevos se aplica cuando una empresa introduce productos nuevos en el mercado. Se distinguen dos estrategias, la de precios de introducción y la de tamizado gradual o desnatado de mercado.

- Precios de introducción o de penetración. Se fijan unos precios muy bajos para animar a la compra. Esta estrategia intenta conseguir diversos objetivos: obtener una alta cuota de mercado rápidamente, conseguir que se pruebe el producto, construir una barrera de entrada para la competencia. Este tipo de estrategia es recomendable con productos fácilmente imitables y, por lo tanto, que posibiliten la rápida aparición de los competidores.

- Tamizado gradual o desnatado del mercado. Con esta estrategia los productos nuevos son introducidos en el mercado con un precio alto para progresivamente ir evolucionado hacia una bajada del precio. Los productos sobre los que se suele aplicar esta estrategia son los innovadores que son difíciles de imitar por los competidores.

\subsubsection{Lineas de producto}

En esta estrategia las decisiones sobre el precio se toman teniendo en cuenta los precios de todos los productos de una línea. Entre estas estrategias destacan: la de líder en pérdidas, la del precio en dos partes y el precio único.

- Líder en pérdidas. Consiste en ofertar a un precio muy bajo (nunca por debajo de coste, lo que es ilegal) un producto de los que configuran la línea con el propósito de hacer atractiva la oferta y que los consumidores acudan al punto de venta. Una vez en el establecimiento, se espera que los clientes compren más productos que el que está en oferta.

- Precio en dos partes. Esta estrategia consiste en dividir el precio del producto en una parte fija, que constituye la cuota de abono del servicio, y otra variable, en función de su uso. Este sistema de fijación de precios es utilizado para fijar tarifas de servicios públicos, como el teléfono y la electricidad.

- Precio único. Se fija el mismo precio para todos los productos o para toda la línea. Esto permite al consumidor tomar su decisión de compra en base a otros aspectos distintos al precio. 


\subsubsection{Precios diferenciales}

Los precios diferenciales se utilizan cuando se vende el mismo producto a distintos precios en función de la situación, momento, lugar, características del cliente, etc. Dentro de estas estrategias cabe destacar la de precios variables, la de descuentos periódicos, descuento por pronto pago, descuento por volumen y la de descuento en segundo mercado.

- Precios variables. Esta estrategia incluye diferentes precios en función de las características del cliente y del producto. El precio es objeto de negociación en cada transacción. Este método es propio de productos de precio elevado como la vivienda, automóviles, la compra de un barco, etc.

- Descuentos periódicos. Esta estrategia no debe confundirse con las rebajas u ofertas. Los descuentos periódicos tienen su origen en la existencia de diferentes niveles de demanda en diferentes momentos del tiempo. Un ejemplo de este tipo de descuentos es el precio de la habitación de un hotel que va oscilando dependiendo del momento de la temporada en el que nos encontremos (baja, media, alta).

- Descuentos por pronto pago. El objetivo de esta estrategia es favorecer el pago a corto plazo o al contado e intentar huir del pago aplazado de 30, $60 \mathrm{y}$ 90 días.

- Descuentos por volumen. Se distinguen entre los acumulables y los no acumulables. En los primeros, de busca la fidelización de los clientes, en los segundos, aumentar las ventas a corto plazo. Los acumulables se practican en todas las compras realizadas por un cliente en un determinado periodo de tiempo. Los no acumulables se aplican en cada una de las compras.

- Descuentos en segundo mercado. Se puede practicar en aquellos casos en los que existan segundos mercados en los que se pueden ofertar los excedentes a precios más baratos. Los compradores del segundo mercado poseen unas características exclusivas (edad, sexo, nivel económico...), las cuales les dificultan pagar el precio habitual del mercado. Con el fin de acceder a este tipo de comprador las empresas deciden ofertar los productos a un precio más económico. Un ejemplo de estos descuentos son los precios de las entradas en teatros y cines para personas mayores.

\subsubsection{Precios psicológicos}

Los precios psicológicos tienen su razón de ser en el modo en que el mercado percibe el valor de los atributos del producto y del producto en general. En esta estrategia de precios se distinguen el precio de prestigio y el precio par-impar.

- Precio de prestigio. El precio alto se asocia a calidad. Si la empresa quiere posicionar su producto como de calidad debe fijar un precio alto. Además, 
para que esta estrategia tenga éxito, se debe conseguir que el cliente perciba la superioridad de dicho producto.

- Precio par-impar. La estrategia de precios impares intenta que el producto se perciba como más económico. Para ello se reduce la cifra del precio haciendo que acabe en un número impar, por ejemplo 99 en vez de 100. Por otro lado, la estrategia de los precios pares intenta simplificar las tareas de gestión y cobro al fijar precios terminados en cifras pares o en múltiplos de las monedas más utilizadas.

\subsubsection{Precios geográficos}

Los precios geográficos son aquellos que se fijan en función de la proximidad geográfica. Dentro de los mismos destacamos la estrategia de libre a bordo (LAB), entrega uniforme y precio por zonas.

- Libre A Bordo (LAB). Se ofrece un precio uniforme para el producto puesto en el transporte de los compradores. El precio variará para cada comprador en función del a distancia pero, por otro lado, simplificará la gestión al homogeneizar el precio.

- Entrega uniforme. En este caso, todos los compradores, sea cual sea su localización, pagan lo mismo. Se utiliza esta modalidad cuando los gastos de transporte son una partida pequeña en el total de la estructura de costes del vendedor.

- Precio por zonas. El mercado se divide en zonas geográficas y dentro de cada una de ellas se establece un precio de entrega uniforme.

\subsection{Distribución}

La distribución es un instrumento de marketing que relaciona la producción con el consumo. Su objetivo es situar los productos a disposición del consumidor final o del consumidor industrial, en la cantidad demandada, en el momento en que se necesite y en el punto de venta donde se desee adquirirlo. El conjunto de organizaciones independientes involucradas en el proceso de poner los productos a disposición de los consumidores o usuarios industriales para su uso o consumo se denomina canal de distribución. Dichas organizaciones independientes o intermediarios son, por ejemplo, los mayoristas y minoristas. 


\subsubsection{Cómo añaden valor los miembros del canal: funciones de la distribución}

La función básica que origina la existencia de la variable de marketing distribución comercial es, tal y como hemos comentado, trasladar el producto desde un punto de origen (fabricante, mayorista, minorista) hasta un punto final (mayorista, minorista, consumidor). Pero además, el distribuidor desarrolla otras funciones que resultan clave para mejorar las ventas:

- Informa. Cada intermediario reúne y distribuye la información del mercado para planificar y mejorar el intercambio.

- Reduce el número de transacciones. Desarrolla una función económica al permitir que el número de contactos se minimice.

- Almacena los productos, los transporta y entrega. Cada uno de los intermediarios almacena los productos para el siguiente intermediario, transporta y los entrega al siguiente intermediario o al consumidor final.

- Ofrece servicios adicionales. El distribuidor responde de la instalación, reparación, asesoramiento, formación, etc.

- Concentra los distintos productos. Cada miembro del canal agrupa para el resto los distintos productos. El detallista compra a diferentes mayoristas productos y marcas para ofrecer así un mayor surtido.

- Financia. Los intermediarios pueden proporcionar crédito, tanto al fabricante o distribuidor como al cliente. Los mayoristas o detallistas suelen financiar también las existencias de sus productos hasta que son vendidos.

\subsubsection{Decisiones en el canal de distribución}

Para que las empresas hagan llegar los productos y servicios a los clientes pueden recurrir a diferentes y variados intermediarios. Cada intermediario constituye un nivel del canal. Desde la perspectiva del fabricante cuantos más niveles existan menor es el control sobre la distribución. Existen cuatro tipos de canal (véase figura 34):

- Canal ultra-corto. No hay intermediaros entre el productor y el consumidor o el comprador industrial.

- Canal corto. El número de intermediarios es reducido (suele ser un intermediario único). Por ejemplo un minorista que ofrece un producto al consumidor final. 
- Canal largo. El número de intermediarios es elevado (al menos dos). Por ejemplo el fabricante abastece al mayorista y este al minorista que a su vez lo hace al consumidor final.

- Canal muy largo. Al canal largo se le introducen adicionalmente otros intermediarios como por ejemplo agentes de ventas, comisionistas, centrales de compra, etc.

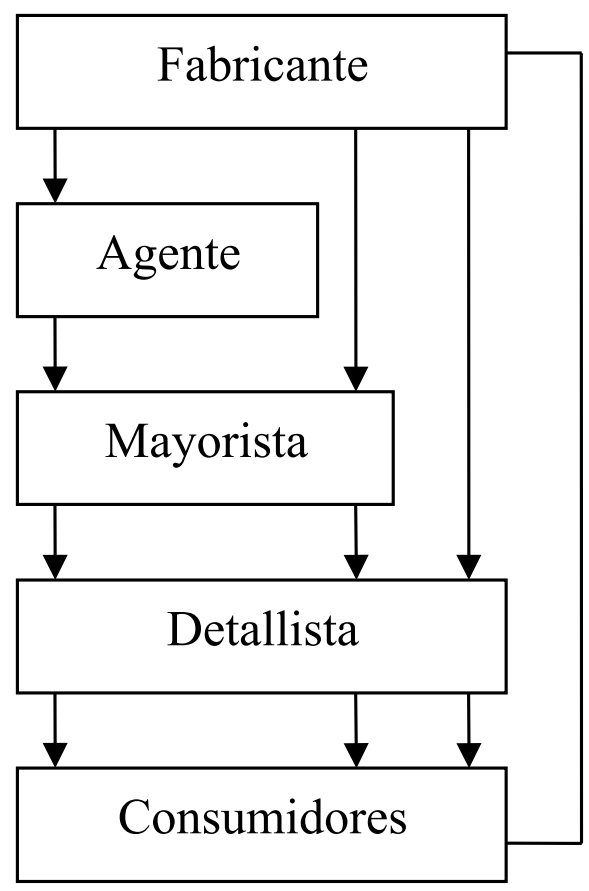

Figura 34. Canales de distribución

Fuente: Elaboración propia en base a Kotler et al. (2006)

Otro aspecto a considerar será la modalidad de distribución que se llevará a cabo en el canal y que dependerá del tipo de producto a distribuir y del canal escogido. En este sentido se distingue entre: distribución exclusiva, selectiva e intensiva.

- Distribución exclusiva. El intermediario tiene la exclusiva de venta en una determinada zona geográfica o mercado. Esta garantía de exclusividad por parte del productor supone para el intermediario el compromiso de no vender productos de la competencia.

- Distribución selectiva. Implica un número reducido de distribuidores y supone el cumplimiento de una serie de requisitos por parte del intermediario como, por ejemplo, el compromiso de compra un determinado volumen de producto. El distribuidor que aboga por esta fórmula puede vender productos de la competencia. La elección del distribuidor se realiza esperando que la imagen del distribuidor refuerce la imagen del fabricante.

- Distribución intensiva. Se pretende llegar al mayor número posible de puntos de venta alcanzando la máxima cobertura de mercado. Generalmente es propia de canales de distribución largos. 


\subsubsection{Los intermediarios del canal}

\subsubsection{Venta mayorista}

El mayorista adquiriere productos o servicios con objetivo de revenderlos o utilizarlos en sus negocios. Se distinguen los mayoristas de servicio completo, los de servicio limitado, los corredores y agentes y, por último, las sucursales y oficinas del fabricante.

- Mayoristas a servicio completo. Prestan toda la gama de servicios como la entrega al detallista, conceden créditos, asesoran, almacenan, etc.

- Mayoristas de servicio limitado. Prestan menos servicios que los anteriores y suelen estar asociados a funciones más especializadas. Por ejemplo: Makro.

- Corredores y agentes. Estos mayoristas no asumen la propiedad del producto. Los corredores actúan suministrando información relativa a precios de la competencia, situación del mercado, producto, etc., tanto al vendedor como al comprador. Mientras que los agentes son intermediarios que trasladan la propiedad de la mercancía a cambio de una comisión.

- Sucursales y oficinas de venta del fabricante. Se diferencian del caso anterior en que no son independientes al ser propiedad del fabricante. Se ofrecen exclusivamente los productos del fabricante.

\subsubsection{Venta minorista}

El minorista vende los productos o servicios al consumidor o usuario final. La venta minorista o detallista se puede clasificar según distintos criterios que hacen referencia a la cantidad de servicios que ofrecen, la amplitud y profundidad de sus líneas, los precios que cobran y su forma de organización.

Según la cantidad de servicios ofrecidos, los detallistas pueden ofrecer tres tipos diferentes de servicio:

- Autoservicio. Comercio generalmente de alimentación o droguería de pequeño tamaño en el que el propio comprador selecciona los productos de la estantería y paga al salir del establecimiento.

- Servicio limitado. Estos detallistas tienen mayor stock y el precio es más alto. Ofrecen ciertos servicios adicionales como la concesión de crédito y la devolución de mercancías.

- Servicio completo. Suelen ser tiendas especializadas o grandes almacenes. Los grandes almacenes suelen tener diversos departamentos que ofrecen 
gran variedad de productos aunque su surtido tiene menor profundidad que el de las tiendas especializadas. Sus precios suelen ser más altos.

Según la amplitud y profundidad de su surtido, los minoristas se pueden clasificar en:

- Tiendas de especialidad. Ofrecen pocos productos pero tienen una gran profundidad en su surtido. Por ejemplo: Muebles La Fábrica.

- Grandes almacenes. Suelen operar en cadena y tienen sucursales en diferentes áreas geográficas. Son superficies de gran tamaño, con distintos departamentos que ofrecen gran variedad de productos aunque su surtido tiene poca profundidad. El servicio es un factor clave. Un ejemplo lo tenemos en nuestro país con El Corte Inglés.

- Supermercados. Su tamaño supera al del autoservicio. Venden productos de alimentación, hogar, limpieza aunque en ocasiones también se pueden encontrar productos de ferretería, jardinería, papelería, etc. Pueden ser pequeños $\left(\right.$ de 400 a $\left.1000 \mathrm{~m}^{2}\right)$ y grandes (de 1000 a $2500 \mathrm{~m}^{2}$ ).

- Tiendas de conveniencia. Pequeños supermercados con una superficie igual o inferior a $500 \mathrm{~m}^{2}$. Tienen la particularidad de estar abiertos las 24 horas del día o al menos 18 horas al día. Venden una línea limitada de productos pero con alta rotación. Van dirigidos a un perfil de cliente que busca comodidad y al que no le importa pagar un poco más por un producto. Por ejemplo, Opencor.

- Grandes superficies. Son superficies de venta de gran tamaño (más de $2500 \mathrm{~m}^{2}$ ). Suelen situarse fuera de las ciudades. Ofrecen gran variedad de productos de alimentación, hogar, electrodomésticos, confección, ferretería, etc. Tienen un gran volumen de ventas, alta rotación y precios bajos. Los hipermercados entran dentro de esta categoría como por ejemplo Carrefour. Otro tipo de grandes superficies son los category killers que son establecimientos especializados de gran tamaño, con amplitud y profundidad de surtido. Un ejemplo de category killer es Decathlon.

Los detallistas también se pueden clasificar en función del precio que cobran:

- Tiendas de descuento. Tienen una oferta muy limitada de productos con alta rotación a precio bajo. Existen las tiendas de descuento duro (hard discount) $\mathrm{y}$ tiendas de descuento blando (soft discount). Las primeras tienen un surtido muy corto, marcas propias a precios bajos y poco o nada de servicio. Un ejemplo de hard discount es Lidl. Las segundas tienen mayor surtido, ofertan marcas publicitarias y practican una política de precios bajos, sobretodo, con las marcas propias. Un ejemplo de soft discount es Dia.

- Detallistas a precios rebajados. Suponen una evolución de las tiendas descuento que compran a los mayoristas a un menor precio. Un ejemplo de 
estos detallistas son aquellas tiendas de los propios fabricantes que venden productos defectuosos o de la temporada anterior (outlets).

Según el tipo de organización los detallistas pueden ser:

- Cadenas integradas o sucursalistas. Dos o más tiendas con el mismo nombre e idéntico propietario. Se obtienen los beneficios de la economía de la escala. Suelen vender productos de alimentación, farmacias, zapaterías y ropa. Un ejemplo de este tipo de cadenas es Zara o El Corte Inglés.

- Cadenas voluntarias. Los detallistas se asocian para constituir una central de compras que consiga mejores precios. La cadena IFA y Spar son cadenas voluntarias.

- Cooperativas de detallistas. Los detallistas se asocian en una cooperativa beneficiándose de lo que esto supone. Es el caso de la cooperativa Gruma en alimentación.

- Franquicias. Se trata de una asociación contractual en la que el franquiciado se beneficia de la cesión del comercial o marca, de los suministros de bienes y de la prestación de una serie de servicios por parte del franquiciador. En contrapartida, el franquiciado adquiere una serie de compromisos como el pago de una cuota de entrada, el pago de un porcentaje sobre las ventas, etc. (Santesmases, 2012). Son ejemplos de franquicias las empresas Benetton y Los 100 Montaditos.

- Asociaciones de comerciantes. Se trata de varios comercios que pertenecen a diferentes propietarios y que integran funciones de distribución y gestión. Un ejemplo sería la asociación de comerciantes del centro de Castellón, Centrics Castelló.

\subsection{Comunicación}

La comunicación comercial es la transmisión de información del vendedor al comprador refiriéndose el contenido de la misma al producto o a la empresa que lo produce o vende. Las cinco herramientas de la comunicación comercial o mix de comunicación son: la publicidad, la promoción de ventas, las relaciones públicas, la venta personal y el marketing directo.

\subsubsection{Publicidad}

Es toda transmisión de información impersonal y remunerada efectuada a través de los medios de comunicación de masas (prensa, radio, televisión...) mediante anuncios pagados por un anunciante que controla su contenido. Los objetivos de la publicidad pueden ser de carácter informativo, persuasivo y recordatorio. 


\subsubsection{Métodos de fijación del presupuesto publicitario}

Los métodos para fijar el presupuesto publicitario son los siguientes:

- Arbitrario. La cantidad del presupuesto que se destina a la publicidad depende de la experiencia o intuición de la gerencia.

- Porcentaje sobre las ventas. Consiste en destinar a publicidad un porcentaje de los beneficios de las ventas pasadas o futuras. Se trata de un método arbitrario ya que tiende a considerar las ventas como la causa y no el resultado de la publicidad.

- Paridad competitiva. El presupuesto se determina por comparación con el de los competidores (por encima, igual o por debajo). Se trata de un sistema arbitrario que no tiene en cuenta los objetivos de la propia empresa. Los datos sobre el presupuesto asignado por la competencia se obtienen de fuentes como Duplo o Repress.

- Lo que se pueda. Se reparte el presupuesto de la empresa por las diferentes áreas y lo que queda se destina a la publicidad.

- Según el presupuesto anterior. Se destina a la publicidad la misma cantidad que el año anterior pero incrementada en función del índice general de precios o de las tarifas de los medios de comunicación.

- En función de los objetivos. Se asigna el presupuesto de acuerdo con los objetivos publicitarios planteados. Este método, a priori, parece el más lógico al tener en cuenta la relación entre publicidad y demanda.

\subsubsection{Desarrollo de la estrategia publicitaria}

La estrategia publicitaria está formada por la estrategia creativa (creación del mensaje publicitario) y la estrategia de medios (selección de los medios).

- Estrategia creativa. La definición del mensaje es la parte creativa. En la misma se establece el qué se dice y cómo se dice. Para el desarrollo del mensaje la agencia cuenta con un documento informativo sobre las características del producto, de la empresa, los competidores, el público objetivo y la duración de la campaña, se trata del briefing. A partir del mismo, la agencia elaborará una primera propuesta de campaña, en la que se expondrá el eje de comunicación, así como el plan de medios. Una vez aprobada la propuesta por parte del anunciante, la agencia elaborará uno o varios bocetos del anuncio, script (prensa), storyboard y animatic (para televisión). Posteriormente se realizará el original.

- Estrategia de medios: La planificación de medios consiste en seleccionar los medios (televisión, radio, prensa) y los soportes publicitarios (Tele 5, Antena 3, 
Onda 0, Cadena Ser, El País, El Mundo...) a utilizar en la campaña. Existe una variedad de modelos de planificación de medios que, con criterios y objetivos distintos, seleccionan los medios y distribuyen el presupuesto. Así los criterios más usuales son: criterios cualitativos (dependen de las características técnicas, afinidad del medio y el producto, estrategia creativa...), criterios cuantitativos (presupuesto disponible, audiencia, alcance, audiencia útil, tarifas, etc.) y criterios mixtos (restricciones legales, competencia...).

\subsubsection{Evaluación de la eficacia publicitaria}

Una campaña de publicidad será eficaz si alcanza los objetivos previstos, y eficiente si lo hace al menor coste posible. Para evaluar la eficacia antes del lanzamiento de la campaña se pueden realizar pretest y durante su desarrollo postest. El objetivo del pretest es evaluar la idea base, el eslogan o cualquier otro elemento del mensaje. Mediante el postest evalúa la notoriedad, recuerdo, reconocimiento, comprensión y actitudes.

\subsubsection{Promoción de ventas}

Conjunto de actividades que, mediante incentivos materiales o económicos (premios, regalos, cupones...) tratan de estimular la venta a corto plazo de un producto. La promoción de ventas puede dirigirse al consumidor, al canal y a los equipos de venta.

- Promociones al consumidor. Tienen como objetivo incentivar al consumidor a realizar la compra a corto plazo. Suele utilizar como herramientas promocionales tanto incentivos monetarios (descuento inmediato, cupón o vale descuento, reembolso...) como incentivos no monetarios (muestras, producto adicional, regalo directo, concursos, juegos...).

- Promociones al canal. Dirigidas a los intermediarios con el fin de obtener su apoyo e incrementar sus esfuerzos de venta. Se utilizan como herramientas promocionales los descuentos en tarifa o por volumen de compra, los descuentos o concesiones por exhibición, los regalos y otros incentivos no monetarios.

- Promociones a equipo de venta. Tienen como objetivo motivar a los vendedores y conseguir que mejoren su rendimiento. Son frecuentes en este tipo de promociones las compensaciones económicas directas, las competiciones entre los comerciales de una misma empresa y las distinciones honoríficas. 


\subsubsection{Relaciones públicas}

Conjunto de actividades realizadas por las empresas o instituciones para potenciar las buenas relaciones con los diferentes públicos y transmitir una imagen favorable de la organización y sus productos. Los destinatarios de las relaciones públicas pueden ser externos a la organización, proveedores, consumidores, intermediarios, banqueros, administración, líderes de opinión, medios de comunicación y similares; e internos a la misma, como empleados, directivos, accionistas y otros. Utiliza diversas herramientas que abarcan, entre otras: las publicaciones internas y externas, exposiciones, noticias de prensa, publicity (formato con características publicitarias pero el emisor no paga al medio por su publicación), actividades de patrocinio (esponsorización y mecenazgo), ferias, exposiciones, identidad corporativa, etc.

\subsubsection{Venta personal}

Forma de comunicación oral e interactiva mediante la cual los vendedores (fuerza de ventas) transmiten información de forma directa y personal de un producto o servicio con el fin de cerrar la venta y crear relaciones con los clientes.

\subsubsection{La dirección de ventas}

La dirección de ventas supone el análisis, la planificación, la implementación y el control de las actividades del equipo de ventas. Esto supone diseñar la estructura de ventas, seleccionar, formar, motivar, evaluar y controlar al equipo de ventas.

\section{Diseño DE LA ESTRUCTURA DE VENTAS}

Las características de las diversas líneas de productos de la empresa, el tipo de cliente, los mercados a los que se dirige, etc., condicionan el diseño de la estructura de ventas. Los tipos más habituales de organización de las ventas son los siguientes:

- Organización geográfica. Consiste en dividir el mercado en distintos territorios o zonas de venta sin tener en cuenta los productos vendidos ni el tipo de clientes. Este tipo de organización es recomendable cuando la cartera de productos ofertados es reducida y los clientes tienen características muy similares. La ventaja de esta organización es la reducción de los costos de desplazamiento. La desventaja es la falta de especialización.

- Organización por producto. Este tipo de organización es recomendable cuando se comercializan muchos productos. Permite una mayor especialización por parte del vendedor tanto en lo referente a los productos comercializados como a la tipología del cliente. La organización por producto puede combinarse con la geográfica. 
- Organización por mercados. La organización de la red de ventas puede hacerse también en función de las particularidades de los clientes y de los mercados. Este sistema supone una mayor especialización y por tanto adecuación a las necesidades de los clientes. Es frecuente combinar esta fórmula con la organización geográfica.

- Organización mixta. Todas las organizaciones anteriores se pueden combinar en el diseño de la estructura de ventas. Además también se pueden diseñar los equipos de venta de acuerdo con un sistema de especialización en tareas: prospección de clientes, recepción de pedidos, asesor técnico, etc.

SELECCIÓN, FORMACIÓN, MOTIVACIÓN, EVALUACIÓN Y CONTROL DEL EQUIPO DE VENTAS

- Selección. La selección cuidadosa de los vendedores aumentará el éxito de la red de ventas. La posesión de ciertas características en el perfil del vendedor supondrá, en muchos casos, el éxito de su misión. En este sentido, un determinado nivel de educación, inteligencia, autoconfianza, capacidad para resolver problemas, facilidad de palabra, empatía, capacidad para el trabajo en equipo, etc., son algunos de los rasgos fundamentales a valorar en el vendedor ideal.

- Formación. Una vez seleccionado el equipo de ventas es sujeto a un proceso de formación continua. Durante esta etapa se enseñará al vendedor las habilidades necesarias para informar correctamente al cliente, persuadirle y prestarle servicio. Además se le mostrará como contrarrestar las objeciones más frecuentes en la venta. Es importante que en esta etapa los vendedores tengan formación precisa sobre las características de los productos que van a vender, sus fortalezas y debilidades. Además deben obtener información sobre los objetivos, características de la empresa y de la competencia.

- Motivación. Entre las acciones que puede llevar la empresa para motivar a los vendedores cabe destacar las siguientes: reuniones periódicas (suponen un intercambio de información y mantienen sensación de grupo), reconocimiento personal, promoción, delegación de tareas, incentivos (monetarios, premios, etc.) y formación continuada.

- Evaluación y control de equipos de ventas. El director de ventas evalúa la marcha del equipo de ventas a través de varios mecanismos: el informe de ventas (el propio vendedor refleja sus planes de venta semanales y mensuales), los resultados de ventas obtenidos en los diferentes territorios, el coste de las ventas, etc.

\subsubsection{El proceso de venta personal}

El proceso de la venta personal suele estructurarse en las siguientes fases: prospección, preparación, presentación, tratamiento de objeciones, cierre y seguimiento. 
- Prospección. Tiene como objetivo la búsqueda de nuevos clientes. Suele utilizar para este fin las referencias de los clientes actuales y de los proveedores, directorios de empresas, ferias, anuncios con respuesta de solicitud de información, web, etc.

- Preparación. Cuando la visita de ventas se realice a un cliente actual, en la preparación debe recopilarse toda la información disponible, tanto de carácter comercial (últimos pedidos, precios, periodos de pago y satisfacción general) como personal (intereses, personalidad...). Si la visita es a un nuevo cliente, por contra, esa información debe buscarse durante los primeros minutos de la visita. También es conveniente hacer un sondeo previo preguntando a los proveedores, los distribuidores o buscando información por Internet.

- Presentación. En un primer momento, en la apertura, se rompe el hielo a través de una breve charla superficial para, posteriormente, realizar una presentación y demostración profunda de los beneficios del producto. En esta etapa el vendedor explica todo lo relativo al producto, sus beneficios y cómo resolver los problemas con el cliente.

- Tratamiento de objeciones. En el transcurso de la venta es probable que surjan objeciones o excusas que realiza el cliente para no efectuar un pedido o para conseguir mejores condiciones. Estas dudas o críticas pueden ser relativas al precio, al producto, a la oportunidad, al origen o similares. Las objeciones pueden ser reales o meros pretextos. Hay diversas técnicas para superar las objeciones: ignorarlas, negarlas, primero estar de acuerdo y luego refutarlas, convertir la objeción en una razón para la compra, preguntar detalles y analizar la situación.

- Cierre y seguimiento. El cierre tiene como objeto que el comprador efectúe un pedido. Una vez superadas las objeciones, el vendedor debe hacer tentativas para cerrar la venta (¿cuándo desea que se lo entreguemos?, ¿qué modelo desea?, etc. ). Es fundamental detectar el momento adecuado a través de las señales (verbales o no verbales) que envía el cliente (¿cuándo lo podría tener en casa?, ¿se puede financiar?). Existen diversos métodos para cerrar la venta como: el resumen de los puntos a los que se ha llegado a un acuerdo, posibilidad única, prueba del producto, preguntar por pequeños detalles, etc. Tras el cierre el vendedor debe realizar una labor de seguimiento y poner en marcha las actividades de postventa necesarias para generar confianza y satisfacción.

\subsubsection{Marketing directo}

El marketing directo supone una relación directa entre el fabricante y el comprador sin pasar por los intermediarios. Supone un conjunto de modalidades de distribución, venta y promoción dirigidas al público objetivo escogido a través 
de sistemas de bases de datos. Existen diversos tipos de marketing directo como el telemarketing, el mailing, el marketing por catálogo, el marketing de respuesta directa por televisión, el marketing en los quioscos y el marketing on line.

- Telemarketing. Implica la utilización del teléfono como un instrumento de comunicación para hacer proposiciones de venta. En los últimos años se ha utilizado mucho provocando cierta saturación y cierta animadversión por parte de los clientes. Suele utilizarse como instrumento de venta de sectores como la telefonía móvil, contratación de seguros, operaciones bancarias, etc.

- Mailing. Implica enviar una oferta comercial o algún elemento publicitario al domicilio de una persona. Este sistema permite segmentar al público mediante la contratación de listas de direcciones y datos a empresas que comercializan con sistemas de bases de datos. Este sistema, en ocasiones, es sustituido por el envío de sms o mensajes a través del correo electrónico.

- Marketing por catálogo. El marketing por catálogo (también denominado El Vendedor Silencioso) se realiza mediante catálogos que se pueden enviar online, por correo o presentar directamente al cliente en su casa o en los puntos de venta. Los catálogos online suponen cierta ventaja sobre los impresos ya que resulta más económico.

- Marketing respuesta directa por televisión. Este tipo de marketing utiliza la televisión como forma de venta. Se basa en la utilización de los siguientes formatos: los anuncios de respuesta directa (describen persuasivamente un producto e informan de un teléfono gratuito para la realización de pedidos) y la televenta (basada en demostraciones sobre el uso de un producto que normalmente resulta una novedad en el mercado). Un ejemplo de este tipo de venta lo tenemos en La Teletienda o La Tienda en Casa.

- Marketing en los quioscos. Se trata de aquellas máquinas (quioscos) situados en determinados emplazamientos como tiendas y aeropuertos para obtener información o hacer pedidos.

- Marketing on line. Consiste en la adopción de las nuevas tecnologías en favor de los objetivos de marketing. Este tipo de marketing utiliza Internet y otro tipo de servicios como blogs, $S E O^{I}(1), S E M^{2}(2)$, programas de afiliación, redes sociales, etc.

1. SEM (Search Engine Marketing) o marketing en buscadores: representa a las acciones asociadas a lograr posicionamiento de un sitio en buscadores a través de enlaces patrocinados.

2. Seo (Search Engine Optimization) u optimización para motores de búsqueda: representa las acciones requeridas para lograr que un sitio web se posicione entre los primeros resultados en un buscador. 


\section{Referencias bibliográficas}

Armstrong, G., Kotler, P., Merino, M. J., Pintado, T. y J. M. Juan (2011): Introducción al marketing, 3. ${ }^{\mathrm{a}}$ ed., Madrid, Pearson Educación.

Kotler, P. y G. Armstrong (2000): Introducción al Marketing, Madrid, Prentice Hall.

Levitt, T. (1996): «Innovative imitation», Harvard Business Review, 63.

Santesmases, M. (2012): Marketing. Concepto y Estrategias, 6. ${ }^{\mathrm{a}}$ ed., Madrid, Pirámide. 


\section{Índice de tablas}

Tabla 1. Estados de la demanda y sus estrategias de marketing ......................59

Tabla 2. Método de construcción de mercado................................................ 53

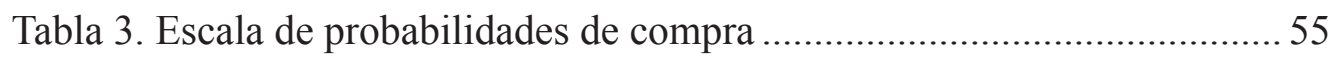

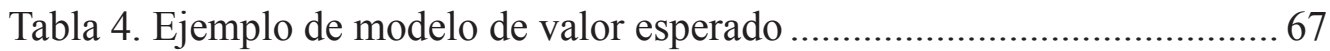

Tabla 5. Tipos de comportamiento de compra ................................................ 85

Tabla 6. Matriz panel del consumidor (cambio de marca)............................. 98

Tabla 7. Clasificación de criterios de segmentación de mercados

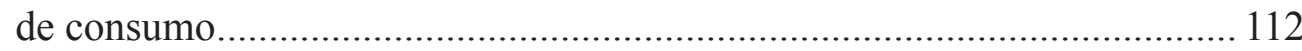

Tabla 8. Clasificación de criterios de segmentación de mercados

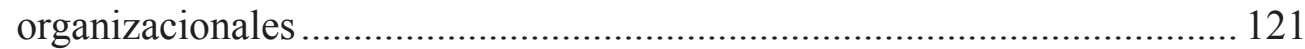

Tabla 9. Segmentación por beneficios del producto-mercado de pasta

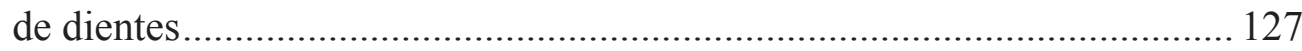

Tabla 10. Evaluación de los segmentos del producto-mercado de pasta

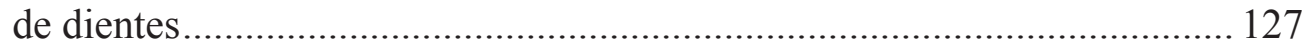

Tabla 11. Estrategias de cobertura del producto-mercado de pasta

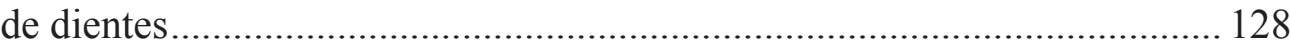

Tabla 12. ¿Qué datos necesitamos para construir la matriz BCG?.................... 148

Tabla 13. Ejemplo de factores explicativos del atractivo del mercado y la posición competitiva de la empresa ................................................ 150

Tabla 14. Ejemplo de evaluación y ponderación de los factores que miden el atractivo del mercado y la posición competitiva para elaborar una matriz GE 


\section{Índice de figuras}

Figura 1. Enseñanza de marketing en la Universitat Jaume I ......................... 14

Figura 2. Logotipo del GIE TEAM (Tecnología, Equipos y Actividades

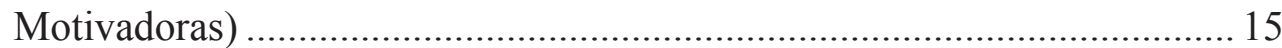

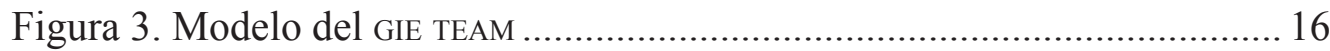

Figura 4. Niveles organizativos de INDITEX …................................................ 23

Figura 5. Modelo del proceso de marketing para crear valor al cliente........... 25

Figura 6. Dimensiones, tareas del marketing y estructura de este manual ...... 27

Figura 7. Definición del mercado de referencia............................................... 40

Figura 8. Diferencia entre industria, mercado de referencia y

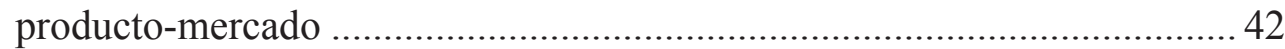

Figura 9. Mercado relevante: estrategias de cobertura del mercado

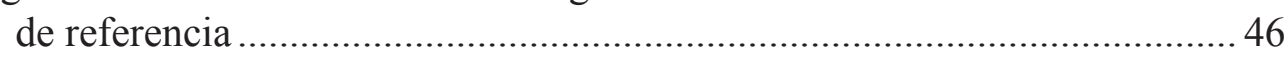

Figura 10. Ampliación del mercado de referencia .......................................... 46

Figura 11. Dimensiones de la demanda de mercado........................................ 48

Figura 12. Modelo de comportamiento estímulo-respuesta

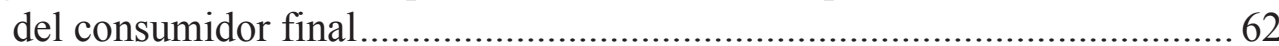

Figura 13. Modelo de comportamiento estímulo-respuesta del comprador

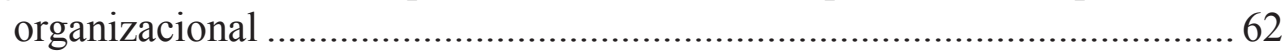

Figura 14. Modelo de cinco fases del comportamiento de compra

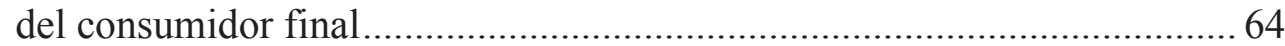

Figura 15. Conjunto de consideración y conjunto evocado ..............................66 66

Figura 16. Proceso seguido por el consumidor en caso de insatisfacción ....... 70

Figura 17. Uso y deshecho de producto postcompra ................................... 71

Figura 18. Proceso de decisión de compra comprador organizacional............ 71

Figura 19. Factores condicionantes de la compra del consumidor final.......... 74

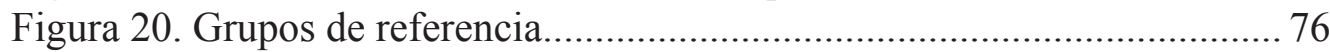

Figura 21. Jerarquía de necesidades de Maslow ........................................... 81

Figura 22. Factores condicionantes de la compra del comprador

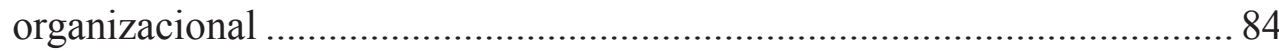

Figura 23. Proceso de análisis de la competencia........................................ 91

Figura 24. Ejemplo análisis de similitudes a través de un mapa perceptual.... 98

Figura 25. La segmentación se realiza dentro del producto-mercado .............. 107

Figura 26. Estrategias de cobertura del producto-mercado ........................... 125

Figura 27. Mapa de percepción elaborado con el análisis factorial................. 138

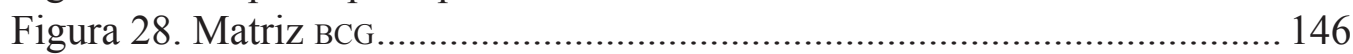

Figura 29. Ejemplo aplicado de la matriz BCG .............................................. 148

Figura 30. Ejemplo del posicionamiento de los productos de una empresa

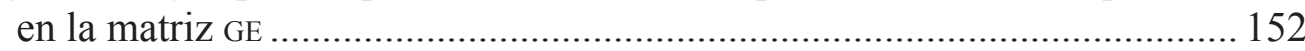

Figura 31. Matriz GE: recomendaciones estratégicas .................................. 152

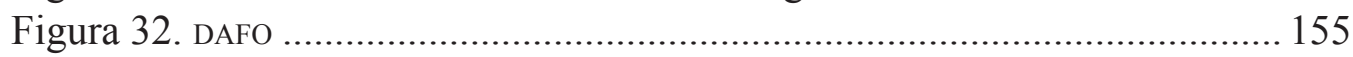

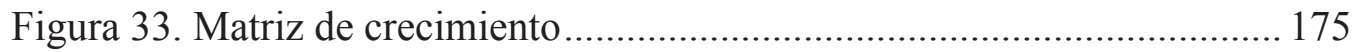

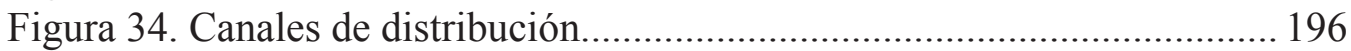



